\title{
Migration, family separation and caregiving across borders
}

Citation for published version (APA):

Poeze, M. (2018). Migration, family separation and caregiving across borders: A multi-sited ethnography of transnational child-raising arrangements between Ghana and The Netherlands. [Doctoral Thesis, Maastricht University]. Datawyse / Universitaire Pers Maastricht. https://doi.org/10.26481/dis.20181206mp

Document status and date:

Published: 01/01/2018

DOI:

10.26481/dis.20181206mp

Document Version:

Publisher's PDF, also known as Version of record

\section{Please check the document version of this publication:}

- A submitted manuscript is the version of the article upon submission and before peer-review. There can be important differences between the submitted version and the official published version of record.

People interested in the research are advised to contact the author for the final version of the publication, or visit the DOI to the publisher's website.

- The final author version and the galley proof are versions of the publication after peer review.

- The final published version features the final layout of the paper including the volume, issue and page numbers.

Link to publication

\footnotetext{
General rights rights.

- You may freely distribute the URL identifying the publication in the public portal. please follow below link for the End User Agreement:

www.umlib.nl/taverne-license

Take down policy

If you believe that this document breaches copyright please contact us at:

repository@maastrichtuniversity.nl

providing details and we will investigate your claim.
}

Copyright and moral rights for the publications made accessible in the public portal are retained by the authors and/or other copyright owners and it is a condition of accessing publications that users recognise and abide by the legal requirements associated with these

- Users may download and print one copy of any publication from the public portal for the purpose of private study or research.

- You may not further distribute the material or use it for any profit-making activity or commercial gain

If the publication is distributed under the terms of Article $25 \mathrm{fa}$ of the Dutch Copyright Act, indicated by the "Taverne" license above, 


\section{Migration, family separation and caregiving across borders}

A multi-sited ethnography of transnational child-raising arrangements between Ghana and The Netherlands

Miranda Poeze

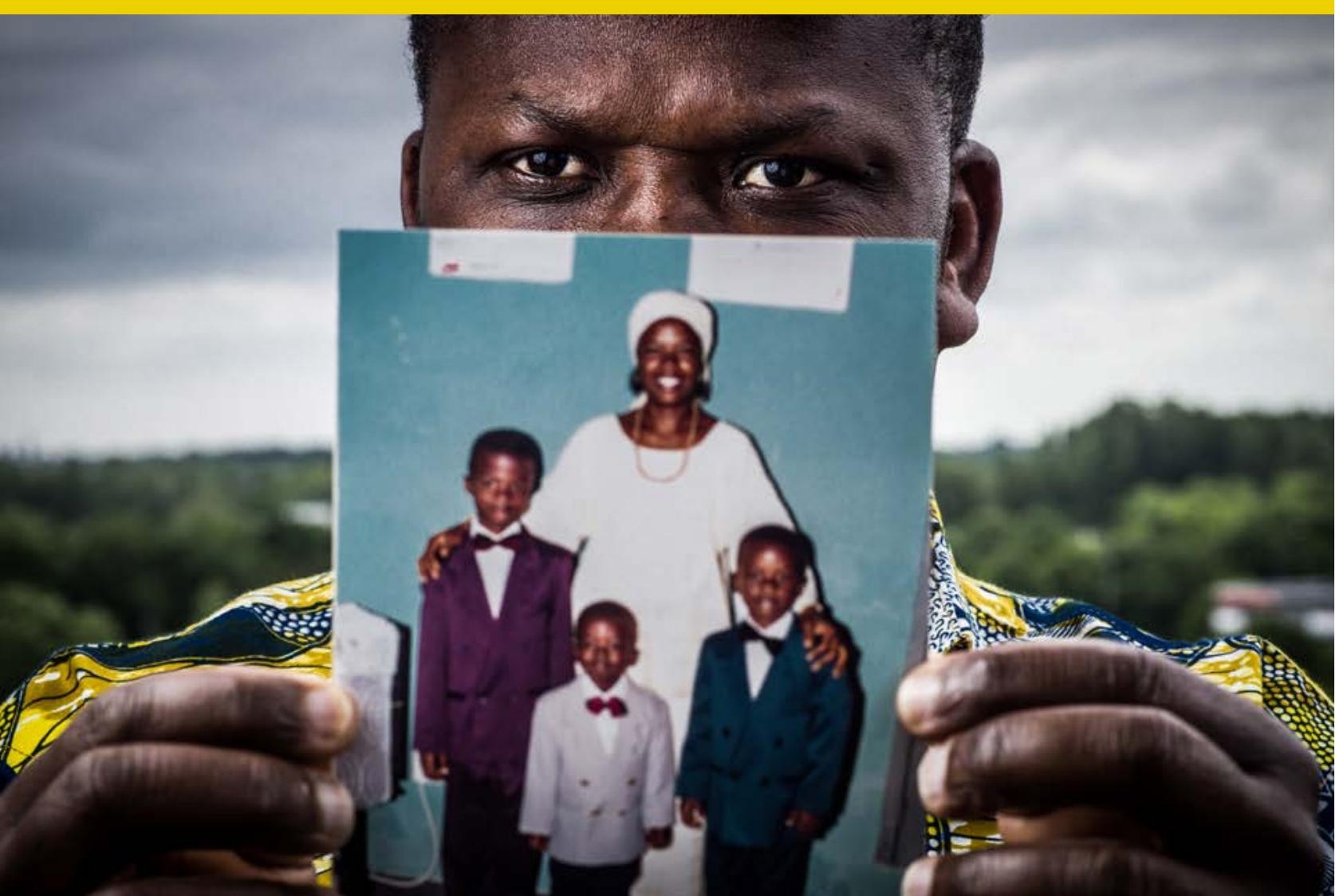


(C) copyright Miranda Poeze, Maastricht 2018

Cover photo: Bas Niemans |www.photosarebullets.org

Printing: Datawyse | Universitaire Pers Maastricht

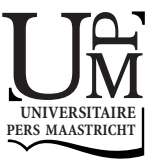

ISBN: 978-94-6380-079-2 


\title{
Migration, family separation and caregiving across borders
}

\section{A multi-sited ethnography of transnational child-raising arrangements between Ghana and the Netherlands}

\author{
Dissertation
}

\author{
to obtain the degree of Doctor at Maastricht University, \\ on the authority of the Rector Magnificus, Prof. Dr. Rianne M. Letschert \\ in accordance with the decision of the Board of Deans, \\ to be defended in public \\ on Thursday, 6 December 2018, at 12:00 hours
}

by

Miranda Poeze 


\section{SUPERVISOR}

Prof. dr. V. Mazzucato

Prof. dr. S. van Walsum $†$ (VU University Amsterdam)

CO-SUPERVISOR

Dr. B.B. Dito

ASSESMENT COMMITTEE

Prof. dr. E. Wesseling (Chair)

Dr. A. Fresnoza-Flot (Université Libre de Bruxelles, Belgium)

Prof. emerita T. Manuh (University of Ghana)

Prof. dr. H.E.G.S. Schneider

This dissertation has received funding from the Netherlands Organization for Scientific Research (NWO) (grant number W01.65.316). 
Acknowledgements 

Although this was my individual project and I bear full responsibility for the end result, there are many without whose help I would not have been able to complete it. To all those who in any kind of way have contributed to it, I want to say: Thank you so much! There are some people whose support has been invaluable and I would like to use these pages to acknowledge them.

Foremost, I would like to express appreciation to my supervisor Prof. dr. Valentina Mazzucato for taking me on board the TCRA-project and for introducing me to the field of transnational families and the Ghanaian migrant community in Amsterdam. I would like to thank you for your encouragements and for all the opportunities you have given me to grow as an academic researcher. Your expertise, guidance and critical comments have been vital to my research project. I also appreciate that you gave me the freedom to find my own way, that there was room for discussion, and that you pulled me in the right direction when I tended to drift off. Finally, I thank you for your patience. I thank my second supervisor Prof. dr. Sarah van Walsumt, who unfortunately could not witness the end result of this work, for being an inspiration and for helping me find my way in the complex migration legislation. I am also grateful to my co-promotors dr. Bilisuma Dito for the valuable discussions and the critical feedback that helped me sharpen my arguments, for the encouragements and for the pleasant 'train talks', and dr. Djamila Schans for guiding me through the first year of my Phd. I would also like to thank the members of the assessment committee Prof. dr. Lies Wisseling, Prof. dr. Hildegard Schneider, Prof. emerita Takyiwaa Manuh and dr. Asuncion Fresnoza-Flot, for the detailed comments to the final draft of the dissertation and for the encouraging words.

I thank my colleagues from the University of Ghana. I am especially grateful to $\mathrm{dr}$. Ernestina Dankyi for being such a wonderful colleague on the TCRA-project. I have learned a lot from you through our stimulating online and offline discussions, and I really appreciated our time in the field together; your warm personality opened doors and brought joy to the sometimes emotionally challenging fieldwork. I also thank you for your efforts to make our team-work work, and for sharing with me your rich data that helped give the unique breadth and depth to this research. I thank dr. Ernest Appiah for helping me get started with my fieldwork in Ghana and for connecting me to the right persons. I also thank you for the entertaining and insightful conversations on our daily trips to the university, and most of all I thank you for inviting me into your home during my first weeks in Ghana. Not only was your home a perfect getaway from the bustling city, it was also the place where I learned to appreciate the Ghanaian cuisine through the wonderful cooking skills of your wife Rosemund, and where I found in Thomas a friend and running buddy. You and your family will always have a special place in my heart. I also thank Prof. Mariama Awumbila, director of the Centre of Migration Studies at the University of Ghana, for giving me access to the university's research facilities and for offering me a place to work. I thank Prof. emerita Takyiwaa Manuh for making time to discuss my interview material during my first stay in Ghana and for the critical comments 
to earlier versions of some of the chapters. I am equally thankful to Jakpa Shu-aib, Rose Omari, my host family in Kumasi and the owners of Legassi Gardens in Accra for making my first trip to Ghana a pleasant one.

I thank my research assistants: Frank, for driving me around Accra; Osei Alexander, for introducing me to the head masters of the schools in Kumasi; Santino, Bernard, Thomas and Collins, for transcribing part of the interviews that I conducted in Ghana; Lena and Vivianne, for coding many of these interviews upon my return; and Corina, Daniel, Abena and Alex, for introducing me to new respondents in the Netherlands. I thank Samuel Danning-Tepran and Agyenim Brefo, for their efforts in teaching me the Twi language. I am also grateful to Veronica van der Kamp and David Adjekumhene, for introducing my research to the Ghanaian migrant community in Amsterdam, which was vital to open doors at the start of my doctoral research.

I would especially like to thank all the Ghanaian stay-behind children in Ghana and migrant parents in the Netherlands whose names cannot be disclosed, but who unselfishly participated in this research and who shared with me some of the most intimate and painful parts of their lives. I am very grateful to all those who shared their authentic stories with me: Meda w'ase papaapa!

I thank the editors of my published chapters, Prof. dr. Loretta Baldassar, Prof. dr. Laura Merla, dr. Majella Kilkey, dr. Ewa Palenga-Möllenbeck, and Prof. dr. Deborah Bryceson for the detailed and insightful comments on earlier drafts and for guiding me through the publication process. I also thank dr. Elena Moore and Prof. dr. Karin Wall, as well as all conference discussants and anonymous reviewers for the critical comments and helpful suggestions on earlier versions of the chapters.

This project would not have been possible without the generous funding of the Netherlands Organization for Scientific Research (NWO). I am grateful for the funding of my doctoral research, including the fieldtrips to Ghana that were initially not included in the project, and for the financial support to create a photobook about Ghanaian transnational families.

I am grateful to Prof. dr. Han van Dijk and dr. Loraine Nencel, as well as the other staff and PhD students of the CERES Research School for International Development, for helping me structure and finetune my doctoral research proposal during the first year of my PhD. I also thank all PhDs and other staff of the Graduate school at Maastricht University for offering a place to present and discuss my research.

Sabine Kuipers, Cindy van Montfoort, Patricia Jaspers, Elisabeth Suwandschieff, and Miranda Gubbels, thank you for helping me with all the administrative work related to my $\mathrm{PhD}$ and the TCRA-project. I also thank Adam Frick and the editors of the American Journal Experts for the English editing, and Datawyse for helping me design the cover, for the final editing and for guiding me through the printing process. 
A supportive network is important to stick through the difficult moments and to make the $\mathrm{PhD}$ period a pleasant time. I was lucky enough to be part of a great team of $\mathrm{PhD}$ and post-doc researchers at the Transnational Migration and Development research group at Maastricht University. I especially would like to thank my former colleagues Joan, Marieke, Karlijn, Kim, Nataliia, and Victor for the stimulating discussions and the valuable feedback that helped me strengthen my research papers. Above all I am grateful that we cared about each other and that we stood together in the sometimes harsh and competitive academic environment. Whenever I look back on my time in Maastricht I smile and reminisce our pleasant breaks - whether they were for coffee, lunch, or dinner - and of course our fun nights out. Karlijn, and Nataliia, I also really appreciate that you hosted me at your homes in Maastricht.

My paranymphs deserve a special mention. I chose you two, because you have been crucial throughout my PhD-life. Sharon, we only met shortly before I embarked on this $\mathrm{PhD}$ journey, but from the beginning when you encouraged me to accept the position when I was hesitant to move to Maastricht, until the end you have been a major support. You provided the necessary distraction and you were never tired of listening to my $\mathrm{PhD}$ troubles. I may not have always followed your advice, but I really appreciate that you were always there, physically or emotionally. Kim, my other paranymph, you have also been supportive in so many ways. We started off as colleagues, but soon you became a friend with whom I could laugh, talk and hang out until late at night. Thanks so much for all the good moments, for the many sleepovers, for your companionship in Ghana, for proofreading the Dutch summary, and above all for your encouraging words that helped me arrive at the finish line.

I am thankful to my former Master thesis supervisor, dr. Joost Beuving, for believing in me academically and for teaching me the fine art of ethnography and qualitative data analysis. Joost, you have been a great academic mentor. You encouraged me to pursue an academic career and you gave me the confidence to apply for the research position at Maastricht University.

I want to thank my friends for keeping me sane throughout my $\mathrm{PhD}$-life. I have not been around much lately, but you are certainly not forgotten. I especially thank: Odin, for being my lifeline and for helping me relocate when I was living a nomad life in Amsterdam; Maarten, for helping me move part of my belongings from Utrecht to Maastricht; Shirley, for softening my move to Maastricht by letting me stay in your lovely house in Utrecht during the weekends; and Bas, for the beautiful pictures that give faces to the stories of transnational family members.

I also want to thank my former colleagues at Ghent University and current colleagues at Vives University of Applied Sciences whom I came to know since I physically left Maastricht University. Your regular questions about the progress of my dissertation encouraged me to complete it. A special thank you to Korneel Holvoet for helping me 
edit the bibliography and to Prof. dr. Koen Stroeken and Leen Van der Vorst for providing me the mental space to write.

Finally, I would like to thank my family. I dedicate this work to my mother who passed away years before I started this project. I thank her for always believing in me, for her unconditional love and support, and for encouraging me to follow my dreams. I also thank my father, who saw me embark on this project but who passed away almost two years before I completed it. Both my father and my father-in-law, Eddi Norton, have been loving grandfathers to my children and provided the necessary care support at times when I had to write. Last but certainly not least, I thank the most important people in my life: Eddi, Lucía and Boaz. Writing my doctoral thesis has had a tremendous impact on our family life and many sacrifices had to me made on my behalf. I express great appreciation to you, Eddi, for helping me through the difficult moments, for encouraging me to persuade, and for being the parent to our children at times when I was not around. Finally, my precious children, Lucía and Boaz, the lights and loves of my life, I thank you for your beautiful smiles that always cheer me up. 


\section{Table of contents}

Acknowledgements

Chapter 1 Introduction 15

1.1 Migration, Family Separation and Child-Raising Arrangements 17

1.2 Studying Transnational Child-Raising Arrangements Between Ghana and the Netherlands: Contributions and Research Questions 20

1.3 Outline of the Thesis 25

Chapter 2 Conceptualising Cross-Border Families and Caregiving 27

2.1 Introduction 29

2.2 The Transnational Turn in Migration Studies 29

2.3 Transnational Families 32

2.3.1 Doing Kin Work across Borders 34

2.3.2 Gendered Parental Caregiving Practices: Transnational Mothers and their StayBehind Children 38

2.3.3 Beyond the Mother-Child Dyad: Incorporating Fathers and Caregivers 41

2.4 Situating Transnational Caregiving in Host and Home Country Contexts 45

2.4.1 Gendered Care Cultures 46

2.4.2 Political and Socioeconomic Contexts 49

2.5 Concluding Remarks $\quad 51$

Chapter 3 A Transnational Methodological Design 53

3.1 Introduction $\quad 55$

3.2 The TCRA Programme $\quad 55$

3.3 Methodological Considerations in the Study of Transnational Phenomena 56

3.4 Multi-Sited Fieldwork and the Implications for doing Ethnography 57

3.5 A Simultaneous Matched Sample Methodology 59

3.6 Samples, Fields and Methodological Tools 61

3.6.1 Stay-Behind Children in Ghana 61

3.6.2 Migrant Parents in the Netherlands: Matched and Non-Matched Samples 65

$\begin{array}{ll}3.7 \text { Teamwork } & 74\end{array}$

3.7.1 Sharing Field Notes 74

3.7.2 Exchange of Field Visits 75

$\begin{array}{ll}3.8 \text { Ethical Considerations } & 76\end{array}$

3.9 Positionality in a Transnational Research Team 78

$\begin{array}{ll}3.10 \text { Concluding Remarks } & 79\end{array}$ 
Chapter 4 Situating the Families in the Multi-Local Contexts

4.1 Introduction 83

4.2 Ghanaian Migration to the Netherlands in Historical Perspective 83

4.2.1 Globalisation and Migration Northwards 85

4.3 The Context of Reception: From a Welcoming to a Restrictive Destination

Country 89

4.3.1 Regulating Family Migration and Controlling its Effects 91

4.3.2 Policies to Discourage Undocumented Migration 95

4.3.3 Coping with a Restrictive Policy Climate: The Role of Support Networks 97

4.3.4 Ghanaian Migrants' Labour Market Position in the Netherlands 98

4.4 Ghanaian Families and Child-Raising Arrangements 99

4.4.1 Ghanaian Family Systems and the Value of Children 99

4.4.2 Motherhood and Fatherhood 100

4.4.3 Social Reproduction within Extended Kinship Networks: Social Parenthood and

Child-Fostering 102

4.4.4 Household Nucleation and Shifting Child-Raising Norms and Practices 103

4.4.5 Child Care in Ghanaian Transnational Families 105

4.5 Concluding Remarks 106

Chapter 5 Ghanaian Children in Transnational Families: Understanding the Experiences of Left-Behind Children through Local $\begin{array}{ll}\text { Parenting Norms } & 109\end{array}$

5.1 Introduction

5.2 Nuclear Family Ideal and Physical Separation 111

5.3 Social Acceptance of Parent-Child Separations $\quad 112$

5.4 Research Methods $\quad 114$

5.5 Children's Experiences of Living in Transnational Families 116

5.5.1 Feeling Cared About 116

5.5.2 The Transfer of 'Motherly' and 'Fatherly' Tasks 121

5.5.3 Children's Ideals of the Nuclear Family 126

5.6 Discussion and Conclusion 127

\section{Chapter 6 Beyond Breadwinning: Ghanaian Transnational Fathering in} the Netherlands

6.1 Introduction

6.2 Transnational Families and Fathering: A Literature Review 134

6.3 Ghanaian Migrants and the Dutch Migration Context 136

6.4 Methodology and Respondent Characteristics 136

6.5 Breadwinning Ideals and Practices 140

6.6 Communication and Visits: Nurturing Intimate Relationships 143

6.7 Intervening in the Care Arrangement 147

6.8 Conclusion 149 


\section{Chapter 7 Transnational Mothers and the Law: Ghanaian Women's}

Pathways to Family Reunion and Consequences for Family Life 151

7.1 Introduction

7.2 Transnational Families, Reunification and Migration Policies 154

7.3 Dutch Family Reunification Policies 155

7.4 Methodology and Respondent Characteristics 156

7.5 Encounters with Family Migration Policies 157

7.5.1 The Income Requirement 158

7.5.2 Proving the Family Bond $\quad 160$

7.6 Consequences for Family Strategies and Relationship Dynamics 161

7.6.1 Family Strategies and the Timing of Reunion 162

7.6.2 Dependencies and Limited Autonomy 164

7.6.3 Coping with Restrictions to Reunification $\quad 165$

$\begin{array}{ll}7.7 \text { Conclusion } & 167\end{array}$

\section{Chapter 8 Navigating Transnational Childcare Relationships: Migrant}

Parents and their Children's Caregivers in the Origin Country 169

8.1 Introduction 171

8.2 Doing Kin Work in Transnational Families: A Review of the Literature 172

8.3 A Simultaneous Matched Sample Methodology and Respondent Characteristics 174

8.4 Arranging Transnational Childcare 176

8.5 Navigating Childcare Relationships 179

8.5.1 Finances 179

8.5.2 Communication 182

8.6 Conclusion 186

$\begin{array}{ll}\text { Chapter } 9 \text { Conclusions } & 189\end{array}$

9.1 Introduction 191

9.2 Key Findings and Contributions to Transnational Family Studies 193

9.2.1. The Home Country Context: Gendered Care Cultures 193

9.2.2. The Host Country Context: The Political and Socio-Economic Contexts 198

9.2.3 Perpetuation and Creation of Inequalities and Shifting Child-Raising Arrangements 201

9.3 Where to go from Here? Directions for Future Research 204

$\begin{array}{ll}\text { References } & 209\end{array}$

Appendices $\quad 225$

Appendix A. Sample characteristics of stay-behind children 225

Appendix B. Migrant parent sample characteristics at time of first interview $\quad 227$

Appendix C. Overview of the most important changes in Dutch family migration

policy, $1982-2013$

Nederlandse samenvatting (Dutch summary) 233 
Valorisation addendum

Curriculum Vitae

253 
1

Introduction 



\subsection{Migration, Family Separation and Child-Raising Arrangements}

Veronica (talk show host): Ladies and gentlemen thanks for joining me this evening. I think Aba I would like to start with you (...) because I know your parents were here [the Netherlands] and you were left behind back home [Ghana] and you joined them. Can you just tell us a bit about your experiences living without your parents?

Aba: Of course, I can do that, but I was very young at that time so I don't know how much I can remember, but I was (...) between six and eight years old when my mum left me with my aunties. I lived with them, I schooled with them. I lived with my cousins, together with my aunty and her husband. Because I was very young I didn't really know what was going on. (...) I knew my mum was not there but (...) I didn't feel anything special or anything extraordinary, I just knew my mum was not with me and I am living with my aunt and someday I am going to join my mum.

Veronica: Is there a difference between how you raise your kids here in the Netherlands compared to the kids back home?

Emmanuel: There is a big difference because those in Africa (...) I haven't stayed with them for a long time. If they see me they sometimes don't feel the fatherly love but those here if they see me they feel the love...

Veronica: That means that the break always gives a gap?

Emmanuel: Yes of course, a great gap.

Rita: I came here when I was 16 years (...) and joined my mother and my father.

Back home in Ghana it was very difficult because I was living with my grandfather and also their children. Sometimes it was difficult for things that I needed, I couldn't get it because there were so many children. They were about seven or something like that and the old man and woman were not strong to provide for us so sometimes when you needed something they had to call my mother to send money to us. It was very difficult.

Veronica: In my case my child was with my sisters. I mean this is a house that I have put air conditioners and everything. I am doing it because my child is living there, but maybe even the school fees when you send them and then the child will call you and tell you that 'mum my school fees are still not paid', but if you ask, you will be in trouble. (...) I remember when I bought things for my son, sometimes the grandmother would tell him, "no, I won't allow you to wear it, your mother is spoiling you." Finally, my son told me, "please, don't ask about it."

Talk show broadcast on local television in Amsterdam, July $2010^{1}$

\footnotetext{
${ }^{1}$ This talk show was co-produced by the Transnational Child-Raising Arrangements project (TCRA) of Maastricht University of which this research is part, and GamTV, a Ghanaian television show which is broadcast on one of Amsterdam's local channels. Veronica van der Kamp-the host of the show-is its director. Veronica dedicated
} 
One of the most important motivations for people to migrate from the Global South to the North is to seek a better future for their children. The dialogue presented above, however, points to an issue that many families from the Global South face: families become split entities in the context of international migration. Migrants often leave their children in their country of origin, by force or by choice, resulting in children staying behind in the care of the other biological parent, or other kin or non-kin. This thesis examines transnational child care arrangements, that is, the whole array of organisation and dynamics within cross-border child care. This includes the forms that families take, depending on several factors: who migrates, who the caregiver is and how many children are involved; the negotiations that are entailed in arranging care, e.g. agreements, tacit and explicit, between parents and caregivers; and the relationships and what flows through them, e.g. tensions and care.

The dialogue above also touches upon an important issue that is further explored in this thesis: where the actor is situated in the care arrangement, socially and geographically, affects daily experiences of living in cross-border family formations. Immigrant parents like Veronica and Emmanuel in the dialogue presented above, need to fulfil the financial demands from family members in the country of origin and navigate long-distance care responsibilities and relationships. At the other end are those who stay behind in their country of origin; the left-behind children like Aba and Rita, who are forced to adjust to care arrangements over which they generally have little control, alongside caregivers - usually women - for whom the burden of work and care is compounded by the care of the migrant's children. This thesis is an account of the complex and interconnected everyday care practices and experiences within Ghanaian families that have become split entities in the context of international migration.

The thesis mainly focuses on Ghanaian migrant parents in the Netherlands. Yet it also touches upon the experiences of children who stay behind when parents migrate to the Global North, and to a certain extent, the people who take care of the children, through the accounts of stay-behind children and migrant parents. More generally, this thesis is an account of how global processes interact with and penetrate everyday localised care practices and experiences when familial caregiving transcends national borders.

Family separation in the context of international migration is not a new phenomenon, for families have lived in a state of separation for as long as people migrate. Yet several simultaneous processes in the second half of the $20^{\text {th }}$ century have increased the number of families who are split entities as a result of international migration and they have changed the terms of such separations. Important have been increases in global migration from the South to the North and the feminisation of the global labour force with women increasingly migrating independently. This has been largely fueled by economic stress in the Global South, a result of Structural Adjustment

one of her weekly talk shows to the topic of my research. Together with five invited Ghanaian immigrants she discussed experiences of parent-child separation in the context of long-distance migration. The show aired several times in July 2010. 
Policies (SAPs) and enforced macro-economic budget cuts (Castles \& Miller, 2009; Manuh, 1994). At the same time, the global recession and the oil crisis of the 1970s instigated anti-immigration sentiments in different popular European immigration countries, including the Netherlands (Wimmer \& Glick Schiller, 2003). In the late 1980s, migration became a political priority in many popular immigration countries, leading to increased restrictions to control migration and to reduce its effects. Family-related migration in particular was considered problematic in terms of integration and chain migration, as well as 'fake' child adoptions and marriages (Kofman et al., 2011), instigating a growing trend to control family reunification and to tighten provisions in most popular European destination countries (Kofman, 2004; Organisation for Economic Co-operation and Development (OECD), 2011). Moreover, it has become increasingly difficult for third-country nationals (TCNs), i.e. immigrants from outside the European Union, to obtain legal residency that provides entry to the formal labour market while retaining the possibility to re-enter their country of origin and to reunite with family members.

Restrictive migration policy climates delimit and constrain family efforts to organise themselves according to their own preferences and forces more and more families to live their family lives across national borders. This does not mean that family separation is always forced; it may also be the result of parents wanting to avoid the extra cost of the trip; not wanting their children to be exposed to the harsh environments of the neighbourhoods where many immigrants settle; and sometimes children themselves prefer to stay in the home country (Bernhard, Goldring \& Landolt, 2009). Moreover, family migration and separation may even become the norm when family members consider it to be the only window of opportunity to achieve economic success (Sorensen \& Olwig, 2002).

In light of increased South-North migration flows and tightened migration policies, it can be expected that more and more people of the Global South live geographically apart from their family members. At the same time, recent technological developments, notably cheaper intercontinental flights and long-distance communication devices, such as the Internet and mobile phones, facilitate cross-border connections of family members who live geographically dispersed (Glick Schiller, Basch \& Szanton-Blanc, 1995; Portes, Guarnizo \& Landolt, 1999). This has created what Bryceson and Vuorela (2002) call transnational families, which they describe as families that live across national borders but who nonetheless maintain a feeling of familyhood. The reorganisation of family and care across national borders, often spanning long distances and for long periods of time, however, calls into question our understandings of family and social reproduction and raises questions about the social and emotional consequences for the individual family members. This is especially the case when parents migrate, leaving children behind in the care of another person, whether this is the other biological parent, or other kin or non-kin.

Without neglecting the positive impacts that transnational migration may have on the material wealth and educational career of children who stay behind in the country of 
origin, parental migration poses challenges to the organisation of child-raising arrangements and qualitatively transforms the role of the parent as the primary caregiver of the child (Mazzucato \& Schans, 2008). Parental migration asks for the adaptation of care arrangements because parents can no longer provide the day-to-day support that requires geographical proximity, and decisions pertaining to the care of the children have to be made across borders. This 'care drain', as Ehrenreich and Hochschild (2002) dubbed the absence of the primary caregiver due to international migration, raises important questions on the emotional costs, everyday care practices and the consequences for family stability. This is even more the case with long-distance migration and prolonged separations, since the geographical distance limits the time that can be spent together and constrains the opportunities to forge and maintain intimate ties (Mazzucato \& Schans, 2008, 2011; Whitehead \& Hashim, 2005). Although the scholarship on transnational families has proliferated over the past decades, significant theoretical and methodological gaps remain in academic literature (Bryceson \& Vuorela, 2002; König \& de Regt, 2010; Mazzucato \& Schans, 2008, 2011), some of which this study seeks to address and which are discussed below.

\subsection{Studying Transnational Child-Raising Arrangements Between Ghana and the Netherlands: Contributions and Research Questions}

This thesis provides an in-depth understanding and a critical analysis of how transnational caregiving practices reshape and reconfigure family care relationships between Ghana and the Netherlands. By studying the shifting constructions of childraising arrangements and everyday care practices and relationships within Ghanaian families 'on the move', this research is part of a theoretical shift in family studies that reconsiders family life in the light of long-distance migration (Baldassar \& Merla, 2014; Mazzucato \& Schans, 2011; Suarez-Orozco, Todorova \& Louie, 2002). It contributes to the growing body of literature on transnational family-making that brings together scholarship on the anthropology and sociology of migration, family sociology and gender studies.

This study is innovative for its inclusion of different actors involved in the transnational child-raising arrangement. Contrary to the bulk of literature that has primarily focused on migrant mothers (Bernhard, Goldring \& Landolt, 2005; Dreby, 2006; Fresnoza-Flot, 2009; Hondagnue-Sotelo \& Avila, 1997; Horton, 2009; MoranTaylor, 2008; Parreñas, 2001, 2005a; Schmalzbauer, 2004) and their stay-behind children (Dreby, 2007; Parreñas, 2005b; Schmalzbauer, 2008), the current thesis also focuses on the experiences of migrant fathers and stay-behind children's experiences with migrant mothers and fathers. The multi-sited research design that is at the basis of the research has facilitated the incorporation of multiple actors, although the bulk of work centres on migrant parents. The examination across geographical boundaries makes for a comprehensive account of transnational child-raising arrangements that delineates the 
complex ways in which cross-border care arrangements and relationships are organised, valued and given meaning, depending on the social and geographical location of the actors. As such, we can come to a better understanding of how transnational care arrangements work, what actors have to do to make it work, and how they experience living in such arrangements. Furthermore, in the analysis of migrant parents' and leftbehind children's experiences, I integrate the often-neglected or underestimated role of the caregiver.

This thesis builds on and contributes to literature that recognises that actions, attitudes and experiences within transnational families are not only shaped by inequalities on the global level and by personal characteristics, but also by people's placement in the local and national context, meaning that the study of transnational family networks should not overemphasise a deterritorialised world. Since transnational phenomena are anchored in and transcend one or more national borders, localities continue to play a key role in migrants' and non-migrants' daily lives and interconnections (Glick Schiller, Basch \& Szanton-Blanc, 1992; Faist, 2012; Goldring, 2002; Kearney, 1995; Schmalzbauer, 2004; Smith \& Guarnizo, 1998). Hence, both migrants' and nonmigrants' lives are locally anchored in multiple ways, obliging migrants and non-migrants to deal with multiple political, social and cultural realities (Grillo \& Mazzucato, 2008; Kilkey \& Merla, 2014). For instance, family members' cross-border actions and mobility, as well as access to rights and legal status, are controlled, limited and enabled by immigration policies that are proposed, reshaped and tightened by the nation-states into which migrants settle_-although European Member States are to some extent confined by the European Union's larger political body.

Accordingly, the significance of locality and nation-state boundaries in structuring daily lives should be recognised in studies on transnational phenomena (Barglowski, Bilecen \& Amelina, 2015; Faist, 2012; Kilkey \& Merla, 2014). Data collection should therefore include elements of both de-territorialisation and territorialisation, or in other words, both cross-border actions and connections, as well as the institutional contexts of the home and host country that influence and curtail cross-border flows, and which in turn are impacted by the transnational lives of migrants and non-migrants (Faist, 2012; Kilkey \& Merla, 2014; Levitt \& Glick Schiller, 2004; Mazzucato, Kabki \& Smith, 2006). In this way, my analysis adds insights to the ways variations among host and home country institutions affect dynamics of transnational child-raising arrangements.

The current study is part of the broader Transnational Child-Raising Arrangements (TCRA) project that includes multiple researchers, disciplines and field sites into one research project. The project, consisting of two quantitative studies and two qualitative studies in Ghana and the Netherlands, allowed for cross-border and cross-disciplinary exchanges that has benefitted the current study in many ways. Importantly, the quantitative research in Ghana facilitated access to a large number of left-behind children, which is the basis for Chapter Five. Moreover, the quantitative research in the Netherlands helped me gain a broader understanding of what I was studying and helped orient me in my investigation. Notable are the quantitative findings that confirmed the 
important role of income and legal status on migrants' well-being (Dito, Mazzucato \& Schans, 2017). My qualitative research helped explain how these aspects work out at the level of transnational family relationships (Chapter Six).

The teamwork also allowed for a methodological contribution to qualitative studies of transnational families for its application of the innovative simultaneous matched sample (SMS) methodology (Mazzucato, 2009a). To my knowledge, this methodology has not been applied to the study of transnational families before. The SMS methodology enables a team of researchers to conduct ethnographic research at the same time in the multiple locations where the different actors of the transnational network are involved. This helps the researcher to overcome the loss of depth that is inherent to a step-wise multi-sited research design and the loss of breadth in case of single-site research (Mazzucato, 2009a). Practically speaking, this meant that I investigated the migrant parents in the Netherlands, while Ghana-based researcher Ernestina Dankyi simultaneously examined the caregivers of these parents' children. The close collaboration and exchange of data from multiple localities provided necessary insights on what was happening on the other side. This helped us to better understand the perspectives of our respondents and allowed me to go into more depth in my own research location. Ernestina Dankyi and myself were able to join the different perspectives of migrant parents and their children's caregivers that enabled the study of interpersonal processes up close and in detail over more than two years and from two localities. While this multi-local perspective informed the whole thesis, it is particularly evident in Chapter Eight.

Finally, the thesis adds original empirical data to the study of transnational families as this qualitative study focuses on the African sending context, taking Ghana as a case study. The bulk of qualitative transnational family studies has concentrated on a few sending regions: Latin America (Bernhard, Goldring \& Landolt, 2005; Boccagni, 2012; Dreby, 2006; Hondagnue-Sotelo \& Avila, 1997; Schmalzbauer, 2004), the Asian-Pacific (Parreñas, 2001; Fresnoza-Flot, 2009; Hoang \& Yeoh, 2012) and East and Central Europe (e.g. Ryan, 2011; Zmegač, 2007).

Recently, a growing body of mainly quantitative studies has emerged focusing on African transnational families, particularly studying stay-behind children's well-being (Cebotari \& Mazzucato, 2016; Cebotari, Mazzucato \& Appiah, 2017; Cebotari, Mazzucato \& Siegel, 2017a, 2017b; Mazzucato et al., 2015), migrant parents' subjective health and well-being (Dito, Mazzucato \& Schans, 2017; Haagsman, Mazzucato \& Dito, 2015; Mazzucato et al., 2017), parents' relationships with the child (Haagsman \& Mazzucato, 2014), and spousal relationships and divorce patterns (Caarls \& Mazzucato, 2015; Caarls et al., 2013). The current study adds to African transnational family studies that are of qualitative nature (Bledsoe \& Sow, 2008; Coe, 2008, 2011a, 2011b; Dankyi, 2014; Dankyi, Mazzucato \& Manuh, 2017; Wong, 2014), which explore relationship dynamics and gender role divisions within transnational families. A focus on the Ghanaian sending context broadens the geographical scope within transnational family studies that apply ethnographic methods. 
The specific family and child-raising practices within the Ghanaian sending context also provide an interesting case for comparative reasons. In Ghana, childcare is considered to be the shared responsibility of biological parents and extended kin, with childcare tasks often transferred between different members of the family (Alber, 2003; Goody, 1982; Mensa-Bonsu \& Dowuona-Hammond, 1996). These norms of 'social parenthood', rendering childcare inclusive and flexible, are reflected in the common practices of child-fostering. Within these informal adoption arrangements children spend part of their childhood in a non-natal home for several reasons, for instance to facilitate their education or to cope with a crisis situation in the home setting (Bledsoe, 1990; Desai, 1992; Isiugo-Abanihe, 1985, 1994; Mensa-Bonsu \& Dowuona-Hammond, 1996; Pilon, 2003). Such family norms problematise the nuclear family ideal in which proximity between parents and children is considered a prerequisite for the wellfunctioning of parent-child relationships and the development of the child. It can be expected that these childcare norms and practices, which have also been observed in other sending regions such as the Caribbean (Olwig, 2012), the Cape Verde (Åkesson, Carling \& Drotbohm, 2012), and Mali (Whitehouse, 2009), result in distinct outcomes from what is found among transnational families from sending contexts where nuclear family ideals prevail (see for example Dreby, 2010 on Mexican transnational families). It therefore provides a valuable perspective on the study of transnational families (Mazzucato \& Schans, 2011).

Due to difficulties identifying migrant households in national statistics, the number of children living in a household from which one or both parents have migrated to the Global North remains no more than an estimate (Whitehead \& Hashim, 2005). Yet several sources suggest that spatial fragmentation among Ghanaian families is prevalent. For example, a large-scale study among different African migrant groups in Europe found that of the Ghanaian migrants interviewed in the Netherlands and the United Kingdom, 10 years after migration, only $28 \%$ had reunited with their child, and most of them in the country of origin (Caarls et al., 2017). Moreover, the Ghanaian national survey showed that $24 \%$ of Ghanaian children lived with one biological parent, while the other parent had migrated nationally or internationally (Ghana Statistical Service (GSS), 2009). On the basis of these sources, one can assume that the prevalence of Ghanaian family separation in the context of international migration is significant and therefore deserving of attention.

The Netherlands provides an interesting receiving context through which to study cross-border family life since it has attracted many Ghanaians who left the African continent in large numbers from the mid-1980s, following political, economic and social reconfigurations in that region (Anarfi et al., 2003). Dutch statistics show a steady growth of Ghanaians over the past decades with an officially registered population of 12,480 in 1996, 15,609 in 2000 and 23,430 in 2017 (Centraal Bureau voor de Statistiek (CBS), 2018a), and an estimated equal number of irregular immigrants (Mazzucato, 2009b; Twum-Baah, 2005). The gender composition has always been balanced. At the start of 
this research in 2010, 12,988 first-generation Ghanaians-the group of interest to this study - were officially registered in the Netherlands (CBS, 2018a).

Ghanaian migrants in the Netherlands are part of 'Europe's "new" immigrant population' (Grillo \& Mazzucato, 2008: 176). As a relatively recent immigrant group, they are qualitatively different from more established migrants in the Netherlands, notably Turkish and Moroccan migrants (Mazzucato, 2008a). The latter largely arrived through 'guestworker' programmes and benefitted from more welcoming family migration policies. They also had more time to establish networks that provide different types of support. 'New' economic migrants, such as those coming from Eastern Europe, and importantly for this study, from sub-Saharan Africa, who began entering the Netherlands in large numbers since the mid-1980s, enter more hostile environments and are confronted with restrictive migration policies. Consequently, the Ghanaian migrant population is relatively young compared to more established migrant groups, and it is severely limited in its possibilities to enter, stay and reunite with family members (Mazzucato, 2008a).

The Netherlands is therefore an interesting context from which to explore the everyday care practices in Ghanaian transnational families from the focal point of migrant parents. Even more so because — at the start of the research in 2010_Dutch policies to control immigration flows were considered as one of the most restrictive in Europe and significantly challenged migrants' rights for family life as is set out in several human right documents (Wiesbrock, 2010). The Dutch sending context allowed me to assess the impact of constraining macro-level policies on the everyday experiences of migrants and the ways they organise their family lives. This assessment is also of relevance to policy makers, who should realise and recognise how their policies generate and perpetuate family relationships in the context of transnational migration (Bernhard, Landolt \& Goldring, 2009).

The following research question is central to the thesis' investigation: How are childraising arrangements between Ghana and the Netherlands-comprising practices, relationships and forms — enacted, reconfigured and maintained by migrant parents and left-behind children, and how are they shaped by family and child-raising norms of the home country and the political and socioeconomic context of the host country? The sub-questions that are examined in the four empirical chapters are derived from the conceptual framework of the thesis, i.e. that individuals should be situated in the multiple local contexts, and consider the different actors involved in the transnational childraising arrangement.

- How do left-behind children experience the separation from their migrant mothers and fathers?

- How does the political and socioeconomic context of the destination country, alongside gendered parenting norms in the origin country, shape transnational fathering practices and emotional experiences?

- What are the experiences of migrant mothers with family reunification laws and how do these laws impinge on mothers' everyday family lives and strategies? 
- How do migrant parents negotiate and maintain relationships with their children's caregivers, and how are such relationships transformed and challenged by the transnational context?

Each sub-question corresponds to an identified gap in the transnational family literature, which are described in more detail in Chapter Two.

\subsection{Outline of the Thesis}

The information provided in the subsequent eight chapters allows me to formulate answers to the questions presented above. Chapter Two provides a conceptual framework through which transnational child-raising arrangements between Ghana and the Netherlands can be explored. It discusses the broader transnationalism scholarship of which transnational family research is a substrand and identifies the gaps that this research seeks to fill. Building on recent contributions to the study of transnational families, this thesis incorporates a broad unit of analysis by including migrant parents, children and to a certain degree also caregivers, and focuses on home and host country contexts. In Chapter Three the research design of the study is discussed. The chapter describes the different field sites, samples and sampling strategies, methods, ethics and particular aspects related to the teamwork. Importantly, it addresses the challenges that the study of transnational phenomena poses to ethnographic research and ways in which I was able to mitigate these through collaboration within a team of researchers in the larger TCRA project.

Chapter Four describes the relevant contexts of the home and host societies. Having identified the importance of gender care cultures of the home society and the political and socioeconomic context of the host country in Chapter Two, this chapter describes these contexts for the current case study. Hence, I consider the historical context of migration and settlement of Ghanaians in the Netherlands against the backdrop of the increasingly restrictive political climate that seeks to reduce migration and to control its effect, notably by constraining low-skilled, undocumented and family migration. Moreover, it discusses in detail Ghanaian cultural norms and practices of family and caregiving.

Because the empirical chapters are written as standalone articles that have been published as journal articles (Chapter Six and Eight) and as book chapters (Chapters Five and Seven), the theoretical, background and methodological chapters inevitably contain some repetition, but they are nonetheless relevant to bring together the different pieces into a single framework.

Chapters Five, Six, Seven and Eight present the empirical findings. The chapters cover the multiple perspectives of migrant parents and left-behind children and the two home and host country contexts in which the transnational family networks and everyday lived experiences are embedded. Chapter Five addresses transnational family arrangements from the focal point of Ghanaian youth, aged 12 to 22, in Accra and 
Kumasi. The focus is on children's experiences of living in transnational families and their relationships with both the migrant parent and the caregiver in Ghana. Chapters Six and Seven discuss from the perspectives of transnational fathers and mothers in the Netherlands, respectively, how the host society's political and socioeconomic contexts affect family mobility, relationships and care practices.

Chapter Six probes how the intersection of gender norms, legal immigration status and access to financial resources steers Dutch-based Ghanaian transnational fathers' attitudes and actual care practices. This chapter draws on ethnographic research with Ghanaian transnational fathers. Chapter Seven explores Ghanaian transnational mothers' encounters with Dutch family migration policies and the impacts such policies have on their pathways to family reunion and the consequences for family relationships and strategies. This chapter adopts a gender-sensitive approach and draws on in-depth interviews with female Ghanaian migrants in the Netherlands with one or more children residing in Ghana.

Chapter Eight investigates the daily work that is entailed in maintaining informal transnational relationships of childcare between migrant parents and kin and non-kin caregivers in the origin country, who are not the children's biological parents. By applying the concept of kin work, me and my co-authors explore the way work is performed within transnational care relationships. This chapter uses data from both the migrant parents in the Netherlands collected by myself and from the caregivers in Ghana collected by Ernestina Dankyi.

In the conclusion, I return to the theoretical discussion around shifting notions of family and care in the light of international migration. This chapter lists the key findings of the research and summarises the implications of the study for transnational family literature. The thesis concludes with several suggestions for future research. 


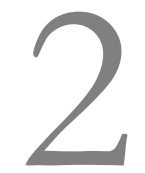

Conceptualising Cross-Border Families and Caregiving 



\subsection{Introduction}

Migrants and non-migrants contribute to the maintenance of family life across borders through their interconnected productive and reproductive work, yet geographical distance poses limitations to the ways in which family life can be practiced and intimate relationships can be maintained. The current thesis is located within transnationalism research that rapidly developed since the 1990s and that considers the multi-local embeddedness of migrants' social networks. More specifically, it draws on transnational family research, a substrand of transnationalism studies, that considers how family patterns and caregiving change, are recreated and given meaning in the context of longdistance migration. With its roots in anthropology and sociology of migration, transnational family research has developed over the course of almost two decades into a burgeoning literature that has explored the multifaceted family lives of migrants and their counterparts in the origin country. It therefore provides a useful analytical framework through which to explore the transnational child-raising arrangements between Ghana and the Netherlands.

Aside from discussing the relevant theoretical contributions in transnationalism research (Section 2.2) and transnational family research (Section 2.3), with a special focus on doing kin work across borders (Section 2.3.1) and gendered parental care (Section 2.3.2), this chapter identifies the gaps in the literature that the current study seeks to address. In Section 2.3.3, I argue for a broader unit of analysis that incorporates different actors that have long remained obscured in transnational family research, notably fathers and caregivers. Moreover, drawing on insights from transnationalism research that recognises the localised nature of transnational networks, and more recent contributions in transnational family studies that emphasises individuals' situatedness in multiple institutional contexts (Section 2.4), this study takes into account two parameters that have to date remained under-researched: gendered care cultures (Section 2.4.1) and the political and socioeconomic context (Section 2.4.2).

\subsection{The Transnational Turn in Migration Studies}

In the early 1990s, anthropologists Glick Schiller, Basch, and Szanton-Blanc (1992) were among the first to rethink the conceptualisation of migration processes. They argued that the former lexicon of 'immigrants' and 'migrants' conjured up images of 'uprootedness', assimilation, and on the other hand return and temporariness, assuming migrants' single focus on either the home or the host society. Such a bio-polar conceptualisation of migration (Rouse, 1992) was no longer applicable to an emerging migrant population who freely moved back and forth and whose social, cultural, political and economic connections spanned both host and home societies, creating new spheres of transnational cultures, identities and communities (Basch, Glick Schiller \& SzantonBlanc, 1994; Kearney, 1995; Rouse, 1992). The authors defined transnationalism as 'the 
processes by which immigrants forge and sustain multi-stranded social relationships that link together their societies of origin and settlement' (Glick Schiller, Basch \& SzantonBlanc, 1992: 1). The concept of transmigrants was introduced to reflect migrants' multiple and continuous cross-border linkages and activities that define their identities and shape their daily lived experiences in relation to more than one nation-state (Glick Schiller, Basch \& Szanton-Blanc, 1992, 1995). Central to this conceptualisation is the idea that transmigrants are simultaneously connected to two (or more) localities (Basch, Glick Schiller \& Szanton-Blanc, 1994; Glick Schiller, Basch \& Szanton-Blanc, 1992, 1995; Glick Schiller \& Levitt, 2006; Levitt \& Glick Schiller, 2004; Vertovec, 1999).

To understand why immigrants invest so much in maintaining ties to the home country, transnational migration has to be considered within the light of the new order of flows of capitalism and the development of an international division of labour (Glick Schiller, Basch \& Szanton-Blanc, 1992; Basch, Glick Schiller \& Szanton-Blanc, 1994). Increased dispersion of capital since the 1960s and 1970s moved industrial production from the core to the periphery, engendering economic dislocations and social reconfigurations in capital dependent countries and forcing workers to move to urban centres in core countries. Continued economic instability, marginalisation and daily forms of discrimination confronted many immigrants in the host countries. As a form of resistance to migrants' disadvantaged position and impossibility_ or undesirabilityto fully integrate in the new country, migrants established and maintained transnational social networks (Basch, Glick Schiller \& Szanton-Blanc, 1994; Glick Schiller, Basch \& Szanton-Blanc, 1995; Portes, Guarnizo \& Landolt, 1999). The nation building projects of origin countries to create transnational political loyalties among immigrants should also not be underestimated in the formation of transnational connections (Glick Schiller, Basch \& Szanton-Blanc, 1995).

The transnational framework has had important consequences for migration studies. It shifted the research objective from causes of migration and migrant adaptation by means of assimilation and ethnic pluralism to migrants' and their descendants' creation of cross-border ties as a form of successful adaptation and resistance to dominant hegemonies (Faist, 1998; Mazzucato et al., 2004; Portes, 1999; Portes, Guarnizo \& Landolt, 1999). Moreover, it problematised assumptions about space, since a one-onone mapping of social, cultural, economic and political processes onto one geographical space was no longer appropriate (Basch, Glick Schiller \& Szanton-Blanc, 1994; Kearney, 1995; Mazzucato et al., 2004). A transnational approach moves away from what Wimmer and Glick Schiller (2003) called 'methodological nationalism', the idea that nation-states provide the natural boundaries in which economic, political, cultural, social and political processes operate. This reformulation of society beyond that of a bounded entity suggests that the daily life of migrants cannot be understood by looking only at what happens within nation-state borders. Rather, migrants' multi-local and multi-layered embeddedness forces us to broaden and deepen our analytical lens (Levitt \& Glick Schiller, 2004). 
Over the past decades, transnationalism has become one of the principal topics of interest in the anthropology and sociology of migration (Vertovec, 1999, 2007). However, the first initiated conceptual framework raised criticism on transnationalism as a phenomenon and as a concept (Mazzucato et al., 2004). Some criticism was directed at the durability of the phenomenon, with scholars anticipating a diminishing significance among future generations (Portes, Guarnizo \& Landolt, 1999). Moreover, scholars argued that the newness of the phenomenon was overestimated and provided evidence of earlier cross-border activities (Foner, 1997a; Morawska, 2004).

Nonetheless, a break from the past could be claimed on the basis of the dramatic change in the magnitude of transnational ties. Alongside the changing global labour market, technological changes have led to rapid proliferations of social networks across borders. Cheaper international air travel, long-distance communication devices and electronic money transfer systems facilitated and increased the speed, scope and quantity of the circulation of communication, goods, people and knowledge between countries (Glick Schiller, Basch \& Szanton-Blanc, 1992; Levitt \& Glick Schiller, 2004; Portes, Guarnizo \& Landolt, 1999; Vertovec, 1999). Improved transportation and communication technologies compressed time and space, shortening the social distance between the origin and destination country to a degree that was never seen before. Glick Schiller and Levitt (2006: 10) also added that the newness should not be seen so much in the phenomenon itself but in 'the change in analytical framework and the changing processes of globalisation.'

Since its first inception, scholars have advanced the theoretical framework, thereby abating some of its previously identified shortcomings. As Levitt and Jaworsky (2007: 131) contend, early transnationalism scholars 'tended to see transnational migration everywhere when, in fact, the range and scope of migrants' transnational practices vary considerably.' Moreover, transnationalism had become a container concept that encompassed all international activities and therefore lacked analytical value (Portes, 1999). In response, Smith and Guarnizo (1998) distinguished between transnationalism 'from below' and 'from above', referring to a type of grassroots transnationalism initiated by individual immigrants as opposed to transnational activities originating from state actors and large-scale organisations. Portes (1999) further delineated 'transnational' to include only activities that emerged and were practiced by individual non-state actors and their networks, making the individual and his or her transnational network the only appropriate level of analysis. According to Mazzucato et al. (2004), this shift in the level of analysis from the individual to social networks has been one of the major contributions of the transnational literature, since it recognises that individual migrants are part of a larger network that transcends national boundaries.

Scholars have further debated the proper parameters. Portes, Guarnizo and Landolt (1999: 219) delimited transnational occupations and activities to those 'that require regular and sustained social contact over time across national borders'. Irregular activities can strengthen the transnational field, but they are not original enough to justify a new topic of investigation, so they reckoned. Others, however, advocate a broader definition 
that includes the majority of transnational practices that are informal and sporadic in nature, but which still have the potential to transform home country conditions, values and practices (Levitt \& Glick Schiller, 2004).

The recognition that migrants' lives are increasingly and with greater intensity located within more than one society has drawn researchers' attention to the study of transformations in the economic, political, cultural, religious and social realms (see Levitt \& Jaworsky, 2007 for an overview). Much scholarly attention is placed on describing the formation of cross-border networks and the social structures that they encompass and redefine (Levitt \& Glick Schiller, 2004; Levitt \& Jaworksky, 2007). Interaction within such cross-border networks contributes to fluid spaces that encompass 'here' and 'there', or what scholars call transnational social spaces (Faist\& 1998; Pries, 2001, 2005) or transnational social fields (Glick Schiller, Basch \& Szanton-Blanc, 1992; Levitt \& Glick Schiller, 2004). They signify real and imagined interactions to which members of crossborder networks attach, among others, shared meaning, norms and identities.

The conceptualisation of fluid social spaces or fields also includes non-migrants because transnational connections extend to and directly or indirectly transform the daily practices and experiences of those who do not move (Levitt, 2001; Levitt \& Jaworsky, 2007; Levitt \& Glick Schiller, 2004). The form and intensity of transnational ties within such spaces can range from, and shift between, temporary and loose or durable and stable, responding to the changing needs and circumstances of individuals in the crossborder networks (Faist, 1998; Pries, 2005). Without overestimating participants' freedom in determining the terms of movement, conditions and opportunities, Pries (2001: 69) has argued that 'transnational social spaces are pluri-local frames of reference which structure everyday practices, social positions, employment trajectories and biographies, and human identities, and simultaneously exits above and beyond the social contexts of national societies'.

\subsection{Transnational Families}

Several scholars pointed to kin networks as an important form of transnational social spaces - or fields - and called upon researchers to examine the implications of transnationalism for kinship systems and family organisation (Faist, 1998; Glick Schiller, Basch \& Szanton-Blanc, 1992). Initially, researchers focused on the social capital that multi-local family networks provided. Researchers argued that transactions based on exchange, reciprocity and solidarity in multi-local family networks are vital to shaping and maintaining the circulation of goods and people across national borders that offer access to multi-local resources (Faist, 1998; Glick Schiller, Basch \& Szanton-Blanc, 1995). Family migration was considered a collective strategy that acted as a type of informal risk insurance and as a way to improve the living standard for those whose economic opportunities are constrained by global inequality, both at home and abroad. Faist (1998), for instance, pointed to migrants' remittance-sending behaviour to family 
members in the home country, as well as import-export businesses and niche economies in the host society.

Yet, much scholarship on transnational phenomena tended to focus on the economic, political and cultural aspects of it, leaving underexplored how family life when enacted transnationally redefines the family as a social institution of production and reproduction (Bryceson \& Vuorela, 2002; Levitt \& Glick Schiller, 2004; Schmalzbauer, 2004). Moreover, the emotional, social and financial costs for the different actors involved, both at home and abroad, were for long left underexplored (HondagnueSotelo \& Avila, 1997; Mazzucato \& Schans, 2008; Whitehead \& Hashim, 2005).

This rapidly changed around the turn of the century, with scholars approaching cross-border family networks as a transnational living arrangement. Bryceson and Vuorela (2002: 3) were the first to introduce the concept of transnational families, which they defined as 'families that live some or most of the time separated from each other, yet hold together and create something that can be seen as a feeling of collective welfare and unity, namely "familyhood", even across national borders.' Despite often prolonged separations, family members maintain a sense of 'co-presence' (Urry, 2003) while physically absent, which, just as with other transnational phenomena, is facilitated by recent improvements in technology and communication systems that enable crossborder movements and communication across distance. Inherent in this notion of transnational family is the idea that families are social constructions that provide a sense of belonging in real and imaged communities (Bryceson, 2002).

In addition to the commonly used concept of transnational families, others have coined terms such as 'global households' (Kofman, 2012), 'migrating families' (Ryan, 2011), 'internationalisation of kinship' (Ho, 1993), and 'transnational households' (Drotbohm, 2009). What they all have in common is that they redefine family units as geographically-dispersed social groups, which may constitute both biological and social ties. This sense of family captures a chosen, fluid and inclusive sense of relatedness that is constantly in flux and renegotiated, as Boehm argued:

Transnational families are, without question, dynamic. Indeed, migrants, whose lives are characterised by frequent movement, continuously maintain, reassert, reconfigure, and transform family. Who is understood to constitute family relations, the physical and symbolic locations of family members, how kinship ties are arranged and maintained, and the meanings and significance attached to particular family relations are never fixed, and notably malleable in the context of transnational migration.

(Boehm, 2008: 786-787)

An important underlying assumption of the concept of transnational families is that it considers family life and emotional bonds as not conditional upon geographical proximity and that families are not necessarily deficient because family members do not physically reside in the same geographically-bounded household (Baldassar, 2007; Baldassar \& Baldock, 2000; Baldassar \& Merla, 2014; Bernard, Landolt \& Goldring, 
2009; Goulbourne \& Chamberlain, 2001). This notion of an unbounded family unit has complicated binary associations of family and household that assume 'that societal and geographical spaces share an exclusive relationship to one another' (Pries, 2005: 172). Notably, in family sociology literature, the family was commonly defined as a nuclear and bounded geographical unit whereby proximity was considered necessary for family life and intrafamilial care (Baldassar \& Baldock, 2000; Bryceson \& Vuorela, 2002). Such ideas about the family as bounded geographical units do not leave room for cross-border family practices and suggest that such families are anomalies for which family reunification is the only desirable outcome.

The notion of transnational families is in line with redefinitions of the family in family sociology from the 1990s onwards. In particular, feminist scholars began to challenge naturalised categories of 'the family', arguing that families can take diverse forms, depending on the social context (see, inter alia, Arendell, 2000; Emery \& Lloyd, 2001; Yerby, 1995). This renewed conceptualisation opened the door for multiple dimensions of what family means, although the family was still very much considered and approached as a unit within nation-state borders (see also Kofman et al., 2011, who make a similar argument when discussing Bourdieu's conceptualisation of social reproduction and the family). Transnational family research has further shifted assumptions of the family from a mono-local to a pluri-local model (Mau, 2007 cf. Drotbohm, 2009), that is, moving the unit of analysis to wider webs of relations spanning multiple locations and transcending national boundaries. As Baldassar and Merla (2014: 6) argue, acknowledging absence and mobility in family life has enabled us to 'theorise transnational families as contemporary family forms in their own right.'

\subsubsection{Doing Kin Work across Borders}

A useful starting point to the analysis of multi-local families and caregiving when parents and children live in different societies is the concept of kin work, introduced by Di Leonardo and defined as follows:

The conception, maintenance, and ritual celebration of cross household kin ties, including visits, letters, telephone calls, presents, and cards to kin; the organisation of holiday gathering; the creation and maintenance of quasi kin relations; decisions to neglect or intensify particular ties; the mental work of reflection about all these activities; and the creation and communication of altering images of family and kin vis-à-vis the images of others, both folk and mass media.

(Di Leonardo, 1987: 442-3)

The notion of kin work emphasises that forging and sustaining kin relationship is not something done in passing or that automatically results from 'being' kin, but instead is something that has to be actively and continuously created and recreated through 
everyday actions that require 'time, intention, and skill' (Di Leonardo, 1987: 443), a type of 'emotional labour', as Hochschild (1983) proposed.

The notion of kin work that defines the family as a set of deliberate practices and activities is part of a critique of feminist anthropologists on the biological definition of the family in functionalist kinship theory. Going back to Radcliffe-Brown and Fordes (1950), the functionalist notion of the family assumes that actors conform to and act upon a pre-existing set of norms that benefits the larger family unit (Kingsbury \& Scanzoni, 2009), and that also assumes a continuous equilibrium of the family institution through internal mechanisms (McIntyre, 1966). Rather than considering the family as a reified structure, the notion of kin work — and, similarly, the concept of 'doing family' (Morgan, 1996) — considers family ties through everyday actions that forge, sustain and redefine the family. 'Caring for' and 'caring about' further distinguishes between contact and emotional support through similar means, as indicated by Di Leonardo in the quote above, and hands-on care practices on the individual level (Finch \& Groves, 1983). ${ }^{2}$

The more fluid, complex and less conventional family networks are, the more vital are deliberate family actions and displays (Finch, 2007). This is all the more in a transnational context where geographical distance poses limitations to the ways in which family can be created and recreated. The taken for granted daily interactions that require proximity are not available to migrants and non-migrant family members. The multilocal nature of family networks across national borders forces family members to develop different and more deliberate kin-keeping actions and displays to overcome and compensate for the geographical distance. At the same time, the actual phenomenon of transnational families depends on enduring kin relationships, in spite of separations across time and space (Reynolds, 2004; Zontini, 2004).

Transnational family scholars have advanced conceptualisations that capture how everyday family practices create a sense of family across national borders. Relevant for the current study is Bryceson and Vuorela's (2002) concept of 'relativising', which refers to the many ways in which family members-migrants and non-migrants-forge and nurture, but also constrain kin relationships. Relativising considers migrants and nonmigrants as active agents who actively and strategically choose whom they maintain ties with and which ones they allow to weaken with time. Another notable contribution is Levitt and Glick Schiller's (2004) distinction between 'ways of being', which refers to actual transnational social relationships and practices that people engage in and that become part of their everyday lives, and 'ways of belonging', which refers to concrete and intentional actions that generate imagined connections to a group.

Caregiving practices are vital to generate a sense of belonging in transnational families (Baldassar \& Merla, 2014). They do not wither in pluri-local family contexts but rather change how they are enacted as well as its impacts (Baldassar, Baldock \& Wilding, 2007). Important is the recognition that transnational caregiving relationships, like those

\footnotetext{
${ }^{2}$ Finch (2007) added that actions can only be effectively considered as 'family actions', once they have been 'displayed' to other members as well as outsiders who acknowledge and accept the actions as such.
} 
in non-migrant families, are not unidirectional, but multidirectional and reciprocal, governed by negotiated care commitments, obligations and responsibilities (Reynolds \& Zontini, 2006). Given the multidirectional and reciprocal nature of care exchange in transnational families, Baldassar and Merla (2014: 7) coined the term care circulation, a concept that considers care to be inherently reciprocal and asymmetrical, governed by the "norm of generalised reciprocity" - the expectation that the giving of care must ultimately be reciprocated, although it may not be realised'. Hence, real or intended care circulates over time and distance, crossing geographical borders. This concept is useful because it allows for a broad perspective that considers complete networks of care as well as a wide range of family forms and migration.

The modes through which kin work and caregiving is done in transnational spaces are diverse, though limited. The sending of remittances is an important means to financially support family members in the origin country, facilitated by recent technological improvements in international money transfers (Baldassar, 2007), although also money flows from the home country to the destination country may be essential financial support for migrants in need (Mazzucato, 2009b). The bulk of remittances is sent to close relatives in the origin country and are a vital financial support, especially for poor families for whom these financial resources may enhance their standard of living in a different ways: improved access to nutrition and education; the purchase and renovation of properties, land and luxury goods; the financing of business ventures; and important life events, such as weddings, baptisms and funerals (Castles \& Miller, 1999; Mazzucato, Kabki \& Smith, 2006; Peil, 1995). Migrant parents may also send remittances to their children's caregiver to ensure that the child is being properly raised (HondagnueSotelo \& Avila, 1997). Monetary remittances also signify emotional support and generate a feeling of connectivity to family members, which in addition to financial support reinforces transnational family relationships (Hondagnue-Sotelo \& Avila, 1997; Kilkey, Perrons \& Plomien, 2013; McKay, 2007; Pribilsky; 2012; Reynolds \& Zontini, 2006).

Migrants and non-migrants also rely on communication technologies to keep each other up to date about their lives, to provide emotional support and practical support, such as giving advice and sharing information on a wide range of topics, as well as organising personal care for long-distant family members (Baldassar, 2007, see also Reynolds \& Zontini, 2006). Mobile phones, webcams, text messaging and the Internet (email, Facebook, Skype, Whatsapp) - all of which has supplemented and by now largely replaced the use of letters, cassettes, fax and landlines - have intensified and diversified the possibilities for a wide range of migrants and non-migrants to engage in each other's lives on a daily basis (Baldassar, 2007; Foner, 2000; Madianou, 2012; Vertovec, 2004). As Wilding (2006: 132-133) stated in reference to the use of emails, a feeling of connectedness with overseas relatives is not so much linked to the content of the message, but it is in the moment of exchange that creates a sense of 'shared space and time' and 'imagined proximity' that the relationship between family members is confirmed. 
Wilding (2006), however, also claimed that we should not over-celebrate ICTs in transnational families. The capacity for instantaneous and spontaneous contact that characterises modern day communication technologies gives rise to renewed expectations among family members to stay in touch on a regular basis, including friends and extended kin who may make high demands on migrants' financial resources. Moreover, it is expected of family members to provide 'timely and accurate information about the health (including emotional) and well-being of family members' (Baldassar, 2007: 401). In a transnational context, however, truth and distance is managed by individual family members who carefully chose what to communicate and to whom. These communication gaps and selective communication that are important facets of long-distance communication in the Information Age are a way to prevent others from worrying or to avoid negative judgements (Baldassar, 2007; see also Schmalzbauer, 2008). Family members on both ends are well aware that distance is used to hide the truth and consequently spend much time and effort into 'reading between the lines', 'listening to the sound of the voice', and 'interpreting silences', or ask others to check on the situation in person and to report back their findings (Baldassar, 2007: 402, see also Mazzucato, 2009b).

Additionally, travel technologies allow for face-to-face contact and emotional support, as well as support that requires proximity: personal support, such as providing hands-on care for minor children and the elderly; accommodating family members; and practical support, such as running errands, accompanying a family member in case of medical issues, or providing help in and around the house (Baldassar, 2007). Return visits enable family members to check up on each other and often provide a moment to witness the true circumstances. As such, visits are particularly important to resolve tensions that may be caused by hiding the truth over distance (Baldassar, 2007). Maybe most important, though, return visits form the basis of feelings of connectedness and emotional closeness in between the visits (Mason, 2004).

Whereas transnational family members' kin work and caregiving exchanges aim at mutual benefit, households should not be framed as cooperative units, because that would overlook the tensions, inequalities and power relationships between individual family members (Dreby \& Adkins, 2010). Baldassar and Merla (2014) also made this clear in their definition of care circulation, in which they emphasise that caregiving exchanges in transnational families are governed by asymmetries. Feeling pressured to respond to non-migrant family members' expectations places high demands on migrants' time and resources, whereas their labour activities in the host country reduces their time to spend with family members or to travel back home (Dreby \& Adkins, 2010). At the same time, those who are unable to meet the needs of non-migrant family members experience feelings of guilt (Drotbohm, 2009).

On the other hand, migrating to more powerful states in the global economic order increases migrants' relative power vis-à-vis those who stay behind in the home country, significantly affecting cross-border interactions (Levitt \& Glick Schiller, 2004). It is especially migrants and non-migrants differential access to mobility, resources, 
communication technologies, educational and employment opportunities and lifestyles that emerges in dramatic ways and that transforms relationships along gender and generational lines (Bryceson \& Vuorela, 2002; Carling, 2008; Dreby, 2010; Glick Schiller, Basch \& Szanton-Blanc, 1995; Levitt \& Glick Schiller, 2004; Madianou, 2012; Mahler, 2001; Schmalzbauer, 2008; Wilding, 2006).

These inequalities may be actively used by migrants to exercise power over nonmigrants. This can produce more equal gender relationships when migrant women take on the role of family breadwinner and gain access to state services (Hondagnue-Sotelo, 2001; Pessar, 2005). At the same time, asymmetries may accentuate, exacerbate and renew inequalities in gender and generational relations. For instance, the geographical distance and migrant women's renewed roles as breadwinners can increase non-migrant adult children's power over adult relatives and younger siblings, when migrant women send remittances to their adult daughters to prevent their non-migrant husbands from spending it on extramarital affairs and drinking, as Parreñas (2005b) found in the Pilipino case.

Research has also pointed to the perpetuation of male dominance when husbands migrate (Coe, 2011a; Mahler \& Pessar, 2001; McKenzie \& Menjívar, 2011). For instance, in her study among Salvadorans, Mahler (2001) found that the technical difficulties and costs of communication obstructed non-migrant wives to initiate long-distance phone calls to their migrant husbands and that a sense of insecurity and anxiety was exacerbated as these women could not make claims on their husbands' financial resources. In general, non-migrants rely heavily on the income sent by their migrant relatives while they have relatively little influence on the lives of their migrant relatives and few ways to ensure that their material needs are met.

Hence, family life, when enacted transnationally is likely to perpetuate, exacerbate, and create intra-household conflicts, inequalities, and power imbalances in striking ways (Dreby \& Adkins, 2010). Acknowledging that kin work and caregiving in transnational spaces are governed by asymmetries draws our attention to where family members are located, geographically and socially, as an important factor in shaping and reshaping everyday family life (Dreby \& Adkins, 2010; Mahler, 2001).

\subsubsection{Gendered Parental Caregiving Practices: Transnational Mothers and their Stay-Behind Children}

Children are central to transnational families. Not only is the wish to improve their living conditions one of the main reasons for adults to migrate, the presence of children in the home country is also an important reason for families to practice more deliberate kin and care practices across distance to maintain a feeling of connectedness and to confirm parent-child relationships (Boehm, 2008; Cohen, 2004; Orellana et al., 2001). Research on transnational parenting is at the heart of transnational family studies, addressing the ways in which transnational parents practice care and negotiate responsibilities and commitments in relation to their children. This work, like the bulk of transnational family literature, was largely developed by anthropologists who located their 
ethnographic studies within wider theorisation on how gender shapes and is shaped by migration (Brettell, 2000, see, inter alia, Brettell \& de Berjeois, 1992; Foner, 1997b; Simon \& Brettell, 1986).

Scholars began to look more closely at how migration impacts women's reproductive activities when a growing number of women from the Global South migrated independently in the late $20^{\text {th }}$ century, attracted by a demand for labour in the Global North (Schmalzbauer, 2004). While filling paid positions in advanced industrial countries, usually in the domestic and care sectors, they left their children-and other dependent relatives - in the care of usually unpaid female relatives. It is this separation of productive and reproductive labour and the reorganisation of caregiving arrangements that has attracted much scholarly attention.

Since the turn of the century, scholars have increasingly examined the impacts of migration on definitions of motherhood and everyday practices of mothering, as well as the gendered experiences of migrant mothers and their stay-behind children. This scholarship finds, on the one hand, that migration can have a liberating effect on mothers when their newfound role as breadwinners provides them more leverage in relation to their husbands (Hondagnue-Sotelo, 2001; Pessar, 2005), and that children may benefit from the material gains of their mothers' migration, for it improves access to education, accommodation, health and nutrition (Duque-Páramo, 2012; Mazzucato \& Cebotari, 2017). One the other hand, scholarship highlights that migration challenges prevailing norms of motherhood, rendering transnational motherhood an emotionally stressful experience for both mothers (Bernhard, Goldring \& Landolt, 2005; Dreby, 2006; Fresnoza-Flot, 2009; Hondagnue-Sotelo \& Avila, 1997; Horton, 2009; MoranTaylor, 2008; Parreñas, 2001, 2005a; Schmalzbauer, 2004) and their stay-behind children (Parreñas, 2005b; Schmalzbauer, 2008).

Negative outcomes on mothers and children are largely explained by Western middle-class gender role expectations that hold the nuclear family and proximity between the mother and her children as a prerequisite for a stable childhood development (Bernardes, 1999; Erel, 2002). Research, mainly within the context of South East Asian and Latin American migration, emphasises that mothers and children evaluate the migration experience and separation in terms of conventional gendered expectations, whereby men are the financial providers and women the primary caretakers and nurturers (Dreby, 2010; Parreñas, 2005a). When the mother migrates, she and her children suffer emotionally because her renewed role departs from the proximity prescribed by the nuclear family ideal. Transnational mothers compensate the physical absence that prevents them from enacting highly valued proximate care tasks with remittances and gifts, thereby creating breadwinning definitions of motherhood (Artico, 2003; Bernhard, Landolt \& Goldring, 2009; Hondagneu-Sotelo \& Avila, 1997; Parreñas, 2005a). This substitution of proximity with money is described by Parreñas (2001) as a 'commodification of love'. However, it is the ability to perform emotional care work, not their financial support, that largely defines women's relationships with their children. Via frequently-occurring telephone calls, messaging and return visits, women attempt to 
perform a kind of 'intensive mothering' from afar to foster intimate ties (Banfi \& Boccagni, 2011; Dreby, 2007; Fresnoza-Flot, 2009; Hondagneu-Sotelo \& Avila, 1997; Madianou, 2012; Parreñas, 2005a; Schmalzbauer, 2004).

Yet long-distance mothering practices cannot replace the emotional bonding and proximate maternal tasks of what is considered 'good mothering' (Bernhard, Goldring \& Landolt, 2005). There is what Parreñas (2005b: 122) called a certain 'naturalness of mother-child bonds', the idea that maternal tasks can only be properly practiced by the biological mother. Hence, many scholars have argued that other caregivers, even close kin, cannot fill the 'vacuum' created by the mother's departure (Zentgraf \& Chinchilla, 2012: 348). Feelings of depression, shame, guilt, hopelessness and estrangement from their children, as well as loss of appetite and constant instability, are therefore common among transnational mothers (Aranda, 2003; Bernhard, Landolt \& Goldring, 2009; Dreby, 2006; Fresnoza-Flot, 2009; Hondagneu-Sotelo \& Avila, 1997; McGuire \& Martin, 2007; Schmalzbauer, 2004). Stay-behind children may add to transnational mothers' emotional stress when reproaching their mothers for having left them (Dreby, 2010; Parreñas, 2005a), or for not recognising them as their mothers (Banfi \& Boccagni, 2011). Painful experiences are exacerbated by family and community members' moral judgements of women for leaving their children with a caregiver, by accusations of abandonment when women do not suffer emotionally (Abrego, 2009; Bernard, Landolt \& Goldring, 2009; Dreby, 2006), and by worries about mistreatment on the part of the caregiver (Moran-Taylor, 2008).

In a similar vein, research among stay-behind children emphasises that they too evaluate the absence of their mother in terms of what prevailing Western gender ideologies prescribe as 'good mothering' (Dreby, 2010; Parreñas, 2005b). Whereas transnational mothering practices can mediate some of the children's negative feelings of separation, they fail to make up for the loss of the mother's physical presence. Particularly in case of protracted separations, children may feel estranged from their mothers, finding it difficult to identify with their mothers abroad and to conform to their mother's expectations. Children of migrant mothers who are 'denied daily acts of nurturing from those who they assume are their rightful caregiver' (Parreñas, 2005b: 123), experience 'a lack of intimacy, feelings of abandonment, and a commodification of mother-child bonds' (Parreñas, 2005b: 120), as was found among the majority of Philippine children being left behind by their mother.

Other studies affirm the emotional suffering and worries among stay-behind children whose mothers have migrated (Dreby, 2010; Duque-Páramo, 2012) and have related feelings of loss with depressive symptoms and feelings of estrangement from the parent upon reunification (Suarez-Orozco, Todorova \& Louie, 2002), intergenerational conflicts, misbehaviour and poor school performance (Dreby, 2007; Ghencea \& Igor, 2004; Moran-Taylor, 2008; Schmalzbauer, 2004), lower physical health (Asis, 2006) and involvement in violence and gangs (Dreby, 2007; Smith, 2006). Artico (2003) also found that relationships between Latina transnational mothers and their stay-behind children became more of a give-and-take relationship, more business-like instead of the 
unconditional parent-child love. For these mothers and children, who usually separate out of necessity (Bernhard, Landolt \& Goldring, 2009; Moran-Taylor, 2008; Suddhi Dhamakit, 2010), reunification, be it abroad—through legal or illegal means_-or in the home country, is the only preferred outcome (Bernhard, Goldring \& Landolt, 2005; Bonizzoni, 2009; Dreby, 2006; Moran-Taylor, 2008; Suarez-Orozco, Todorova \& Louie, 2002). The wish for reunification is what Parreñas (2005b) called a longing for the 'proper order of gender' (p. 126).

Such research underlines that gender is an important organising principle in the experiences of mothers and children and shows that the perpetuation of gender expectations in the transnational context results in ambiguous experiences: whereas mothers leave to provide a better future for their children, the separation might lead to unintended costs, such as emotional suffering, loss, and strained relationships (Mazzucato \& Schans, 2011). Yet, as Horton (2009: 21) has warned, 'privileging the exploration of transnational separations through the single analytical lens of gender...reduces the embodied distress of mothers and children to mere "gender false consciousness".' In other words, consequences of separation are not homogenous, but in addition to gender expectations, need to be related to the characteristics and circumstances of mothers and children (Duque-Páramo, 2012; Schans \& Mazzucato, 2011), such as the quality of the relationship between the mother and the child prior to migration, the quality of the relationship between the mother, child and the caregiver, the quality of spousal relationships, the socioeconomic position of the caregiver, support networks at home and abroad, the age of the child at separation, the length of separation, type of parental migration (mother or mother-and-father) and the frequency of longdistance communication.

\subsubsection{Beyond the Mother-Child Dyad: Incorporating Fathers and Caregivers}

Without doubt, mothers are at the centre of reproductive care work and the consequences of their migration for both mothers and the children they leave behind deserves much scholarly attention. Nonetheless, an underlying assumption in this conceptualisation of family care is worth questioning: that the mother-child dyad is the most important family and caregiving relationship, marginalising all other actors and care exchanges. The present thesis counters this assumption and follows Mazzucato and Schans' (2011) suggestion that in order to fully understand how family functions in transnational space, we need to dilate the unit of analysis to incorporate other actors that have remained more or less unnoticed in this field of research, notably fathers and caregivers (see also Baldassar \& Merla, 2014).

Because fathers are not identified as primary caregivers (Bernhard, Landolt \& Goldring, 2009; Parreñas, 2005a), transnational family scholarship has hardly treated transnational fathering as a topic in its own right. There is a tendency to either discuss fathers within the same heading as mothers under 'parents' (Castañeda \& Buck, 2011), to study them from the perspective of those left behind (Parreñas, 2005b, 2008), as an 
aspect of transnational spousal relationships (Menjívar \& Agadjanian, 2007), or to compare fathering in relation to mothering (Abrego, 2009; Dreby, 2010). Such works predominantly demonstrate that masculine ideologies of the breadwinning and authoritative father render transnational fathering unproblematic, uncomplicated, guiltfree and socially accepted. Migration facilitates men's breadwinning role, and it is in terms of their economic success and desire to maintain some degree of authority that they evaluate the relationship with their children (Dreby, 2006; Hondagnue-Sotelo \& Avila, 1997; Parreñas, 2005a, 2008). Hence, whereas moral obligations prescribe mothers to make great sacrifices in terms of long-distance communication and return visits (Abrego, 2009; Palenga-Möllenbeck, 2013; Schmalzbauer, 2004), fathers only feel pressured to fulfil financial demands (Dreby, 2006; Pribisky, 2012) while at the same time they are likely to shirk financial responsibilities for their wives and children back home (Coe, 2008; Landolt \& Da, 2005). Parreñas (2008) found that the reinforcement of hegemonic gender scripts in transnational social space caused emotional distress among children left behind who longed for emotional intimacy with their physically absent fathers.

This thesis builds on more recent feminist and family sociology scholarship that has argued that men's care work can hardly be distinguished from women' care work (see Biblarz \& Stacey, 2010; Doucet, 2006; Ranson, 2010), although expectations of caregiving are still highly gendered (Doucet, 2011). The shifting paradigm towards the 'new father' in literature on fathering in developed countries has moved beyond the gender binary of caring mothers and breadwinning fathers (Coakley, Shears \& Randolph, 2014; De Souza, 2014):

In the developed economies of the 21 st century, fathering is no longer a role centred on breadwinning, with new ideologies and expectations of fathering as active and engaged. This fundamental change in fathers' engagement with raising children, which is interlinked with mother's changing engagement with the labour market, raises new questions on how fathers are managing to do both.

(Cooklin et al., 2014: 2)

Such works recognise men's time spent with their children and their involvement in emotional care work and the important role of fathers for children's well-being and development (Bögels \& Phares, 2008; Cabrera et al., 2000). This scholarship has informed more recent transnational family research that has rejected stereotypes of transnational fathers as disengaged, authoritarian and uncaring, both from the perspective of migrant men (e.g. Dreby, 2010; Grzuwacz et al., 2006; Kilky, Plomien \& Perrons, 2014; Schmalzbauer, 2005; Winters, 2014) and stay-behind children (Nobles, 2011). Men's involvement in emotional and nurturing tasks have also been reported among Zimbabwean transnational fathers in South Africa (Chereni, 2015), suggesting that men's broader connectedness to family life and caregiving is not geographically 
limited. ${ }^{3}$ My study is situated in this recent body of literature that assesses the full range of men's experiences and that recognises that transnational fatherhood is a distinct phenomenon that should be studied in its own right (Carling, Menjívar \& Schmalzbauer, 2012), from the perspective of fathers as well as children.

Other actors that should be moved to the centre of the analysis are kin and non-kin caregivers. The mediating role of non-migrant mothers in relationships between migrant father and left-behind children has been widely recognised (Avila, 2008; Chereni, 2015; Hoang \& Yeoh, 2012; Kilkey, Plomien \& Perrons, 2014; Menjívar \& Agadjanian, 2007). However, the role of caregivers who are not the child's biological mothers is given only scant attention. These caregivers are usually female close relatives, notably the child's grandmother and aunt, but can also include male and more distant relatives and non-kin (Dreby\& 2010; Mazzucato \& Schans, 2011; Moran-Taylor, 2008). When these other kin and non-kin caregivers are discussed, this is mainly in terms of the migrant mothers' emotional suffering and family destabilisation. This is for instance the case when there are suspicions that caregivers misuse remittances, treat children improperly or when children reproach their mothers for leaving them in bad care situations (Menjívar \& Abrego, 2009), or when migrant mothers worry that they lose their maternal role to the caregiver (Avila, 2008; Bernhard, Landolt \& Goldring, 2009; Dreby, 2010; Menjivar, 2012).

More recent studies that have taken into account the perspective of kin and non-kin caregivers indicate that these caregivers play an important role in doing family in transnational space (Dankyi, 2014; Dreby, 2010; Yarris, 2012). They are what MoranTaylor (2008: 91) called the 'unsung heroes and heroines' who facilitate migrant parents' absence for longer periods of time by performing necessary hands-on domestic and care tasks and provide financial and emotional support for children (see also Artico, 2003; Dankyi, 2014; Dreby, 2010; Yarris, 2012). Hence, the 'outsourcing of care' to kin and non-kin (Leinaweaver, 2010: 73) functions as important social capital for families to cope with migration and absence (Bonizzoni, 2009). Caregivers fill the emptiness-a 'care deficit' or 'care slot' - that is created when parents move abroad.

The involvement of kin and non-kin caregivers is usually described in case of female migration, since fathers are more likely to rely on the children's mother (but see Fresnoza-Flot, 2014 on Filipino non-migrant fathers' caregiving practices). Thus, when mothers move abroad, female kin and non-kin caregivers take over the proximate caregiving practices that were previously performed by the mother, thereby facilitating her migration. As Fresnoza-Flot (2009: 255) argued for Filipino women in France, the involvement of female extended kin caregivers in the lives of their children back home 'represents a valuable solution to their absence, and thus qualifies as a strategy of indirect mothering'.

Research has further shown that when children are left in the care of their grandparents, care exchanges circulate in multiple ways: children stay in the care of

\footnotetext{
${ }^{3}$ Other literature on African fathers, however, points to more traditional conceptualisations of fatherhood in terms of economic support and authoritarian style (Nyarko, 2013; Rabe, 2005; Richter and Morell, 2008).
} 
loving and trustworthy caregivers, while children practically support their grandparents and migrant parents provide financially for their parents and their children (Dreby, 2010; Leinaweaver, 2010; Moran-Taylor, 2008; Olwig, 2012; Reynolds \& Zontini, 2006).

The transnational context, however, poses various challenges to trust and reciprocity that are vital for care arrangements to sustain. Caregivers may worry over their financial dependency on migrant parents' monetary remittances and protracted care arrangements, and they may face difficulties to maintain control over adolescents (Dankyi, 2014; Dankyi, Mazzucato \& Manuh, 2017; Dreby, 2010; Moran-Taylor, 2008). On the other hand, the geographical distance limits migrant parents' ability to personally check on the child's circumstance, thereby elevating concerns over the misuse of finances, decision-making power, abuse and neglect of children (Åkesson, Carling \& Drothbohm, 2012; Bernhard, Goldring \& Landolt, 2005; Crawford-Brown \& Rattray, 2002; Dreby, 2010; Hondagneu-Sotelo \& Avila, 1997; Menjívar, 2012; Moran-Taylor, 2008; Schmalzbauer, 2004). Tensions between caregivers and parents are most likely to arise over finances, discipline and control (Bernhard, Goldring \& Landolt, 2005; Reynolds \& Zontini, 2006), although Dreby (2010) found in the case of Mexican transnational families that whether or not conflicts arise largely depends on the type of caregiver.

Research has further shown that the quality of the parent-caregiver relationship_-or perceptions thereof-reflect on other family relationships. For instance, Haagsman and Mazzucato (2014) found that migrant parents' perceptions of the relationship with their stay-behind children associate with how they perceive the relationship with their children's caregiver. Other literature has pointed to the importance of qualitative relationships between parents and caregivers for children's emotional well-being, because unsupportive, conflict-ridden care arrangements make children vulnerable and at risk of abuse or neglect (Dreby, 2010; Moran-Taylor, 2008). Although, as Øien (2006) rightly argued, a parent's trust in the caregiver does not guarantee a relationship free of abuse for the child, the aforementioned studies do suggest that a conflict-free and trustworthy relationship between parents and caregivers is vital to family stability and intersubjective experiences of the different actors involved.

The practices that go into doing family in relationships between parents and caregivers and how these practices and relationships are governed by asymmetries that complicate role negotiations between individual family members is left underresearched. Moreover, while studies found that caregivers may help children to understand their parents' absence (Artico, 2003; Bernhard, Goldring \& Landolt, 2005; Dreby, 2010; Moran-Taylor, 2008), that left-behind children can become strongly attached to their caregiver in the absence of the parent (Carling, 2007; Lashley, 2000), and that children may perceive caregivers as 'more legitimate authority figures than their parents' (Smith, Lalonde \& Johnson, 2004: 117), little is known about the ways in which stay-behind children evaluate the relationships with their caregivers and the factors that define it. 
This thesis argues that a narrow focus on the mother-child dyad fails to capture a nuanced and complete comprehension of how families are (re)constituted and how care is exchanged in transnational social space. Alternatively, I incorporate fathers and caregivers in this study, alongside mothers and children, as central actors in reproductive care work. The thesis poses the following questions in relation to their roles in transnational families: What strategies and opportunities do fathers employ to support their children in the home country? What paternal caregiving norms prevail? Beyond sending remittances, how do fathers provide emotional care and guidance? How do children in the origin country evaluate their relationship with migrant mothers, fathers, and with their caregivers? What considerations go into selecting a caregiver? And, what strategies do migrant parents employ to foster trustworthy and reciprocal relationships with their children's caregivers?

\subsection{Situating Transnational Caregiving in Host and Home Country Contexts}

In my examination of family and caregiving practices, relationships and consequences from the point of view of the different actors involved in the transnational child-raising arrangement, I draw on insights from transnationalism literature that recognises individuals' situatedness in multiple institutional contexts. Migration scholars who have developed conceptualisations of transnationalism have emphasised that transnational social spaces are not deterritorialised, exhibiting free-floating and unbounded networks, but are locally anchored (Faist, 2012; Goldring, 2002; Levitt, 2001; Levitt \& Glick Schiller, 2004; Pries, 2001, 2005; Smith \& Guarnizo, 1998). ${ }^{4}$ Indeed, as Faist (1998: 244) argued, 'aspects of the lives of transmigrants remain highly localised, albeit characterised by a profound bi- or sometimes even multi-focality.' Consequently, Pries (2001: 59) argued, the process of transnationalisation can best be described as a 'process of restructuration or disembedding and re-embedding of social and geographical spaces.' Recognising the spatial dimension of transnational processes moves our analysis to the complex and shifting interaction and interconnections between multiple strata of the local, national and transnational (Levitt, 2003; Ryan, 2011). Faist (1998: 217) described these interconnections as 'triadic relationships between groups and institutions in the host state, the sending states and the minority group'. As such, the transnational frame does not replace earlier, nationally-bounded frames, but rather combines multiple frames of reference from the local up to the global (Pries, 2005).

The recognition of the continued importance of the local contexts moves our analysis to the 'multiple sets of laws and institutions' (Levitt and Glick-Schiller, 2004: 10) that influence the range and profundity of everyday practices and interconnections in transnational space (Portes et al., 1999). The current study draws on and contributes to

\footnotetext{
${ }^{4}$ The local anchoring of transnational processes in multiple nation-states is what sets it apart from decentred processes of globalisation (Kearney 1995).
} 
a recent body of literature that has begun to recognise that transnational family practices and caregiving exchanges are locally anchored within the institutional contexts of sending and receiving countries and that transnational processes in turn are 'reterritorialised', i.e., impacting localised norms and institutions (Bonizzoni \& Boccagni, 2014; Mahler, 2001; Mazzucato \& Schans, 2011; Ryan, 2011; Zentgraf \& Chinchilla, 2012). Particularly notable in this respect is the recent contribution by Kilkey and Merla (2014), whose analytical framework of a 'situated transnationalism' allows for an examination of how transnational caregiving arrangements are situated within the different institutional contexts, defined as migration, welfare, gendered care and working-time regimes, of the home and host societies.

It is through these place-specific institutional contexts that transnational caregiving is shaped and their impacts mediated. Whereas the different regimes and their parameters are worth investigating, it is impossible to integrate them all in a single study. The current study limits itself to a thorough and systematic examination of two parameters which have long remained under-researched in transnational family scholarship: 'gendered care cultures', that is, 'norms on appropriate division of labour and appropriate forms of care for dependents' (Kilkey \& Merla, 2014: table 3, p. 216), and nation-state policies that regulate 'exit/entry/residency rights for migrants and family members' as well as 'policies governing the insertion of migrants and their family members into the labour market' (Kilkey and Merla, 2014: table 3, p. 216). In the last two sections of this chapter, these parameters will be discussed in more detail.

\subsubsection{Gendered Care Cultures}

Anthropologist of the late twentieth century have detailed significant cross-cultural variations in systems of family and gendered caregiving that counter ideas of the naturalised Western middle-class nuclear family as the ideal-typical conceptualisation of the family (Goody, 1982; Weismantel, 1995; Selin, 2014). Hence, who practices care for whom at a certain point in time is not a universal given but is largely defined by the local cultural context in which the actors operate (Carling, Menjívar \& Schmalbauer, 2012; Cole \& Cole, 2001; Drotbohm, 2009).

To fully understand how cultural norms guide family relationships and caregiving practices in a transnational context, Mazzucato and Schans (2011: 709) call for 'a balanced focus on both sending and receiving countries'. According to these authors, an understanding of cultural patterns and structures has largely remained absent in transnational family studies, which instead has more commonly assumed Western cultural ideals of the family that emphasise a privileged position of the mother-child bond and proximity. However, many immigrants come from societies where broader definitions of family are present, including wider circles of extended kin and non-kin as vital in childcare. It is important to take these variations into account when examining care arrangements in the light of transnational migration.

Anthropologists have noted that, in societies in Africa, the Caribbean, Latin America and Southeast Asia, extended care networks of usually female kin and non-kin hold a 
central role in child rearing, grounded in norms of social parenthood and culturally accepted practices of child-fostering (Akresh, 2005; Andres, 2009; Andvig, 2000; Desai, 1992; Goody, 1982; Leinaweaver, 2010; Lloyd \& Desai, 1992; Mensa-Bonsu \& Dowuona-Hammond, 1996; Soto, 1989). Child-fostering is described as the relocation or transfer of children from their natal homes to foster parents (Isiugo-Abanihe, 1985). This practice serves important functions of collective cost sharing, help in case of death or divorce, educational attainment, household assistance, or company (Bledsoe, 1990; Desai, 1992; Isiugo-Abanihe, 1994; Mensa-Bonsu \& Dowuona-Hammond, 1996; Pilon, 2003). In these societies, the inclusion of other kin and non-kin in childcare and the separation of the child from the birth parent in practices of child-fostering is not only accepted and considered as 'normal', but may also be the preferred living arrangement for children.

Evidence from societies in which child-fostering is prevalent shows that parent-child separations and involvement of other kin and non-kin caregivers in the context of migration are culturally accepted (Åkesson, Carling \& Drotbohm, 2012; Bledsoe, 1990; Coe, 2008; Olwig, 2012; Peil, 1995; Suarez-Orozco, Todorova \& Louie, 2002; Whitehouse, 2009). Contrary to findings among transnational families from societies where nuclear family models prevail, mother-child separations are not stigmatised, nor is family reunification necessarily the preferred outcome. Instead, sending children to their parents' origin country or leaving them behind when parents migrate is considered a common strategy to discipline children, to immerse them in the home country culture and to take them out of hostile neighbourhoods in the receiving country (Guarnizo, 1997; Goody, 1982; Levitt, 2001; Loucky \& Moors, 2000; Soto, 1989; Whitehouse, 2009). Research among migrants from societies in which child-fostering practices prevail has also pointed to fostering in the destination country in order for children and parents to make the most out of the migration context, materially and immaterially (Goody, 1982; Øien, 2010; van Walsum, 2000).

Cultural understandings of family and caregiving that favour the involvement of extended care networks and normalise mother-child absence, challenge Western nuclear family ideals that prioritise the mother-child bond and intimacy created in proximity. Several studies among migrants from host societies where extended care networks hold an important place in child rearing found that caregivers can adequately substitute for the parent's nurturing acts and adequately alleviate feelings of loss in the context of migration (Olwig, 1999, 2012; Whitehouse, 2009). Such findings contradict assumptions that caregivers cannot fully substitute for the mother's absence because mothers are considered the primary nurturers of their children (Artico, 2003; Bernhard, Landolt \& Goldring, 2009; Parreñas, 2001, 2005a).

Whereas child fosterage improves 'bonds of solidarity, mutual help and harmony in the African family' (Notermans, 2008: 357), this should not give rise to preconceived conclusions that foster arrangements are therefore problem-free. Recent studies that focus on subjective experiences of family members through everyday fostering practices have critiqued earlier findings from the structural-functionalist tradition that treated the 
household as a homogenous unit in which all members collaborate for the collective good of the family (Goody, 1982).

This new literature instead sheds light on differing and conflictive interests and outcomes, arguing that fostering arrangements are not always cooperative units. In a study on child-fostering in an urban centre of Cameroon, Verhoef (2005) observed three types of fostering arrangements of which two were characterised by power asymmetries, maternal exclusion, and ongoing conflicts and struggles over responsibilities of the child. Conflictive adult relationships had serious consequences for the fostered children, who exhibited 'frequent sickness, difficulty sleeping, enuresis, rashes, nightmares and/or poor appetite' (Verhoef, 2005: 385). In her study on everyday experiences of child-fostering in Cameroon, Notermans (2008) found that children were more critical and emotional towards their fostering arrangement than adults.

Ambivalence in foster arrangements and conflicting expectations among parents and children have also been found in the transnational context. Olwig (2012: 938) found that children in the Caribbean only felt emotionally close to the foster parent and defined themselves as being part of the foster parents' family when they were 'being treated as a relative who is not ordered around'. Moreover, she found that parents emphasised more the material aspects in the relationship with their children, whereas children emphasised more the emotional aspects alongside material care (see Coe, 2008 for similar findings in the case of Ghana).

At the same time, it is important to recognise changes in family structures and childraising institutions as a result of migration (Mazzucato \& Schans, 2011) and other global processes (Therborn, 2006). Whereas child-fostering may create a context of 'normality' with regard to being raised by a non-biological parent and living geographically separated from the birth parent, traditional kinship fostering is no blueprint for the transnational context. The geographical distance and high travel costs alter the conditions and expectations on which traditional fostering practices are based, complicating parents' and caregivers' efforts to forge and maintain relationships of trust (Mazzucato \& Schans, 2011). Migration shifts the financial responsibility from the caregiver to the migrant parent (Pertierra, 2002), while the reconfiguration of asymmetrical power relationships between parents and caregivers through differential access to material and financial resources can be a source of conflict (Åkesson, Carling \& Drotbohm, 2012; Heymann, 2006). Moreover, international migration may alter expectations of what is considered 'good care', as well as the roles and responsibilities of parents and caregivers. Unforeseen circumstances may impose stress on the different actors (Åkesson, Carling \& Drotbohm, 2012), while at the same time access to long-distance communication technologies allows parents an active role in their children's upbringing and a means to negotiate childcare with their children's caregiver.

To fully capture changes in family structures and parent-child relationships as a result of migration, there is a need to focus on what family and caregiving mean to individual family members in a given context, and how relationships are maintained and experienced, beyond Eurocentric family notions. This examination will also contribute 
to anthropological studies since it brings to light the ways in which globalising processes alter local meanings and practices of family and caregiving (Mazzucato \& Schans, 2011).

\subsubsection{Political and Socioeconomic Contexts}

A second challenge for transnational family studies is the continued importance of larger structural factors that provide an enabling and constraining context in which migrants and their transnational networks operate (Faist, 1998). A narrow definition of transnationalism that assumes freedom of movement has been refuted by transnationalism scholars who have recognised that the state and her policies constrain and facilitate migrants' options for transnational practices and connections (Faist, 1998; Levitt, DeWind \& Vertovec, 2003; Vertovec, 2007; Waldinger \& Fitzgerald, 2004). Foremost, the state and its policies control the exit from and entry on its territory and regulate residency rights (Faist, 1998; Waldinger \& Fitzgerald, 2004). ${ }^{5}$ However, to date, there is limited knowledge on how migration policies affect migrants' family lives, even though, as Mazzucato and Schans (2011) have argued, incorporating migration policies and immigrants' legal status in transnational family studies is of paramount importance, for these policies tend to become stricter in most popular destination countries.

Perceived problems of integration and an increased focus on security in migration policy discourses has restricted conditions for entry of individuals and their family members. This poses challenges to the ways in which migrants can organise their family lives because migration policies define what family is and who can and cannot migrate as a family unit and reunite after arrival (Boehm, 2008; Dreby \& Atkins, 2010; Kofman, 2004). First, restrictive family migration policies can prolong separations (Åkesson, Carling \& Drotbohm, 2012; Bernhard, Landolt \& Goldring, 2009; Strik, de Hart \& Nissen, 2013), incite alternative routes to family reunion (Bonizzoni, 2009; Fonseca \& Ormond, 2008) and reduce the strategy of sending children to the origin country to avoid the risk of children being denied re-entry (Bledsoe et al., 2007). Post-reunification readjustments can also be problematic, especially after lengthy separations (FresnozaFlot, 2015). Second, legal status largely determines the ways in which migrants can care from afar. Research has stressed the limited options of reunification for undocumented migrant mothers and how a lack of face-to-face contact due to their undocumented states has them rely on ICTs, monetary remittances and gifts to generate feelings of connectedness, thereby exacerbating feelings of guilt and creating conflicts between migrant mothers and their stay-behind children (Banfi \& Boccagni, 2011; Bonizzoni, 2009; Fresnoza-Flot, 2009; Horton, 2009; Menjívar, 2012; Zontini, 2004).

How migrants' economic opportunities and constraints curtail family and caregiving practices in transnational space has also received scant attention in transnational family studies (Hoang \& Yeoh, 2012). Migrants’ socioeconomic status is largely shaped by state

\footnotetext{
${ }^{5}$ Borders however are not watertight. How porous they are, along with the ways in which they impose on migrants' abilities to forge and maintain cross-border communities, largely depends on 'the variability in the degree to which internal and external boundaries are institutionalised and the means and intensity by which states police them' (Waldinger \& Fitzgerald, 2004: 1178).
} 
migration policies since legal status determines access to the formal labour market, in addition to health care, housing and public services (Van Meeteren, San \& Engbersen, 2008). Thus, undocumented migrants have limited opportunities for financial gains, given their marginal position on the labour market, but also because their qualifications and certificates may be useless without a residence permit. Limited economic opportunities on the host society's labour market, combined with the relatively high costs of living, can prolong migrants' stay abroad (Mazzucato, 2009b) and with that, family separation.

Moreover, differences in migrant parents' access to financial resources defines the ways in which parents can meet their children's material requests, as well as the frequency of communication via mobile phones and the Internet (Bryceson \& Vuorela, 2002; Hoang and Yeoh, 2012; Parreñas, 2005a, Wilding, 2006; Zentgraf \& Chinchilla, 2012). Geographical distance is an important factor in the costs of long-distance communication via mobile phones (Mahler, 2001), while differential access to the Internet and computers varies by geographical location and the migrants' socioeconomic status (Parreñas, 2005a). Migrants on a tight budget may choose to send money or save for future reunification instead of spending it on communication (Zentgraf \& Chinchilla, 2012).

Parents' access to economic resources, alongside legal status, also determines the options for face-to-face contact between parents and their children. Whereas undocumented migrants mainly rely on kin networks of support in the home country (Zontini, 2004), 'migrants of privilege' (Croucher, 2009), i.e. highly-skilled and middleclass documented migrants, can cross borders with relative ease and have better social and material resources to organise and perform transnational caregiving (Baldassar \& Wilding, 2014; Wong, 2014). As Baldassar and Wilding (2014: 246) argue, in these families, distance is more or less "normalised" since the opportunities to maintain intimate relationships across borders 'continually generate the feeling of being a wellconnected family.'

The question that is under research in this thesis is how larger macro-economic and structural factors, notably economic and political opportunities and constraints of the host society, curtail migrants' family strategies, opportunities and caregiving practices. The focus in this thesis is on two areas. First, several studies have signalled political and economic constraints and opportunities as important in shaping transnational fathering practices and mediating emotional repercussions of father-child separations (Kilkey, Plomien \& Perron, 2014), but a detailed examination is lacking. This thesis seeks to fill this gap. Second, I focus on the gendered experiences with and implications of restrictive conditions for family reunification. Whereas migrant status has been given attention in literature on transnational mothering, little is known about the ways in which family reunification policies and practices of implementation impinge on migrant mothers' everyday lived experiences and family strategies (but see Bonizzoni, 2009; Fresnoza-Flot, 2015; Van Walsum, 2000, 2009a). 


\subsection{Concluding Remarks}

Located within broader transnationalism research that considers migrants' and nonmigrants' connections to two (or more) countries, this thesis employs insights from transnational family literature that has moved beyond a conceptualisation of the family as a bounded geographical unit. Drawing on recent family sociological theory, I approach families as broad units of analysis, encompassing social and biological ties, and I consider family and caregiving in terms of everyday practices. In analysing how the different actors create and recreate family life across borders, I expand the unit of analysis to include alongside mothers and stay-behind children, also the less visible members, notably fathers, but also caregivers by including them in the assessment of left-behind children's and migrant parents' experiences, and transnational caregiving relationships. ${ }^{6}$

Moreover, I pay special attention to the ways in which geographical distance accentuates, reinforces or recreates asymmetries and dependencies that govern family and care practices, and how these complicate multi-local caregiving relationships and exchanges. My analysis follows theorisation within the transnational literature that considers transnational spaces as simultaneously territorialised and deterritorizalised, or as Ryan (2011: 87) puts it, 'migrants may not be entirely bounded by the local but neither are they entirely free and unfettered within transnational space.' By drawing on anthropology of kinship and recent advances in transnational family literature that recognise the continued power of the nation-state, this research is part of a theoretical move that assesses how institutional contexts shape transnational care responsibilities, resources and consequences for family relationships and individual members in their respective localities.

From this conceptual discussion, I have deduced four gaps in the literature that are worth examining and that make up the empirical chapters of this thesis. In Chapter Five, I assess the experiences of left-behind children, taking into account the cultural and gendered norms and practices of childcare and parenting. I move the focus to migrant fathers' care practices and experiences with separation in Chapter Six and discuss these in relation to gendered care norms as well as the migrant's legal and socioeconomic status. Chapter Seven assesses mothers' experiences with reunification policies. Finally, in Chapter Eight, the relationships between migrant parents and their children's caregivers is discussed, taking into account how cultural norms and practices of childcare govern such relationships and how cultural norms are in turn reshaped by the transnational context.

In the next chapter, I discuss the methodological implications of our conceptual framework that gives prominence to the different actors of the transnational childraising arrangement, along with host and home country contexts.

\footnotetext{
${ }^{6}$ Dankyi (2014) has examined in more detail Ghanaian caregivers' care practices and experiences.
} 



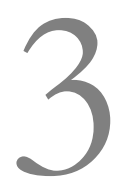

A Transnational Methodological Design 



\subsection{Introduction}

The transnational methodological design of this research responds to the context of cross-border child-raising arrangements and enables the examination of how family and care practices and experiences intertwine with spatial parent-child separations from the perspectives of different actors. This chapter will motivate the choice for a transnational methodological design, explain how the research benefitted from such a design and highlight some of its challenges. It emphasises how the teamwork that was at the basis of the larger research project 'Transnational Child-raising Arrangements between Ghana and the Netherlands' (TCRA), and in which this research is embedded, facilitated such a design. The detailed information in this chapter is essential to comprehend the innovative but at the same time complex methodology of this research. Moreover, this chapter responds to the need for more documentation on designs and processes of research that involve vulnerable persons and research topics (Van Liempt \& Bilger, 2009), as well as to the need to discuss teamwork in a research field that is more commonly reserved for individual researchers.

Section 3.2 provides a short discussion of the TCRA programme and an explanation of how the individual project is integrated in and benefitted from embeddedness in the larger research project. In Section 3.3, the focus shifts to specific aspects of the individual research project. Here I discuss the methodological considerations of studying transnational phenomena and explain why an ethnographic case study design was most appropriate for this study. To integrate different actors of the transnational child-raising arrangement 'here' and 'there', a multi-sited research approach was applied (Section 3.4).

Benefitting from the teamwork of the TCRA project, the current study takes the multi-sited approach one step further by employing the innovative Simultaneous Matched Sample methodology (Section 3.5). This methodology has been applied to other transnational research settings, but this study is the first to apply it to the field of transnational families. Section 3.6 sets out the data collection and discusses field sites, sampling strategies, respondent characteristics and methods. The organisation, benefits, considerations and implications of the teamwork will be discussed in Section 3.7. Finally, ethical considerations (Section 3.8) and implications of researcher positionality for collecting and interpreting data (Section 3.9) are discussed.

\subsection{The TCRA Programme}

This research is incorporated in the larger 'Transnational Child-Raising Arrangements between Ghana and the Netherlands' programme (TCRA) ${ }^{7}$ that aims to understand how life-chances of different actors of the care network in Ghana and the Netherlands, i.e. migrant parents, stay-behind children and caregivers, are affected by geographical

\footnotetext{
7 The TCRA project is funded by the Science for Global Development (WOTRO) division of the Netherlands Organisation for Scientific Research (NWO) (grant number W01.65.316).
} 
separation and the rearrangement of care across borders, and how existing child-raising institutions operate when the actors are located in different countries in the Global North and South (Mazzucato, 2008c).

The TCRA programme is methodologically innovative for its multi-sited and mixedmethod research design that is enabled by collaboration in an interdisciplinary and international team of researchers with various methodological specialisations. The multicountry approach and application of both quantitative and qualitative methods enables a holistic understanding of cross-border child-raising arrangements from multiple perspectives and on multiple scales. The triangulation of multiple sources, methods and researchers also enhances the credibility of the research (Baxter \& Eyles, 1997). Figure 3.1 provides an overview of the four sub-projects, indicating their methodological approach and geographical and thematic focus. The current study is of qualitative nature with the main fieldwork located in the Netherlands (displayed in bold in Figure 3.1).

Figure 3.1 TCRA projects by geographical focus and methodology

\begin{tabular}{lll}
\hline & Ghana & The Netherlands \\
\hline Quantitative & $\begin{array}{l}\text { The effects of transnational child-raising } \\
\text { arrangements (TCRAs) on children and } \\
\text { schools }\end{array}$ & $\begin{array}{l}\text { Effects of TCRAs on migrant parents' integration } \\
\text { and well-being }\end{array}$ \\
Qualitative & $\begin{array}{l}\text { Effects of TCRAs on kin and non-kin } \\
\text { caregivers }\end{array}$ & $\begin{array}{l}\text { Effects of TCRAs on migrant parents and the } \\
\text { impact of migration policies on care choices }\end{array}$ \\
\hline
\end{tabular}

Source: Mazzucato (2008)

The interdisciplinary teamwork provided ample opportunities for collaboration in all phases of the research that benefitted my individual research in different ways. For instance, the outcomes from the quantitative study directed me to interesting issues that were of interest for further exploration. In turn, the quantitative studies benefitted from this smaller-scale qualitative study as it directed attention to important mechanisms within transnational care relationships and informed the interpretation of quantitative results. Moreover, I was able to discern whether the observations made on a small-scale were in line with what was found based in larger and more systematic data collection. Other advantages for the individual study resulting from the teamwork and interdisciplinary and multi-sited nature of the research will be discussed in more detail in the different sections of this chapter.

\subsection{Methodological Considerations in the Study of Transnational Phenomena}

The study of transnational phenomena, such as the geographically-dispersed childraising arrangements that are the topic of this study, asks for a readjustment of more conventional methodological strategies, since the location of the object of study in multiple places no longer holds the nation-state as the most relevant context for 
empirical study (Levitt \& Glick Schiller, 2004; Mazzucato, et al. 2004; Pries, 2001). Mazzucato (2009a) identified two methodological implications for the study of transnational phenomena. First, she urged researchers to redefine the unit of analysis since transnational literature recognises the individual migrant to be part of a network that encompasses members in different countries (see also Portes, Guarnizo \& Landolt, 1999). Hence, a transnational methodological design should be attuned to home and host country (or countries) perspectives.

A second methodological implication that can be derived from theoretical transnational literature is the acknowledgement of simultaneous engagement of people with more than one locality and the ways in which this simultaneity impacts the social fabric of cross-border networks (Mazzucato, 2009a). This simultaneity is facilitated by recent technological developments that ease communication and travel over long distances as well as the impact on the lived experiences of the different members of the transnational network, depending on where they are situated, both socially and geographically.

The above discussion thus points to two important elements that have to be incorporated in the methodological design of transnational child-raising arrangements: shifting our focus from the individual to the network and capturing simultaneity. Here, two methodological strategies were employed to incorporate these elements. First is the application of multi-sited fieldwork, an approach that has been adopted by a growing number of migration scholars over the past decades and which allows for the inclusion of host and home country perspectives. Second, the challenge of conducting ethnography in two (or more) countries while capturing simultaneity by single researchers was overcome by employing the innovative simultaneous matched sample methodology (Mazzucato, 2009a). The next sections will set out the specificities of these two methodological strategies and indicate how they have benefitted this research.

\subsection{Multi-Sited Fieldwork and the Implications for doing Ethnography}

To examine transnational child-raising arrangements, ethnography was chosen as the principal research method. Ethnography involves:

the ethnographer participating, overtly or covertly, in people's daily lives for an extended period of time, watching what happens, listening to what is said, asking questions - in fact, collecting whatever data are available to throw light on the issues that are the focus of the research.

(Hammersley \& Atkinson, 1995:1)

Ethnography is particularly well-suited for revealing mechanisms and processes in social fields (Miles \& Huberman, 1994). It enables the researcher to zoom in on the ways in which macro structures impinge on everyday lived experiences, meanings and interactions (Fitzgerald, 2006). This provides a 'thick description' (Geertz, 1973) of how 
actors make sense of their actions and intentions and everyday life situations by revealing 'meaning structures that provide the blueprint for social action' (Herbert, 2000: 551). Ethnography is particularly well-suited for the study of how transnational social fields are created and maintained:

participant observation and ethnographic interviewing allow researchers to document how persons simultaneously maintain and shed cultural repertoires and identities, interact within a location and across its boundaries, and act in ways that are in concert with or contradict their values over time. The effects of strong and weak indirect ties within a transnational social field can be observed and those connections, whether they take the form of institutional or individual actors, can be studied.

(Levitt \& Glick Schiller, 2004: 1013)

Conducting ethnography at a single site incorporates a one-sided perspective that may reveal experiences of persons located in the transnational family, but this fails to capture interpersonal processes between actors located in multiple localities and the multiple contexts that impinge on these processes (Carling, Menjivar \& Schmalzbauer, 2012). To overcome these shortcomings, this study adopted what Marcus (1995) coined a 'multisited ethnography' that allows the researcher 'to follow the people' and that responds to processes of globalisation and transnationalism that ask for a necessary break from the more conventional single-site ethnography.

A multi-local research design is a 'form of (geographical) spatial de-centeredness' (Falzon, 2009: 2), which acknowledges that a focus on a single locality is no longer adequate nor appropriate. As Falzon (2009) argues, a multi-sited ethnography incorporates multiple 'locations' or 'places' and enables the researcher to better understand relationship dynamics, for it has the advantage of including those who migrate as well as those who stay in the country of origin, but who nonetheless uphold transnational relationships and engage in cross-border actions (Levitt \& Glick Schiller, 2004). It is therefore well-suited for the investigation of transnational social spaces.

The choice for fieldwork in both Ghana and the Netherlands, where the different actors of the child-raising arrangements were located, was motivated by an interest in gaining insight into care practices and interpersonal relationships. Including the different contexts where care is being sent, received, and demanded or expected allowed me to observe how care is practiced, interpreted and given meaning in the different contexts as well as its implications for the different actors' daily lives.

Although many transnational family scholars in recent years have adopted multi-sited ethnography (Baldassar, 2007; Dreby, 2010; Drotbohm, 2009; Mahler, 2001), and others have advocated this approach for being most suitable to capture the complex dynamics and changes over time in transnational connections (e.g. Carling, Menjívar \& Schmalzbauer, 2012; Levitt \& Glick Schiller, 2004), only a few have discussed the theoretical and practical implications of a multi-local methodological research design. 
One of the main implications relates to the changing nature of ethnography in its classical form, where the individual researcher understands the cultural and social life of a clearly geographically-demarcated group or society in its entirety. Due to practical constraints, the individual researcher who moves alone between the different sites has to make a trade-off between depth and breadth (Falzon, 2009; Fitzgerald, 2006; Hammersley \& Atkinson, 1995; Marcus, 1995; Mazzucato, 2009a). Dividing time and resources between the different fieldsites challenges the individual researcher to grasp the full cultural and social life; neither is it evident that the researcher establishes the intimate relationships with respondents that one expects of conventional ethnography (Hannerz, 2003). According to Hannerz (2003), this redefinition of ethnographic practice is not necessarily problematic, because the multi-sited ethnographer is more focused on what she is looking for and the kind of relationships that characterise the field.

At the same time, however, the 'ethnography' in 'multi-sited ethnography' may be misleading, since it often really entails 'non-ethnographic qualitative research' (Mazzucato, 2009a). The latter may best be described as 'observation and interviewing methods in more circumscribed, short-term, distant, and 'thin” ways' (Fox, 2004: 311). Given the challenges to maintain depth in multi-sited ethnographic research, we should acknowledge the limitations of this methodology (Mazzucato, 2009a), as well as its implications for what ethnography in such studies really entails.

I too was confronted with these limitations in the multi-sited fieldwork. Due to time constraints, I was forced to collect 'not so thick data' among part of the sample (see Section 3.6). This data allowed me to understand meaning structures from the perspectives of migrant parents and stay-behind youth, and the impact of locally bound institutions on the family members' everyday lived experiences. At the same time, my understanding of dynamics within care relationships remained limited. Since I was unable to capture simultaneity, I had little insight into how relationships are maintained, redefined and, importantly, how they change over time.

These shortcomings inherent to multi-sited fieldwork were solved by the adoption of the Simultaneous Matched Sample methodology that enabled the inclusion of a selected number of migrant families with whom long-term and intensive contact was maintained.

\subsection{A Simultaneous Matched Sample Methodology}

In an effort to balance breadth and depth and to incorporate notions of simultaneity of linkages, while recognising that migrants and non-migrants are part of networks that span geographical borders, Mazzucato (2009a) proposed a Simultaneous Matched Sample methodology. She refers to this methodology as follows:

using a sample of informants who are linked to each other by being part of a same social network and studying these informants in a simultaneous fashion so 
that information obtained from one informant in one locality can be immediately linked up with information from another informant in another locality.

(Mazzucato, 2009a: 217)

Within the framework of the TCRA programme, it was possible to organise and employ the SMS methodology.

Contrary to the use of matched samples in a step-wise research design where the individual researcher moves between the different sites, the SMS method relies on teamwork by which each researcher covers one side of the transnational network. Hence, instead of moving between the sites, the researcher can dedicate herself to one geographical location and create long-term and intensive contact with respondents that enables the collection of rich data on the social and culture life of the respondents within their respective localities (Mazzucato, 2009a). In this way, the SMS method mitigates the uncertainties that multi-sited fieldwork poses to traditional ethnographic practice.

Practicing a more classical ethnography in a multi-sited context is particularly relevant when researching vulnerable populations, such as migrants who are in precarious legal situations, and sensitive topics related to the intimate sphere of the family, like emotions, finances and conflicts (Mazzucato, 2009a). Such cases require relationships of trust between the researcher and respondents that is often only achieved through long-term commitment on the part of the researcher and repeated visits to respondents.

Our matched sample involved the different members who were linked to each other through transnational relationships of care, that is, migrant parents, their children and their stay-behind children's caregivers. Ghana-based researcher Ernestina Dankyi conducted ethnographic fieldwork among the caregivers, but included in the matched samples also the stay-behind children, while I simultaneously conducted ethnographic fieldwork among the Ghanaian migrant parents in the Netherlands of these same families.

This methodological setup created the opportunity to capture simultaneity in space and time which led to a deeper understanding of people's daily lives and relationships in different localities. Our presence in real time on both sides of the relationship allowed us to observe how persons on different sides of the care relationship experience and respond to a single event and actions from the other side. Our presence also helped verify what is said about transnational interactions. This 'investigator triangulation', as Baxter and Eyles (1997: 514) call the involvement of multiple researchers who study the same phenomenon, helps reveal everyday explicit and implicit practices. This cannot always be captured in an interview based on recall information, because respondents may fail to link or overlook consequences to earlier cross-border actions, or they may forget certain events, especially smaller ones (Mazzucato, 2009a). 


\subsection{Samples, Fields and Methodological Tools}

Having established the methodological design, I will now specify the different samples and field sites that were covered, as well as the methodological tools employed. Figure 3.2 provides a schematic overview of the different samples and their geographical location, the methodological tools and where collaboration with Ernestina Dankyi occurred.

\subsubsection{Stay-Behind Children in Ghana}

Although the initial research plan was to cover only the experiences of migrant parents in the Netherlands, shortly after the inception of the research programme I established the need to include a broader contextual understanding of children's perceptions in transnational family arrangements. This was left unexplored in the two qualitative projects, which focused on caregivers in Ghana and migrant parents in the Netherlands. Having first-hand knowledge of a wider group of children's perceptions and experiences living in transnational family arrangements also enabled a better contextualisation of the data collected among the migrant parents's care experiences, relationships, practices and choices.

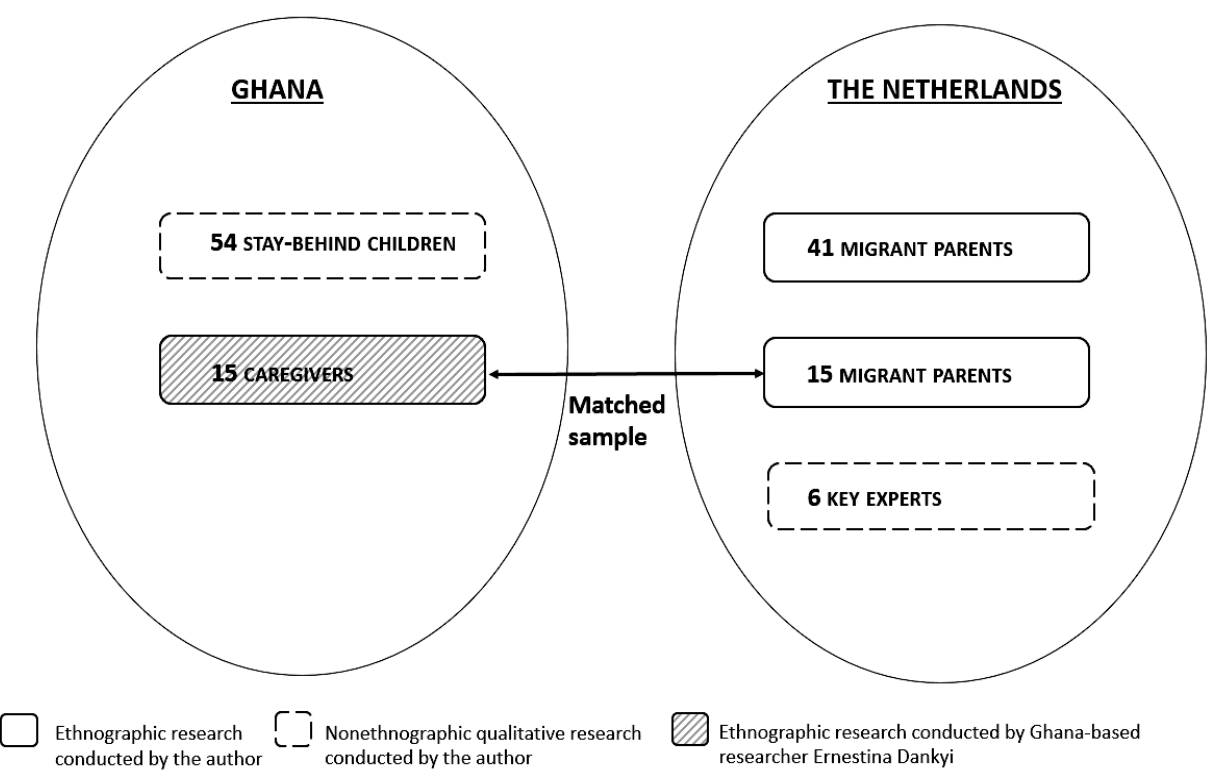

Figure 3.2. Overview of field sites, samples and methodologies 
A total of 65 school-attending children were interviewed during a three-month stay in Ghana at the end of $2010 .{ }^{8}$ Conducting this large number of interviews within a limited period of time was facilitated by the TCRA programme: pupils could be pre-selected from a survey that had been carried out in Ghana among 2,670 pupils in junior and secondary high schools in different Ghanaian cities the year before. Hence, contacts had already been established with the schools and first names of children with overseas parents were available from the database.

Prior to the field visit, a wide variety of children were selected together with dr. Victor Cebotari, who at the time was responsible for the quantitative data of the left-behind children's survey. Schools in Accra, the capital of Ghana, and Kumasi were selected, both of which are urban regions known for their high ratio of migration to the West, as indicated by remittances received from abroad (Mazzucato et al., 2005). The survey had also included schools in Cape Coast and the more rural Brong Ahafo region in the northern part of Ghana. Including pupils from these regions would have broadened my understanding of regional differences, but limited time and resources forced me to reduce the number of field sites.

I selected only those children of whom at least one of the biological parents resided in 'the West' for at least one year. I strove to incorporate diversity in family type, i.e. mother-abroad, father-abroad, father-and-mother-abroad, in the length of separation from the migrant parent, the number of times the child had changed caregivers, days of absence during the last school year, number of times the child was absent due to illness, and the child's emotional well-being as measured by the Strength and Difficulties Questionnaire (Goodman, Meltzer \& Bailey, 1998).

I ensured an equal share of children by sex, level of quality of the school-high or low, as categorised for the purpose of the survey - and city. Pupils from both junior and secondary high schools were included to account for differences in age-generally, the age ranges from 11 to 14 years in junior high schools and from 14 to 18 years in secondary high schools. Dankyi's (2010) previous experience with interviewing leftbehind children in Ghanaian schools, revealed that it was easier for older children to express emotions and to reflect on experiences, which informed my decision to select more children from SHS.

Post-doctoral researcher of the TCRA programme dr. Ernest Appiah, who had been responsible for carrying out the survey, contacted the different headmasters of the school by phone, briefly explained the purpose of the interviews, obtained permission and made appointments for face-to-face meetings. Given his already established contacts with the schools, this stage progressed smoothly. Reconnaissance visits to the schools in Accra were made together with dr. Ernest Appiah, where we explained the aims of the research in more detail, after which we asked for permission to interview the children on school premises. ${ }^{9}$

\footnotetext{
${ }^{8}$ Ernestina Dankyi interviewed 12 out of 65 children.

9 The schools in Accra included: Ghana International School, Grace Preparatory, New Generation, Silicon Valley and St. Mary's.
} 
All headmasters agreed to participate, though one wanted to seek permission from the children's caregivers. ${ }^{10}$ I presented the list of student names that I had selected for the interviews and provided their dates of birth to help teachers identify the children. A few of the pre-selected children had left the school. The same procedure was followed to prepare for the interviews in Kumasi, though this time a research assistant who had participated in the survey facilitated contact with the schools. ${ }^{11}$ Children were asked for permission to be interviewed and recorded prior to the interview. All interviews were conducted at the schools during breaks or after school hours and in a secluded place to guarantee privacy and to reduce background noise.

The decision for a formal interview setting, instead of more child-friendly methods such as drawing and storytelling, proved effective in the Ghanaian context, where children and adults are not likely to occupy the same spheres in everyday lives. Hence, children are not used to having informal chats with adults in which they express their emotions and opinions.

In particular, younger children would answer questions with a simple 'yes' or 'no' and found it difficult to explain their emotions and opinions. This 'matter-of-fact style of answering', which Dreby (2010: 237) also experienced when interviewing Mexican stay-behind children, is particular to societies that do not teach children to share their views. In Ghanaian society, obeying and respecting adults are key features in children's socialisation. As Twum-Danso (2009) points out, these adult-child interactions are inherent to the Ghanaian education system, where teachers do not allow children to question them or to express their opinions. Hence, Twum-Danso (2009) explains, 'children grow believing that they are not worth being listened to. They find it hard to formulate their thoughts and opinions because they are never asked for their views, they are told what to think' (p. 382). Children who do not act in conformity with these norms, for instance by sharing their opinions or by disagreeing with adults, are considered 'social deviants, disrespectful and are thus punished or insulted—as witches or devils' (TwumDanso, 2009: 384).

This expected behaviour is problematic in child participatory research because children are not used to sharing their opinions, or they want to give the right answer to please the adult researcher. I was aware of these adult-child interactions during the interview setting and tried to overcome this by probing further, asking for examples and by giving children ample time to think about their answers. I noticed that older children could better articulate their views and emotions with respect to different aspects of their lives and transnational child-raising arrangements.

The interviews were semi-structured and started with open questions that provided room for children to reflect on their experiences in their own wordings, rather than imposing the concerns of the adult researcher on the child (Tammivaara \& Enright, 1986). Drawing on the existing literature and preliminary interviews with Ghanaian

\footnotetext{
${ }^{10}$ In this case, I did not obtain permission to interview three out of the six selected children.

11 The schools in Kumasi included: Ahmadiyya, Cambridge, Froebel, KSTS, South Suntreso and Wesco Demonstration.
} 
migrant parents in the Netherlands, I had established a topic list that would loosely guide the interview. The list included a broad range of topics that related to the different aspects of transnational family life: the care situation prior to the parent's departure; the organisation of the care arrangement and the departure of the parent; the relationship with the parent(s), caregiver, and others in the care network; the care received; and changes in the care arrangement and relationships. Questions were also asked about the quality of relationships with others in the household, aspirations for migration and reunification, and general perceptions about parent-child separations inside and outside the context of international migration. Children who had lived abroad were asked about their migration and (re)integration experiences.

The topic list was treated with great flexibility, since they were meant to encourage children to speak about certain topics, while I ensured that children had ample opportunities to express themselves and to elaborate on topics they felt necessary. This created depth in the data and generated a wide range of narratives. The interviews lasted 45-90 minutes, were conducted in English, and recorded with the child's permission. The interviews were subsequently transcribed and analysed using the qualitative data software Atlas.ti.

Of the total of 65 interviewed children, 11 were excluded from the analysis because they had experiences with migration, but not with family separation, or another relative than their biological parent was abroad. Of the remaining 54 children, the primary destinations of the children's parents included The United States and The United Kingdom, and to a lesser extent in Germany, the Netherlands and Italy. Most parents had departed when the child was between the age of six and thirteen years old, with fathers being more likely than mothers to leave children below the age of six years and for longer periods of time. Children in father-away families were most likely to be cared for by their biological mother. In case of mother-away families, female kin were the most likely caregivers, with fathers the second most likely. The majority of children of whom both parents were abroad stayed in the care of female kin (see Appendix A for an overview of respondent characteristics).

The one-off interviews were well-suited for exploring a wide range of children's experiences in transnational family arrangements. However, not having observed the child in the home situation and exclusively relying on the perspectives of children prevented me from gaining a deeper understanding of the care relationships and to verify what the child told me with what actually happened. For instance, I had to be careful in how I treated the information provided by children that concerned their parents' remittance behaviour or the spending behaviour of caregivers, since children are often unaware of the financial arrangements made between parents and caregivers. Moreover, I realised that migrant parents may overcompensate their absence by sending luxury gifts which the caregiver may in turn withhold on account of fears that luxury items may be stolen in school, or that they might create problems with other children. Children, however, may interpret this as mistreatment by the caregiver. 
Although the one-off interviews did not allow me to check if children presented a better or worse version of their reality, the large number of interviews allowed me to compare children's narratives and to look for patterns. This enabled insight into how children experienced certain issues, even though this may have been different when seen from another actor's perspective. Moreover, the one-sided account from the child's perspective failed to provide thorough insight into the situational factors on children's emotional experiences. Rather, this study analysed the range of experiences by taking into account gendered care cultures.

\subsubsection{Migrant Parents in the Netherlands: Matched and Non-Matched Samples}

The bulk of data for this thesis was collected among Ghanaian migrant parents in the Netherlands from mid-2010 until mid-2013. As shown in Figure 3.2, data was collected among 15 matched cases and 41 non-matched cases. Because the data collection among these two samples ran parallel, they will be grouped together in the discussion on field sites, access and building trust. Where relevant, the specificities of the matched sample will be identified. The discussion of the matched sample focusses on the Dutch side of the data collection, though reference will be made to the Ghanaian fieldwork where relevant. For a detailed discussion of the fieldwork conducted in Ghana, see Dankyi (2014).

\section{The field sites}

In the Netherlands, around $50 \%$ of officially registered Ghanaian migrants reside in Amsterdam (CBS, 2018b), with two-thirds residing in the multicultural district Zuidoost (Southeast) $(\mathrm{O}+\mathrm{S}, 2006)$. The highest concentration of Ghanaians can be found in the Bijlmer (short for Bijlmermeer), a suburb of the district of Zuidoost. Ghanaian presence in this suburb is evidenced by the numerous shops that sell typical Ghanaian food items and fabrics, Ghanaian hairdressers and ethnic associations, and a money transfer that exclusively handles transfers to Ghana. On weekends, the streets fill up with Ghanaians dressed in typical Ghanaian cloth who make their way to one of the numerous churches that can be found on almost every corner. The city district of Zuidoost is also home to several events where Ghanaian clothing, music, dance and theatre are promoted, such as the famous Kente Festival. Given the great share of Ghanaian migrants, the multicultural district of Zuidoost (and more specifically the Bijlmer) was a logical choice as the main field site for this study.

The city district of Zuidoost was also considered an interesting field site for its social diversity. The website of the Bijlmer museum chronologically describes how the Bijlmer changed over the years from an area where mainly low-income earners settled to an area where a more diverse group settled in terms of socioeconomic position ("Bijlmer in tijd", n.d.). The city district was established in the 1960s in response to the Amsterdam housing shortage and contained mainly high-rise apartment houses, while the rest of the district would consist of low-rise high-density housing, surrounded by numerous green areas. 
The district failed to attract the middle and high-income families it had aimed for. Instead by the early 1970s, the residents of the Bijlmer were dominantly young (under 35 years), single, and low-class. Many were Surinamese who had come to the Netherlands around the time of independence. For long, the area had to contend with high rates of vacant housing, criminality and drug use in public places, while many of its inhabitants faced poverty and unemployment. Affordable social housing and the illegal subletting of rental properties would later attract a more diverse group of non-Western origin, among which Ghanaians in the late-1980s.

In the early-1990s, authorities sought to tackle the problems by renovating and destructing high-rise flats, by constructing low-rise housing, and by establishing shops, businesses, offices, restaurants and cultural centres. Selling many of the new low-rise housing aimed at attracting high-income earners ("Bijlmer in tijd", n.d.). A recent survey showed that the district's reputation has improved, although criminality is still considered problematic (Huijzer \& Jakobs, 2013). Its population continues to be the poorest of Amsterdam, with the largest share of persons depending on social benefits (OIS Amsterdam, 2015). Nonetheless, the share of home-owners has increased over the years: in 2015, a little under one-third of all houses in the district of Zuidoost were owner-occupied (OIS Amsterdam, 2015).

Even though the housing prices are relatively low compared to those of the rest of Amsterdam, it can be asserted that the expansion of the property market has attracted a more diverse population in terms of socioeconomic status. I expected to find among the property owners some middle-income Ghanaian migrants. Moreover, since undocumented migrants are concentrated in the largest cities (Engbersen et al., 2002), and more specifically in neighbourhoods where most documented migrants settle (van der Leun, Engbersen \& van der Heijden, 1998), I expected the district of Zuidoost to be the most likely place to come into contact with undocumented Ghanaian migrants. Thus, locating the fieldwork in this district facilitated my search for a diverse sample of respondents in terms of legal and socioeconomic status, thereby gaining access to a wide range of experiences.

Although the main focus was on the Bijlmer and larger district of Zuidoost for reasons mentioned above, the search for respondents was not limited to these geographical areas. Several respondents resided in other districts of Amsterdam, while 11 respondents resided in The Hague, the city with the second-largest share of Ghanaian immigrants in the Netherlands (CBS, 2018b). These respondents were included in the sample, not only because it proved generally difficult to find respondents and to convince them to participate in the research (see below), but also because my focus on the Bijlmer was above all a result of pragmatic considerations, that is, having access to a large and wide variety of Ghanaian migrants. Hence, there were no particularities among the Ghanaian migrants in the Bijlmer that would lead to expectations that this group was qualitatively different from Ghanaian migrants in other parts of Amsterdam or The Hague. True, I found fewer undocumented and middle-income Ghanaian migrants 
outside the Bijlmer, but the living and working conditions and the organisation of social and religious life were very similar to those who lived in the district of Zuidoost.

\section{Sampling strategies: selection criteria and gaining access}

Respondents in Amsterdam would be part of two different though related samples: a matched and a non-matched sample. To balance feasibility with a wide range of experiences, we aimed for 20 matched cases that would be followed with some regularity over the course of the fieldwork. At the same time, I considered it necessary to include a larger sample of migrants whose family members in Ghana were not part of the study - the non-matched sample-which enabled me to check the findings of the matched sample against a wider sample of respondents. Moreover, I wanted to include cases in which care relationships were considered to be of bad quality or simply nonexistent, which would be more difficult to capture in the matched sample since we relied on double consent and therefore some degree of communication between the parent and caregiver. The inclusion of these negative cases added depth and strength to my analysis and improved the internal validity of this study. Because I wanted the data collection to be open to analytical ideas that developed during the course of the fieldwork, I added respondents to the non-matched sample until the point of saturation, i.e. when adding new cases did not result in a better understanding of research problems (Glaser \& Strauss, 1967).

The first selection criterion was having experiences with separation from a child in Ghana below the age of 21 years. For the matched sample, we only selected parents whose children and children's caregivers resided in the Ashanti and Greater Accra regions to facilitate Ernestina Dankyi's frequent visits to the families. For both samples, only those respondents who had lived at least one year in the Netherlands were selected, so there was some history of transnational family experiences to draw upon.

The sampling strategy aimed at including different categories of transnational parents based on gender, socioeconomic and legal status, family type (father-, mother- or fatherand-mother-abroad), and relationship to the caregiver. In case both parents lived together, I would randomly select one of the parents. These were the minimal criteria that enabled the necessary inclusion of respondents with varying levels of transnational mobility and connection, and that would allow for a wide range of experiences. At the same time, the sampling procedure was open to analytical considerations that developed during the course of the fieldwork.

Gaining access to respondents and retaining them as part of the research proved time-consuming, mainly due to issues of distrust that are common in research on marginalised and vulnerable groups, such as undocumented migrants (Engbersen et al., 2002; Van Liempt \& Bilger, 2009), and in research that investigates the sensitive topic of family separation (Dreby, 2006). It proved particularly difficult to have women participate in the research. ${ }^{12}$ It was therefore necessary to adopt several strategies to

\footnotetext{
${ }^{12}$ I could never really determine why it proved so difficult to access female migrants. What I did observe was that women were more often involved with Dutch law, which could mean that the potential risks of participating in a
} 
access respondents. During my first time in the field in the Summer of 2010, I made use of the contacts of Prof. dr. Valentina Mazzucato from her previous research among the Ghanaian community of the district of Zuidoost. The relationships of trust she had established with several key informants were of paramount importance to introduce the research to the Ghanaian community and to gain access to respondents. Together with Veronica van der Kamp, we organised a television show around the topic of child-raising arrangements, an excerpt of which was included in the introduction of this thesis. A week after it aired on local television, we organised a phone-in on a Ghanaian migrant radio station that aimed at further introducing the TCRA project to the Ghanaian community. We also asked people to share their experiences. Ten people who called in agreed to participate in the research.

Upon re-entry in the field in early-2011, after the fieldwork in Ghana, I continued the search for respondents. Snowball sampling proved complicated because parents were reluctant to introduce potential respondents in their networks (see Dreby, 2010 for similar experiences). Moreover, the urban setting in the Netherlands limited the possibility of chance encounters, since people's activities are usually indoors (Mazzucato, 2009b). Successful gateways to access a wide variety of respondents included research assistants, mainly from the Ghanaian migrant community, who had been involved in the survey research of the TCRA project, as well as migrant organisations and Ghanaian churches.

Having migrants consent to participate in the matched sample proved even more complicated, for it required double consent from the migrant parent and the caregiver in Ghana. Already at an early stage, I would have to ask migrant parents who did not know me very well for the contact details of their children's caregivers. Following Mazzucato's (2009a) suggestion, I only asked respondents in the Netherlands to participate in the matched sample once I felt that some degree of trust was established, which usually required a few meetings. Moreover, Ernestina Dankyi introduced herself to the respondents during one of her field visits so the parents would personally know the researcher who would contact their children's caregiver in Ghana.

Trust was also relevant to gain consent from the caregivers in Ghana. One effective way was to be introduced to the caregiver by the migrant parent. I also asked the migrant parent to explain the purpose of the research and to ask the caregiver's permission to be contacted by Ernestina Dankyi (see Mazzucato, 2009a for similar experiences). In a few cases, caregivers declined when Ernestina Dankyi contacted them. The research collaboration and simultaneous presence on both sides facilitated the search for new

research project were higher for women than for men. First, Ghanaian women seemed more likely than men to obtain a residence permit through marriage, an observation also made by Van Dijk (2002b). In general, marriages that provide access to a residence permit are looked upon with great suspicion by immigration officials and subjected to extensive examination. Fear of losing the documented status if the marriage is considered as fraudulent, and probably also their partner's fear of being connected to an illegal activity, could help explain women's reluctance to bring a Dutch researcher into their lives. Second, I noticed that, more often than men, women expressed the desire to reunite with their children in the Netherlands. It may have been that they feared that exposing their situation to an outsider could impede their current or future chances of a successful reunification. 
cases to the sample (Poeze \& Dankyi, 2013). Eventually it was possible to include 15 matched cases in our sample.

\section{Respondent characteristics}

The multiple entry points ensured that a large variety of parents could be accessed with diversity in characteristics related to the parent and his or her family network. The heterogeneity of the sample allowed for the exploration of a range of transnational childraising experiences. Here, I will jointly discuss the characteristics of the matched and non-matched samples.

Like the majority of Ghanaian migrants in the Netherlands (see Chapter Three), the migrants of this study originated from the southern part of Ghana. Accra and Kumasi were the major cities from which the migrants of this study originated, which can at least be partly explained by our selection criteria (see above). The ethnic origin of the respondents reflects the ethnic composition of Ghanaians in the Netherlands (Caarls, 2015; Kraan, 2001), with the majority belonging to the matrilineal Akan, the largest ethnic group of Ghana, and to a lesser extent to the patrilineal Ga-Adangbe.

Of the 56 migrant respondents in the Netherlands, 32 were female and 24 were male (see Appendix B for an overview of respondent characteristics). In the matched sample, there were six mothers and nine fathers. In the total sample, the age ranged from 30 to 65. The length of separation from the children ranged from 1 to 25 years for men-with an average of 13 years - and from 2 to 24 years for women - with an average of 14 years. Respondents had between one and six children in Ghana, whereas about one-third also had children in the Netherlands. Some of the children of one of the male respondents resided in the United Kingdom. The majority of male respondents were married (79\%), all to Ghanaian women who resided in Ghana or the Netherlands, and in one case in the United Kingdom. Being married or in a relationship was less common among the female respondents (41\%). Of the married women, 11 had a Ghanaian husband in the Netherlands, one in Ghana, whereas one woman was married to a native Dutchman.

Of the 56 respondents, 16 could be categorised as father-away families, 27 as motheraway families, and 13 as father-and-mother-away families. Who cared for children differed by family type. In father-away families, the children's mother in Ghana was more often the children's caregiver, followed by paternal relatives, most often the father's mother. In mother-away families it was primarily the mother's mother who cared for the children, whereas in four cases the caregiver was the children's non-migrant father. In mother and father-away families, the majority of caregivers were the mother's mother. Among all family types, there were three cases in which the caregiver was unrelated to the migrant parent.

The decision to migrate was usually motivated by the expectation to better provide for their children in material terms, while some women had also left Ghana to escape violent domestic situations or to join a spouse abroad. Parents usually migrated when their children were at a young age and initially planned to stay for only a few years, but all postponed their return because they had grown linkages to the Netherlands or 
because they believed they needed to secure more money for a decent living in Ghana. The majority of respondents had entered the Netherlands on a temporary tourist visa, and to a lesser extent as students or as family migrants. Two had applied for asylum. A few had stayed for longer or shorter periods of time in another European or African country before making their way to the Netherlands.

Means of entry largely determined-documented status. Those who came as students held a temporary status for the duration of their study programme, whereas family migrants received a dependent-documented status. Respondent who overstayed their three-month tourist visa ended up in illegality. Those who had been able to acquire a documented status in the Netherlands had done so by marrying a Dutch denizen or citizen. Of the male respondents, 10 were undocumented, while 13 held a Dutch residence permit or citizenship. At the time of first interview, three female migrants were undocumented against 29 documented female migrants.

The socioeconomic position of respondents largely depended on their legal status, labour market position and presence or absence of a Dutch-based spouse's income, ranging from those who were barely subsisting to those who were prosperous. Documented male respondents worked largely full-time jobs-both casual and permanent-in the formal cleaning sector, factories and restaurants, while one male respondent worked as a pastor and one in the public sector. The documented women of this study primarily occupied low-skilled labour positions in tertiary sectors, jobs that are common for Ghanaian women in the Netherlands (Black et al., 2013). Both undocumented male and female migrants of this study primarily held casual and parttime jobs in the informal cleaning sector. Given the insecure and ad-hoc nature of the work, undocumented migrants often worked multiple jobs. Only a few of the undocumented migrants held a job for a longer period of time.

\section{Methods}

The bulk of data was collected by employing ethnographic methods over different periods between mid-2010 to mid-2013. ${ }^{13}$ As an ethnographer, physical presence and long-term involvement through fieldwork and face-to-face contact allowed me to study my respondents in their 'natural surroundings' and to focus on the everyday realities of their transnational family lives. The longitudinal nature of my research enabled the observation of changes in the legal status, employment, and relationship status on the side of the parent, and the impact these had on the daily lives of migrants and their transnational activities. In case of the matched sample it also allowed me to gain insight into the impact on the daily lives of the family members in Ghana.

The long-term approach is important, as migration should not be studied as a single event at one point in time, but rather as a process (Levitt and Glick Schiller, 2004). Studying respondents and their family members over a three-year period allowed me to observe and document dynamics within transnational care networks, that is, the creation,

\footnotetext{
${ }^{13}$ I left the fieldwork for six months, once for maternity leave (four months) and once to teach at Maastricht University (two months).
} 
transformation and longevity of transnational relationships of care, as well as the ways in which people on both sides respond to crisis situations and opportunities presented.

I used different methods to achieve data triangulation: in-depth interviews, nonparticipant observations during the interviews and social visits, a network-mapping tool (see below), informal meetings and phone calls between visits. I studied more intensively and in-depth the matched cases since these enabled the study of dynamics from both sides of the relationship. From the non-matched samples, I conducted 32 one-off interviews and multiple interviews with nine respondents (ranging from two to four interviews per respondent).

As is typical for research in urban settings-and maybe even more in the Global North-I was dependent on appointments to meet with respondents (Mazzucato, 2009b). This limited my observations in informal settings. The interviews usually took place in respondents' homes, although first interviews with undocumented migrants often took place in a public setting, such as a park or a restaurant. Given their precarious status, multiple meetings were necessary before the migrants allowed me into their homes, unless I had met them through mutual contacts.

My presence in people's homes allowed me to observe migrants' daily routines in their own surroundings and witness how respondents interacted with their Dutch-based spouses, children and other kin and non-kin. Parents would often show me photos of their Ghana-based children, partner and other relatives that provided additional insight into their past and present family lives. Moreover, parents had the tendency to call their children in Ghana during or after the interview, either by phone or via Skype, for me to 'get to know' who the parent was talking about. Observations were further made on informal visits, weddings, meetings of home town associations and church services to which I was invited by respondents with whom I had established close relationships. Because of a lack of knowledge of Ghanaian languages, it was however impossible to listen in on phone calls and informal conversations. Such conversations were translated when I asked for it. Although this provided relevant information, I missed out on details and nuances that were not translated after the fact.

The interviews were conducted in English. Only one interview necessitated an interpreter. In the early stage of the research, interviews were tape-recorded with the permission of the respondents, but due to the sensitive nature of the information that people revealed—or declined to reveal while recording-I soon switched to taking detailed notes.

A topic list guided the interviews, but enough room was left for respondents to discuss issues that they felt were of importance. The interviews covered a whole range of topics around the parent's past and present family life and migration experiences: family lives and child-raising arrangements prior to migration, their own experiences as a fostered child, the organisation of migration and child-raising arrangements, changes in the child-raising arrangement, their past and present relationships with their children and spouse, their working and family lives in the Netherlands and their experiences with 
reunification. Legal documents were consulted for respondents who had applied for temporary or permanent family reunification.

The longitudinal and qualitative approach of the research proved essential, as it allowed ample room for open conversations and relationships of trust to be established. Trust was essential to discuss vulnerable and intimate issues, but also to bring to the surface emotions that often remain hidden from the view of the researcher. It is important to gain insight into emotions, because alongside daily routines, acts and conflicts, they belong to the sphere of 'intimate knowledge' (Marcus, 1995: 99) and are vital to understand what transnational family life means (Levitt, De Wind \& Vertovec, 2003). Long-term and intensive personal interaction with respondents, repeated visits, assistance with legal issues, Ghanaian assistants and my knowledge of their home towns and sometimes family members combined to foster relationships of trust that enriched and improved communication. Yet despite long-term relationships, some migrant parents remained hesitant to share the more sensitive aspects of their lives (see Dreby, 2010 for similar experiences).

The often emotional stories that parents revealed after several meetings forced me, as it does many qualitative researchers, to balance and rebalance my involvement and attachment (Fox, 2004). Parents usually thanked me after the interview for the opportunity to share their intimate and sometimes painful experiences that they usually kept to themselves. At the same time, I also became involved in some of my respondents' lives and at times helped out. For instance, I provided respondents with practical and legal information, translated and wrote letters, made phone calls to lawyers and organisations, and I carried items for them to their family members in Ghana. At all times, I carefully navigated my relationship with the respondents and my position as a researcher.

A network-mapping tool was conducted with all respondents of the matched sample - including children and caregivers in Ghana by Ernestina Dankyi. I additionally conducted this exercise with ten respondents of the non-matched sample. The networkmapping tool is a name-generator questionnaire that is well-suited for social network analysis (Burt, 1984; Campbell \& Lee, 1991; Mazzucato, 2009b). This tool was used to map the broader care networks of one of the children in Ghana from the perspective of the different respondents (Mazzucato, Dankyi \& Poeze, 2017). It was tested for cultural relevance with several Ghanaians in the Netherlands and Ghana. Questions that did not generate a response were adjusted or omitted.

I used this care network-mapping exercise after an introductory meeting with the respondents. Respondents were asked to indicate the names, locations and relationships to them of persons responsible for the material, emotional and social care of one of the selected children. ${ }^{14}$ More questions were asked to generate additional names. For instance, parents were questioned about whom he or she could have asked to care for

\footnotetext{
${ }^{14}$ Material care referred to e.g. paying for school fees, providing food, cooking for the child. Emotional care referred to e.g. helping the child when he or she is feeling down. Social care referred to e.g. educating the child on how to behave.
} 
the child while he or she was abroad, if somebody who was asked declined, and with whom the parent has arguments regarding the child's care. Questions were asked to reveal the persons responsible for the child's schooling and health, and respondents were asked to indicate if this person is very important or somewhat important. Questions were also asked about transnational relationships, such as the frequency of contact and the forms of communication, who decides when to communicate with the child, who decides who the child lives with and when to send money and gifts to the child.

To get a clear overview of where the children lived at each point in time, an age grid was used. Parents were asked to indicate for each child the history of caregivers and locations. During the network-mapping exercise, respondents were prompted to further explain their answers.

The care network-mapping tool evoked important analytical insights (Mazzucato, Dankyi and Poeze, 2017). It shed light on members on the periphery of the care network, including migrated relatives and network members in other parts of Ghana and the Netherlands, who could not be included in the ethnographic data collection given the pre-selected field sites and type of respondents in Ghana and the Netherlands. This helped assess the wider network of care and the respondent's place in it. Moreover, it revealed the type of people involved in the care of the child, the type of care each provided from the viewpoint of the respondent and the quality of the relationship.

Most important, however, were insights that arose when we compared the maps of the different members. Since we largely asked the same questions to the different respondents in the matched sample, the comparison of the maps revealed how care was perceived from the viewpoint of the respondent's place in the child-raising arrangement. The comparisons also brought discrepancies and similarities to the forefront, which allowed us to better understand how transnational child-raising arrangements function. More detailed descriptions of the tool and its contributions for this research are discussed in Mazzucato, Dankyi and Poeze (2017).

Finally, interviews with six key experts in the Netherlands were conducted. ${ }^{15}$ Key experts were identified on the basis of their expected knowledge of transnational family life, the Ghanaian community or legal issues, and included the following: a reverend of a Pentecostal church, a community and church leader, a chairman of a Ghanaian migrant organisation, the founder of an association of Ghanaian women, the president of an organisation providing assistance to Ghanaian families, and a migration lawyer. Without suggesting that the interviews with key experts from the Ghanaian community are representative for the community's response to family separation, the interviews did shed light on the functioning of extended family relationships and financial expectations of those back home, and parents' attitudes with regard to cohabitation with their child. It also highlighted the kind of problems encountered with kin and non-kin caregivers and with family reunion and the law, as well as gendered experiences, and the role of churches and associations in the Ghanaian migrant community. Moreover, the interview

\footnotetext{
${ }^{15}$ Interviews with key experts in Ghana were conducted by the Ghana-based researchers. This data is not included in my dissertation.
} 
with the migration lawyer who had extensive experience with counselling Ghanaian clients highlighted some important issues this group faces in dealing with (family) migration law.

\subsection{Teamwork Te $^{16}$}

Given the innovative methodological approach of this research, it is worth mentioning some aspects of the SMS methodology which we identified as particularly useful with respect to studying members of the same family in two field sites by two researchers.

\subsubsection{Sharing Field Notes}

Over the course of the fieldwork, Ernestina Dankyi and I continuously shared summaries of each other's field notes that included the most important observations, (signs of) tensions, and issues that we believed were of particular interest to the other researcher. We also shared the network maps that we collected on both sides. Our physical presence on each side of the relationship and the sharing of information of daily lived experiences among multiple families made important underlying dynamics in care relationships visible and allowed for a broader contextualisation of our own data. At the same time, it informed and deepened our questioning (Mazzucato, 2009a). Moreover, in comparing the data from the other side with our own observations during our regular email contact, we could compare spoken words with actions and unveil inconsistencies. Miscommunication between the respondent and the researcher was at times at the basis of inconsistencies. We also came to understand that inconsistencies could reflect important transnational relationship dynamics, notably the information gap that exists between family members on different ends of the relationship that serves to keep care relationships intact and to diminish distrust, despite often challenging circumstances. This is explained in more detail in Chapter Eight.

Sharing field notes also pointed us to important events that would otherwise be more difficult to capture, allowing us to immediately follow up on such events and to observe how respondents on both sides responded to a single event or action. An example of how the SMS methodology enables the observation of the simultaneity of events (Mazzucato, 2009a) is the apprehension and imprisonment of one of our undocumented male respondents in the Netherlands. We first learned about his situation when Ernestina Dankyi visited the non-migrant spouse in Ghana. Ernestina Dankyi's regular visits to the wife and her children allowed her to witness the impact that the migrant's imprisonment had on the everyday lives of those in the origin country. Given the relatively long duration of the imprisonment—he was in jail for eight months — such events and its impacts may be observed when one researcher moves between countries. This is however more complicated when it comes to shorter-term events. For instance,

\footnotetext{
${ }^{16}$ Sections 3.7 and 3.8 draw heavily on Poeze and Dankyi (2013).
} 
in one case an aged caregiver was hospitalised for one month, during which time she left her granddaughter - the child of her migrant daughter — with the neighbours. Our presence on both sides and the exchange of field notes allowed us to observe how this single event unfolded on both sides of a relationship. In this particular case, the child was happy with the move because it relieved her from caring for her aged grandmother. Meanwhile, in the Netherlands, the migrant mother lamented the move as she worried about the care provided by the neighbour whom she did not trust, and she subsequently proceeded to search for possibilities to reunite with her daughter in the Netherlands, while continuously monitoring her daughter on the phone. Had we not been physically present on both sides, such observations would have been more difficult to capture since it often depends on the timing of the fieldwork if the researcher is in the right place at the right time.

\subsubsection{Exchange of Field Visits}

Our teamwork also included visits to each other's field sites. Apart from the fieldtrip in 2010 when I interviewed stay-behind children, I also visited Ghana in the summer of 2012. This last time, I also visited some of the children and caregivers of the matched sample. Ernestina Dankyi visited the Netherlands on a more frequent basis and for several months at a time.

Field visits revealed relationship dynamics, such as how caregivers struggled to communicate their worries to the migrant parent. A clear example of this is when, during a visit to one of the families in Ghana, the caregiver asked me to enter her bedroom. Visibly frustrated with the care situation, she pointed to the mess that the children had made and insisted that this was reported to the migrant mother in the Netherlands, hoping that the mother would push her efforts for reunification a bit harder. The caregiver had never complained to the migrant parent about the children, afraid of damaging the relationship and her own position as a reliable caregiver, and considered my presence to be one of the few means to reveal to the migrant parent her dire situation.

This visit to Ghana also facilitated contact with my respondents in the Netherlands and often opened up a new range of topics, given that I had witnessed what they were talking about. Moreover, my respondents asked me to bring items to their family members in Ghana. As Mazzucato (2009a) argued, carrying items to the other side is a means through which the researcher can, at least partially, show reciprocation to the respondent for the time they have invested in the research. It also provides a wealth of information on what is being sent and how it is organised, as well as on the difficulties to organise such flows. At the same time, she warns that becoming a carrier of goods influences our research results, because such goods may not have been sent in the absence of the researcher. To cope with these two sides of the coin, I abstained from actively inciting my respondents to send items yet consented when asked explicitly to do so.

The extended stays of Ernestina Dankyi in the Netherlands during the different phases of the research benefitted the sampling as discussed before, but also gave us the 
necessary time to tune our methodological and theoretical approaches. The back-andforth visits provided a means to better understand and interpret each other's summaries because during these visits we would discuss detailed observations of living conditions and physical features on the other side, which were not captured in the notes we shared. We also discussed non-verbal cues, such as body gestures and facial expressions, information that is accessible only to the researcher who conducts the interview. This is important because such cues may lead to variations in interpretation of the interview material, since only the researcher knows how this non-verbal communication influenced the way the interview unfolded (Baxter \& Eyles, 1997).

Our lengthy conversations during Ernestina Dankyi's stay in the Netherlands also helped us overcome problems associated with differences in our research education and theoretical approach. In other words, we could point our noses in the same direction in order to unravel and clear up miscommunication and we could discuss our expectations. It also allowed us time to consider ownership of our data. As Mazzucato (2009) argued, sharing data requires a particular mind frame of the individual researchers. Being trained as an anthropologist, it was not evident to adjust my research tools for the sake of comparability, to have less freedom in how I organised the research, and to share data with another researcher. Regular face-to-face meetings in which these issues were discussed were necessary to facilitate this process.

\subsection{Ethical Considerations}

Researching sensitive topics and people in vulnerable situations, such as irregular migrants and minors-persons or groups that are vulnerable since they may be stigmatised and generally have limited power over their own lives-raises ethical considerations, for it may put these persons or groups at potential risk (Van Liempt \& Bilger, 2012). During all phases of the research, I made sure that no harm was done to the respondents. For instance, I did not probe to know the 'juicy details' as Van Liempt and Bilger (2012: 456) describe the collection of data for the sake of getting to know all the facts that are not directly relevant for the research. Instead, I listened to what respondents considered important. Moreover, I informed my respondents about the type of data I was collecting, the progress of the research and for what purposes I would use the information so that respondents could make a well-informed decision about whether or not they wanted to participate.

I realised that this was complicated; participants may not always be familiar with research processes and therefore are unable to foresee the consequences of their participation (Block et al., 2012). I therefore would try to be as specific as possible, give respondents time to make a well-informed decision, answer any questions and try to ensure that respondents were participating for the right reasons.

Informed consent was an oral agreement between myself and the respondents, i.e. migrant parents and stay-behind children, as well as with the headmasters of the 
children's school and some of the parents of the children that were interviewed. My decision for oral agreements-rather than written ones—-had several reasons. First, in the Netherlands and Ghana, ethical procedures did not require written consent. Second, I realised that written consent has little meaning coming from people who do not have a complete understanding of research projects and processes, and who are either not proficient in English or are illiterate. Moreover, I felt that consent was needed at different times of the process, which meant that oral consent was requested repeatedly from those who participated in the research over a longer period of time.

Most problematic was an informed and meaningful consent from the children, because similar to the classroom setting of Block et al.'s (2012: 78) research with refugee students, the children in this research 'were potentially "captive research participants", and the school setting reproduced 'disparities in power' between the children, the headmasters and the researcher that 'may have meant that students would feel that they had little choice but to participate'. I tried to diminish these effects by emphasising to the children that they were allowed to decline to participate and that this would have no negative consequences.

I ensured respondents' anonymity and confidentiality by using synonyms. The SMS methodology, however, evoked specific ethical issues in this respect. First, the differences in stories and our exchange of field notes uncovered important insights into transnational relationship dynamics, but also forced us to think about how to deal with information that other family members did not know about and that may be potentially harmful when revealed. We dedicated ourselves to demonstrating trustworthiness to our respondents and were careful not to divulge what respondents had said to family members on the other side. Such a procedure would need to be amended if one notices conditions of abuse, where research ethics guidelines advise reporting this to the legal guardians but also to relevant authorities such as child protection. In this research, we did not encounter such cases.

Second, we risked exposing families when providing details on the matched cases in written material to others in the community, but also to the families themselves. This is a delicate and complex process because it is not always possible to know what information may cause harm when made public. Such cases therefore ask a great deal of sensitivity and accuracy on the part of the researcher (Van Liempt \& Bilger, 2012). We realised that this was even more so in our study as respondents actively withheld information from the other side in an effort not to damage the relationship. Consequently, we continuously asked ourselves what data we could publish without harming the families. For instance, the delicate relationship between Joyce and her aunt which we describe in detail in Chapter Eight could have possibly been fuelled with even more frustrations after publication, since it contained information unknown to the other side, thereby possibly threatening the longevity of the care relationship and with that the safety of the children. Since it was an important case to illustrate and substantiate our findings, we decided to publish it, but we were careful not to expose the family members. 
Hence, we used pseudonyms and took out any identifying details so that it was impossible to trace the information back to this particular family.

\subsection{Positionality in a Transnational Research Team}

As Madison (2012: 9) reminds us, 'doing fieldwork is a personal experience', referring to the impact of the researcher's positionality in observing and interpreting data. It is the researcher's own culturally-learned thinking and way of being, that is connected to place and time, that should be taken into account when discussing our fieldwork. Or, as Basch, Glick Schiller and Szanton-Blanc (1994: 16) argue, 'our perceptions, whether we objectify them by identifying them as 'data' or as 'texts', are influenced by our position in the world and our position about the state of the world.' We should therefore recognise the implications of the similarities and differences between us, the researchers, and our respondents (Baxter \& Eyles, 1997; Madison, 2012).

Working in a transnational research team complicates the challenges related to the researcher's positionality. This may be even more the case when this team involves researchers from the sending and receiving society. Ernestina Dankyi, as an 'insider' based on ethnic identification and shared language, had the advantage that respondents were more inclined to trust her, and she therefore had easier access to our research group than me. Especially at first contact, I could be looked upon with suspicion and be held accountable for 'my' legal system that pushed people in dire situations, although some people also approached me hoping that I would be able to help them with legal issues.

At the same time, as an 'outsider' analysing the data from a Western perspective, I sometimes pointed to important phenomena that Ernstina Dankyi overlooked due to her familiarity with her own cultural norms and values. Moreover, due to my position I also had more room to ask for clarification and details, which Ernestina Dankyi could not because of her expected shared knowledge of social and cultural norms and practices. We tried to profit as much as possible from our differential positions. Thus, we made use of Ernestina Dankyi's visits to the Netherlands to search for respondents, to build rapport and trust, whereas I would follow up on information that needed more explanation.

Our collaboration also revealed how our own background influenced the interviews and our interpretation of the results. For instance, from Ernestina Dankyi's responses to some of the stay-behind children's answers I learned to be careful not to interpret children's answers from my own sociocultural context, and likewise, to respond in that way. Hence, I perceived children's household tasks and received physical punishment from my Western frame of reference that led me to pity them and over-pathologise their situation. Ernestina Dankyi's responses to the children and our conversations helped me overcome this tendency and to place the children's experiences in their own sociocultural context. 
However, as Barglowski, Bilecen and Amelina (2015) rightly argue, 'in discussing the epistemological and practical implications of insider and outsider research, we must be careful not to essentialise identifications' (p. 218). Hence, when sharing two identifications, this does not necessarily imply that experiences are related, nor do ethnic identifications make one an 'insider'. Differences based on gender, age, migration experiences, and educational level may cause distance or proximity when shared with an ethnic 'outsider'. For instance, I shared with the respondents experiences of migration to the Netherlands through my migrant partner, as well as of parenthood. Moreover, I shared with them knowledge about the Dutch labour market, the education system, and legal issues. As such, Ernestina Dankyi and myself were both 'insider' and 'outsider', depending on the types of identifications.

Working together as a team of researchers from different backgrounds and positions vis-à-vis the respondents helped me to not take for granted potentially important data, to combine perspectives, and to balance insider and outsider research. It helped me overcome, or at least minimise, the subjective lens of a researcher working alone, thereby enhancing the validity of my results (Barglowski, Bilecen \& Amelina, 2015). However, to take advantage of the teamwork it was essential to continuously discuss our field notes, observations and interpretations by emailing on a frequent basis and by discussing notes more in-depth during regular moments of face-to-face contact.

\subsection{Concluding Remarks}

This chapter discussed the transnational methodological design of this research that was enabled through embeddedness in the larger TCRA programme. The teamwork provided many advantages, such as the comparison of results against a wider sample, the ability to interview a large number of children over a short period of time and the simultaneous study of different actors of the same transnational child-raising arrangement, both in Ghana and the Netherlands. The collaboration with Ghana-based researcher Ernestina Dankyi enabled the joint collection and interpretation of data that allowed in-depth insight at both ends, and that bridged the boundaries between depth and breadth (Mazzucato, 2009a). At the same time, I was able to capture the impact of people's inclusion in transnational relationships on their everyday lived experiences in real time. Continuous communication proved essential to benefit from the teamwork both on the level of data collection and interpretation.

Data that was collected among different samples 'here' and 'there' provided different perspectives to the same phenomena and revealed how the diverse institutional landscapes intertwined with experiences of spatial parent-child separation in the context of international migration, depending on where the actors were located, both socially and geographically. Triangulating data collected by different researchers and employing various methodological tools allowed me to understand the dynamics within everyday relationships of care across borders, to observe changes and witness interpersonal 
Chapter 3

processes. The ethnographic approach proved essential, for it provided ample room for relationships of trust to establish between the researcher and the respondents and for emotions to come to the surface, although gaining access and maintaining respondents remained challenging and time-consuming. 


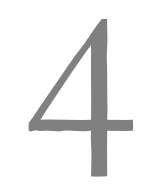

Situating the Families in the Multi-Local Contexts 



\subsection{Introduction}

This chapter locates transnational families between Ghana and the Netherlands within the multi-local contexts. Situating Ghanaian transnational child-raising arrangements in the social, political and cultural realities of both the host and home country allows for a better understanding of micro-level meanings, practices and experiences, for it is in the complex interplay of 'local opportunities, national policies and international possibilities' (Ryan, 2011: 87) that migration strategies are shaped and transnational families and care practices are formed, maintained and transformed. Hence, migrants and their nonmigrant family members are not completely bound by geographical borders, but their behaviour, practices and experiences are shaped by the different localities in which they are embedded. Following this theoretical stance, this chapter discusses in greater detail the relevant geographically-bound opportunities and restrictions.

This chapter starts with a historical background of Ghanaian migration to the Netherlands (Section 4.2), followed by a description of the Dutch context of reception and relevant migration policies that Ghanaian immigrants who largely entered the country from the late 1980s have been confronted with (Section 4.3). Particular focus is on family migration policies that condition family reunification (Section 4.3.1) and policies aimed at curbing undocumented migration (Section 4.3.2), as these are most important for the present study. Section 4.3.3 describes what this restrictive policy climate means for Ghanaian immigrants in the Netherlands and discusses the role of support networks to cope with policy restrictions. Section 4.3.4 shortly considers the Dutch labour market position of Ghanaian immigrants.

Section 4.4 provides a detailed account of family life and child-raising arrangements in the Ghanaian sending context, which helps to understand continuities and changes in child-raising practices and norms in the transnational context. It describes extended family systems and the importance of children in them (Section 4.4.1), motherhood and fatherhood roles and responsibilities (Section 4.4.2), as well as the crucial role of extended kin care networks and the normality of parent-child separation (Section 4.4.3). Section 4.4.4 discusses how current trends of modernisation and urbanisation change more traditional customs of family life and child-raising in particular, which is followed by insights from recent literature on child care in Ghanaian transnational families (Section 4.4.5).

\subsection{Ghanaian Migration to the Netherlands in Historical Perspective}

Ghanaian migration has for long been an important way of life in response to various external factors (Adepoju, 1988), with most migration occurring within the West African region (Castles \& Miller, 2009; GSS, 2012). In the second half of the twentieth century, Ghana also became an important immigration country, largely prompted by changing economic, political and social configurations. The economic prosperity and demand for 
labour in Ghana, underwritten by cocoa farms and the development of gold mines, attracted a large number self-employed traders and wage labourers mainly from within the West African region (Anarfi, 1982; Rouch, 1959; Van Hear, 1982). Large-scale immigration continued until Ghana experienced political instability following independence in 1957 and extreme economic crisis in the 1960s, resulting from drops in crop prices, and increased inflation and unemployment (Anarfi et al., 2000; Oppong, 2004; Peil, 1995). ${ }^{17}$

In the 1960s, when Ghana's economy further declined and corruption and inflation reached unprecedented proportions, both immigrants and Ghanaians - usually young and of working-age - moved abroad to seek better economic opportunities (Peil, 1995; Van Hear, 1998). Nigeria became the main destination country for Ghanaian migrants for its booming economy and high demand for labour, a result of the drastic increase in oil prices since 1973 (Akyeampong, 2000). Facilitated by the establishment of the Economic Community of West African States (ECOWAS) in 1975, which introduced rules for the free movement, residence and employment of citizens of the member states for up to 90 days, millions of Ghanaians — mainly from the South — left to find work in Nigeria (Onwuka, 1982; Peil, 1995). During the economic boom, the Nigerian government allowed many to overstay their visa (Van Hear, 1998). Most of these first migrants were highly-skilled professionals, notably doctors, lawyers and teachers (Peil, 1995). Others moved to Nigeria and other neighbouring countries to further their training, with many staying after completing their study programme (Anarfi et al., 2003).

Ghanaian emigration to neighbouring countries intensified in the 1980s when more skilled, but also unskilled and semi-skilled Ghanaians, left the country in large numbers in search of work (Anarfi, 1982). Unskilled immigrants mainly worked in the construction and service sectors in oil-rich Nigeria. In general, stays tended to be short with family members usually staying behind in the origin country (Higazi, 2005; Yeboah, 1986). Those who stayed longer maintained strong ties to the homeland, a phenomenon that is also observed among second and third generations (Peil, 1995).

Ghanaian migration to Nigeria came to a halt when in 1983 and 1985 two million ECOWAS nationals were expelled by Nigeria's military regime, of which around one million were Ghanaians (Brydon, 1985). Similar to the earlier expulsion of immigrants from Ghana (1969), as well as expulsions later in Gabon (1995) and Côte d'Ivoire (1999) (Adepoju, 2001), the expulsion in Nigeria can be directly linked to the country's economic downturn. In Nigeria, though, the economic crisis was instigated by the global decrease in oil prices and the government's mismanagement of the oil boom (Adepoju, 2001). This would have disastrous consequences for Nigeria's economy as spending exceeded revenues, eventually resulting in the introduction of austerity budgets in the

\footnotetext{
${ }_{17}$ With the exception of a downturn in 1999-2000, recent economic stability has renewed Ghana's status as an important destination country in contemporary migration flows (Bakewell \& de Haas, 2007). In addition to other fast-growing cities in West Africa, such as Lagos and Dakar, Accra has attracted a large proportion of especially low-skilled labour migrants (Castles \& Miller, 2009). In the past two decades, Ghana has also received a growing number of non-African immigrants, notably merchants from the Persian Gulf and Asia, a phenomenon that precedes the pre-independence period (Akabzaa et al., 2010).
} 
early 1980s (Van Hear, 1998). To shift attention away from the country's deteriorating situation, Nigerian authorities pushed forward migrants as scapegoats. Migrants were blamed for the increased unemployment and crime rates of the country and for stealing the jobs of locals. The expulsion of Ghanaians from Nigeria unfolded in dramatic ways: migrants had to leave behind valuable assets and those who returned faced shortages of food and commodities due to extended drought in Ghana the same year (Akyeampong, 2000; Higazi, 2005).

Many, however, returned to Nigeria in the late 1980s as wages in Ghana continued to lag behind those of Nigeria (Peil, 1995), and nowadays Nigeria remains one of the most important destination countries in the region (GSS, 2012). At the same time, Ghanaians were attracted to other countries in the region, notably to Côte d'Ivore for its flourishing economy and welcoming migration climate, but also to Togo, and to a lesser extent to Libya and Liberia (Peil, 1995). Some also moved further away. Skilled Ghanaians, for instance, increasingly migrated to South Africa, especially after independence in 1994 in the prospect of a booming economy (Adepoju, 2001; Castles \& Miller, 2009; Peil, 1995).

\subsubsection{Globalisation and Migration Northwards}

Over the past decades, intercontinental migration from West Africa, and Ghana in particular, has rapidly increased, even though the total number remains limited compared to intraregional migration (Bakewell \& de Haas, 2007; GSS, 2012). Early migration from Ghana to the Global North was rooted in colonial ties and mainly concerned travel for education to Anglophone countries (Peil, 1995). After independence, the destinations for Ghanaian students diversified to include Eastern Europe, Russia and North America, although British education was still preferred. Whereas migration for education declined in the 1980s when the value of the Ghanaian currency decreased and funding became harder to find, parents' efforts to send their children abroad remained high (Peil, 1995). By the end of the 1970s, Ghanaians increasingly migrated to the Global North for economic purposes (Fosu, 1992). Among them were many highly-skilled Ghanaians, most notably health professionals, such as doctors and nurses, who moved to North America and the United Kingdom to find better job opportunities and higher wages (Peil, 1995).

From the mid-1980s onwards, economic, political, demographic, social and cultural transformations on the African continent had profound impacts on Ghanaian intercontinental migration dynamics (Adepoju, 2001). Augmented globalisation processes since the 1980 s played a significant role in the economic and social unrest that Ghana experienced from renewed economic policies and political instability (Anarfi et al., 2003; Awumbila et al., 2008; Piel 1995). Particularly disastrous for the country were the World Bank and IMF's structural adjustment policies (SAPs), implemented in 1983 in response to increased economic decay (Peil, 1995). Compulsory austerity budgets, and failure to deliver promises of improved average wages from progress in trade and industry, pushed the country in further economic decline, affecting particularly the lower 
and middle-classes (Adepoju, 2006; Akyeampong, 2000). Securing employment in the formal sector was problematic, while civil service declined and industrial employment was lacking behind the demand for labour (Peil, 1995). At the same time, an increasing number of highly trained professionals filled the already tight labour market (Akyeampong, 2000). These conditions motivated many Ghanaians to search for better opportunities overseas, or aburokyere in local parlance, literarily meaning 'the other side of the cornfield' (Oppong, 2004). Technological improvements since the early 1990s, notably more economical airline costs and greater access to long-distance communication, have facilitated this move out of Africa (Peil, 1995).

The changed economic market also fuelled independent female migration from Ghana. Until the 1970s, women usually migrated for marriage or to join their husband abroad (Surdakasa, 1977). From the 1980s and especially from the 1990s onwards, women increasingly participated in intercontinental migration flows as independent migrants who sought employment and education abroad (Adepoju, 1995, 2000). Two factors can account for this. First, Ghanaian women, especially those coming from the Southern regions, entertain a high level of economic autonomy, which provides women freedom, but also requires them to be self-sufficient (Peil, 1995). These women are generally financially independent, have a strong work ethic and make large financial contributions to the household (Manuh, 1997). This autonomy is confirmed by recent census data showing that $63 \%$ of women in the Southern regions who are economically active decide for themselves how their earnings are spent, compared to 30\% who do so in accordance with their husbands (Ghana Statistical Service (GSS), Ghana Health Service (GHS) \& ICF International, 2015: 291).

Second, women's efforts to provide for their families have been complicated by the implementation of the SAPs in the 1980s. The SAPs, with its cuts in macro-economic budgets, implemented fees for health and education, and declining job opportunities for men, increased women's workloads and pushed them into dire living conditions (Oppong, 1997). One of the results of this feminisation of poverty - a more general consequence of enforced implementation of SAPs in poor countries (Ehrenreich \& Hochschild, 2002) - was that women who would traditionally stay home, would now migrate in search of economic opportunities (Oppong, 1997). Increased marital dissolutions and female-headed and single-parent families, especially in urban areas, further exacerbated women's economic hardships (Manuh, 1997; Mikell, 1997). ${ }^{18}$ Moreover, women's precarious socioeconomic position can be related to their reliance on agricultural work, where they are underrepresented as farm owners and managers, and often perform unpaid work for husbands and extended kin, whereas their large share in trade and sales generate only small financial benefits (Manuh, 1997). These factors combined have amplified the participation of skilled and unskilled Ghanaian women in migration flows, who sought alternative means to provide for their children and other dependents (Manuh, 1994). The intensification of independent female migration may

${ }^{18}$ Ghanaian census data show that the rate of women divorced (5.5\%), separated $(2.9 \%)$ and widowed $(10.0 \%)$ is higher compared to men $(2.7 \%, 1.7 \%$ and $1.6 \%$ respectively) (GSS, 2012: table 12, p. 33). 
indicate that mothers have increasingly left behind children in the country of origin when they move over longer distances and for longer periods of time in search of better opportunities to provide for their families back home.

In past decades, Ghanaian men and women predominantly migrated to the Global North to improve and secure their family's standard of living. Often preceded by migration from the rural areas of Ghana to the cities, many Ghanaians who are attracted to Ghana's cities in search of work move further when the dream of better opportunities is left unrealised (Konadu-Agyemang, 1999). The move abroad can be considered a household strategy where the family negotiates who migrates, when and how (Oppong, 2004), especially among poor and low-skilled migrants (Tiemoko, 2004). It is also the family who pools resources to cover the costs of the move and who decides how remittances are used, with those who invest in the move expecting to be financially reciprocated (Oppong, 2004; Tiemoko, 2004). Apart from increasing the living standard of those back home, an important element of Ghanaian migration is the accumulation of foreign currencies that paves the way for the dreamed off return to Ghana as citizens of higher socioeconomic class who receive respect and recognition based on their material wealth (Akyeampong, 2000; Piel, 1995). Like African migration in general, Ghanaian migration can best be viewed as circulatory, that is, 'non-permanent movements in circuits within and across national boundaries, which begin and (must) end at "home"" (Adepoju, 2006: 28).

Real or imagined prospects of improving one's life from abroad have attracted many Ghanaians who no longer expect to find this in their home countries. These prospects are fuelled by the availability of international media that have portrayed the 'good life' in developing countries (Castles \& Miller, 2009: 156-7). Ehrenreich and Hochschild (2002: 18) expressively called this attraction for northern prosperity that is transmitted by the global spread of Western television and movies, a 'material striptease', for what people in the south know about the north mainly comes in terms of what people have in a material sense. The idea that social success is achieved through wealth accumulation in the Global North is also spread through the middle-class houses of well-to-do (former) Ghanaian migrants, usually on the outskirts of Accra and Kumasi. These so-called 'burger houses', a reference to some of the early houses that were built with remittances from Ghanaians who resided in Hamburg (Peil, 1995: 362), are an important status symbol for migrants and provide an opportunity for a permanent return in the future (Owusu, 2003). With poor conditions in the home country, migration provides a means to achieve success through hard work; or in local parlance, to become woyayie, somebody who has been successful in life (Van Dijk, 2002b: 180). As Akyeampong (2000) argues, migration is 'an important space to remake one's self, even to overcome the social liabilities of birth' (p. 187).

The aforementioned factors have contributed to large-scale intercontinental migration and diversification of destinations and migrants_-skilled, semi-skilled and unskilled workers, students and family migrants_-from the mid-1980s onwards (Anarfi et al., 2003; Peil, 1995). Ghanaians began to move to non-traditional destinations, such 
as Canada, as well as to non-Anglophone countries in Europe, notably Germany, Italy and the Netherlands, but also to Asia and the Middle East, where trading networks were established (Akyeampong, 2000; Castles \& Miller, 2009; Higazi, 2005; Peil, 1995). In 1999, 75,843 Ghanaian migrants were officially registered in a non-African country (Twum-Baah, 2005). Three years later, the number had more than doubled to 158,212. The United States, Germany and Italy were the major receivers of Ghanaians in the Global North (EUROSTAT, 2001). In European destination countries, the number was 33,425 in 1999 and 61,124 in 2002 (Twum-Baah, 2005), making it the largest sub-Saharan African migrant population in Europe around the turn of the century (Akyeampong, 2000).

Almost ten years later, Ghana census data show that the majority of intercontinental migrants reside in Europe $(37.7 \%$ of all Ghanaian migrants), whereas a smaller proportion can be found in the Americas (23.6, combined North, South/Caribbean) (GSS, 2012: table 15, p. 38). Because the large number of Ghanaian immigrants without legal residence permits are not included in official figures, the real number of Ghanaians living outside of the African continent is greatly underestimated (Akyeampong, 2000). Figure 4.1 shows the number of Ghanaians that have obtained a Dutch entry and residence permit between 1995 and 2011. The number of officially registered Ghanaian immigrants in the Netherlands increased from 12,480 in 1996 to 20,829 in 2010 (CBS, 2018a). ${ }^{19}$

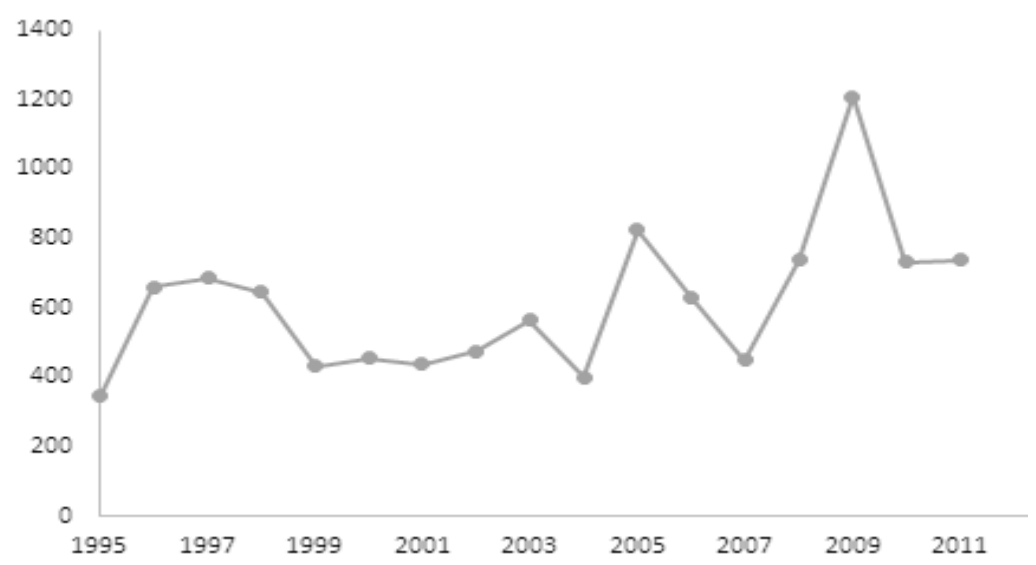

Figure 4.1. Number of Ghanaians obtaining a Dutch entry and residence permit, 1995-2011 Source: CBS (2016)

${ }^{19}$ In 2017, 23,430 Ghanaians were officially registered in the Netherlands (CBS, 2018a). 


\subsection{The Context of Reception: From a Welcoming to a Restrictive Destination Country}

Ghanaian immigrants in the Netherlands are part of 'Europe's "new" immigrant population' (Grillo \& Mazzucato, 2008: 176). As such, they are qualitatively different from more established migrant groups in the Netherlands, notably Turkish and Moroccan migrants (Mazzucato, 2008a). The latter largely arrived at a time in which the Dutch host society can best be described as welcoming, since it provided opportunities to enter and stay legally, and reunification with family members was relatively easy (Bonjour, 2009). Alongside immigrants from the former colonies Indonesia and the Moluccas, and later Suriname (Geddes and Scholten, 2016; Van Ours \& Veenman, 2005), the Dutch state welcomed - and actively recruited - temporary unskilled 'guestworkers' from Morocco, Turkey and Southern European countries who arrived in the country in large numbers in the 1950 s and 1960s to contribute to post-war reconstruction (Heijke, 1986). ${ }^{20}$ Until 1975, these immigrant groups benefitted from welcoming family migration policies with which the Netherlands hoped to attract unskilled migrants (Bonjour, 2009). ${ }^{21}$ Just as in other industrialised Western European countries, family reunification was perceived as key in the health and well-being of labour migrants and was therefore facilitated (Fonseca \& Ormond, 2008).

In the mid-1970s, political interest for migration-related issues grew (Bonjour, 2009). Not only was the country facing an economic recession, but also the idea of immigration as a permanent phenomenon slowly gained momentum. Whereas immigrants from Southern European countries returned home when employment opportunities diminished, many from Morocco and Turkey reunited with family members and opted for permanent settlement (Nicolaas \& Sprangers, 2000). In response to a decreased labour demand, low-skilled economic migration was restricted, whereas the integration of those who had already settled in the Netherlands was included in the minority policy of the 1970s and 1980s that strived for minorities' social emancipation, the reduction of socioeconomic marginalisation, the prevention of discrimination and the improvement of legal status (Bonjour, 2009). The multicultural approach that the Netherlands applied aimed at integration with the retention of one's own cultural identity (Wiesbrock, 2010). During this time, family migration remained relaxed, with the idea that families should be able to organise their lives according to their own preferences (Bonjour, 2009; Van Walsum, 2008).

'New' economic migrants, such as Ghanaians who entered the Netherlands in large numbers since the late 1980s, had few means to legally enter and stay in the country.

\footnotetext{
${ }^{20}$ Undocumented immigrants, who were perceived as devoted and undemanding workers, were also welcomed (Van der Leun, 2003).

${ }^{21}$ Fears that cultural differences would impose negatively on the cohesion of Dutch society resulted in the temporary closing down of family migration in 1955 (Bonjour, 2009). In the 1960s, the moral perspective that family was the 'normative core' of the nation that required protection (Van Walsum, 2008), combined with the economic benefits of labour and family migration, outweighed the allegedly negative consequences, resulting in a renewed relaxation of family migration policies in the early 1960s (Bonjour, 2009).
} 
Since the mid-1970s this was only possible through family reunification and asylum. With the high influx of immigrants and asylum seekers in the early 1990s, and the increased marginal position of immigrants and their children - reflected in high rates of unemployment and school dropout-integration issues became the focus in political debates (Bonjour, 2009; Joppke, 2007a). The equal rights that were central to the minority policy changed to self-responsibility, self-reliance and active citizenship in the integration policy of the 1990s (Bonjour, 2009). Along with this came a shift from the right to family life in the interest of the individual to that of the general interest of the state. Solutions to the structural problems of immigrant groups were sought in the reduction of immigration flows and the integration of immigrants already settled (Bonjour, 2009). To this end, conditions to restrict and select migration were implemented, which this time also applied to family migrants.

Despite a flourishing economy, Dutch migration policy became one of the most restrictive in Europe in the 1990s, largely set in motion by xenophobic feelings and the promotion of exclusion and assimilation in migration policies (Entzinger and Fermin, 2007). Bonjour (2009) describes how, since the turn of the century, concerns over integration and the idea of limiting migration dominated the political debate and transcended the moral right to family reunification. As a result, family migration became more prominent in the political debate, with a special focus on cultural integration. Problematic integration was no longer perceived as a consequence of discrimination, but considered a result of the poor commitment on the part of the migrant.

Migration and integration became the most important points on the Dutch political agenda and were inextricably linked to maintenance of Dutch nationality and corresponding norms and values, and the legitimacy of the political system. The accent was placed on cultural differences and its threat to Dutch value systems. Fingers pointed especially at spouses who came as family migrants; they were considered the cause and consequence of problematic integration. Moreover, concerns were raised over the abuse of family formation through marriages of convenience. Integration as an argument in family reunification policies shifted from social and economic to cultural integration, especially concerning the emancipation of Muslim women from forced marriages, hostile domestic situations, and honour killings (Bonjour \& de Hart, 2013). Xenophobic feelings and the promotion of exclusion and assimilation in migration policies reinforced further restrictions on family, labour and asylum migration, especially since the murder of right-wing politician Pim Fortuyn in 2002 (Engbersen, Van der Leun \& De Boom, 2007; Entzinger \& Fermin, 2007).

Despite the hostile attitude towards immigrants, the government coalition formed in 2007 applied a more liberal stance to migration and integration issues and emphasised the two-way process of integration. To this end, several reforms in favour of new immigrants were introduced (Wiesbrock, 2010), although in general a restrictive turn in family migration policies since the mid-2000s can be observed (Bonjour \& de Hart, 2013). In 2014, 3.6 million residents of 'non-native' backgrounds were registered in the 
Netherlands, of which 1.8 million were foreign-born, amounting to $21 \%$ of the total Dutch population (OECD, 2015).

\subsubsection{Regulating Family Migration and Controlling its Effects}

For the purpose of this study, it is interesting to zoom in on family migration policies and regulations. Family migration been the most important means for Ghanaians to legally enter and stay in the Netherlands for the past two decades (see Figure 4.2) as other means have become less accessible. At the same time, for those who reside in the Netherlands, it is also the most important legal means through which one can reunite with overseas family members.

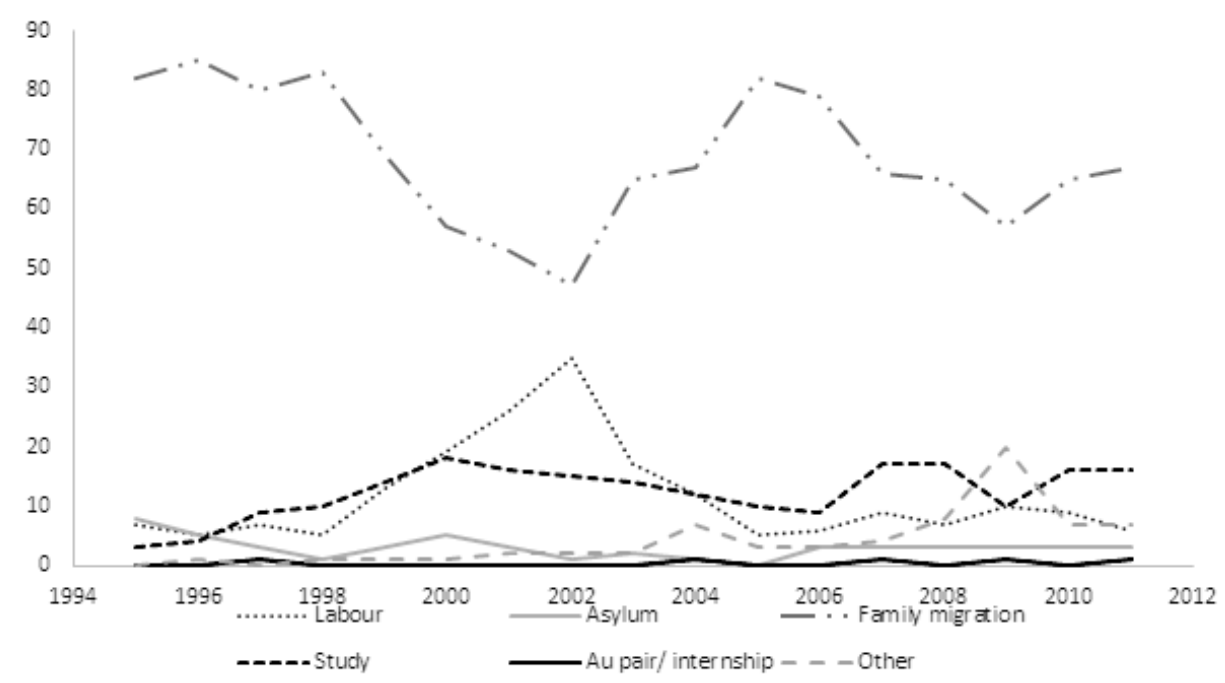

Figure 4.2. Means through which Ghanaian immigrants obtain an entry and residence permit, percentage, $1995-$ 2011

Note. 'Other' includes for instance those who come to the Netherlands to receive medical treatment Source: CBS(2018b)

Since the early 1980s, the Dutch government introduced and modified a series of measures to restrict family migration and to control its effects (see Appendix $\mathrm{C}$ for an overview). Until 2010, a different set of regulations was applied to family reunification and formation. Reunification referred to reunion with family members of the applicant in the Netherlands with which a family bond existed already in the origin country, while formation encompassed reunion with newly-wed spouses, including spouses in the Netherlands without a legal residence permit. Measures to restrict family migration were particularly targeted at family migrants from 'non-western' countries, based on the rationale that the 'exotic family norms' of gender inequality and condemnation of homosexuality that these migrants brought should be reduced as they formed a threat to Dutch society (Van Walsum, 2008). More relaxed requirements for family reunion 
applied to asylum seekers during the first three months after obtaining their refugee status, highly-skilled migrants whose admission is based on wage criteria, and family members of EU citizens whose admission is regulated by less stringent regulations based on the freedom of movement within the EU (Wiesbrock, 2010).

The income requirement, the pre-entry test and the age requirement for spouses have been criticised for being discriminatory and selective (Strik, de Hart, \& Nissen, 2013). For instance, Human Rights Watch (2008) criticised the pre-entry integration test for being in violation with international human rights obligations based on its discrimination on nationality, as the test only applies to certain non-western migrants. Moreover, they concluded that the pre-entry test restricts family migration, slows down the integration process of newcomers and that it is in conflict with Article Eight on the right for family life of the European Convention on Human Rights (ECHR) (see Box 3.1).

Since the early 2000s, supranational institutions have to some extent prevented further restrictions to family-related migration. They also have been influential in individual applications. Whereas Article Eight on the right for family life was a detrimental factor in Dutch policy formation since the mid-1980s, it was not until the introduction of the European Directive on Family Reunification that came into force in 2003 that member states lost control over national policy formation vis-à-vis supranational institutions (Bonjour, 2009). The European Directive on Family Reunification provides a minimum set of guidelines to which member states have to comply in order to protect the respect for family life, according to Article Eight of the ECHR (Council of the European Union, 2003). It has strengthened the legal position of TCNs to protect their right for family life relative to the situation prior to 2003, which has resulted in the rejection of several policy propositions that were found to be in conflict with Article Eight, such as the five-year reference period in the 'effective family bond' criterion and the alignment of requirements for family reunification and formation (Bonjour, 2009; College voor de Rechten van de Mens, 2014; Van Walsum, 2009).

\section{Box 4.1. Article Eight of the European Convention on Human Rights: The right to respect for private and family life}

1. Everyone has the right to respect for his private and family life, his home and his correspondence.

2. There shall be no interference by a public authority with the excercise of this right except such as in accordance with the law and is necessary in a democratic society in the interests of national security, public safety or the economic well-being of the country, for the prevention of disorder or crime, for the protection of health or morals, or for the protection of the rights and freedoms of others.

Source: European Directive on Family Reunification (2003/86/EC)

Notwithstanding the important role of the Directive in regulating national policy formation, it leaves much freedom for European member states in national family migration cases to prevent too much interference with sovereign rights of member states 
(van Walsum, 2009). The Dutch government has been rather successful in formulating the European guidelines in such a way that existing regulations are minimally changed and that further restrictions can be justified (Bonjour, 2009; Strik, de Hart \& Nissen, 2013).

The stringent regulations have had profound consequences for those who wished to enter the Netherlands on the basis of family migration. The introduction of the five-year reference period in the 'effective family bond' criterion caused an overall $5 \%$ drop in the number of children arriving in the Netherlands on the basis of family reunion in 2001 compared to the year before, and a 31\% decrease in 2005 compared to 2000 (CBS, $2018 b)$. The impact of the five-year reference period can also be seen when looking at figures for the year after the criterion was withdrawn; in 2007, 16\% more non-Dutch born children were reunified with one or both parents than in 2006 (CBS, 2018b).

For Ghanaian children, the impact was even more pronounced. In 2001, 25\% fewer children were permitted to join their parent in the Netherlands compared to the year before (CBS, 2018b). In subsequent years, the number decreased even further. In 2004, the number of children entering the Netherlands on the basis of family reunion equalled only $55 \%$ of the those admitted in 2000 , the year prior to the introduction of the fiveyear reference period. Yet, in contrast to the overall decline in the number of children arriving on the basis of family reunion in the Netherlands in 2005- the year before the effective family bond criterion was exonerated-family reunification with Ghanaian born children reached a peak. This can best be explained by the relatively large number of applications compared to earlier years, because the rejection rate continued to be high: $54 \%$ in 2005 and $55 \%$ in 2006, compared to $43 \%$ in 2007 and $38 \%$ in 2008, as shown in Figure 4.3 (unpublished figures INDIAC, 2013).

From Figure 4.4, we can further observe that the rejection rate increased from $39 \%$ in 2009 to $55 \%$ in 2010 and to $58 \%$ in 2011. This is not particular to Ghanaian children, since the overall rejection rate for minor children applying for family reunification increased from 39\% in 2009 to 48\% in 2010 and to 59\% in 2011 (Defence for Children and Unicef, 2012). The increased rejection rates cannot be explained by family migration policy alone, as no further restrictions were implemented at that time. 


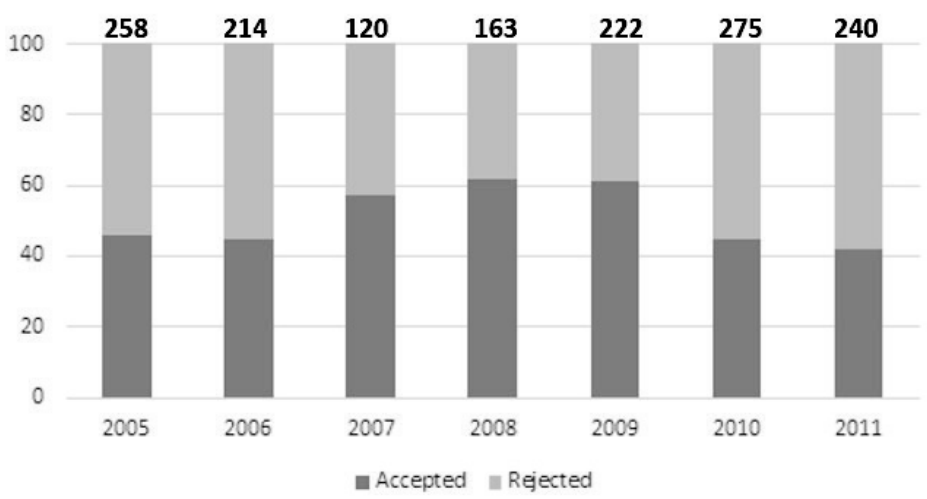

Figure 4.3. Rate of acceptances and rejections of applications for family reunification with Ghanaian children below 18 years, including total number of decisions, 2005-2011

Note. Excluding category 'other decisions'

Source: Unpublished figures INDIAC (2013)

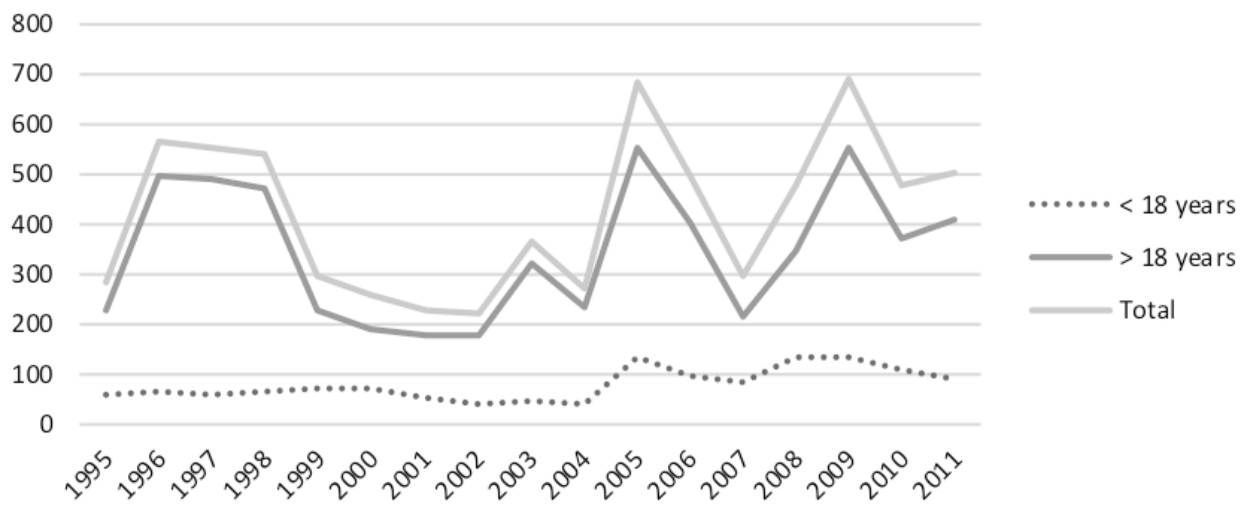

Figure 4.4. Ghanaians obtaining a Dutch entry visa on the basis of family migration, adults and children, 19952011

Source: CBS (2016)

The number of Ghanaian spouses who entered the country on the basis of family migration also reflects changes in family migration policy (see Figure 4.4). Hence, the number declined at the time of the introduction of the income requirement and it increased when the civic integration test was introduced and, later, the Integration from Abroad Act (see also Joppke, 2007b). Furthermore, the number declined after the distinction between family reunification and formation was eradicated, which can be explained by the increased age limit for family reunions with a partner and the increased difficulty level of the pre-integration test.

At the time of this study, few Ghanaian immigrants applied for family migration on the basis of the freedom of circulation as set out in the European Directive 2004/38/EC. This freedom of circulation means that citizens or denizens from one 
European member state can apply for family migration in another member state while complying with fewer requirements in light of the free movement within the European Union. Government officials fear that this so-called 'Europe route' is used as a counterstrategy to imposed requirements for family migration whereby people move to a neighbouring country, apply for family reunion, and subsequently move back to the previous country. In 2005 and 2006, the rate of decisions for family migration with Ghanaian children on the basis of free movement equalled approximately 1\% of regular decisions (unpublished figures INDIAC, 2013). This increased to $5 \%$ in 2007 , to $12 \%$ in 2008 and dropped again to $9 \%$ in 2010 and to $11 \%$ in 2011.

While the use of the 'Europe route' in case of family reunion with minor children remained minimal, its usage skyrocketed with regards to family reunion with a partner, especially since 2008, when five times as many decisions were made for family migration with a partner on the basis of free movement within the EU than decisions for regular family migration. In 2009, the difference of usage between the two was by a factor of as many as 19. The disparity shrank back to four times as many decisions in 2010 and 2011. The shift towards the 'Europe route' coincided with a low number of decisions for regular family migration since 2006. Rejection rates for family reunion with partners on the basis of free movement within the EU rapidly increased in 2008 to $46 \%$ (compared to $8 \%$ in 2007), reflecting the growing political attention for abuse of this route, as well as increased controls on marriages of convenience.

\subsubsection{Policies to Discourage Undocumented Migration}

In light of the abovementioned migration policy context, Ghanaian immigrants were severely limited in their possibilities to enter, stay and reunite with their family members (Mazzucato, 2008a). Like other migrant groups, Ghanaian migrants bypass the restrictive official migration channels by legally entering the country on a three-month tourist visa (Burgers \& Engbersen, 1999). Those who overstay their visa end up in 'illegality', hoping to one day secure a residence permit. ${ }^{22}$ Because of the hidden and informal nature of Ghanaian undocumented migration official numbers are lacking, but their share is estimated to equal those of Ghanaian documented immigrants (Mazzucato, 2009b; Twum-Baah, 2005). ${ }^{23}$ Alongside tightened migration policies, the high number of undocumented migrants in the past decades can also be attributed to the economic demand for cheap labour and the growing presence of transnational networks that enable entry and residence of undocumented migrants (Engbersen et al., 2002).

After many years of having tolerated 'spontaneous migrants' in the unskilled labour market, The Netherlands, like other northern European countries since the early 1990s, has reinforced measures to discourage and control undocumented migration (Broeders

\footnotetext{
22 Other categories of undocumented migrants are rejected asylum seekers and those who enter the Netherlands illegally over land with assistance from human traffickers or smugglers (Engbersen et al., 2002).

23 Based on apprehension data it was estimated that in the late $1990 \mathrm{~s}$, there were a total of 65,000 to 91,000 undocumented migrants in the Netherlands - excluding European citizens (Engbersen et al., 2002). The figure for 2005-2006 amounted to 62,320 to 113,912, also excluding Europeans (Van der Heijden et al., 2006).
} 
and Engbersen, 2007: 1592). These measures mainly aimed at curbing undocumented migration, notably by excluding these immigrants from the labour market and public services (Broeders \& Engbersen, 2007; Engbersen, Van der Leun \& De Boom, 2007; Van der Leun, 2006). The rationale behind this policy strategy is that the living and working conditions of undocumented migrants are complicated and frustrated to such a degree that migrants want to leave the country (Broeders \& Engbersen, 2007). It is also believed that access to the welfare system works as a magnet for undocumented migrants and as an obstacle for those who are considering a return to the country of origin (Chiswick, 2000).

Restrictions were first introduced in 1991, when the social security number was linked to a residence permit. ${ }^{24}$ Before the implementation of this regulation, undocumented migrants could be employed on a relatively stable basis while occupying 'semi-formal tax-paid jobs' (Van der Leun \& Kloosterman, 2006: 64). This became impossible when social security numbers were linked to residence permits, which excluded undocumented immigrants from the formal labour market, moving them gradually into informal sectors (Van der Leun \& Kloosterman, 2006).

A second restriction to curb undocumented employment involved the Employment of Aliens Act in 1994, obliging all employees to identify themselves. Third, the Benefit Entitlement (Residence Status) Act was implemented in 1998, making access to taxsupported public services conditional upon a residence permit. ${ }^{25}$ Hence, without a residence permit, migrants are excluded from education (for those above 18 years of age), social assistance, public housing, non-emergency health care and all social security allowances (Engbersen, San \& Leerkes, 2006; Van der Leun, 2003). Fourth, indirect employment of foreign workers without a work permit was penalised under the Act on Chain Liability. Since then, employers risk fines and imprisonment while employees risk deportation (Van der Leun \& Kloosterman, 2006). The probability of being caught increased since the turn of the century when internal controls were reinforced and the capacity of police and labour inspections intensified (Engbersen et al., 2002; Engbersen, Van der Leun \& De Boom, 2007).

Another strategy to discourage and prevent undocumented migration is administrative detention and deportation of undocumented migrants (Broeders \& Engbersen, 2007). Although previously undocumented migrants could only be apprehended in case of concrete indications, since the 1990s they can also be arrested in case of reasonable doubt (Engbersen et al., 2002). Illegal residence and work became punishable in the Netherlands in 2013, with the penalty consisting of detention or a fine. ${ }^{26}$ The length of detention in the Netherlands ranges from less than 28 days to 18 months (Adviescommissie voor Vreemdelingenzaken, 2002; Van Kalmthout \& Hofsteevan der Meulen, 2007). Like other European member states, the Netherlands has increased its detention capacity to facilitate expulsion of undocumented migrants and

\footnotetext{
${ }^{24}$ Vc 1991.

${ }^{25}$ Staatsblad, 1998, p. 204.

${ }_{26}$ TK 2012-2013, 33512 nr. 2.
} 
rejected asylum seekers (Van Kalmthout et al., 2007). In spite of these measures, the actual number of deportees has been low; in the early 2000s this figure was around 40\% (Van Kalmthout, 2007), a result of financial, legal and moral obstacles (Broeders, 2010). In response to the low expulsion rate, the Dutch state issued a regularisation programme in 2007, granting 30,000 people a residence permit, mostly those who were awaiting a definitive decision of their asylum application (Diepenhorst, 2012). At the same time, the detention of undocumented migrants, even without expulsion, may be considered an effective control mechanism, functioning as a 'factory of exclusion' by keeping undocumented migrants at the margins of society and for giving off the signal of a restrictive detention regime that could deter future migrants (Broeders, 2010: 182).

In spite of the reinforcement of internal and external controls, undocumented migration is prevailing and even increasing as migrants and organised networks have adopted counterstrategies to circumvent policy restrictions (Broeders \& Engbersen, 2007). At the same time, however, increased controls to curb undocumented migration has the adverse consequence that undocumented migrants are pushed further underground (Broeders \& Engbersen, 2007). Due to the high rate of undocumented migrants from Ghana in the Netherlands, these policy restrictions also have adverse consequences for this migrant group and pose particular problems with respect to their family lives, as will become evident in the subsequent chapters.

\subsubsection{Coping with a Restrictive Policy Climate: The Role of Support Networks}

In response to the restrictive policy climate and the exclusion of undocumented migrants from public services and the formal labour market, 'illegal markets' developed where passports, social security numbers and other documents are produced, sold and lent within social networks of relatives, friends, acquaintances and 'businessmen'. They operate in different spheres of, among others, the labour market, housing and relations (Broeders \& Engbersen, 2007). Such informal circuits are very difficult to control for the state and may be considered as a counterstrategy against restrictive migration regimes. Ghanaian immigrants in the Netherlands often turn to local networks who provide punctual and short-term assistance, help migrants cope with difficulties experienced in their daily lives, facilitate contacts to a wider network and function as intermediaries between migrants and Dutch organisations (Chelpi-den Hamer \& Mazzucato 2007). Ghanaian immigrants also turn to transnational contacts for support, such as for information on marriage partners (Mazzucato 2009b). Middlemen and middlewomen who operate on illegal markets are crucial contacts for those who wish to obtain entry or residence permits for family members (Mazzucato 2007).

In the Netherlands, Ghanaian churches_most notably the Pentecostal and Charismatic churches which have expanded rapidly since the 1980s - are also key in newly and established immigrants' support networks. ${ }^{27}$ Pentecostal churches have

\footnotetext{
${ }^{27}$ Latest Ghanaian census data show that Pentecostal and Charismatic churches are the most prominent religious affiliations in Ghana, with $28.3 \%$ followers (GSS, 2012: table 16, p.40). Other churches found in cities with large
} 
especially attracted urban and mobile Ghanaians for the international linkages they establish outside of Ghana, the entrepreneurial style of leadership and the emphasis on Western-oriented consumption and organisation of social relations (Van Dijk, 2002b).

The Pentecostal Church plays an important role in the lives of migrants, from organising prayer camps for prospective migrants to ensuring success of the migration experience and promoting good relations between Ghanaians and the host population. They also help strengthen links with the home country and provide unity and support among migrants abroad (Tonah, 2007; Van Dijk, 2002b). Within churches, Ghanaian migrants can find networks of information on jobs, housing and legal documents, and counselling on a range of different issues. In this way, churches provide 'an important substitute for kinship and family networks, while extending the emotive religious experience initiated by Pentecostal Churches in the homeland' (Akyeampong, 2000: 209). Although incidental financial support may be provided, Ghanaian churches in the Netherlands provide little financial support in case of crisis events (Mazzucato, 2007). Instead, migrants tend to rely on local friends, relatives and hometown members for financial help.

Finally, ethnic associations that perform the role of recreating Ghanaian culture, through the celebration of important rituals according to Ghanaian customs, provide assistance to Ghanaians abroad (Akyeampong, 2000). For instance, one of the numerous ethnic associations in Amsterdam Southeast provides, among other things, legal and educational advice and support, and assistance with translations and administrative work (Interview with the vice-president of an ethnic association, December 2012). Ghanaian churches and ethnic associations also function as support networks for local and transnational family life by providing counselling and personal advice on child-raising. They also intervene and negotiate in case of family crisis and post-reunification problems and provide legal support for family reunion.

\subsubsection{Ghanaian Migrants' Labour Market Position in the Netherlands}

The strong support networks within the Ghanaian migrant community, alongside the historically high rates of economic participation of men and women in Ghana (Oppong \& Bleek, 1982), may help explain why Ghanaians are highly active on the Dutch labour market, as illustrated by high levels of employment (Black et al., 2013) and low levels of reliance on the Dutch welfare system (Mazzucato, 2009b; Twum-Baah, 2005). Nonetheless, the generally low educational level of first-generation Ghanaian migrants in the Netherlands, unrecognised diplomas, language difficulties and discrimination have resulted in a weak labour market position. The employment rate of Ghanaians is low compared to that of the national average, and the majority hold jobs below their skill level in sectors that are typical to foreign-born persons, notably the cleaning and restaurant sectors (Black et al., 2013). In general, jobs in the cleaning and catering sectors

Ghanaian immigrant communities are Ghana Presbyterians, Anglicans, Catholics and Seventh Day Adventists (Peil, 1995). 
tend to be poorly paid, temporary, lack good conditions and provide little job security (Castles \& Miller, 2009).

The sectoral distribution is similar for documented and undocumented migrants from Ghana (Black et al. 2013), although the latter mainly work as private housekeepers in households of usually native Dutch persons, as babysitters within the ethnic community and in catering sectors. Such jobs in the informal sector tend to be low-paid, with a reduction of the monthly income over the years, and provide few opportunities for upward mobility (Van der Leun \& Kloosterman, 2006). The growing presence of undocumented migrants in general in these sectors is largely a response to labour market restrictions since the 2000s, as these jobs are relatively difficult to detect by immigration police. At the same time, the move underground has also increased exploitation and vulnerability in the labour market (Broeders \& Engbersen, 2007).

\subsection{Ghanaian Families and Child-Raising Arrangements}

To fully understand how family relationships and caregiving practices are shaped and reshaped in a transnational context, both the host and home country contexts should be taken into account. This section details Ghanaian family and caregiving norms and practices in order to enable a better understanding of how norms and practices shape family life and caregiving when practiced across national borders, as well as how these institutions are changing in a transnational context.

\subsubsection{Ghanaian Family Systems and the V alue of Children}

In Ghana, family and kinship are the centre of social structure (Nukunya, 2003). The organisation of the family is contingent upon the extended family system that emphasises collectivistic notions of the family, cohesiveness and group responsibility (Nyarko, 2014). In such family systems, the rights, obligations and duties of the person extend beyond that of the nuclear family, building on localised lineage systems that determine succession, inheritance, role relationships and both marriage and residential patterns (Nukunya, 2003).

The majority of Ghanaians in the Netherlands belong to the matrilineal Akan (Caarls, 2015; Kraan, 2001). The Akan comprise almost 50\% of the Ghanaian population, making them the largest ethnic group of Ghana (GSS, 2012: table 13, p. 34). Consequently, their matrilineal system, one which follows female filiation, is the predominant lineage system in Ghana. The smaller ethnic groups of the Ewe, the Ga and the Tallensi, as well as many other groups in the north of Ghana, are patrilineal societies in which descent follows the male line (Nukunya, 2003). ${ }^{28}$

\footnotetext{
${ }^{28}$ A third kinship system is double descent, where dimensions of both matrilineal and patrilineal family systems are incorporated (Nyarko, 2014).
} 
Having children is highly valued in Ghanaian society, and marriage is an important means of bearing them (Oppong \& Bleek, 1982). The lineage structure largely determines marriage and residence structures. Marriage is the most common marital status for both men (43.1\%) and women (42.2\%) (GSS, GHS \& ICF International, 2015), reflecting high expectations of marriage in Ghana (Manuh, 1997). Most common are monogamous marriages (GSS, GHS \& ICF International, 2015). ${ }^{29}$ Couples usually live in the husband's father's compound house in patrilineal marriages, and in the wife's family compound house in matrilineal marriages (Nukunya, 2003). Among both the matrilineal Akan and the patrilineal Ga, duolocal residence patterns are common, i.e. husbands and wives do not co-reside but rather stay with their own kin groups, because ties with the own lineage supersede other ties, including conjugal ones (Manuh, 1997; Nukunya, 2003; Takyi \& Gyimah, 2007).

Although fertility rates among women have decreased in past decades, Ghanaian families continue to be large (Manuh, 1997; GSS, GHS \& ICF International, 2015). ${ }^{30}$ The high fertility rate can be ascribed to early marriage and low rates of contraceptive use (Manuh, 1997), but also to a preference for large families (GSS, GHS \& ICF International, 2015). One of the explanations for this preference is the key role of children in extended family systems (Nyarko, 2014). Because the influence and status of the lineage system largely depends on its membership, a large lineage is wanted. Moreover, children provide important sources of support for their parents, including economic assistance, future security and social status (Nyarko, 2014; Oppong \& Bleek, 1982). However, reports beginning in the 1960s indicate that the declining economic value and rising financial costs of children, alongside pressures to maintain an appropriate lifestyle, have resulted in a lower fertility rate, especially among educated elites in urban areas (Caldwell, 1968).

\subsubsection{Motherhood and Fatherhood}

Traditionally within West African societies, the daily caretaking of the child is the responsibility of women, while men are considered the breadwinners (McDaniel \& Zulu, 1996; Mensa-Bonsu \& Dowuona-Hammond, 1996). Ghanaian women receive little care and domestic support from their husbands, independent of the lineage system (Manuh, 1997), although among adolescents, the importance of both males and females in gendered socialisation has been recognised (Goody, 1982). In Ghanaian society, independent of the lineage system, the mother is a central figure for her children, and relationships tend to be warm and affectionate (Nukunya, 2003; Oppong \& Bleek, 1982). Clark (1999: 720) described for the matrilineal Ashanti, a group belonging to the Akan, that the bond between a mother and her children can hardly ever be dissolved because

\footnotetext{
${ }^{29}$ Polygynous marriages, i.e. having more than one wife, have declined sharply from one-third of all marriages in the 1990s (Manuh, 1997) to $16 \%$ for women and $7 \%$ for men in 2014 (GSS, GHS \& ICF International, 2015)

${ }^{30}$ In the late 1990s, more than six children per woman were born, with a slightly higher rate for those in rural areas compared to women in urban areas (Manuh, 1997). More recent figures show a decrease to 4.2 children per woman (GSS, GHS \& ICF International, 2015: 60).
} 
of 'the biological event of childbirth [that] establishes a culturally undeniable debt to the mother for her pain and blood and the invaluable gift of life'. In matrilineal societies, the mother is also the person who connects the child to the kin group (Nyarko, 2014).

Yet rather than physical presence and personal child care, it is financial support that is 'the most definitive of maternal devotion and a greater focus of maternal identity and child bonding' (Clark, 1999: 720). The 'ideal of the working mother' and the absent necessity for physical nurturing is what is accentuated in maternal roles and responsibilities. This 'materiality of love', inherent to intergenerational relationships in Ghana (Coe, 2011b; Van der Geest, 2002), is characteristic of both mother-child and father-child dyads (Clark, 1999). As the head of the household, the father is expected to bear the bulk of the financial responsibilities, including feeding, clothing and school fees, independent of whether the child resides with the mother or the father (Allman, 1996; Boni, 2001). Given the importance of financial support, the father has always been an important figure in the child's upbringing, including in matrilineal societies:

Rights over youngsters were and are not attributed to a single party, the matrilineage, but were rather negotiated dynamically between different agents, the father being one of them. Whoever catered for the child (paid debts, maintenance, medical expenses) was often recognised as having privileged rights over the youngster.

(Boni, 2001: 27)

In the case of divorce in patrilineal societies, children automatically belong to the father's lineage, resulting in a forced separation from the mother. In matrilineal societies, to the contrary, fathers who divorce the child's mother tend to be marginal in their children's lives, since children belong to the mother's lineage (Oppong \& Bleek, 1982), and consequently, fathers lose their children to the mothers (Takyi \& Gyimah, 2007). Only well-off fathers who take on financial responsibility for the child may take the child with him (Oppong \& Bleek, 1982), as fathers too have the legal right to decide where the child resides and to claim custody over their children (Boni, 2001). This is uncommon and usually concerns older children, although this practice has been described in relation to migrant fathers and stay-behind wives and children (Coe, 2011b).

Generally, in Ghanaian academic and popular literature, men are described as husbands and fathers who frequently abandon their wives and children and fail to meet their family's financial responsibilities, especially following divorce (Assimeng, 1999; Oppong \& Bleek, 1982); or they only attend to their children's needs when they grow older and become more successful (Coe, 2011b). While common, failure to support a child financially is not socially accepted. To the contrary, it is considered an obstruction to the child's future success and is regarded as a sign of emotional neglect on the part of the father (Coe, 2011b). Moreover, it 'incurs both a debt and social stigma' (Boni, 2001: 32), and as Mikell (1997: 112) states, challenges 'notions of manhood'. Men who fail to provide financially for their children's upkeep lose paternal custody over their children. 
Hence, as Boni (2011: 36) states, 'father's rights rest ideologically - and at least partly so in practice - on his capacity to "care for".

Fathers are also the disciplinarians, who are expected to educate the child according to societal norms (Nukunya, 2003). Ghanaian parenting style is authoritarian with child rearing centring around respect, responsibility and reciprocity (Twum-Danso, 2009). Discipline, including corporal punishment, is a common and preferred feature in children's upbringing to install respect, obedience, work ethic and honesty in children (Coe, 2008; Twum-Danso, 2009). In matrilineal societies, the father's role as authority figure may be transferred to the mother's brother when children do not live with their father (Nukunya, 2003).

\subsubsection{Social Reproduction within Extended Kinship Networks: Social Parenthood and Child- Fostering}

Within Ghana, as in many other parts of Africa, biological parents do not carry the sole responsibility for child care (Richter \& Morell, 2008). Rather, child rearing is a shared responsibility of the extended family. Clark (1999) described for the matrilineal Ashanti that the primacy of economic responsibilities in maternal care could be linked to a weak relationship between physical childcare and maternal bonding, meaning that day-to-day childcare that requires proximity is not necessarily the mother's concern, and may just as well be performed by another adult:

An Asante mother does accept the responsibility to make sure that her children are well cared for, but she does not feel that a mother would care for her children better than another attentive, capable relative of reasonable age might.

(Clark, 1999: 720)

The delegation of parental rights and responsibilities to persons outside the nuclear family is not particular to the Ashanti. In Ghana in general, both male and female extended kin assume different parental roles and therefore have an important place in child rearing (Alber, 2003; Goody, 1982; Hashim, 2005; Mensa-Bonsu \& DowuonaHammond, 1996; Nyarko, 2014). Underlying the practices of social parenthood is the idea that the education of children is such an important process that it cannot be the sole responsibility of the biological parents; the involvement of other kin is crucial in order for children to be socialised in a disciplined and trained manner (Nukunya, 2003; Verhoef, 2005). The involvement of other kin in child rearing and socialisation is not limited to a particular age. For instance, other women breastfeed the child when the mother has insufficient milk (Nukunya, 2003), and any older person of the community has the right to punish children for deviant behaviour (Nyarko, 2014).

Inclusive norms of parenting that include extended kin are informally institutionalised in the practice of kinship fostering. Although fostering does not necessarily imply mobility, it often entails a transfer of the child from the natal to a nonnatal home, usually of kin members, where they are fostered for at least part of their 
childhood (Anarfi, et al., 2003; Goody, 1982; Isiugo-Abanihe, 1985; McDaniel \& Zulu, 1996). Fostering a child is often considered an obligation for extended kin and serves several important functions of collective cost sharing, particularly for poor families, and the function of help in cases of 'crisis care' following divorce, death or co-wife rivalry (Isiugo-Abanihe, 1994; Mensa-Bonsu \& Dowuona-Hammond, 1996). It also serves to strengthen kin ties, for training or educational purposes, to help in the household or to perform paid or unpaid labour, and for companionship for widowed women or childless couples (Anarfi et al., 2003; Bledsoe, 1990; Desai, 1992; Goody, 1982; Lloyd \& Desai, 1992; Notermans, 2008; Pilon, 2003).

Contrary to formal adoption, where parental rights are transferred to the adopting parents, in the informal practices of kinship fostering parental roles are delegated to other kin (or non-kin), while biological parents retain their parental status, legal rights, duties and the potential for their children to provide old-age care when needed (Goody, 1982; Isiugo-Abanihe, 1985). The informal nature of the arrangement means that rights and responsibilities between foster and biological parents are negotiated and based on reciprocal relationships of trust (Alber, 2003; Goody, 1982). Although the biological mother often keeps an eye on the child and continues to fulfil her maternal responsibilities by sending gifts and food, distance is maintained to demonstrate confidence in the foster parent (Notermans, 2008). The birth parent's distance from the foster arrangement also serves to secure a 'fine-tuned training process' (Bledsoe, 1990: 83). In her study on child-fostering in Sierra Leone, Bledsoe (1990) observed that parents considered the hardship and daily struggles experienced by children in foster care as beneficial to the child's development and therefore avoided interference in the care arrangement.

The relationship between children and the foster parent is expected to reflect relationships between children and their biological parents. Hence, relationships are close and children are taken up in their foster parents' kin group (Nukunya, 2003). This also means that the foster parents carry the same role responsibilities as the birth parent, including financial support for the child (Desai, 1992). Such practices of parental role delegation show how in societies like Ghana, parenthood is not so much built on blood ties, but on care practices. As Twum-Danso (2009) holds, when discussing parenting and child rearing in these contexts, it is more useful to speak of adult-child relationships than to refer only to the dyadic parent-child relationship.

\subsubsection{Household Nucleation and Shifting Child-Raising Norms and Practices}

The central role of extended kin in child rearing in Ghanaian society and the separation of the child from the birth parent in practices of child-fostering is not only socially accepted and considered 'normal', but may also be the preferred living arrangement for children (Goody, 1982). At the same time, globalisation and urbanisation have altered more traditional motivations for fostering. For instance, within Ghana, educationrelated fostering has become more prominent, with children moving from rural to urban areas, usually to live with better-off kin, to attend schools (Goody, 1982; Isiugo-Abanihe, 
1985). Moreover, urbanisation and women's involvement in labour market segments that are less compatible with childcare have brought about new reasons for fostering (Anarfi et al., 2003).

Concurrently, processes of modernisation and urbanisation have altered the role of the extended family in child rearing. While the family remains key in Ghanaian society, the structure of the Ghanaian family where productive and reproductive roles and responsibilities, behaviour and values are organised within the extended kin group is slowly shifting towards the nuclear family that comprises a partner, siblings, children and aged parents (Nukunya, 2003; Nyarko, 2014; Wusu \& Isiugo-Abanihe, 2006). Reliance on the extended family for childcare support is therefore also declining. Such changing patterns are particularly observed within urban centres since urban accommodation designed for nuclear families generally does not allow for large families to co-habitate (Oppong, 1981). Moreover, in urban areas adults tend to be occupied with their own income-generating activities and education (Awumbila et al., 2011; Badasu, 2004).

In addition to practical limitations to extended family care, the Pentecostal Church plays a crucial role in changing family structures through advocating ideologies of the nuclear family, both in Ghana and the diaspora (Meyer, 1999; Van Dijk, 2002b). As Van Dijk (2002b) argues, one of the main concerns of the Pentecostal Church is progress in life and the pursuit of wealth and prosperity. An important means to achieve this is the severing of ties with extended family, notably by delimiting reciprocity through financial support. By keeping extended family relationships at a distance, economic resources are kept within the nuclear family. To this end, conjugal and monogamous marital relationships as well as nuclear family systems, and especially parent-child relationships, are valued over the interest of the extended family (Coe, 2011b). The long tradition of Christianity has also altered the role of the father in matrilineal societies, with fathers now being highly valued to the detriment of the traditionally strong relationship between the maternal uncle and a nephew (Coe, 2011b). Nuclear family ties are further reinforced by family inheritance rules implemented in the 1980s that shifted inheritance of property within matrilineal systems from the children of the mother's brother to the children of the father (Manuh, 1997).

Changing dynamics of the family and the diminishing importance of the kin group is reflected in children showing little respect to unrelated elders, and in biological parents bearing the sole responsibility of training and correcting their children, in overprotection, and openly confronting those who physically punish the children, including teachers (Nyarko, 2014). Besides, the absence of extended kin support has negative impacts on children, who may receive inadequate childcare (Oppong, 2006), as well as on women, who experience increased stress as daily care providers (Clark, 1994).

Nonetheless, kinship care in urban centres has not completely dissolved. Instead, as Nukunya (2003) argues, kin relationships have become more flexible with persons taking on new roles that replace traditional ones. In matrilineal systems, for instance, a more distant maternal relative might take on greater responsibility in the absence of the maternal uncle. The continued importance of the kin group, despite its changing nature, 
is also reflected in ongoing practices of kinship fostering, both in rural and urban centres. Recent census data show that $14.7 \%$ of Ghanaian children below 18 years of age live with neither their birth mother and father (excluding orphans). For $12.5 \%$, both parents were alive, for $0.9 \%$ only the father was alive, and for $1.3 \%$ only the mother was alive (GSS, GHS \& ICF International, 2015: table 2.10, p. 21). Although fosterage starts at an early age (Notermans, 2008), the majority of fostered children in Ghana are between the ages of 10 and 17 years, with more girls $(16.5 \%)$ than boys $(12.8 \%)$ in foster care. ${ }^{31}$ Moreover, in Ghana, a higher proportion of fostered children resides in urban areas $(17.2 \%)$ compared to rural areas (12.5\%) (GSS, GHS \& ICF International, 2015: table 2.10, p. 21).

\subsubsection{Child Care in Ghanaian Transnational Families}

From the aforementioned Ghana census data, it is impossible to establish how many of these families are part of a transnational arrangement. However, qualitative studies underline that transnational family arrangements within the Ghanaian sending context are common (Coe, 2008, 2011a, 2011b; Manuh, 1999; Mazzucato, 2008b). The magnitude of transnational child-raising arrangements is corroborated by Caarls et al. (2013), who found that among the total of 410 migrant respondents in the Netherlands and the United Kingdom, 15\% had children below the age of 18 at the time of first migration. Of these, $75 \%$ left their children in Ghana, usually for longer periods of time.

Migration of the biological parent has for long been an important reason for fosterage in West Africa (Brydon, 1985; Whitehouse, 2009). Leaving behind children in the care of another relative when parents leave their town or country may be a preferred option, as is sending children-so-called 'postal babies'-back to the parent's home country (Akazbaa et al., 2010: 65; see also Bledsoe \& Sow, 2011; Coe, 2008), as well as fostering children in the host country (Goody, 1982; Øien, 2006; van Walsum, 2000). Spending time in the parents' origin country emerges children in their ethnic culture, language and family, even at a very young age (Peil, 1995; Whitehouse, 2009), while it also relieves parents from the daily struggles of combining paid work with childcare in the absence of informal support networks (Akazbaa et al., 2010; Peil, 1995). Depending on the social and economic resources of the migrant parent, children may be sent to the origin country for longer or shorter periods of time (Whitehouse, 2009).

Child-fostering norms facilitate_-and in a few cases even force_-kin and non-kin caregivers to become involved in transnational child-raising arrangements (Dankyi, 2014; Dankyi, Mazzucato \& Manuh, 2017). The social acceptance of leaving children with a kin or non-kin caregiver for longer periods of time helps explain why Ghanaian stay-behind children (Mazzucato \& Cebotari, 2017) and migrant parents (Dito, Mazzucato \& Schans, 2017) do not necessarily experience a lower well-being compared to those who are not involved in a transnational care arrangement.

\footnotetext{
${ }^{31}$ Studies on child-fostering within West African societies have indicated that fostering takes place at all times during the childhood with a gender bias towards girls (Goody, 1982; Isiugo-Abanihe, 1985; Desai, 1992; McDaniel \& Zulu, 1996; Notermans, 2008).
} 
Recent qualitative studies have also provided interesting insights into shifting dynamics and patterns within transnational child-raising arrangements. A relevant example is Dankyi's (2014) study among Ghanaian kin and non-kin caregivers who care for left-behind children in the absence of the migrant parent. Besides the small networks that these caregivers can rely on for help, which is in line with current shifts in Ghanaian family care (see Section 4.4.4), she found that the transnational context also poses specific challenges to caregivers. She noted that transnational caregivers do not only practice time-consuming day-to-day care for the migrant's children, but that caregivers also have to manage remittances, communication and expectation of themselves, as well as of others inside and outside their networks. This 'management of care' is necessary to smoothen the care arrangement, yet it can cause profound stress on the part of the caregiver as they have to make many sacrifices (see also Dankyi, Mazzucato \& Manuh, 2017). Since migrant parents exercise control over the care arrangement via return visits, remittances and long-distance communication, caregivers also feel that they have little say in the way children are cared for. This breaks away from more traditional and collaborative care arrangements because parents take on a more prominent role in the foster arrangement, thereby diminishing the autonomy of the caregiver. Moreover, in order to avoid being questioned by the migrant parent, caregivers tend to practice a kind of 'careful parenting' instead of the more disciplined and strict training that is expected for children (see Section 4.4.2) and that has for long been an important reason to send children to foster parents (Bledsoe, 1990).

\subsection{Concluding Remarks}

This chapter has situated transnational child-raising arrangements within the relevant historical and geographical contexts. I described how Ghana moved from an immigration to an emigration country in the 1960s in response to internal and external changes. While most Ghanaians moved within the region for a long period of time, this trend steadily shifted when in the 1980s a diverse group of Ghanaians increasingly migrated to the Global North. Ghanaian migration to the Netherlands intensified in the late 1980s, at a time at which migration policies became more restrictive for all types of immigration, including family migration. This trend has continued up to the start of this research in 2010, with profound consequences for Ghanaian immigrants and their family members. I have shown that Ghanaians responded to this by making use of several counterstrategies, notably by entering and staying in the country through 'illegal' means. However, the tightening of policies pertaining to undocumented migrants has pushed these immigrants into dire positions in the receiving country. Both documented and undocumented immigrants mobilise social networks to survive in the restrictive policy climate. Despite this policy climate, Ghanaians are highly active on the labour market, although several factors render it difficult for Ghanaians to take on high skilled positions, pushing them into low-paid ethnic and migrant niches. 
The chapter moved from the receiving country context to the sending country context, for which important family norms and practices have been discussed. The important role of the family in structuring society, and the place of children herein, transitioned into the different roles of mothers and fathers and the central role of extended kin in child care. I also discussed several shifts with regards to family care practices, roles and relationships as a result of modernisation, urbanisation, as well as the growing influence of the Pentecostal Church. I showed that despite these shifts, the number of children in foster care remains high. Moreover, I discussed recent literature that underscores that transnational family arrangements in the Ghanaian sending context is a common phenomenon whereby the normative frames guide family decisions and facilitate transnational child-raising arrangements. At the same time, the transnational context poses certain challenges to transnational family arrangements. Thus, families have to deal with these two contexts; on the one hand, there is a context that facilitates migration and family care, while on the other hand structural conditions presented by migration alter the nature of family care arrangements. It is the ways these families juggle these two contexts upon which this thesis focuses. 



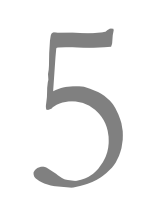

\section{Ghanaian Children in Transnational Families: Understanding the Experiences of Left-Behind Children through Local Parenting Norms}

A slightly different version of this chapter has been published as: Poeze, M., and Mazzucato, V. (2014). Ghanaian children in transnational families: understanding the experiences of left-behind children through local parenting norms. In L. Baldassar and L. Merla (Eds.), Transnational families, migration and the circulation of care (pp.149169). New York: Routledge. Sections, tables and figures are re-numbered in order to fit the thesis format. 



\subsection{Introduction}

The migration of parents to more-developed countries is often motivated by the prospect of securing a better future for their children at home. However, the physical distance between a parent and child necessitates a reordering of care arrangements and raises questions concerning the emotional impact of parental migration for left-behind children (D’Emilio et al., 2007; Mazzucato \& Schans, 2011; Whitehead \& Hashim, 2005). In particular, in Western societies, it is believed that intimacy between parents and their children can only be created through physical proximity and that physical separation interrupts healthy childhood development. However, in many societies, caregiving and parenting norms allow for a more flexible and inclusive notion of parenthood, with caring for a child being not only the responsibility of the biological parents but also that of the extended family network (see also Olwig, 2014). In such societies, physical separation between a parent and child is socially accepted and, at times, even favoured. We argue that the presence of such normative principles of parenting results from the circulation of care (Baldassar \& Merla, 2014) for children amongst a wider network of actors, than only the biological parents, and that such principles, together with how care is enacted, will impact the way children perceive their transnational care arrangements.

Few studies have examined the impact of the cultural contextualisation of parenting on left-behind children's perceptions of living in transnational families (Mazzucato, 2013). Furthermore, the African continent has remained underexplored in the vast literature on transnational families (Grillo \& Mazzucato, 2008; but see Åkesson, Drothbohm \& Carling, 2012; Bledsoe \& Sow, 2008; Kastner, 2010) and rarely is the focus on the perspectives of children (Coe, 2008). We seek to address these gaps through a study of fifty-four Ghanaian children's oral accounts of their experiences in a transnational child-raising arrangement. As we analyse these accounts, we interpret the experiences of left-behind children in relation to local parenting norms.

\subsection{Nuclear Family Ideal and Physical Separation}

Previous qualitative studies amongst transnational families from Southeast Asian and Latin American sending contexts have emphasised that left-behind children suffer emotionally when they are separated from their parents (see Dreby, 2007; Parreñas, 2005b). Parreñas (2005b: 120) argues that children left in the home country by their migrant parent express 'a lack of intimacy, feelings of abandonment, and a commodification of mother-child bonds'. Although these negative feelings were alleviated by the support of family members and children taking into account that the parents' absence was for the welfare of the family, the emotional suffering was considered to be profound.

Negative outcomes on left-behind children have mainly been explained by gender role expectations that are particular to family norms that hold the nuclear family and 
'intensive mothering' as prerequisites for a stable childhood development (Bernardes, 1999; Erel, 2002). The biological parent is expected to perform all caregiving tasks, necessitating geographical proximity between the parent and child (Bowie, 2004). When a parent moves abroad, the child is negatively affected because his or her situation departs from the proximity prescribed by the nuclear family ideal. In particular, when a mother moves abroad, children suffer from the physical separation. Regular phone calls and the sending of remittances cannot fill the geographical gap and the geographical distance poses challenges for the mother to fulfil her role as the primary caregiver (Hondagneu-Sotelo \& Avila, 1997; Parreñas, 2005b). Although it is acknowledged that feelings of loss can be alleviated when other female members of the family serve as the main caregiver (Åkesson et al., 2012; Parreñas, 2005b; Smith et al., 2004; Suárez-Orozco et al., 2002), the caregiver's role is seen as limited given that nurturing tasks are exclusively reserved for the biological mother. Thus, the suffering of children in transnational families in which the mother has migrated abroad is explained by the principles of the nuclear family ideal (i.e., love and care necessitate proximity with the child) that cannot be fulfilled in transnational family structures.

Although studies focusing on the effects of father migration on children are scarce (but see Kilkey, 2014), the few such studies reveal elevated cases of teen pregnancies, alcohol and drug abuse, robbery and emotional distress as a result of communication problems and a lack of emotional intimacy between the children and their fathers (D'Aubeterre, 2000; Parreñas, 2008). Here, it is also argued that non-proximate forms of care (e.g., remittances, phone calls and return visits) cannot foster the development of an intimate relationship between a father and child, ultimately resulting in a lack of care provision for the child. One study found less negative effects of parental migration on children living in Mexico, but this was compared with families in which the father was away due to divorce (Nobles, 2011).

\subsection{Social Acceptance of Parent-Child Separations}

The importance of parental physical proximity in the upbringing of a child, also called biocentrism, has been a dominant concept in the discourse on kinship and parenting in Euro-American societies and has influenced researchers' approaches when dealing with these issues. The idea that all children need face-to-face contact with their biological parents for intergenerational intimacy to emerge and that nurturing tasks can only be successfully carried out by biological parents undermines the fact that familial relationships and related emotions are cultural constructions and thus does not do justice to the culture-specific aspects of caregiving and parenting (Bowie, 2004; Schneider, 1984). Nonetheless, such a static and exclusive definition of parenting has dominated many studies on transnational families and the impact of parental migration on leftbehind children. 
Parental ideologies and definitions depend on the local context (Cole \& Cole, 2001) and influence the way that children feel about their caregivers and the care that they receive. In contrast to Euro-American societies, observations made in the Caribbean, Latin America and West Africa show that it is socially accepted for families to separate and for children to circulate between family and non-family members (Goody, 1982; Isiugo-Abanihe, 1985; Leinaweaver, 2007; Pilon, 2003). In these countries, child fostering is a common practice, with children transferred between their natal homes and the households of others for at least part of their childhood and for a variety of reasons. Here, child care is not centred on the core household but is considered a collective endeavour in which other kin and non-kin actively participate (Alber, 2003; Goody, 1982).

Ghana is one of the countries in which social parenthood and child fostering are important child-care practices (Goody, 1982; Hashim, 2005). Although modern-day realities have led to changes in the Ghanaian family structure with a decline in kin support in child raising, particularly in urban regions (Oppong, 2006), according to the 2008 Ghana Demographic and Health Survey, still 18.6 percent of all children under the age of eighteen are fostered (GSS, 2009).

The norm of social parenthood and the practice of child fostering bring into question the ideal that all parenting tasks are the sole responsibility of the biological parent and the assumption that the child and parent always need to be in close proximity of each other. However, this is not to say that parent-child separations are always unproblematic. The first studies conducted on child fostering in West Africa in the 1970s and 1980s focused on the importance of child fostering in terms of its social and economic functions (Goody, 1982) but not in terms of its impact on children. In a more recent study based in East Cameroon, Notermans (2008) observed that foster children were more critical about child fostering than their parents, most notably as a result of tensions arising in the everyday lives of the children.

While child fostering creates a context of 'normality' with regard to being raised by a non-biological parent and living geographically separated from the birth parent, the transnational context presents different conditions under which parent-child relationships develop at a distance. International migration creates differential access to material and financial resources, it brings with it different expectations of the roles of parents and caregivers on the upbringing of the child (Mazzucato, 2011) and modern communication technology renders possible parental involvement in upbringing from afar (Madianou \& Miller, 2011), all of which combine to impact children's experiences. Conditions abroad as well as pre-migration, such as the ability of the parent abroad to send remittances, the quality of the relationship between the migrant parent and the child's caregiver, the quality of the relationship between the parent and child before the departure of the migrant and the socioeconomic positions of the migrant and the caregiver also affect children's experiences of parental migration. Figure 5.1 depicts the way in which pre-migration and situational factors related to the conditions of migration interact with cultural parenting norms to influence children's emotional experiences. In 
this chapter, we focus on the frequently neglected aspect of parenting norms in affecting the emotional experiences of left-behind children.

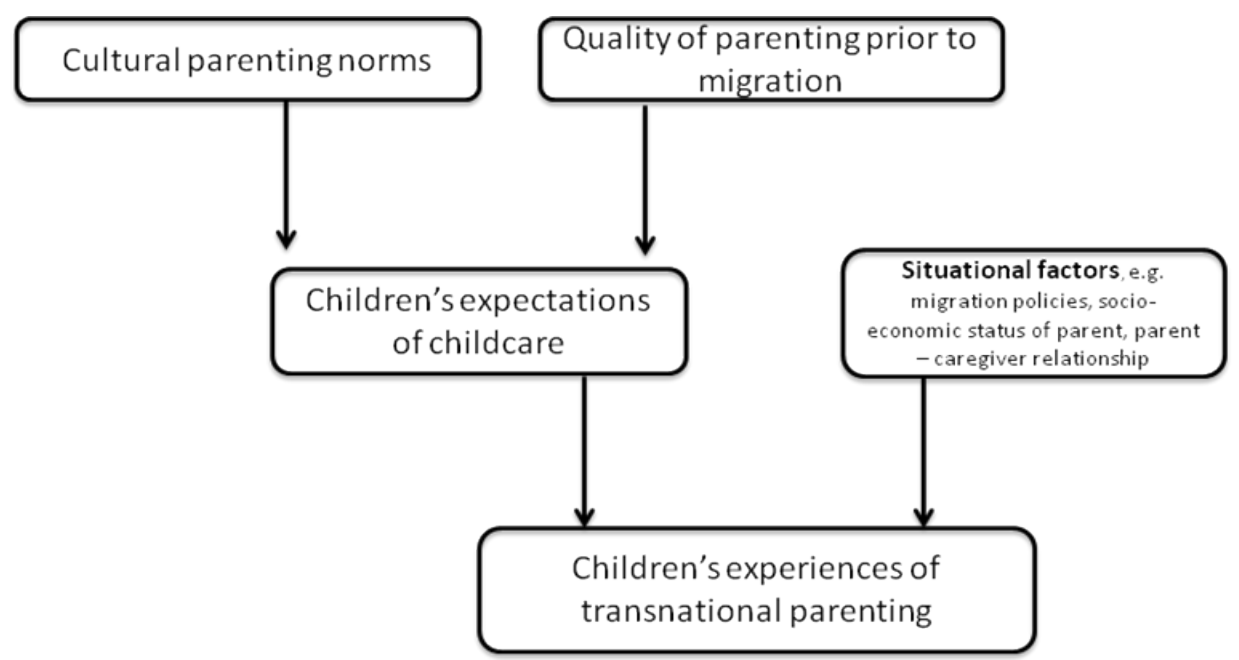

Figure 5.1. Influential factors on children's experiences of transnational parenting.

\subsection{Research Methods}

In-depth interviews were conducted over a three-month period in 2010 with fifty-four Ghanaian children and adolescents aged twelve to twenty-two, who had either one or both parents living in a Western country at the time of the interview. The children were selected from a larger survey of Ghanaian school children $(\mathrm{N}=2,670)$ carried out in four different localities in mid-2010 as part of the 'Transnational Child-Raising Arrangements between Ghana and the Netherlands' (TCRA) research project. ${ }^{32}$ Children were selected for in-depth interviews from Accra $(\mathrm{n}=25)$ and Kumasi $(\mathrm{n}=$ 29), both of which are urban regions known for their high ratio of migration to the West, as indicated by remittances received from abroad (Mazzucato et al., 2005). The main criteria for selecting the children were based on TCRA type, that is, having a mother abroad $(n=17)$, a father abroad $(n=25)$ or both parents abroad $(n=12)$. By studying these three family configurations, we took the diversity in the structure of transnational families into account. We selected both boys $(n=21)$ and girls $(n=33)$ who attended either junior high schools (JHS) $(n=24)$ or secondary high schools (SHS) $(n=32)$. We strove to incorporate diversity in the number of caregiver changes experienced by the children and the children's emotional well-being as measured by the Strength and Difficulties Questionnaire (Goodman et al., 1998).

${ }^{32}$ www.tcra.nl 
A majority of parents of the selected children were residing in the United States and the United Kingdom. Other parents resided in Germany, the Netherlands and Italy. Table 5.1 shows that for the majority of cases, parental migration took place when the child was between the ages of six and thirteen. Fathers were more likely than mothers to leave the children before the age of six. Children who had at least a father abroad were younger and separated from their parent for a longer period of time compared with children who had at least a mother abroad. In our sample, the majority of caregivers were female and kin (see Table 5.2).

The interviews were conducted at schools during breaks or after school hours. We sought permission from the schools to interview the children. The school setting was perceived as a place where children would feel safe and free to voice their opinions without the influence of caregivers or other adults. Each interview lasted between fortyfive minutes to one and a half hours and was recorded with the child's permission. The interviews were subsequently transcribed and analysed with the aid of the qualitative data software Atlas.ti.

Although some child-centred studies call for 'child-friendly methods', such as drawing, we found, in line with Notermans (2008), that in-depth interviews in a formal interview setting were most effective in terms of allowing children to express themselves. In contexts such as Ghana, where it is common for children and adults to occupy different spheres in their daily lives (Notermans, 2008), the formal interview setting aligned most closely with children's ideas about ways to express themselves to adults. Younger children attending JHS showed occasional difficulties in describing and explaining their emotions. When this occurred, we probed further, asked for examples and gave children ample time to think about their answers.

Table 5.1. Number of Children by Type of Transnational Child-Raising Arrangement (TCRA) Type, Age at Separation and Length of Separation

\begin{tabular}{|c|c|c|c|c|c|}
\hline \multirow[t]{2}{*}{ TCRA Type } & \multirow{2}{*}{$\begin{array}{l}\text { Children's Age at } \\
\text { Separation }\end{array}$} & \multicolumn{2}{|c|}{ Years of Separation } & \multirow{2}{*}{$>10$} & \multirow{2}{*}{ Total } \\
\hline & & $0-5$ & $6-10$ & & \\
\hline \multirow[t]{3}{*}{ Father abroad } & $0-5$ & 0 & 1 & 7 & 8 \\
\hline & $6-13$ & 3 & 12 & 1 & 16 \\
\hline & $>13$ & 1 & 0 & 0 & 1 \\
\hline \multirow[t]{3}{*}{ Mother abroad } & $0-5$ & 0 & 0 & 3 & 3 \\
\hline & $6-13$ & 7 & 4 & 0 & 11 \\
\hline & $>13$ & 3 & 0 & 0 & 3 \\
\hline \multirow[t]{3}{*}{ Mother and father abroad } & $0-5$ & 0 & 1 & 8 & 9 \\
\hline & $6-13$ & 1 & 1 & 0 & 2 \\
\hline & $>13$ & 1 & 0 & 0 & 1 \\
\hline Total & & 16 & 19 & 19 & 54 \\
\hline
\end{tabular}

Note. The length of separation and age at separation reflect the departure of the first parent who migrated. Source: Own fieldwork, Transnational Child-Raising Arrangements project, Ghanaian children data, Ghana, 2010. 
Table 5.2. Caregivers by TCRA-type and sex

\begin{tabular}{|c|c|c|c|c|c|c|}
\hline \multirow[b]{3}{*}{ TCRA-type } & \multicolumn{6}{|c|}{ Caregiver } \\
\hline & \multicolumn{2}{|c|}{ Left-Behind Parent } & \multicolumn{2}{|c|}{ Family Member } & \multicolumn{2}{|c|}{ Non-Family } \\
\hline & Mother & Father & Female & Male & Female & Male \\
\hline Father abroad & 21 & 0 & 4 & 0 & 0 & 0 \\
\hline Mother abroad & 0 & 6 & 10 & 0 & 1 & 0 \\
\hline Mother and father abroad & 0 & 0 & 9 & 2 & 1 & 0 \\
\hline Total & 21 & 6 & 23 & 2 & 2 & 0 \\
\hline
\end{tabular}

Source: Own fieldwork, Transnational Child-Raising Arrangements project, Ghanaian children data, Ghana, 2010.

Issues addressed during the interviews related to the quality of their care relationships with the parent(s), caregiver and people in the wider care network before and after the migration of the parent. Questions were asked about the departure of the parent, the arrangements made for care, the type of care received before and after departure, positive and negative experiences in the care relationships and changes and continuities in the children's relationships with their overseas parents and within their care arrangements.

Given the exploratory nature of the study, we interviewed many children from diverse situations to gain a wide array of children's experiences in transnational families. Future work would benefit from more in-depth methods and interviews with children's parents and caregivers to enable a greater understanding of the material conditions of the child's living arrangements and thus deeper insight into situational factors on children's emotional experiences (Figure 5.1). In this study, we do not address situational factors; instead, we focus on the gamut of children's experiences and seek to understand these experiences through the lens of cultural parenting ideologies and the framework of care circulation.

\subsection{Children's Experiences of Living in Transnational Families}

\subsubsection{Feeling Cared About}

The gender role expectations that children have for parents who move abroad typically reflect cultural parenting ideologies. These expectations inform the way in which children interpret the behaviour of their migrant parents. Children expect their migrant parents to maintain an active role in their upbringing, but the care that a migrant father and mother provides does not necessarily need to be geographically proximal. Below, we recount how children expressed feeling cared about by their migrant parent and pay particular attention to the differences between the children of migrant mothers versus fathers.

When describing their feelings about a father's departure and their feelings of closeness with him, children first referred to the way in which their father was or was not providing for their material needs. Children felt positively about their father's 
decision to move abroad especially when they expected an improvement in their material conditions, which could manifest in the form of luxurious gifts, such as laptops and cell phones, but also in the form of money for school fees and the prospect of a family house. In addition, being able to ask for and be given anything the child desired was considered an important advantage of having a father abroad:

Emmanuel: When he was here, he wouldn't buy these things but would have said that it is waste. But when he went there [abroad], and when I told him, 'dad, I want this', then he would send it.

Interviewer: So everything you ask for, he sends?

Emmanuel: Yes, and that makes me happy.

(Emmanuel, seventeen years old)

In some cases, a father's increased ability to provide material care was described as an improvement in the relationship:

Interviewer: Has the relationship with your father changed in any way since he left?

Seth: It is the same . . . and even better.

Interviewer: How?

Seth: The money he has given me, he has increased it, and the things he has been buying for me here, when they went there [abroad], they have increased these things too.

(Seth, twenty-two years old)

Children can feel loved and cared for by the father despite the geographical distance, and migration with the prospect of remittances can even increase these feelings of being loved. However, the association of fatherly love and care to finances also means that feelings of neglect and disappointment may arise when the father does not provide materially for the child or does not do so to the extent that the child expects. Meredith (thirteen years old) complained that the material care from her father living in the United Kingdom was limited to her school fees and believed that he was providing more for her half-siblings, who were living with him. This thought compelled her to ask her father on the phone whether he loved her half-siblings more than her. Francisca saw her relationship with her father as not good in terms of the lack of regular remittances:

Interviewer: So now the relationship with your father, since he is gone for eight years, how do you see this relationship?

Francisca: It is not good.

Interviewer: Why is that?

Francisca: Sometimes he has not been sending us money for two or three months.

(Francisca, fourteen years old) 
A father's absence in a child's life in the form of absent material care was even met with anger, as in the case of Poomah, especially when the relationship with the father had been weak before departure:

I think one day I was in school when he called me and I asked, 'who is this?', and he told me, 'it's your dad'. Then I asked him, 'what do you want from me'? He was annoyed that I asked him what he wanted from me, and I said, 'yes, you have not been catering for me since I was born from JHS to now SHS, so what do you want from me that you are calling me'? So I just cut the line.

(Poomah, eighteen years old)

In cases where the migrant father played an active part in the child's life before departure, it was easier for a child to understand his father's lack of material provision. For these children, a lack of material care was unlikely to motivate a severance of the relationship with their father. However, they did mention disappointment and a lack of fatherly love and care.

For Francisca, her father's lack of material provision made her feel reluctant to take care of her father in the future, indicating the reciprocal nature of the parent-child relationship:

He doesn't take care of us. At first, I said that I would not take care of him when

I grow up, but my mother said that is not good, I should take care of him.

(Francisca, fourteen years old)

Children described the quality of care received from their migrant mothers in different terms. Migrant mothers are expected to provide emotional care. From the interviews, it became clear that the physical absence of the mother was not necessarily problematic in terms of providing emotional care and for children to feel love and cared about. Mothers were able to maintain their emotional caring role from a distance through regular communication:

I'll say that she was always with me, even though she was not here . . because she called me frequently. . . I like her so much because like, if I need anything I tell her, if something is bothering me, I tell her. Because she has been there for me all the time, that's why.

(Kwabena, eighteen years old)

Consequently, feelings of neglect and abandonment can result when mothers do not provide the emotional care expected by their children during phone calls. For example, Barbara's mother sent remittances on a regular basis through Barbara's aunt and caregiver. However, her mother had not contacted Barbara since she left for Austria five years ago. This situation became a source of complaint for Barbara: 
Barbara: Sometimes I just forget about her, that I have a mother. The woman I am staying with [mother's sister], she treats me better. She cares about me. So sometimes I easily forget about my mum.

Interviewer: So you feel like she doesn't care about you?

Barbara: To me no. Mmmmm ... somehow.

Interviewer: Why is that?

Barbara: Because since she travelled, she has not called me. She doesn't call me at all, unless I have to call her. She will never call me.

(Barbara, seventeen years old)

In addition to providing emotional care, mothers also need to take care of the material conditions of the family, especially when the father is absent due to death or divorce, which is a common situation in Ghana. According to the Ghana Statistical Service (2008), 7 percent of women are divorced or separated and 2.1 percent are widowed. From the interviews, we can see that many fathers do not hold an active role in financially providing after divorce. Children perceive the need for single mothers to take on this extra parenting task and consider migration as a way to help them accomplish this. Jackeline, whose parents were divorced and whose father did not contribute financially to the family, provided the following explanation for the migration of her mother:

She said she was going to work so that she can take care of us, that's why she had to leave and I said, 'ok, if she is going to work she can go' because when she was in Ghana, she had nothing to do, she was just sewing some people's clothes and they paid little for that. That's why she was going, to take care of us.

(Jackeline, twelve years old)

As a result of such household dynamics, financial care was considered an important component of the children's evaluation of their relationship with their migrant mothers. Nonetheless, the inability of the mother to respond to financial needs of the family did not tend to produce feelings of neglect or abandonment because children typically expect this role to be fulfilled by the father and consider financial care to be a burden on the mother, given the perceived difficulty for women to secure an income.

Although migrant fathers are mainly expected to focus on material care, and migrant mothers are expected to focus more on emotional care, children do value the social and emotional care that they receive from migrant fathers. For example, Sara explained she felt that her father was caring for her when he asked about her school performance:

I think it is a good thing [that he asks about her educational performance]. Even at a time when he was not talking about it, I started to feel, 'why is my daddy no more thinking about me'? So when he asked me of my studies again, I became very happy, and it makes me feel cared for and loved.

(Sara, seventeen years old) 
Phone calls are important ways to provide social and emotional care across geographical distance (see also Baldassar, 2008b; Merla, 2010). Children value the opportunity to express their feelings, talk about personal issues, receive advice and be asked about their school performance and the care they receive from the caregiver. When care is not provided during phone conversations, as in the case of Ivana, negative feelings can arise:

[The conversations are] always about money, money, money . . . I've written to him [father] before . . . and I really, really poured my heart out. But when he called, I don't know whether he didn't want to talk about it because he only asked me about school, academics and stuff. That was all.

(Ivana, eighteen years old)

In addition to frequent phone calls and remittances, return visits from both the mother and father add to feelings of being cared about. Return visits provide children with an opportunity to spend time with their parents in person and share experiences that cannot be realised over the phone. Such visits were even more important if the child had no visual memory of the parent, as was often the case for children whose migrant fathers had left when the children were very young. For example, Vanessa met her father for the first time when she was thirteen years old on his first return visit. Although Vanessa was only able to spend one week with her father, she described this period to be one of the happiest moments of her life and felt closer to him after meeting him physically:

Interviewer: How would you describe the closeness? Because in one week, how close can you be?

Vanessa: Whenever he went out I went with him. We were always together. We look alike, I am the photocopy of my father. We walk the same, everything. Even when he came, he didn't trust anyone, but he could even leave his own purse with me and go out. I did everything for him when he was here for that one week.

(Vanessa, sixteen years old)

Children can also feel disappointed with their parents when they fail to make return visits, as shown by the case of Benjamin:

Benjamin: Last time he called me I was angry.

Interviewer: Why?

Benjamin: Because I feel bad for not seeing my father for about all my life, so I don't feel happy, and I tell him every time he calls, and he says he will be coming. The main motive that I was angry was that he lied to me that he will be coming [to Ghana] in December last year and he didn't, so I never return his calls, I haven't called him again.

(Benjamin, sixteen years old) 
Thus, while children may hold different expectations for migrant mothers and fathers, both parents are expected to maintain an active role in the upbringing of their child. However, the care provided by the migrant father and mother does not necessarily need to be provided in geographical proximity. Through the sending of remittances, regular phone calls and return visits, children can feel that their migrant parents are caring for and about them. The acceptable nature of non-proximate care is grounded in parenting ideologies that allow parenting tasks to be transferred to caregivers other than the biological parents.

\subsubsection{The Transfer of 'Motherly' and 'Fatherly' Tasks}

When children talked about their relationship with the caregivers, in case this was not the left-behind mother or father, they often described the caregiver as treating them like his or her own children. Comments such as 'she is like a mother to me' and 'she treats me like I'm her own child' were heard regularly during the interviews. In their explanations, children referred to the care that a biological mother would give her child, as shown in Sylvester's descriptions of his stepmother, who took care of him while his father was abroad:

She was trying to be like our mother, so anything we ask of her, she does, and she does anything for us. The things we need, she normally talks to our father and tells him the things we need so that our father will provide it for us.

(Sylvester, seventeen years old)

When a caregiver provides motherly care in the absence of the biological mother, children no longer need to experience a lack of parental care as a result of migration and the physical distance between the parent and child. Gottlieb, feeling sad about the departure of his mother five years ago, explained:

The stepmother I am living with, she treats me like a real son, so now I live very comfortably. I take her as my own mother, so I don't feel like if this guy is having his or her mother around, I don't miss her [biological mother], I know I have a mother who loves me.

(Gottlieb, thirteen years old)

In these cases, when the child felt that the caregiver was fulfilling the role of a mother, children often referred to the caregiver as 'mother'. Nonetheless, the biological mother has not been replaced by the caregiver; rather, the definition of mothering has been broadened to incorporate other people. This was further illustrated by Gottlieb when he described his relationships with his biological mother and his stepmother:

I am more close to my mum [in the UK] because she is my mother, but my stepmother, she is ... she is now my mother. She has taken like the position of my mother in my heart now, but still my mum is the one I really love, really! 
Kwabena's comments also show how a caregiver can take over some of the biological mother's caring tasks to help alleviate the effects of her absence:

When I was with my aunty, she made me feel . . she was not treating me bad, so that I'll miss her [mother]. She was treating me good, so like, I see everything as normal because most of the time, my aunty was there for me.

(Kwabena, eighteen years old)

Thus, although the relationship with the biological mother is still perceived as unique, caregiving is not exclusively reserved for the biological mother. Nonetheless, because the caregiver is considered to be just helping out in the structure of the transnational family, children do not regard all of the care tasks to be transferrable to the caregiver. Most importantly, the caregiver is not expected to provide financially for the child, which is considered the responsibility of the biological parents.

In the Ghanaian context, it is not only the primary caregiver who plays an important role in the provision of care. Other persons in the care network can also perform motherly and fatherly tasks and be considered additional parents. In this way, care can be seen to circulate through extensive networks of kin and friends. In the following excerpt, Henrietta describes the role of her father's brother in her upbringing:

Henrietta: I've taken him to be a father.

Interviewer: Why is that? What kind of things does he do for you?

Henrietta: He encourages me and he calls to check on me when I'm in school, hebehaves like a father to me, and he treats me like his own children.

(Henrietta, seventeen years old)

In particular, male figures in the wider care network are involved in the disciplining and physical punishment of left-behind children. Obeying and showing respect for adults in society are important duties of Ghanaian children, and those who disobey or disrespect any adult can be physically punishment (Twum-Danso, 2009). Also, children themselves see advice and physical punishment as necessary ingredients on the journey to adulthood. In fact, children feel cared for by the adults who perform these tasks and would not consider it problematic if care tasks of this nature are delivered by a person other than their biological parent or caregiver. Emmanuel, whose father was abroad and lived with his mother, provided the following explanation:

Emmanuel: Both of them [father and mother], anyone can call him [father's friend].

Interviewer: And then he would come to the house?

Emmanuel: Yes, to talk with us.

Interviewer: To talk?

Emmanuel: Ok, we are grown now so he doesn't discipline [physically beat] us anymore.

Interviewer: And before? 
Emmanuel: He used to cane us.

Interviewer: Can you give an example of some of the things that he would come for, like some of the trouble you would make?

Emmanuel: When they sent me [to buy something] and I didn't go. Then he would come, they would talk to him about me, and then he would cane me.

$[\ldots]$

Interviewer: How did you feel that this man was disciplining you?

Emmanuel: I knew him, so I took it. I knew him closely, so I took it like that. We call him our father. We've taken him as our father, so I wasn't having any problems with that.

(Emmanuel, seventeen years old)

When accepting discipline from people other than their biological parents, children compared the amount and means of disciplining to the way in which their biological parents used to discipline them. The care provided by their biological parents was their frame of reference. A deviation from this could be perceived as problematic by the children:

Interviewer: What are bad things about having your mother abroad?

Ralph: She has a brother. I don't like him. He beats too much. He likes beating. Interviewer: Why does he do that?

Ralph: I don't know.

Interviewer: He comes to your house sometimes and beats you?

Ralph: Yes, he beats us.

Interviewer: Is it your mother who tells him to go to the house or he just comes?

Ralph: He just comes to the house. But now he stopped.

Interviewer: Why?

Ralph: Once, me and my brother ran away from the house and my mother spoke to him and told him to stop and then he stopped. . . . Once, after classes, I came home late, and then my phone, the battery was low, so I couldn't call. I came, and he called and told me that he would come and lash me. I phoned my mother and told her that he is coming to lash me. She phoned him and told him not to lash me. And then he came! He came to lash me! He is the oldest, so when my mother told him not to come, he told her she should go away, she should not disturb him. He would come to lash us.

Interviewer: And your father didn't do that before?

Ralph: No.

Interviewer: But isn't it normal for parents to discipline their children?

Ralph: It is normal for parents to lash their children. But it was too much, he was overdoing it.

Interviewer: And when your mother was here he didn't come to beat you?

Ralph: No. 
(Ralph, fourteen years old)

Whether a care task is considered a 'fatherly' or 'motherly' care task depends on the activities the person is performing instead of the sex of the person. Kwame's (age sixteen) father used to take care of his son's material needs while his mother was abroad. After his father's death, his father's sister in the United Kingdom took over these financial tasks:

Kwame: I feel like she is my father now because she provides the school fees for me.

Interviewer: So why would you not say that she is like a mother to you?

Kwame: I'm not saying that she is like a mother to me because I feel like my mother is alive, my mother is performing all the duties as a mother, and she is the one performing other duties as my father, so I consider her as my father.

(Kwame, sixteen years old)

Due to a combination of care provided by different persons in the child's care network and the acceptance that not all parenting roles have to be fulfilled by the biological parents, children come to accept their transnational caregiving situation as normal. Due to the availability of multiple mothers and fathers, parental migration does not necessarily lead to a perceived lack of parental care. It is even impossible to distinguish between the experiences of children with one parent abroad and those with both parents abroad because in all of these cases it is the combination of care provided by the migrant parents, caregiver and wider care network that determines a child's experiences.

Although life in a transnational family is supported by cultural norms of parenting, it can also cause children to feel pressured to hide the fact that they miss their migrant parent for fear that these feelings might be seen as a critique of the care that is received from their caregiver, as Sheila described:

My aunty, I didn't want her to see it. Maybe sometimes, when I'm feeling sad, I'll go and sit at a place where no one will see me, and then when I finish crying, I come back because I don't want her to think that maybe, maybe because my mum has left, maybe she's not taking care of me ... so I am doing it in private.

(Sheila, twenty years old)

Physical separation due to parental migration does not necessarily lead to negative experiences for the child when tasks are performed well by all of the parties involved. However, the care provided by caregivers and persons in the wider care network is not always sufficient. The presence of the caregiver's own children was often cited as a source of negative experiences. Children complained that most of the money sent by their parents ended up being spent on the care of the caregiver's own family. As a result, there was not enough money for school fees and supplies. In several cases, children even had to miss school for extended periods of time. As children are often unaware of the exact amount of money that their parents are sending and the agreements that their 
parent and caregiver made concerning remittance distribution, caution must be exercised when drawing conclusions based on children's accounts alone. Nonetheless, our interviews revealed that left-behind children felt neglected as a result of unequal financial care provision for the children of the caregiver and themselves. Caregivers were also reported to make significant demands on left-behind children, especially the girls, in terms of taking up household chores and babysitting the caregiver's own children. These demands shifted the focus away from education and resulted in lower school performance. Children also felt neglected when they were beaten excessively and blamed for everything, as Abigail experienced in the house of her aunt:

Anytime we the children we do something [wrong], even though they [the children of her aunt] will be at fault, she will blame me for it and insult me, she never liked me.

(Abigail, sixteen years old)

Conflict between the parent and caregiver is another cause of insufficient care from the caregiver. When the conflict is not resolved and the parents have no means to relocate the children, it can have a negative impact on the quality of care provided to the child. Josephine explained that the situation changed for the worse when her aunts, who were taking care of her, got into a conflict with her migrant parents. Although she did not know the source of the conflict, she experienced the impact it had on the care she received:

Josephine: Something came between my parents and my aunties.

Interviewer: What came between them?

Josephine: I didn't really get it. . . I I was in school, so I didn't really get the story. When I went home, my daddy was complaining about my aunties, but I didn't get the story well. So now, our aunties are not on free terms with us, like at first.

Interviewer: How are they relating with you?

Josephine: Now everything is changed. First, when we needed something ... they gave it to us. But right now, if we need something, they want us to tell our daddy to bring it; if not, then they are not going to give the thing to us. . . . They get angry at any time, and sometimes, if there's no food in the house, no one wants to cook the food for us to eat. They are doing things on their own.

(Josephine, sixteen years old)

Not only do children expect their migrant parents to maintain an active role in their upbringing, they also expect their parents to ensure a good quality of care. When children suffered from poor experiences with the caregiver, they complained about it to their migrant parents over the phone, expecting their parents to improve the situation. Expectations of mothers and fathers did not differ in this regard. When left-behind 
mothers took care of the children, children complained to the migrant father when they perceived the care provided by their mother as inadequate and expected their fathers to improve the quality of care. When migrant parents did not respond to such complaints, children often found themselves in prolonged periods of inadequate care and emotional distress. Some children even threatened their overseas parent by claiming that they would run away from home if the situation did not improve.

\subsubsection{Children's Ideals of the Nuclear Family}

We have argued that the norm of social parenting in Ghana can help children perceive their life in a transnational family through a positive lens. This is especially true when good care is provided by all of the involved caregivers, including the migrant parent. However, children also expressed a longing for the nuclear family ideal, particularly in situations of inadequate care. The wish to live with both parents was based on the assumption that living with biological parents would automatically improve their care arrangements. Another manifestation of children's desire for a nuclear family was observed in the children of divorced parents. For these children, a return to a nuclear family represented their longing for their biological parents to be on good terms with each other and, in turn, for there to be fewer financial problems and better communication with the migrant parent. However, it may not be necessary for all persons to live in the same household. With one parent abroad and one parent in the household with the children, a nuclear family situation could still be accomplished if everyone is willing to talk to each other on good terms during regular phone conversations.

Moreover, children expressed a desire for physical proximity with their migrant parent. The main motivation for this desire was children's expectation that their relationship with their parents would become closer if they could live together:

Interviewer: So do you think that if your father had been in Ghana for all those years, if he hadn't gone abroad, do you think your relationship with him would have been different?

Emmanuel: Yeah, I think so.

Interviewer: In what way?

Emmanuel: That we would have gotten a lot closer.

Interviewer: In what way, because you say that you are still close to him?

Emmanuel: Like feel him. Now I can't feel him. Sometimes I think about talking to him face-to-face, but I can't talk to him face-to-face. I have missed him.

(Emmanuel, seventeen years old)

This 'feeling' of the parent's presence could not be developed through short return visits, remittances and phone calls:

Frank: I miss him a lot; I have never been able to stay with him for even 2 months. 
Interviewer: So what do you miss if you haven't seen him for more than 2 months in a row?

Frank: Father caring, I want to feel father caring.

Interviewer: What is that, 'father caring'?

Frank: Like you will be at home, and during weekends, your father will be taking you out and advising you and telling you some old folk tales and so manythings but I don't feel it now.

(Frank, sixteen years old)

The ideals of a nuclear family that underlie these feelings and experiences can be attributed to similar ideals propagated by the Pentecostal church, which has been influential on children in urban Ghana (Coe, 2008; Olwig, 2014). We found that schools were often the place where children missed the physical presence of a parent the most. In particular, visiting days at boarding school and parent-teacher meetings were cited by children as moments when they would see parents come to visit and take care of their schoolmates. This sense of longing for the physical presence of the parent was observed more frequently in Accra, where children typically live in small households, than in Kumasi, where children typically live in larger households and are surrounded by larger care networks. Relative to the Accra children, the Kumasi children were also visited more often by people other than their biological parents.

\subsection{Discussion and Conclusion}

In this study, we interviewed Ghanaian left-behind children living in transnational families in which one or both of the parents migrated to 'the West', analysed their experiences and explored the best ways to explain this phenomenon. We proposed a model that interprets the experiences of left-behind children through the lens of societal norms on parenting. Our data showed that the experiences of left-behind children are influenced by their expectations about parenting, which derive from the social norms of parenting, the way care is circulated and enacted and their experiences with their parents prior to migration.

In Ghana, we did not see that children experience transnational family life as their parents' failure to fulfil a social ideal, as reported elsewhere in the world (Bernhard, Landolt \& Goldring, 2009; Parreñas, 2005b). Instead, the norm of social parenthood resulted in a general acceptance among left-behind children that care can be provided by a non-biological parent caregiver and wider care network, evident in the 'circulation of care' (Baldassar \& Merla, 2014), even in the absence of parents due to migration. The flexible and inclusive child-care and family norms in Ghana help children to cope with and even value their lives in a transnational family context.

Different expectations exist with regard to fathers versus mothers. Fathers are overwhelmingly expected to provide financial care, with children perceiving financial 
provisions as the mode of care associated with their fathers. However, children also value acts that show emotional and social care from their fathers. In contrast, mothers are mainly expected to provide emotional care. Given that many children belong to households headed by a single female in which the mother has the responsibility of being the financial provider, children come to perceive the mother's migration as necessary for financial reasons and appreciate her financial provisions.

Parents can provide emotional care from abroad through regular phone calls and return visits, as left-behind children do not see the absence of physical proximity in the provision of emotional care as necessarily problematic. The reason relates to the Ghanaian context in which social parenthood constitutes an important mode of caregiving. In this context, the biological parent is not expected to be solely responsible for all parenting tasks, and children see it as acceptable for the caregiver and others to perform certain parental tasks that the biological parent is unable to perform as a result of physical separation. Whereas biological parents are expected to maintain their parental roles from abroad through securing good care arrangements for the child and showing care through remittances, phone calls and return visits, children tend to accept it when certain 'motherly' and 'fatherly' tasks are taken over by other people. Having multiple mothers and fathers helps parental care to circulate-despite the physical absence of the biological parents.

While care circulation allows children to accept and value aspects of their transnational living arrangements, the quality of care is also important in determining how a child will perceive such arrangements. Not all care arrangements function well, and not all children feel as though they are receiving adequate care. In the case of transnational fathers, the most important factor concerns the lack of material care, although a lack of emotional care can also induce feelings of parental neglect. Mothers who do not provide emotional care create sadness in their children. In addition, leftbehind children who feel maltreated, exploited or neglected by their caregivers in Ghana tend to suffer emotionally, socially and educationally.

Technologies enhance the circulation of care (see also Merla, 2014). Despite the distance, parents were still able to provide care and guard their role as primary authority figures through regular phone calls, return visits and remittances. Likewise, children felt most cared about by migrant parents who sent regular remittances and made frequent phone calls in which they were asked about personal issues and given advice. In contrast, a lack of return visits, remittances or phone calls could keep a child in a state of longing for his or her migrant parent.

It is interesting to compare child fostering, a longstanding form of care circulation that is a common practice in Ghana, with the transnational child-raising arrangements described in this chapter. Child fostering practices, such as social parenthood norms, create a context in which it is socially acceptable to be raised by people other than biological parents. This situation differs from some other contexts and parts of the world that have been described in the transnational family literature (Bernhard, Landolt \& Goldring, 2009; Parreñas, 2005a). We also note important differences between local 
child fostering and transnational child-raising arrangements (Øien, 2006). Bledsoe (1990) noted that biological parents were not expected to intervene after foster parents started to care for their children. This was because a good upbringing entailed some hardship ('no success without struggle'). For this reason, parents were unlikely to intervene even in negative child fostering situations. Whereas proper disciplining is also part of what children in the context of transnational child-raising perceive as good child care, parents are expected to, and do, intervene in the case of poor child-raising arrangements due to the unique reasons for fostering in this context and the expectations regarding a biological parent's role in caring from afar. Local child fostering is often a situation in which a parent who is less well-off entrusts the care of his or her child to a foster parent who is better off (Verhoef, 2005). In contrast, in a transnational child-raising context, the migrant parent is seen as 'better off' than the local caregiver, thereby creating the expectation (on the part of the child and local caregiver) that the parent will be involved in the upbringing, at least in the form of material support.

Cheaper flights and modern communication technology, such as cellular phones and the Internet, make it possible for migrant parents to give advice to and be involved in the emotional care of their children (see also Baldassar, 2008b). At the same time, geographical distance makes it more difficult for migrant parents to check on their children's situation through regular visits. This all results in different forms of care circulation than in local child fostering arrangements, where care in transnational arrangements is expected to circulate both transnationally and locally. This creates an interplay of expectations that are based on social parenthood norms in which a local network of people provide the day-to-day material and emotional care for children and in which the nuclear family and biological parents, specifically, have old as well as new expectations on them resulting from their migratory project. More research in this area is necessary to help us better understand how local child fostering norms can facilitate transnational child-raising arrangements and how child fostering differs from transnational child-raising arrangements in terms of expectations, rights and responsibilities of the various actors in the care arrangement.

Furthermore, we have seen in this chapter that local norms of parenting are neither static nor comprehensive. As argued by other scholars, nuclear family ideals are also present in Ghanaian society through processes of urbanization (Oppong, 2006) and modern religions (Van Dijk, 2002b). We noted that when children experienced a lack of quality care in Ghana or divorce, they could begin to consider the nuclear family as an ideal. The coexistence of both the societal norm of social parenthood and the ideal of a nuclear family help us understand why children's experiences of living in a transnational family tend to be so complex and at times ambivalent.

Nonetheless, it is clear that the norms of social parenthood help Ghanaian children in their transnational family life and that migration does not necessarily imply a deterioration of the level of care provided for the left-behind children remaining in the home country. This study showed that the manner in which children experienced the separation from their biological parent tended to be mediated by their expectations with 
Chapter 5

regard to their migrant parents, their caregiver and others in the care network. These expectations were guided by social parenthood norms and shaped within a context in which child fostering is common. 


\section{Beyond Breadwinning: \\ Ghanaian Transnational Fathering in the Netherlands}

A slightly different version of this chapter has been accepted for publication as: Poeze, M. (in press). Beyond breadwinning: Ghanaian transnational fathering in the Netherlands. Journal of Ethnic and Migration Studies. The sections and the table are renumbered in order to fit the thesis format. 



\subsection{Introduction}

Over the past two decades, a growing body of transnational family literature has explored how parental care roles are reorganised when parents and children are resident in different countries. The bulk of literature addresses migrant mothers' long-distance care practices across space and time, when children stay behind in the origin country (e.g. Hondagnue-Sotelo \& Avila, 1997; Parreñas, 2005a; Zontini, 2004). Scholarship has been slow to recognise the role of men in transnational families and the impact of father-child separations on parental roles (Mazzucato \& Schans, 2011). Moreover, we know little about the impact of fathers' international migration and physical absence on the continuation of the family unit and the welfare of different family members.

That men have been side-lined in transnational family studies may be attributed to dominant discourses of the caring mother and authoritative and breadwinning father, and so paternal migration has long been considered as another way in which fatherly absence is materialised (Akesson, Carling, \& Drotbohm, 2012). Few studies in the transnational family literature address how fathers crossing borders influence parenting roles (Chereni, 2015; Dreby, 2006; Kilkey, Plomien \& Perrons, 2014; Pribilsky, 2004). Men's perspective is of importance to fully understand transnational family life beyond the conventionally researched mother-child dyad, and to recognise that transnational fatherhood is a distinct phenomenon that should be treated in its own right (Carling, Menjívar \& Schmalzbauer, 2012; Mazzucato \& Schans, 2011). Moreover, a focus on transnational fathers allows for the deconstruction of 'male migrants as independent and non-relational, at a time when ...there is intense advocacy to recognise the connectedness of men in general to family-life' (Kilkey, Plomien \& Perrons, 2014, p.179).

Drawing on ethnographic research with 24 Ghanaian transnational fathers with some or all of their children resident in Ghana, this chapter compares fathers' attitudes and practices in relation to their legal immigration status and socio-economic position. It contributes to an emerging body of literature that focuses on gendered care-giving norms associated with structural conditions in the host country, which are key to migrant workers' differential strategies to meet parental care expectations and responsibilities for children in the origin country (Fresnoza-Flot, 2009; Kilkey \& Merla 2014; Parreñas, 2005a). Whereas structural factors are signalled as important in studies on transnational fathering (Kilkey, Plomien \& Perrons, 2014), it has so far not been a main object of study. Moreover, studies on transnational fathering tend to concentrate on 'underprivileged' migrants, notably undocumented and low-wage earners, leaving the full range of experiences under-explored, especially pertaining to relatively well-off and documented fathers.

By comparing Ghanaian transnational fathers' attitudes and practices along the axes of legal and socio-economic status, this chapter provides an analysis of the ways in which migrants' differential position in society shapes transnational fathering in the highly normative arena of childcare. Questions posed relating to fathers' provisioning of 
financial and emotional support to their children and their structural conditions include: What strategies and opportunities are deployed to support children 'left-behind' in their home country? How is material well-being enhanced or jeopardised? Beyond sending remittances, do the fathers manage to provide emotional care and guidance? What aspects of childcare arrangements are sources of destabilization with respect to transnational family life? And how is the psychological coherence and well-being of the family affected with regard to father-child relationships?

\subsection{Transnational Families and Fathering: A Literature Review}

The existing small body of literature on transnational fathering examines how gendered expectations inform practices and attitudes of fathering across borders. Usually such studies emphasise that the transnational context reinforces gender ideologies of mothers as family carers and fathers as breadwinners and decision-makers (Abrego, 2009; Avila, 2008; Dreby, 2006; Menjívar, 2012; Parreñas, 2008). Consequently, father-child separations in the context of international migration are depicted as socially accepted and often described as uncomplicated (Palenga-Möllenbeck, 2013). It is in terms of their economic success and desire to maintain some degree of authority that fathers evaluate the relationship with their children (Dreby, 2006). Hence, they do not feel guilty-or at least not to the same degree as women-for leaving their children in the origin country, since the migration context provides them with opportunities to fulfil their economic responsibilities.

The reinforcement of masculine ideologies is observed in men's communication with their children. In the case of the Philippines, Parreñas (2008) argues that migrant fathers focus on authority and breadwinning rather than being attuned to the emotional needs of their children. In this way, the transnational context moves fathers from heads of the households and care providers to long distance breadwinners, or 'fathers only by check' (Castañeda \& Buck, 2011:102). Concurrently, family members in the origin country, notably (ex)wives, claim that male migrants are likely to shirk financial responsibilities for their wives and children, usually ascribed to men's infidelity (Coe, 2011a; Landolt \& Da, 2005; Menjívar \& Agadjanian, 2007). In the case of Latino men, Avila (2008) found evidence that male migrants in the United States did not suffer from the stigma of being considered a "bad father" associated with lack of remittance-sending to family members back home, suggesting acceptance of a sense of negligence and irresponsibility on the part of the migrant father. This starkly contrasts with migrant women who suffer emotionally from feelings of guilt, shame and loneliness during geographical separation from their children and endeavour to sustaining engagement in emotional care for their children back home throughout their absence (e.g. Hondagnue-Sotelo \& Avila, 1997; Parreñas, 2005a).

More recent scholarship, however, has rejected stereotypes of transnational fathers as

disengaged, authoritarian and uncaring (e.g. Chereni, 2015; Kilkey, Plomien \& 
Perrons, 2014; Pribilsky, 2004; Winters, 2014). Largely informed by a shifting paradigm towards the 'new father' in literature on fathering in developed countries that moves beyond the gender binary of caring mothers and breadwinning fathers (e.g. Cooklin et al. 2014; De Souza, 2014). Such studies emphasise migrant men's breadwinning roles, while underscoring their involvement in active nurturing.

This broader view on transnational fathering is reflected in men's more ambivalent experiences regarding separation from their children. While absent fathers project positive feelings about their ability to secure a better standard of living for their family back home, guilt and emotional suffering arise when they are unable to fulfil their children's material needs (Dreby, 2006), or provide physical protection (Grzywacz et al., 2006). Heavy drinking and feelings of loneliness and depression were found among Mexican and Central American migrant men in cases of long-term separation and inability to visit their children and wives back home (Schmalzbauer, 2005; Worby \& Organista, 2007).

Transnational migrants' care-giving practices and associated emotional experiences are heavily shaped by the structural conditions in the host country. Transnational family scholars have only recently returned to the original emphasis on structural conditions and the continued persistence of nation-stations in shaping transnational social relationships emphasised in Glick Schiller, Basch, and Blanc-Szanton's seminal work (1992) and Fouron and Schiller (2001). Legal immigration status and socio-economic position affect family formation and fathers' ideals, practices and experiences of transnational care work (Boehm, 2008; Hoang \& Yeoh, 2012; Kilkey \& Merla, 2014).

Focusing on transnational mothers, empirical studies found evidence that legal status and class define the possibilities for maintaining emotional bonds with children by determining the quantity and quality of contact through return visits and long-distance communication (Bernhard, Landolt \& Goldring, 2009; Fresnoza-Flot, 2009; Menjívar, 2012; Parreñas, 2005a). Findings from qualitative studies are corroborated by large-scale studies demonstrating that legal and socio-economic status transcend gender differences in explaining the emotional well-being of transnational parents (Dito, Mazzucato \& Schans, 2017) and patterns of transnational communication (Hoang \& Yeoh, 2012). Such studies emphasise how the legal and economic boundaries, which constrain undocumented and low-income documented migrants practicing long-distance parenting differ markedly from the experiences of 'migrants of privilege' (Croucher, 2009). Migrants with more resources are capable of crossing borders with relative ease and have more opportunities to mobilise economic, social and material resources to perform transnational care (Baldassar \& Wilding, 2014; Fresnoza-Flot, 2009).

Men's gendered experiences as transnational fathers have remained understudied for decades. This chapter moves beyond the simple breadwinning assumption, to examine intersecting gender ideologies and the role of structural conditions, notably legal immigration status and socio-economic position, in shaping transnational care practices. To date this approach has not been systematically applied to the study of transnational fatherhood. 


\subsection{Ghanaian Migrants and the Dutch Migration Context}

Lacking economic opportunities at home, Ghanaians from different ethnic, socioeconomic and educational backgrounds move abroad to improve their living conditions (Awumbila et al., 2011). Migration to the Global North rapidly increased in the early 1980s, following economic and political upheaval in Ghana and other West African countries (Peil, 1995), with the Netherlands being an important destination. In 2014, 22,556 Ghanaians were officially registered as living in the country, with a balanced gender composition (CBS, 2018a). Like other European countries, policy restrictions since the late 1980s have limited the means to legally enter and reside in the Netherlands, especially for those coming from the Global South. For Ghanaian migrants, family migration is the most important means to obtain residency in the Netherlands, yet the rejection rate is high, ${ }^{33}$ reflecting tightened migration policies. In response, many Ghanaians, like other migrant groups, enter the Netherlands on a three-month tourist visa and stay after their visa expires (Burgers \& Engbersen, 1999). This has resulted in a significant undocumented Ghanaian migrant population (Mazzucato, 2008a), who face serious strains on their living and working conditions, especially since the implementation of the Benefit Entitlement (Residence Status) Act (1998) that prohibits undocumented migrants' access to all public services (Engbersen, San \& Leerkes, 2006).

The employment rate among Ghanaian male migrants in the Netherlands is high, although lower than that of the national average (Black et al., 2013). While a middle-class is emerging among the Ghanaian migrant community (van Dijk, 2002a), most hold elementary occupations in the tertiary sector (trade and services), predominantly domestic work and cleaning jobs. This can be explained by the relatively high proportion of unskilled and semi-skilled migrants in the Netherlands (Mazzucato, 2005), and by unrecognised diplomas, language difficulties and discrimination for higher skilled Ghanaians (Black et al., 2013).

\subsection{Methodology and Respondent Characteristics}

This paper is part of a larger project that addresses childcare relationships and kinship networks of care within Ghanaian transnational families called 'Transnational ChildRaising Arrangements between Ghana and the Netherlands'. ${ }^{34}$ The present study draws on ethnographic research conducted by the author between mid-2010 and mid-2013, among 24 Ghanaian male migrants in the Netherlands, who had at least one child in Ghana below the age of 21 at the time of study. ${ }^{35}$ Respondents predominantly resided in Amsterdam Southeast, a multicultural district of Amsterdam, where two-thirds of all

\footnotetext{
33 Unpublished figures of the Dutch Immigration and Naturalisation Service (2013) show that between 2005 and 2011, 75 per cent of applications for family reunification made by Ghanaians in the Netherlands were rejected.

34 'Transnational Child-Raising Arrangements' (TCRA) research project. For further details, refer to www.tcra.nl.

${ }^{35}$ In the overall research project, the age limit was set at 21 to include children and youth.
} 
Ghanaian migrants in the Netherlands reside (O+S, 2006). Three respondents resided in other districts of Amsterdam and two in The Hague. Potential discrepancies in oral narration and practice, i.e. what a father says he does regarding his child's welfare and what actually happens, were screened by collecting data on the broad range of men's migration experiences and care practices and relationships through different methods: multiple in-depth interviews, visits to social gatherings, observations and regular telephone calls. ${ }^{36}$

The average age of the respondents was 45 (ranging from 33 to 60). The length of separation from the children ranged from 1 to 25 years, with an average of 13 years. Whereas this paper focuses on fathers with Ghanaian-based children, with all men having children in Ghana (ranging from 1 to 6 children), eight men also had children in the Netherlands (ranging from 1 to 3), and one had two children in other countries. Five men were divorced or single, while the rest were married to Ghanaian women who resided in Ghana $(\mathrm{n}=8)$, the Netherlands $(\mathrm{n}=10)$, and the United Kingdom $(\mathrm{n}=1)$. Eleven respondents were undocumented, while 14 held a Dutch residence permit or citizenship. The socio-economic position of respondents depended on their legal status, labour market position and availability or absence of a Dutch-based spouse's income, ranging from those who were barely subsisting to those who were prosperous. Undocumented migrants primarily held casual and part-time jobs in the informal cleaning sector, while documented migrants worked largely full-time jobs (both casual and permanent) in the formal cleaning sector, factories and restaurants, while one worked as a pastor and one in the public sector. Table 6.1 provides a detailed overview of the most important respondent characteristics and differences in material welfare and emotional outcomes.

\footnotetext{
${ }^{36}$ Respondents were contacted through various ways: making announcements on community radio stations, in churches, and through the networks of key informants and Ghanaian interviewers who had previously been involved in the larger Transnational Child-Raising Arrangements-project. I selected respondents who varied in terms of legal and socio-economic status, presence of children in Ghana and the Netherlands, care arrangement and duration of migration, to allow for the exploration of a range of experiences. Interviews were mainly conducted in English. Ten of the respondents were part of a simultaneous matched sample methodology (Mazzucato, 2009a), in which Ernestina Dankyi, a Ghana-based researcher, simultaneously studied the men's children and their caregivers. The sharing of data and two informal visits to some of the children and caregivers facilitated the broader contextualization of fathers' experiences and care practices.
} 


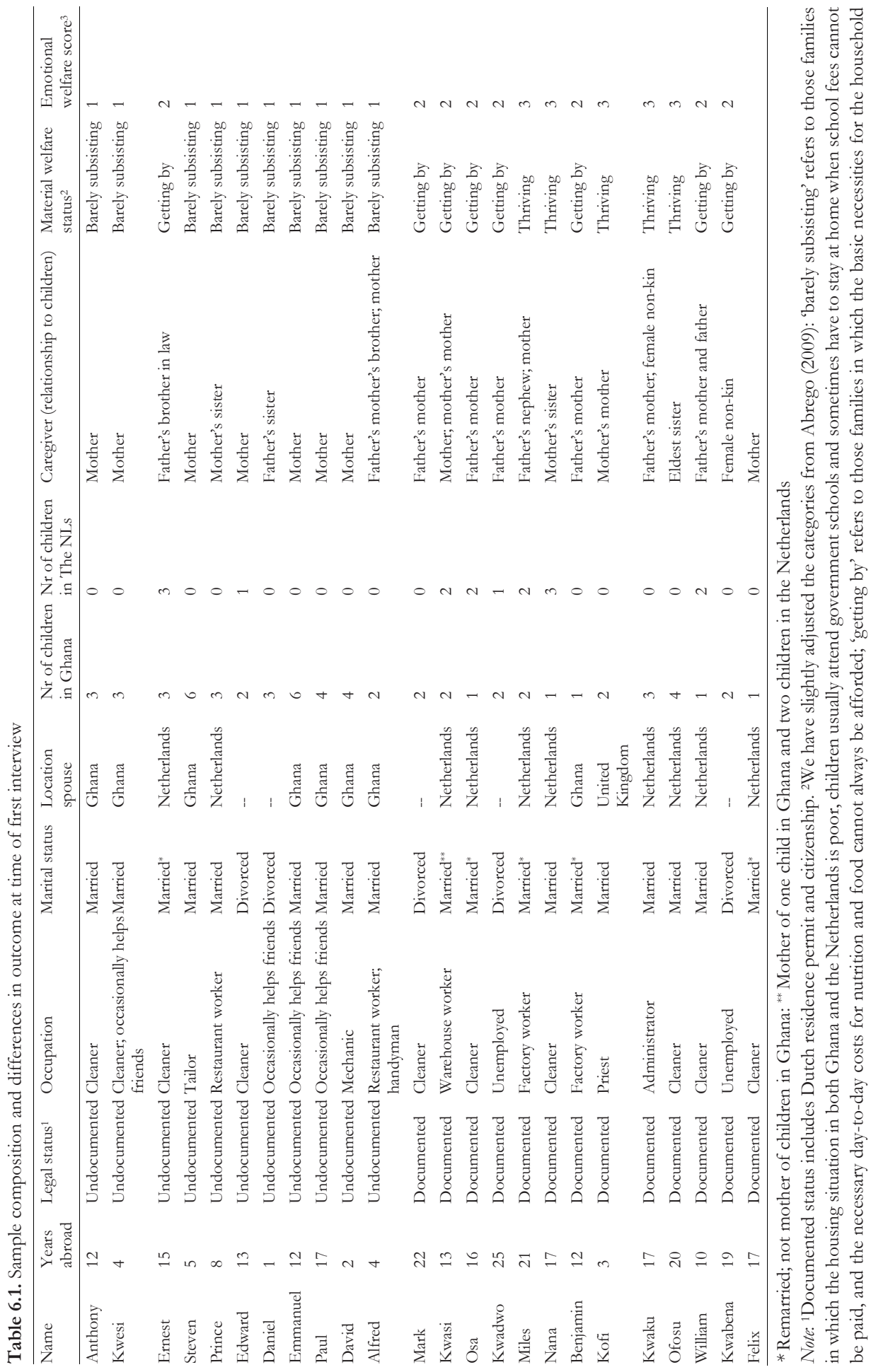


Beyond Breadwinning

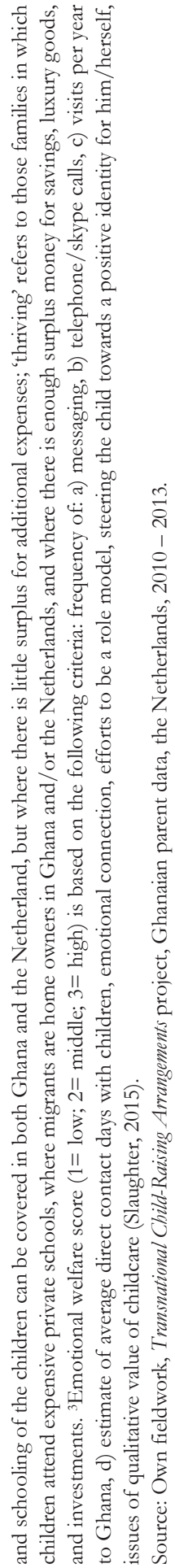




\subsection{Breadwinning Ideals and Practices}

Common discourse and scholarship on Ghanaian families report daily caretaking of the child as the woman's responsibility, while men are considered to be the financial providers (Mensa-Bonsu \& Dowuona-Hammond, 1996; Manuh, 1999). Although women too are expected to financially contribute to the household, men are assumed to bear the bulk of financial responsibilities, including feeding, clothing, and school fees (Boni, 2001; Oppong, Okali \& Houghton, 1975). Given the importance of financial support, the father has always been a central figure in the child's upbringing, also in the matrilineal family structure of the Akan ethnic group, to which the majority of respondents belong, where lineage follows female filiation. It is in terms of the 'traditional patriarchal definition of masculinity, where fathers have defined gender roles of economic responsibility' (De Souza, 2014: 4) that Ghanaian fathers' migration projects are framed. All interviewed fathers cited enhanced earning to provide schooling and a better life for their children as their main objectives for migrating to the Netherlands. Against the background of costly school fees and men's insecure labour market position in Ghana, migration is perceived as a means towards more economic stability and social mobility for the family.

Migrant men's ability to fulfil financial needs of the family back home, the strategies adopted to acquire economic resources and linked to that, their perceptions of the parental role are largely defined by their structural conditions. Access to the labour market, public services and eligibility for government subsidies is determined by legal immigration status, which influences the migrant's socio-economic status. At the same time, legal and socio-economic status does not completely overlap. Although all undocumented migrants are barely subsisting, there are differences in material welfare status among those with a residence permit; some are getting by while others are thriving economically (see Table 6.1).

However, all male migrants categorised as 'getting by' and 'thriving' send their children to high quality schools and transmit remittances on a regular, usually monthly, basis to their children and the children's caregiver, while half also invest in extracurricular classes. Documented immigration status is key in their family welfare status. Except in one case of an undocumented couple 'getting by', all others in the 'getting by' category had obtained legal residency by marrying a Ghanaian woman with Dutch residency. These migrants do not cite the need to economise to financially support children in the home country.

Migrants who are 'barely subsisting', by contrast, are undocumented and face multiple challenges earning low incomes, and experiencing frequent and lengthy periods of unemployment, exploitation by employers and immigration detention. More than 90 percent of the interviewed undocumented men struggled to fulfil their role as family providers on a regular basis. Only 18 percent of them had children attending high quality schools. Among undocumented migrants, money transfers to families back home are more sporadic as they depend on the men's work availability. Nonetheless, more than 
50 percent sent monthly transfers to their Ghanaian families. The sums of money sent were generally small but constituted a large percentage of their financial resources.

Many choose to deny themselves basic necessities, such as meals and clothes, avoid social activities, postpone other migration goals, e.g. building a house and providing for other relatives in Ghana, in order to financially support children back home. Some interviewed men sporadically borrowed small sums of money from transnational social networks when income was not forthcoming due to (temporary) unemployment. Yet, borrowing money is considered 'a disgrace' and is kept to a minimum as much as possible.

The great efforts made by the Ghanaian men of this study to financially support their children can be explained by the real and symbolic meaning of money in parent-child relationships. Boni (2011: 36) states that a Ghanaian 'father's rights rest ideologically_ and at least partly so in practice—on his capacity to "care for"'. Failure to support the child financially is considered an impediment to the child's future success and a sign of emotional neglect on the part of the father (Coe, 2011b). Fathers who fail to live up to their material duties may lose paternal custody after divorce. Failure to provide incurs both a debt and social stigma' (Boni, 2001: 32), and as such, financial support reinforces or challenges 'notions of manhood' (Mikell, 1997: 112).

Nana, who was able to send his daughter in Ghana to one of the top schools in the country and who reunified with two of his children in the Netherlands, commented:

When my children go back to Ghana, the people see them and they respect me. They give me honour for taking care of my children. People respect you for that. When they see your children, they assess whether you are a man or not. Because, if your children are not doing well, they know that it is you, the man, who is not doing well.

(Nana, documented, father of four)

Financial support is an important means to bond with children for both men and women (Clark, 1999; Coe, 2011b) and a way to show an absent presence in the case of geographical separation, as one migrant narrated: 'The children know that I am there for them, because they know that I take care of them financially'. This is consistent with findings among Ghanaian stay-behind children, who consider transnational fathers' inability to send remittances as a sign of abandonment, whereas financial support reinforces a sense of closeness and feeling cared for (Coe, 2011b; Poeze \& Mazzucato, 2013). Accordingly, and independent of their structural conditions, migrant men celebrate the material achievements of their migration projects. Whereas migration separates fathers from their children in terms of geographical distance, fulfilment of material child support adds to positive perceptions of fatherhood. The contrary also appears: inability to financially provide results in self-perceptions of 'irresponsible' and 'bad' fathers, accompanied by emotional suffering, as the following quote illustrates: 
It is difficult to be responsible for the children. Now I don't have money for their schooling. My daughter started school in September. She called me and told me, 'you need to send me money now'. But even paying the rent here is difficult. I was grieved in my heart. There are other people who give my children money, a little bit, but I am the one responsible for them.

(Daniel, undocumented, father of three)

Such negative self-perceptions are aggravated by children's material demands. Not wanting children to worry over their situation, fathers avoid talking about their living and working conditions until they perceive their children old enough to understand their father's economic constraints rather than assuming he does not love them. At that point fathers hope their children can appreciate their fathers' circumstances and realistically calibrate their material demands accordingly.

Migrant men's finances are linked to their marital situation in various ways. Firstly, having a wife in the Netherlands may result in higher income levels as generally Ghanaian women in marital relationships are economically active. On the other hand, having a wife and children in the Netherlands may result in less income and emotional time being directed to the father's children back in Ghana. Second, a lack of regular remittances can seriously strain on transnational marital relationships. Migrant men who struggle to survive financially are prone to complain about their Ghanaian-based wives' inadequate contribution to the family's finances and their heavy dependence on the migrant remittances. One interviewee opposed the idea of his Ghana-based spouse working because it would infer that his migration project was not successful (see also Menjívar \& Agadjanian, 2007). However, usually the men wanted their Ghana-based wives to cover some of the financial responsibilities. A perceived lack of agreement over family finances can lead to serious consequences for the marital relationship. The case of Edward, an undocumented migrant, is illustrative. Edward had been living in the Netherlands for nearly ten years when he sent his wife $€ 1,000$ to invest in a small shop, so she would be able to support the children financially, and he could save up money for a 'white paper marriage' that would take him out of illegality. ${ }^{37}$ But the mysterious 'disappearance' of the money and his wife's failure to start a viable business were followed by marital conflict, as Edward explained agitatedly:

I wanted her at least to try something to release the heavy burden off my shoulders. I don't know what happened to the money I sent her, but nothing was set up. I got angry with her and told her that I am the one doing everything!

(Edward, undocumented, father of three)

The interviewed migrant men generally failed to acknowledge the heavy burden that their Ghana-based spouses faced when the remittances they sent fell short of needs and

\footnotetext{
37 'White paper marriages' are an important means for undocumented migrants to obtain Dutch residency. At the time of research, such marriages to a Dutch citizen or denizen for the sole purpose of obtaining a residence permit sold for up to 14.000 euro $(€)$.
} 
wives had few means to mobilise supplementary financial support and hands-on care from extended kin networks (Dankyi, 2014). Accordingly, accusations fly back and forth, with migrant men disapproving of the ways in which their Ghana-based spouses manage the remittances, while wives blame their migrant husbands for neglecting their families and resort to adultery accusations. These tensions and discord are most common in transnational marital relationships of undocumented migrants, where remittances are typically erratic and inadequate.

\subsection{Communication and Visits: Nurturing Intimate Relationships}

Alongside emphasis placed on the breadwinning role, over three quarters of the Ghanaian fathers cited efforts to achieve a more 'engaged' fathering ideal, as aimed at nurturing intimate relationships and 'fatherly love' through frequent long-distance communication and face-to-face visits. How and whether they were able to realise these ideals depended largely on their legal and socio-economic status in the Netherlands. This is illustrated by the case of Kwaku:

Kwaku and his wife Akua, a well-resourced couple, sent their three Dutch-born children to Ghana before they turned two years old, to be cared for by their paternal grandmother. In spite of the young age at which the children were sent to Ghana, Kwaku experienced little impact of geographical separation on his relationship with his children. After nearly 18 years of separation from his children, Kwaku described the contact with his children to be close, enabled through regular phone calls, messaging, social media and annual visits.

(Kwaku, documented, three children)

Access to cross-border mobility of the father-and in the case of Kwaku also of his Dutch passport-holding children—and modern electronic communications facilitated emotional bonding across borders. In the other four 'thriving' families, tourist visas for children to visit their parents in the Netherlands were relatively easily arranged, given the family's income level..$^{38}$ Documented and higher income male migrants have the means to make regular visits perform a more 'engaged' fatherly role, thereby 'normalising' to some extent the geographical distance (Baldassar \& Wilding, 2013). Regular visits between parent and children sustain intimate relationships, generating feelings of emotional connectedness between visits (Mason, 2004).

In combination with frequent communication, usually several times per day, relationships are considered to be 'open' and 'free'. In addition to disciplining and morally guiding children, typical fatherly tasks in Ghana (Twum-Danso, 2009), the migrant men categorised as economically 'thriving' felt their children could tell them

\footnotetext{
${ }^{38}$ In 2015 the official income requirement for dispensation from the immigration ban was a regular income of $€ 1628$ per month, fixed for couples and single parents (www.ind.nl).
} 
anything they had on their mind, share their secrets, seek their advice about friendships and schooling and joke with them.

Intimate communication is further facilitated by online communication. Seeing each other on the webcam, sharing videos and photos and messaging, gives fathers a presence in their children's daily lives. They can follow their children's development at close range and gain a feeling of emotional togetherness. For example, Kwasi explained the functional importance of Whatsapp in his relationship with this Ghana-based daughter:

I Whatsapp [WA] with her even more than I speak with her on the phone. The way we communicate on the WA enables us to share a lot of things. Sometimes she sends me a message, some videos, and in return I send her some videos. ... We talk about everything. Sometimes we talk about her mother [Kwasi's wife]. especially when her mother is not happy about her. I remember some time ago, she had permed her hair with her own money and her mother did not approve. I told her: 'your mother should understand because you are now sixteen'. And she said: 'you understand me better!' [laughs] So yes, we talk about a lot of different issues... Sometimes I teach her about life. Sometimes she doesn't understand why things are happening to her and I tell her that life is not always the same. Sometimes things change ... Her mother doesn't talk to her that much, but she and I chat for many hours every day'.

(Kwasi, documented, father of four)

Exposure to Dutch norms of fatherhood through Dutch-born or reunited children has impacts on the father's attitude to his children in Ghana. Kwasi recounted how his relationship with his three daughters in Amsterdam transformed him as a father, making him more receptive to all kinds of requests from them. This extended to his relationship with his daughter in Ghana, which he described as 'closer' and 'more equal' compared to the emotionally distant relationship he had had with his own father.

Contrasting under-resourced migrants, both undocumented fathers and documented fathers with limited financial resources, rely heavily on long-distance phone calls to bond with their children and to mitigate the negative implications of their absence. As Prince, whose undocumented status prohibited him from visiting his children in Ghana throughout the eight years he and his wife lived in the Netherlands, stressed:

Both me and my wife are always accessible for the children by phone. We try to keep the relationship alive through phone calls. Every week we spend $€ 30$ on telephone cards. I use them the most. I call them three times a week for about 30 minutes.

(Prince, undocumented, father of three)

In spite of relatively low telecommunication tariffs between the Netherlands and Ghana, undocumented and low-income fathers generally keep their phone calls short when financial resources are limited. The dominance of masculine ideology of the 
breadwinning father results in migrant men prioritizing school fees and other necessary expenses over phone calls. The contentious relationship between financial support and communication was most pronounced for fathers who were unable to send remittances to their families due to unemployment. Protecting themselves from having to rebuff their children's financial demands, from accusations of abandonment by Ghana-based spouses, and from feeling too guilty about their financial failure, these fathers tended to temporarily withdraw from communicating with their children, resuming contact as soon as their financial situation allowed. Emotional bonding was further complicated by fathers' role as disciplinarians, since the short phone calls tended to be used for scolding and morally guiding their children. Some men resolved this by delegating discipline to other male figures.

Whereas fathers aimed at following their children's daily lives up close through regular mobile phone communication, they also realised the limitations of this form of long-distance bonding. The common 'practice of hiding' the true circumstances of their children, by those who stay behind to prevent migrant fathers from worrying while not being able to do anything (Baldassar, 2007) was well known to the fathers, and inadvertently led to their general feeling of not knowing exactly how their overseas children were faring. As is common among transnational families (Baldassar, 2007), the limitations of ICTs resulted in a longing for co-presence that would allow them to check on the situation back home and share their true feelings.

Lengthy separations often combine with male migration patterns, which are closely related to family formation and expansion such that male migrants often leave Ghana when children are young or when wives are pregnant. Accordingly, they have spent little time with their children prior to migration. Edward, who left Ghana when his youngest daughter was two years old, described his efforts to forge an emotional bond:

I remember when she was about six or seven, I wanted to talk to her on the phone and she took the phone and it was like, 'Who is this?' But later she knew. And now that she is maturing, she knows that her father in the Netherlands is sending money. But because she doesn't really know me, I try to be extra nice to her. I am trying very hard to be close to her. She talks to me and she calls me anytime. Sometimes she flashes me and then I call her back. I always return her call. And I buy her things, I sent her boxes with provisions, shoes, dresses, these kinds of things. But one time my daughter here in the Netherlands pointed out to me that when I talk to my daughter in Ghana, it is only about 'daddy, I need chop money, daddy I need this'; we didn't really talk. Our conversations were only about her material needs. So, the connection between us was not so good. My oldest daughter, talked with her and told her, 'when daddy calls, ask him about other things'. So now that situation is changing.

(Edward, undocumented, father of three)

As Wilding (2006: 134) notes, 'connected presence' through ICTs is incorporated in existing relationship practices. Hence, whereas close relationships with children are 
easier to continue with ICTs, fathers especially struggle to communicate with children who have no or only vivid memories of them. Children may be shy to talk to their longabsent father who is a stranger and may even become 'a figure of fear' (Hoang \& Yeoh, 2012: 322). Fathers with children unwilling to speak on the phone, have little or no point of entry for gaining insight into their children's lives to establish the basis for conversation with them.

Exchanging pictures may help to keep the presence of the other alive in the absence of face-to-face contact (Fedyuk, 2012). At the same time, seeing images of their children may make it painfully clear to fathers how much they missed not seeing their children grow up. Benjamin, who had finally obtained a Dutch residence permit enabling him to travel to Ghana to see his child after an interlude of eight years, describes his feelings as he realises that a visit cannot automatically bridge the emotional gap:

When Benjamin left Ghana, his son Emmanuel was two years old. Benjamin used to call his son regularly but struggled to perform a more involved fathering role because his son was hesitant to speak to him on the phone. Benjamin explained: 'I wanted to be a father to him, I wanted to know what he wanted, and whether he wanted to know something about me.' Eight years after he had left Ghana, Benjamin obtained his Dutch residence permit and for the first time visited his son. Benjamin explained: 'I asked him, “do you know who I am?” He answered, "yes, you are my father", because he knew that I would come and he had seen my pictures. When I talked to him he only answered with "yes" or "no". He wasn't talking much. But every morning he came to my bedroom to greet me. He would just sit there without saying anything. After some time, he started to ask me for things like my I-Pod. But it was ok, at least he started talking.' Benjamin believed his visit had a positive impact on the relationship with his son: 'Ever since, he has opened up and tells me more. Now he learns from me. But he only speaks to me when he needs something. If I don't ask him anything, he doesn't tell me anything.

(Benjamin, documented, father of one)

Fathers visiting their children for the first time try hard to (re-)establish affectionate relationships by spending time with them and by bringing them luxury gifts. Yet fathers whose limited finances restrict frequent visits cite a continuing emotional distance and contrast this with the close emotional bonds they have with children living with them in the Netherlands.

Undocumented and low-income men cite feelings of sadness about the lack of emotional attachment and feelings of guilt over the separation. They miss spending time with their children, worry that they lack knowledge of their children's welfare, that their children will forget them and that exerting their disciplinary authority will increase the emotional gap between them. As Wilding (2006: 134) argues, 'in some circumstances, a telephone call $\mathrm{r}$ email is simply not sufficient to show care for kin in need'. ICTs also provide few opportunities to fathers when their children go astray or fail to perform well 
in school, which is likely to result in feelings of guilt among the migrant fathers. Anthony, who had not seen his children in 15 years expressed his regrets:

I feel that the connection is not good. There needs to be attachment and fatherly love. Although there is material care, I feel sad sometimes because of the lack of emotional attachment between myself and my children.

(Anthony, undocumented, father of three)

A majority of the less-resourced men expressed the hope of bridging the emotional gap with their children through family reunification in the host or home country in the near future. Yet minor improvements in their legal or economic situation, shame attached to the stigma of 'the failed migrant', and wives' and children's attitudes against return migration delay their actual move back to Ghana, whereas precarious legal and socioeconomic statuses of the men prevent them from meeting the requirements for family reunification in the host country.

\subsection{Intervening in the Care Arrangement}

The marital relationship with the children's mother is identified as an important factor in facilitating or obstructing the migrant father's involvement in transnational childcare (Avila, 2008; Dreby, 2006; Parreñas, 2005a). Left-behind wives play a key role in motivating fathers' contact with their children but strained marital ties and divorce may seriously hinder fathers' involvement in their children's lives. In the matrilineal Akan ethnic group, children 'belong' to the maternal side of the family. In the case of divorce traditional norms ordain that children would stay with their mother's kin group (Takyi \& Gyimah, 2007). However, fathers may claim custody over their children and lay claim to deciding where children reside if they financially support the child (Boni, 2001).

Although public discourse and scholarship on Ghanaian fatherhood suggests that many men ease away from their paternal responsibilities following divorce (Boateng, 1996), I did not find evidence that fathers' childcare responsibilities rested on the migrant men's marital responsibilities. True, migrants with limited financial resources struggled to support multi-local families. But for others their migrant status provided opportunities for fathers to maintain or consolidate relationships with children following divorce by informally claiming custody over the child and moving them from the child's mother to paternal kin. This was usually motivated by concern about lack of adequate paternal guidance, especially for adolescent boys and suspected misuse of remittances by mothers, as Mark's narration below about the decision to move his children from his ex-wife to his mother indicates:

She [children's mother] didn't pay the children's school fees! The children were staying at home. When I heard this, I was very angry. I didn't have my papers, nothing, and I sent all the money I had to her to take care of the children and pay 
for their school fees. One day I asked somebody who was travelling to Ghana to go and check out what was happening to my children. When he returned he told me that the children were staying at home!

(Mark, undocumented, father of two)

Ideally children's move to paternal kin is made in mutual agreement with their mother, but in reality, the decision can be foisted on the mother and the child and meet with resentment, particularly when there has been limited direct contact with the father and his kin group prior to the move. In a few cases teenage sons were transferred to paternal relatives at the time of the father's migration when marital relationships were intact. Usually this decision is motivated by worries about the child's behaviour subject to the 'soft hand' of the mother in the father's absence. Whereas some mothers appreciated the father and his relatives taking the responsibility of caring for teenage sons, others resented the move.

That migrant men were able to realise the move to paternal kin can be explained by the migration context of shifting gender power relationships and global wage inequalities, in which matrilineal norms give way to the childcare preferences of the father. While not particular to the migration context, men's role as long-distance family breadwinners accords them greater decision-making power over their children's care relative to the mother. Men actively use their income-earning position and family inequalities embedded in long-distance migration to exercise power over their children's care arrangement, notably by threatening the mother with the withdrawal of financial support for the children. Such situations can lead to serious transnational family discord.

Men's mobility and access to financial resources strongly influence their ability to intervene in the care arrangement. Visits enable fathers to mobilise care beyond their kin networks. In two interviewee cases, fathers organised paid-care in Ghana. Alternatively, fathers expressed the wish to reunite with their children in the Netherlands in case no reliable caregivers were available, although the preference to keep children in the Ghanaian educational system was more often emphasised. But limited resources restrain men from mobilizing alternative care, as contacts with wide social networks erode over the years. In such cases, teenagers are likely to live without adult supervision and older children are forced to care for younger children. Such care arrangements cause profound worries and ambivalent feelings for migrant fathers in view of their responsibilities for their children's material and emotional support. In one case, the children's precarious care situation in Ghana resulted in serious marital strains, as the undocumented migrant father and his migrant wife quarrelled over the mother's desire to return home to care for her children. While the father shared his wife's emotional worries, he urged her to stay in the Netherlands to help him provide financially for the children back home. 


\subsection{Conclusion}

This chapter has probed Ghanaian migrant men's father practices across borders and their economic and emotional impact on the welfare of the family unit. Fathering practices and attitudes are shaped by gender roles and structural conditions within the host nation-state. This Ghanaian-Netherlands case study confirms earlier findings that the gender stereotype of the breadwinning and disciplinarian father is prevalent in the transnational context (Abrego, 2009; Dreby, 2006; Parreñas, 2008). The men in this study primarily assessed their paternal role in terms of material achievement and prioritised financial support for their families.

Yet, contrary to the narrative of the uncaring and distant migrant father who neglects and fails to care for his stay-behind children's emotional needs (Parreñas, 2008), this chapter argues that Ghanaian fathers emphasise more 'engaged' parenting ideals alongside breadwinning responsibilities. Through face-to-face visits, long-distance communication and interventions in care arrangements, fathers seek to nurture emotional bonds with their children and maintain an active role in their children's emotional development, as documented in recent scholarship on transnational fatherhood (Chereni, 2015; Kilkey, Plomein \& Perron, 2014).

By comparing care practices and attitudes along the axes of legal and socio-economic status, this study challenges the assumption that gender alone determines transnational fathering. Rather, through the intersection of gender roles, legal immigration status and access to financial resources, men steer their fathering across national borders. Emotional distance plagues fathers facing financial constraints or illegal residence in the Netherlands. They are likely to reinforce the traditional gender norm of mothers not fathers being responsible for their children's emotional support.

For undocumented and low-income migrants who are legally and financially incapable of bridging the emotional gulf arising from physical distance, migration becomes a double-edged sword: they celebrate the material benefits of income derived from migration for the enhancement of their children's education, but they question the consequences of their physical absence for their offspring and struggle over the emotional distance that proves difficult to bridge. Their geographical separation that prevents a more loving and caring father figure, compounds the day-to-day struggles of migrant men at the margins of society.

The experiences of these men are contrary to findings among more 'privileged' Ghanaian migrant fathers, for whom structural opportunities open up possibilities to perform a fathering ideal beyond gendered expectations. Migration facilitates a more complete fathering role by providing the economic rewards foundational for building a promising future for their children's education and occupational advance in later life. Online communication devices and regular visits between sending and receiving countries bridges geographical and emotional distance between a father and his children.

At the same time, men's financial and emotional support roles may lead to transnational family discord, since back-and-forth accusations are often triggered by 
father's insufficient remittances or mother's inefficient utilization of the remittances for the children's welfare. Moreover, global wage inequalities and men's role as family breadwinners increases their decision-making power vis-à-vis that of the children's mothers. It may push stay-behind mothers into dependent positions and forced separations from their children. Such findings are in accordance with earlier studies documenting transnational marital conflict and stay-behind women's weakened position (Coe, 2011a; Menjívar \& Agadjanian, 2007).

Above all, this chapter stresses that better life chances for children in the South is not merely an economic concern. Emotional exchange between fathers and children is equally vital. The long-term effects of transnational family life on children and youth staying behind in the origin country are increasingly being questioned. Childhood alienation towards a parent, particularly a son towards his father can lead to deep discontent and anger. In a large-scale study among Ghanaian stay-behind youth, Mazzucato and Cebotari (2017) found evidence that father migration and strained relations between the migrant father and his stay-behind family were associated with low levels of well-being. Moreover, simply 'money-transferring fathers' may imprint a model of migrant fathers as family breadwinners among sons in the origin country, eventually prompting their move to the Global North in adulthood (Castañeda \& Buck, 2011). Long-term second generational effects are specific to the local context and evolution of transnational family patterns in different parts of the globe, requiring future research.

Our research findings demonstrate the centrality of parental care provided by migrant fathers to their stay-behind children, and its impact on the well-being of the children and the fathers themselves. The long-term consequences of inability to maintain emotional connections with children in the origin country deserves wider awareness and attention on the part of family welfare and state immigration agencies in countries of origin and destination. In short, having a positive father role model, who provides material development and emotional comfort for his family, is axiomatic. 


\section{7 \\ Transnational Mothers and the Law: Ghanaian Women's Pathways to Family Reunion and Consequences for Family Life}

A slightly different version of this chapter has been published as: Poeze, M., and V.

Mazzucato (2016). Transnational mothers and the law: Ghanaian women's pathways to family reunion and consequences for family life. In M. Kilkey and E. Palenga-

Möllenbeck (Eds.), Family life in an age of migration and mobility: Global perspectives through the life course (pp. 187-211). Palgrave Macmillan UK. Sections and the table are renumbered in order to fit the thesis format. 



\subsection{Introduction}

Transnational family literature has problematised and theorised spatial family separations when parents migrate and children stay behind in the country of origin, particularly focusing on the gendered nature of transnational parenthood (e.g. Hondagneu-Sotelo \& Avila, 1997; Parreñas, 2001; Zontini 2004). These studies note that despite prolonged separations and emotional difficulties, migrants adopt long-distance caregiving practices that serve to maintain a sense of 'familyhood' across national borders (Bryceson \& Vuorela, 2002). Likewise, it is shown how such changed care practices impact broader family processes around gender roles and care responsibilities. However, transnational family processes are not influenced by individual practices alone; they are impacted by and respond to multiple sets of formal and informal institutions (De Hart, van Rossum \& Sportel, 2013; Kilkey \& Merla, 2014; Levitt \& Glick Schiller, 2004). In most popular European destination countries, migration policies have become increasingly restrictive (OECD, 2011), constraining mobility options within families, as policies determine the rights for TCNs to migrate together as a family unit or to reunite with family members once migrants settle in the destination country.

Within transnational family scholarship, an emerging body of literature focuses on how migration policies impact transnational families and the consequences for family relationships (Bernhard, Landolt \& Goldring, 2009; Bonizzoni, 2009; Fresnoza-Flot, 2009, 2014; Menjívar, 2012). This chapter contributes to this literature by analysing how Dutch migration policies, including encounters with those who apply the policies, shape transnational mobility within Ghanaian families. More concretely, it focuses on Ghanaian migrant mothers' pathways to family reunion with their children in Ghana. We apply a gender-sensitive analysis to disentangle whether and how gender factors into female migrants' experiences with family migration policies and how this shapes family dynamics.

Ghanaian migrants in the Netherlands provide an appropriate case to explore these issues. Large-scale migration from Ghana to destinations in the Global North originated in the 1980s, following changing economic policies and political instability in West Africa (Peil, 1995). Drought in different parts of Ghana, the mass expulsion of Ghanaians from Nigeria, and Structural Adjustment Programmes (SAPs), influenced female migration as men's income-generating activities diminished and women had to find alternative means to acquire household income (Manuh, 1994). Currently, Ghanaians are among the largest West African migrant populations in the Netherlands, with an official registered population of 22,556, of which a little over half are women (CBS, 2018a), and an estimated equal share are undocumented migrants (Mazzucato, 2008a).

In the same period that Ghanaian migration to the Netherlands increased, Dutch family migration policies tightened, reflecting broader trends in Europe and beliefs that family migration is problematic in terms of its magnitude, consequences for integration, abuse of family migration provisions and forced marriages (Kofman et al., 2011). Caarls et al. (2013) found that only 27.7 per cent of Ghanaian parents interviewed in the 
Netherlands and the United Kingdom had reunited with their child or children ten years after they migrated. The high prevalence of Ghanaian transnational families may at least partly be explained by legal barriers to family reunion: of the applications for family reunion with Ghanaian children between 2005 and 2011, approximately 50 per cent were rejected (unpublished figures of the Dutch Immigration and Naturalisation ServiceInformation and Analysis Centre). Our in-depth analysis of family migration and migration policies shows discrepancies between the normative frameworks that underlie family migration policies and female migrants' family lives. Moreover, it shows that restrictive migration policies constrain women's flexibility, a key aspect of Ghanaian family life, and limit agency and shape dependencies within families.

\subsection{Transnational Families, Reunification and Migration Policies}

Recent tightening of migration policies in many countries in the Global North restrict family mobility, intersecting in complex ways with gender, culture, family composition and labour market characteristics (Ní Laoire, Grassi \& Poeze, 2013). Migration policies restrict migration as a family unit and reunification after arrival, thereby perpetuating transnational family configurations (Boehm, 2008; Dreby \& Adkins, 2010). Studies have examined how migration policies, particularly citizenship status, shape transnational caregiving and the experiences of family members, during separation and reunification (Bernhard, Landolt \& Goldring, 2009; Cohen, 2000; Fresnoza-Flot, 2009; Menjívar, 2012). They indicate that undocumented and precarious legal statuses prolong separations, produce uncertainties with regards to family reunion, and shape the means to practise long-distance mothering.

Only few studies include a broader set of laws, notably family migration policies, in understanding the interplay between migration policies and mobility of family members between national borders, revealing the legal barriers and alternative pathways to family reunion and difficulties reconnecting after years of separation (Bonizzoni, 2009; Fresnoza-Flot, 2015). Studies have noted that family migration policies do not serve the interests of all citizens equally; gender, class, and ethnicity are axes along which the right to family life is divided (Kofman, 1999; Kraler, 2010). In case of partner migration, female migrants face more difficulties to meet the income requirement (Kraler, 2010; Leerkes \& Gulu-Glasgow, 2010; Strik, de Hart \& Nissen, 2013), and sponsors have to cope with suspicions from authorities over the nature of the relationship in the case of non-European partners (Fleischer, 2011; Kraler, 2010). Moreover, women's dependent legal status, i.e. residency based on the relationship during the first years, reduces their agency and reinforces tensions and dependencies in the household (Kraler, 2010; Suksomboon, 2011).

Restrictive conditions to family migration (re)define the boundaries between the public and private and the productive and reproductive spheres (Strasser et al., 2009). As Kofman et al. (2011: 13) argue, these conditions 'define the composition of the family 
and restrict its flexibility, frequently reinforce gender inequalities and truncate the cohabitation of generations.' Family migration policies produce certain types of families and constrain the choices for migrants to organise their family lives according to personal preferences (Strasser et al., 2009). At the same time, families may cope with and overcome restrictive family migration policies by mobilising local and transnational support networks (Bonizzoni, 2009; Leerkes \& Gulu-Glasgow, 2010). Studies that address family life and migration policies, however, primarily focus on spousal reunifications and the constructed family dynamics following partner reunification, while few studies focus on migrant parents' encounters with family migration policies and the ways such policies affect transnational family constellations and relationships (see Bonizzoni, 2009; Fresnoza-Flot 2014 for exceptions to this).

Moreover, we know little about the reunification processes of African transnational families. The few studies that analyse migrant parents' pathways to family reunion with their children, focus on South East Asian and Latin American transnational families. In such contexts, mother-child separations are shunned upon, causing feelings of sadness, pain and depression (Bernhard, Landolt \& Goldring, 2009). Although in certain situations reunification may be avoided or postponed, such as preventing children being exposed to the hostile neighbourhoods where many migrants settle and work, generally living together is the preferred option (Fresnoza-Flot, 2015; Hondagneu-Sotelo \& Avila, 1997; Menjívar, 2012).

In contrast, in West African sending countries, mother-child separations are 'normalised' and accepted. In these societies, childcare does not only centre around the birth-parents but involves extended kin and non-kin care networks (Goody, 1982). In the context of long-distance migration, geographical separation between mothers and children is informally institutionalised as a family strategy, providing families devises to cope with challenging circumstances, for children to maintain the cultural identity, and to receive education and care in the home country (Coe, 2008; Whitehouse, 2009). In this chapter, we build on this literature and ask how norms around child raising and tight migration policies link together in Ghanaian mothers' pathways to family reunion, and how these impact on women's family strategies and relationships.

\subsection{Dutch Family Reunification Policies}

In the Netherlands, the relatively liberal attitude towards family reunification since the 1950s, shifted towards a more restrictive one in the early 1990s, after growing concerns over the negative impacts of migration on society. In an attempt to reduce migration and to enable integration of already established immigrants, migration policies were tightened and restrictions were imposed to reduce and control family migration by making a selection before migration (Bonjour, 2009). In the last two decades, multiple measures have been taken to limit the entry of migrants and their family members. 
Important shifts have occurred in Dutch family migration policies over the past decades as to who qualifies for family reunion and under what conditions. Only members of the nuclear family, i.e., spouses and biological and legally adopted children under the age of eighteen who are financially dependent on their parents, are eligible for family reunion. To decrease financial dependency on the state and to increase responsibility of the applicants, income requirements were introduced (Bonjour, 2009; Leerkes \& Gulu-Glasgow, 2011), which has increased to a minimum level of income that excludes those relying on government assistance. Moreover, the income has to be durable and stable, that is, it has to exist for at least one more year from the moment of application. Concurrently, the criteria for proving the family bond have shifted over the years. Until 2006, the 'effective family bond' criterion stipulated that parents had to prove a family bond with their child before and during migration through continued authority and financial provision. Since 2006, all children below the age of eighteen years who are biologically or legally related to the migrant are assumed to hold an effective family bond with their parents (Van Walsum, 2009a). The documents to prove the family bond include birth certificates, parental custody, a letter of consent from the other biological parent if he/she is not a co-applicant, or proof that the other parent is deceased. DNA tests are increasingly used if official documentation does not provide sufficient proof. Finally, family migrants are legally dependent on the relationship with the sponsor for their residence permit. In 2012 this increased from three to five years. If the relationship ends within this period, the family migrant loses her residency and all rights related to it, and is expelled, unless an abusive relationship can be proved.

\subsection{Methodology and Respondent Characteristics}

Data for this chapter come from a larger multi-sited and mixed-method research project that examines transnational family life between Ghana and the Netherlands. This chapter draws from a sub-project conducted between 2010 and 2013 that involved ethnographic research amongst 32 Ghanaian transnational mothers in the Netherlands, 6 of whom were part of a simultaneous matched sample, meaning that the children and caregivers in Ghana were studied over the same research period. Our respondents had experience living separately from all or some of their children, while some also had experience with reunification. The main field location was Bijlmermeer, a suburb of Amsterdam that hosts the largest concentration of Ghanaians in the Netherlands, while eight respondents resided in The Hague. Respondents were contacted using various gateways: making announcements during church services and the community radio, through key persons in the Ghanaian community, using pre-established contacts of one of the researchers, and snowballing. Data were collected through repeated visits with each respondent, including in-depth interviews, non-participant observations and visits to social gatherings, such as weddings, church services and meetings with home-town associations. Regular and long-term contact was maintained through telephone calls. 
Interviews were mostly conducted in English, the respondents' second language, and lasted from one to four hours. They covered a wide array of topics, including respondents' migration history, family life and caregiving arrangements, the process of reunification and support networks. The legal files of those respondents who had applied for reunification were also consulted. Ethnographic data were complemented with interviews with an immigration lawyer and five key persons within the Ghanaian migrant community.

In contrast to men, the wish for family reunion and experiences with family migration policies often emerged in the narratives of women. A difference in interest in reunification between men and women was confirmed by key persons in the Ghanaian migrant community and the migration lawyer. Although some of the issues that we raise may also pertain to men, our focus on women aims to scrutinise their experiences with family migration policies and the consequences for their family lives. The migration and family profiles of the participants are set out in Table 7.1.

\subsection{Encounters with Family Migration Policies}

For Ghanaian mothers, reunification with their children in the Netherlands is not a straightforward process. Five out of the thirty-two women we interviewed had reunited with some but often not all of their children through official reunification programmes, while in two cases the outcomes were pending at the time of study. Three had reunited through unofficial channels, which we will discuss in more detail later. Citizenship status played an important role in determining the timing of family reunion through official reunification programmes, because undocumented migrants and those with a temporary permit are ineligible for family reunion. Of the four women who reunited with their children through the official reunification procedure, three had done so the year after their status was regularised. Marriage with a Dutch or other European denizen or citizen was the most common way for Ghanaian migrant women to obtain a residence permit. Yet lengthy periods of undocumented stay prevented women from applying when children passed the 18 years age limit.

In addition to citizenship status, we identified two key barriers that at least partly explain the low rate of family reunion among Ghanaian women: the income requirement and proving the family bond. 
Chapter 7

Table 7.1. Respondent characteristics (at time of first interview)

\begin{tabular}{|c|c|c|c|c|c|c|}
\hline Name & Migrated parent & $\begin{array}{l}\text { Years } \\
\text { since } \\
\text { leaving } \\
\text { Ghana }\end{array}$ & $\begin{array}{l}\text { Marital } \\
\text { status }\end{array}$ & $\begin{array}{l}\text { Children in } \\
\text { NL }\end{array}$ & $\begin{array}{l}\text { Timing reunification } \\
\text { (years since arrival in } \\
\text { NL) }\end{array}$ & $\begin{array}{l}\text { Channel of family } \\
\text { reunification }\end{array}$ \\
\hline Ama & mother \& father & 19 & married & No & -- & \\
\hline Sophia & mother \& father & 12 & married & Yes & 10 ( 2 children $)$ & $\begin{array}{l}\text { official reunification } \\
\text { procedure }\end{array}$ \\
\hline Abena & mother & 15 & single & No & -- & \\
\hline Candice & mother & 17 & single & No & -- & \\
\hline Joyce & mother & 3 & married & No & 4 ( 3 children) & $\begin{array}{l}\text { official reunification } \\
\text { procedure }\end{array}$ \\
\hline Nicole & mother & 8 & single & Yes & -- & \\
\hline Meredith & mother & 13 & single & No & -- & \\
\hline Ivana & mother & 9 & single & No & -- & \\
\hline Jacqueline & mother \& father & 19 & married & Yes & -- & \\
\hline Esther & mother \& father & 8 & single & Yes & 7 (1 child) & $\begin{array}{l}\text { official reunification } \\
\text { procedure }\end{array}$ \\
\hline Wendy & mother & 3 & married & No & -- & \\
\hline Abigail & mother & 21 & single & No & -- & \\
\hline Vanessa & mother & 17 & single & No & -- & \\
\hline Charlotte & mother & 20 & single & Yes & 15 (1 child) & tourist visa \\
\hline Florence & mother & 13 & married & Yes & -- & \\
\hline Rita & mother & 4 & married & No & -- & \\
\hline Catherina & mother & 21 & single & Yes & 22 (1 child) & student visa \\
\hline Barbara & mother & 16 & single & No & -- & \\
\hline Morisha & mother & 10 & married & No & 9 ( 2 children & official reunification \\
\hline Kate & mother & 24 & single & No & -- & procedure \\
\hline Poomah & mother & 21 & married & Yes & 9 (1 child $)$ & tourist visa \\
\hline Daniella & mother & 2 & single & No & -- & \\
\hline Efua & mother & 20 & single & Yes & -- & \\
\hline Anna & mother & 21 & single & No & -- & \\
\hline Rhoda & mother & 18 & single & Yes & 9 ( 2 children $)$ & tourist visa \\
\hline Dorcas & mother & 11 & married & No & -- & \\
\hline Henrietta & mother \& father & 21 & single & Yes & 8 (1 child) & $\begin{array}{l}\text { official reunification } \\
\text { procedure }\end{array}$ \\
\hline Mary & mother & 6 & single & Yes & -- & \\
\hline Edna & mother & 14 & married & No & -- & \\
\hline Rosemund & mother & 20 & married & Yes & -- & \\
\hline Nana & mother & 6 & single & No & -- & \\
\hline Cecilia & mother & 20 & married & Yes & -- & \\
\hline
\end{tabular}

Source: Own fieldwork, Transnational Child-Raising Arrangements project, Ghanaian parent data, the Netherlands, 20102013.

\subsubsection{The Income Requirement}

Significantly, the income requirement - both the level and stability - is a major impediment for Ghanaian migrant women to reunite with their children and, similar to 
legal status, largely functions as a 'self-selection mechanism', i.e., those who cannot meet the requirement do not apply (Strik, de Hart \& Nissen, 2013). Overall, Ghanaian women in the Netherlands are less likely to be employed compared to men and the native population (Black et al., 2013). Moreover, the women of our study primarily occupied low-skilled labour positions in tertiary sectors, both informal domestic work, babysitting, and catering, and professionalised cleaning work, home-care and nursing in homes for the elderly, jobs that are common for Ghanaian women in the Netherlands (Black et al., 2013). These jobs are generally low-paid, part-time and without (long-term) contracts. While higher-educated women had actively searched for higher-skilled jobs, language problems, difficulties validating diplomas and discrimination hindered mobility in the labour market.

Meeting the income requirement is further complicated by family life-course events, notably pregnancies, births and divorce. Due to the nature of their work, pregnant women are often taken off the work schedule and short-term contracts are not renewed. Work-family reconciliation is further complicated by mothers' limitations to delegate their reproductive responsibilities for Dutch-based children as they lack care support. Fathers of Dutch-born children are often absent when the relationship terminates, or the relationship is never established. Moreover, women lack other forms of formal and informal care support as the night and weekend shifts that are characteristic of domestic and care jobs conflict with regular day-care and school hours, while the costs of other forms of childcare are so high that single women cannot afford them. Concurrently, women lack the extensive care networks they relied on in Ghana, as parents and other extended kin are ineligible for family reunification. Whereas other studies have shown that local support networks allow migrant mothers' engagement in paid labour (Ryan, 2007), we found that for the Ghanaian mothers, local informal networks were generally weak and in most cases only allowed for sporadic care support. These circumstances limit women's gendered 'work-care strategies' (Wong, 2014) that allow work schedules to be organised around the care for children, and hamper women's ability to adjust their labour market activities to fit the income requirement.

The family situation plays a key role in determining if women can meet the income requirement. Esther was the only single mother with young children in the Netherlands for whom the income requirement was no barrier at the time she wished to reunite with her daughter. Her local support networks were of paramount importance; a neighbour took care of her two children while she left for work early in the morning and her manager at the job agency offered her a long-term contract after she informed her about her family situation. However, more often, women who comply with the income requirement are in a relationship in which either the partner has full-time and stable income or in which partners combine income and share domestic and care responsibilities. As such, the income requirement not only disadvantages women, particularly single mothers who have children in both countries, but it also reduces women's autonomy and produces dependencies on employers and partners. As will be elaborated below, dependency on the partner can place women in vulnerable positions. 


\subsubsection{Proving the Family Bond}

While common concerns of family reunification procedures are that they tend to be highly bureaucratic and lengthy (Bonizzoni, 2009), we found that this particularly applied to proving the family bond. The women of our study experienced a lack of information, feelings of arbitrariness in outcomes, and suspicion from immigration officials about the 'genuineness' of the family bond, similar to what is found among reunification procedures for spouses (Kraler, 2010).

Until 2004, the Dutch Consulate in Accra applied a strict verification policy (Mazzucato, 2008a), which resulted in mothers experiencing 'administrative suspicions' (Strasser et al., 2009) with regards to the authenticity of birth certificates. Until recently, births in Ghana were often not registered, especially in rural areas, and obtaining the right names and dates on the documents proved difficult, as Ghanaians usually have multiple names and different regulations in regard to when new-borns should be officially registered. Mothers experienced a lack of understanding from immigration officials about these cultural practices, causing significant delays in the reunification procedure.

Suspicions were further experienced with verification mechanisms adopted to check the factual information on the birth certificate. The Dutch Embassy in Accra sent detectives to hometowns to establish if there was a family bond between the mother and her child (Mazzucato, 2008a). A different answer from just one person, usually someone unknown to the mother, was reason enough to jeopardise the reunification procedure, as Efua explained about her case:

One day a person from the Embassy visited the house of my children, who were living with my sister and mother, to ask about my children. My mother said, 'these are the children of Efua'. [...] Everybody said, 'Peter and Mary's mother is in Europe'. They met one girl, the maidservant of my sister. I didn't know her and she didn't know me. And the girl said that my son was the son of my sister. [...] In Ghana, when children live with your sister, all the children will call her 'mama'.

(Efua, mother of four)

These 'inconsistent' answers and the lack of understanding of cultural practices around caregiving caused suspicions among immigration officials. Mothers actively sought means to prove that they were the biological mothers of their children. For instance, Efua provided a letter from the family of the children's deceased father stating that she was the children's mother. Moreover, at the time when these verification mechanisms were still in place, mothers sometimes resorted to informing family members back home of the 'right answers' to prevent suspicions. At the same time, mothers had to cope with corruption, as detectives could demand bribes and high fees to make sure that the right answers were reported (Mazzucato, 2008a).

The consequent delays to family reunion often interact with other criteria that further delay or prevent family reunion altogether. For example, by the time Efua was able to 
disprove the suspicions, her relationship had ended. Unemployed and solely responsible for the care of her two Dutch-born children, as her ex-husband withdrew from all his parental responsibilities, she was unable to meet the income requirement. Moreover, prior to 2006, time was an obstacle to prove the 'effective family bond', as the longer the separation, the more difficult it was to prove that the parent maintained 'effective custody' over the child (Van Walsum, 2009a). From 2002 to 2006, the criterion included a maximum separation of five years. After these five years, children were expected to be rooted in the country of origin, and the family bond was considered to be broken. These time constraints caused significant hurdles to family reunion, as women faced difficulties in obtaining legal residency and meeting the income requirement within this period.

Cases after 2006 attest to moralising ideals of mothering that creep into the assessment of immigration officials in particular cases, including ideals of family proximity, intensive mothering and the age at which a woman gives birth to her child. From a relationship with an undocumented Ghanaian migrant, Esther, undocumented herself, got pregnant and gave birth to a girl in the Netherlands. To prevent her daughter from growing up in illegality, and to sort out her own life, she decided that it was best to send her child to her parents in Ghana. Seven years later, shortly after Esther married a Dutch resident and obtained residency, she started the procedure to reunite with her daughter. In her encounter with the immigration official, Esther experienced suspicions, because: 'the woman [immigrant official] could not believe that a mother would send her child to another country'. In another case, Evelyn was informed by her lawyer that her application would likely be rejected. Because she had legal residency and a stable job for many years, she would not have a 'good reason' to account why she had waited so long to reunite with her daughter. According to the migration lawyer we interviewed, in recent years, parents have to prove 'enough' family life, such as financial provision, authority and contact, to be eligible for reunification, which suggests that parents still have to prove some kind of 'effective family bond'. At the same time, by applying Western notions of proximate and intensive mothering, immigration officials do not take into consideration mothering ideals that may favour mother-child separation for the betterment of the family or that migrant mothers have to adapt their family life and childcare practices as a result of their living and working conditions.

\subsection{Consequences for Family Strategies and Relationship Dynamics}

Restrictions to reunification and complex and lengthy procedures, prolong separations and cause stress in the personal and relational realms (Bonizzoni, 2009; Leerkes \& KuluGlasgow, 2011). Moreover, it creates inequalities and conflicts within families that nonmigrant families do not have to address. Restrictive family migration policies take away the flexibility that allow Ghanaian mothers to practise their motherhood ideals and act upon circumstances to maintain their families. Moreover, the conditions for family reunion produce inequalities in Ghanaian female migrants' family relationships. 


\subsubsection{Family Strategies and the Timing of Reunion}

For Ghanaian mothers, geographical proximity to their child is not the best option per se. The Ghanaian women had all migrated to seek economic betterment for their children and extended kin, while some women had additional motives, for instance, to (re)establish intimate spousal relationships or to escape situations of domestic violence. The primary motivation to migrate for economic reasons reflects both women's limited opportunities in Ghana as well as the 'working mother ideal' that characterises Akan women in Ghana (Clark, 1999). In this matrilineal kinship group, motherhood is primarily valued in terms of a woman's ability to provide economic support to her children.

In Ghana, family ideals are inclusive and fluid: parenthood and childcare do not solely centre around biological parents, as extended kin also play a pivotal role in nurturing and caring for children (Clark, 1999; Goody, 1982). For different reasons, including mothers' engagement in income-generating activities, children are cared for mostly by female kin and oftentimes transferred between natal and non-natal homes, a practice referred to as child-fostering. This 'culturally sanctioned practice' (Adepoju, 2005) and norms of inclusive mothering mean that mother-child separations are not frowned upon but considered a necessary condition for the betterment of the family.

While the women of our study commonly argued that ideally 'every child should live with his or her mother', they also reasoned that there were situations and circumstances that asked for alternative care arrangements, which did not necessarily relate to international migration. Hence, for the women of our study, separation from their children had often already occurred prior to migration; some mothers sent their children to live with kin when they moved to seek economic betterment elsewhere in Ghana or to finish their education, while others shared the household with extended kin who performed domestic and care tasks while the mothers were working.

Against the backdrop of these child raising norms, mothers did not always express the wish to live within a geographically proximate distance to their children. Instead, their geographical and temporal family trajectories largely depended on their working and living circumstances and their children's living circumstances and phase in the life course. The case of Wendy is exemplary. While still in Ghana, Wendy, a highly educated single mother, left her six-month-old child with her mother so that she could focus on her full-time job. A year later, she moved to the Netherlands on a one-year student visa, leaving her son in the care of her mother. In the Netherlands, Wendy married a documented Ghanaian man, obtained residency, and gave birth to a son. When asked why she had not brought her son from Ghana in the meantime, as she could meet all legal requirements, she argued:

I thought about bringing my son, and I still think about it. [...] But I do not feel comfortable with the Dutch educational system. And also because of the language. And also, I don't want to depend on a man, to have him support my children and myself. [...] The best option is for him to stay with my mother at this 
moment. I am also comfortable with him staying with my mother. I want the best for him. And sometimes I think: will I be as good to care for him as my mother?

(Wendy, mother of two)

Wendy's quote illustrates important considerations concerning women's family strategies and timing of reunification. Firstly, women hesitated to bring children beyond their infant years, worried about integration and educational difficulties due to differences in educational systems, societal values, and language. Accordingly, women sometimes preferred to postpone reunion until children had finished their Secondary High School (SHS) in Ghana, so that upon reunion children could enrol in Englishtaught programmes at a university. Second, transnational child-raising arrangements allow women to earn and control an independent income, which are important aspects for mothers and wives in Ghana and serve the interest of the child in matrilineal lineages (Clark, 1999). Delaying family reunion to secure income or legal residency was often reflected in statements such as, 'I first have to organise my own life'. Third, Wendy's quote illustrates the acceptance of kin and non-kin taking care of children and the absence of guilt and shame about not being physically present to raise their children, contrary to what has been noted for transnational mothers elsewhere (Bernhard, Landolt \& Goldring, 2009; Parreñas, 2001). As Olwig (2012: 934) argues for the Caribbean, family separation in such contexts does not result in self-presentations of the 'impoverished mother' but rather of a 'responsible mother who acts in the best interest of the child, as well as of the rest of the family, by taking advantage of the opportunities that presented themselves'.

While care networks in Ghana provide necessary social capital for mothers to cope with separation, criteria for reunification, notably proving the family bond, takes away flexibility in raising children and condition caregiving choices. The need for reunification may arise in case of fears regarding teenage behaviour in the care of grandparents, lack of intimacy among mothers and children in case of lengthy separations and the lack of face-to-face contact and 'care crisis', e.g. death, illness, mistrust, or incapacity. Yet, after many years of separation, they may no longer be eligible for family reunion. Moreover, the eighteen-year age limit may force women to reunite with children before they finish SHS in Ghana. ${ }^{39}$ Some mothers deliberately delayed the application process, like Morisha, who applied for reunification a day before her daughter turned eighteen so she could finish SHS. Reuniting with children before they completed SHS to meet the age requirement was often met with frustration, as was the case of Sophia and her two daughters. Sophia complained that while her daughters' friends attended university in Ghana, her daughters had to start at the lowest educational level in the Netherlands due to language problems. Accordingly, she decided to leave her youngest daughter in Ghana until she finishes SHS.

${ }^{39}$ In Ghana, most students complete their secondary education between the ages of 17 and 20. 


\subsubsection{Dependencies and Limited Autonomy}

In the realm of family migration, dependencies on the partner are produced. For Ghanaian migrant mothers in the Netherlands, a legal relationship ${ }^{40}$ with a Dutch or other European citizen or denizen is crucial to reunite with children, as it is the primary means to obtain residency and the right to reunification. While some women entered into a transnational marriage after which they moved to the Netherlands, more often, they married in the Netherlands where they stayed without residency. The condition of legal dependency makes women dependent on their relationships for their residence permits and on their partners' consent to family reunion with children during the first years. Dependencies may be prolonged, as women largely depend on their partners to meet the income requirement for family reunion, as we discussed earlier.

In women's daily lives, dependencies are manifested in reduced autonomy that coerces women to accept their partners' behaviour and limits their possibilities to escape from abusive relationships. Nicole's case is illustrative. Shortly after Nicole came to the Netherlands - on the basis of family formation - the relationship with her husband deteriorated; he controlled her whereabouts and cheated on her. Nicole never raised complaints and endured his behaviour, worried that her partner would terminate the relationship and she would lose her residency and chance to reunite with her daughter. When Nicole filed for reunification, her husband failed to consent and ended the relationship four years after she arrived in the Netherlands. Nicole obtained residency and started a relationship with a Ghanaian man with whom she would have two children. Nicole explained why she never asked her new boyfriend to assist with the reunification procedure:

I already had a bad experience one time. I didn't want that to happen again. I didn't want to depend on a man again, that he would tell me in the middle of the process, 'I will not do it'. Because he knows, this woman depends on me, so I can do whatever I like to her. With my former partner, I knew that if he would stop the process, I wouldn't be able to bring my daughter here.

(Nicole, mother of three)

Efua, who also came to the Netherlands on the basis of family formation, related the abuse by her husband to the dependency on him for her residency and wish for reunification with her children:

When I came here, I wanted to be a hairdresser like I was in Ghana, but my husband said no. He said no to everything. I had to stay inside, and I had a lot of stress. I also experienced physical abuse. Everything happened because I was completely dependent on him. [...] When we spoke about my papers [residence permit], he beat me until I was bleeding. [...] That relationship was not good at

\footnotetext{
${ }^{40}$ Until 2012, it was possible to obtain a Dutch residence permit on the basis of a legally recognised relationship. Since 2012, this has narrowed to marital relationships.
} 
all, because I wanted to bring my children to Europe. That man really punished me for that.

(Efua, mother of four)

Especially for women who are confronted with strained care arrangements, the decision to enter into a dependent relationship, stay in an abusive one or to escape with the possibility of losing the right to family reunion is complicated; each choice intensifies suffering, more so in case of domestic violence. Moreover, the need for reunification in concert with the dependencies provide ground for financial exploitation. Joyce narrated that her partner forced her to pay 7,500 dollar (\$) before he helped her reunite with her children, on top of the $\$ 9,000$ she had already paid him for their 'paper marriage'.

While male and female migrants without children in the home country are confronted with limited autonomy due to legal dependencies (Kraler, 2010; Strasser et al., 2009), having children in the home country may exacerbate and prolong women's suffering. These effects seem particularly pronounced for women compared to men; women more often cited the wish to reunite with their children and they are generally more prone to situations of emotional and physical abuse.

\subsubsection{Coping with Restrictions to Reunification}

Legal barriers to reunification shape the everyday lived experiences of family members 'here and there' and women's strategies to cope with or overcome separation. Ghanaian mothers' efforts to reunite with their children often coincided with family life changes, e.g. marriage and pregnancies, in the Netherlands. While bearing children in the host country and establishing 'duplicate families' (Horton, 2009) is a way of coping with the separation from children, it often creates jealousy among children who stay behind (Schmalzbauer, 2004), and guilt among mothers for unequal devotion of attention. This is especially the case when separations are lengthy, and when some children are reunited while others are no longer eligible for reunification due to their age. Mothers regularly expressed the emotional hardships of having to cope with jealousy among children as well as accusations that continued separation indicates a loss of commitment or motherly love. Coping with children's responses is complicated, as children may not always understand their mothers' problems with the law. Barbara, whose application for reunion with her three children was rejected as the investigation at the Dutch Embassy raised doubts over the family bond, lamented:

If you stay in one place and your children are in Ghana and time passes by, your children will never feel mother love for you. Never! And they compare: mama, this woman invites their children to come with them, they take their children with them, why not you? They think I'm useless! Or they think: my mother doesn't want to take me. But I try my best.

(Barbara, mother of two) 
One mother narrated that the absence of her eldest son in Ghana also had its impact on her children in the Netherlands, as 'the children here don't get everything of me'. She explained that every occasion they spend time together as a family, she feels sad because her son is not there. Complaints of degrading health, including depression, recurring headaches, sleeping problems, and, in two cases, heavy drinking, were also related to ineligibility for reunification, often compounded by care crises in Ghana.

To maintain the maternal role and to cope with resentment from children back home, mothers relied on material compensation and regular phone calls. In contrast to the Filipino mothers discussed by Madianou (2016), the use of information and communication technologies (ICTs) in mothering from a distance was limited to mobile phone devices, which were appreciated for their relatively low cost and spontaneity in communication. Poor internet access in Ghana (both reception and costs) posed a barrier to the use of other technologies, as did the fact that many older children left behind in Ghana stay in boarding schools where they are not allowed access to ICTs. Visits home were also viewed as an important transnational mothering practice, but undocumented status, limited financial resources, care for young children in the Netherlands, and fears of losing one's job impeded regular visits home. Likewise, those in the reunification process often postponed visits to save money for the visa fees and plane tickets for their children or waited for their lawyers to give them the green light to arrange the paperwork back home. These procedures, however, could linger for many years.

Furthermore, while regular visits ease the pain of separation, irregular visits aggravate the emotional pain of continued separation. In tears, Nicole explained about the departure at the end of her first visit to her daughter in seven years:

She made me cry. I asked her to come to the airport to see me off. I was there for six weeks. And at the airport, she was crying. She had in her mind that her mother had been away for seven years, and now that she had been here, she was going to leave her again. She thought: when is my mother coming back to take me?

(Nicole, mother of three)

Migrants often circumvent restrictive family migration policies and reestablish family life by unofficial or de facto reunification (Boehm, 2008; Bonizzoni, 2009; Fonseca \& Ormond, 2008). Unable to reunite with children through formal reunification procedures or to have children complete SHS before reunion, three Ghanaian mothers brought young adult children on a tourist visa, whereas two others tried but were unsuccessful; in most European countries, visits are restricted due to fears that family members will settle in the destination country (Kofman, 2004). Alternatively, one mother reunited with her daughter by arranging a student visa. Yet, alternative routes to reunion have a great impact on the post-reunification process, as others have also noted (Fresnoza-Flot, 2015). Especially children who are brought on tourist visas have to cope with insecure living conditions in the Netherlands and potential apprehension and 
deportation, as was the case for two children in this study. The difficulties in bringing children on tourist visas, the related risks, and the acceptance of mother-child separations in case of reliable care networks, may explain why informal reunification routes for minor children were rare, in contrast to what has been found among other migrant groups (Bonizzoni, 2009; Fresnoza-Flot, 2015). At the same time, mothers' reliance on alternative strategies to reunite with children emphasises the narrowness of opportunities afforded within the system of family migration policies.

\subsection{Conclusion}

In this chapter, we explained mobility and immobility in families between Ghana and the Netherlands by focussing on pathways to family reunion and the role of migration policies. We have demonstrated that for Ghanaian women in the Netherlands, residency does not guarantee choice in the geographical and temporal trajectories of their family lives. We identified the income requirement as a central obstacle to family reunion, particularly disadvantaging women as a result of the complex intersection of gendered care responsibilities, family composition, labour market characteristics and the absence of localised support networks. In this way, family migration policies are socially selective (Kraler \& Kofman, 2009); women's options for family reunion are limited, especially for single mothers whose reproductive labour is unacknowledged. Moreover, we have indicated that Ghanaian women are confronted with suspicions of the mother-child bond, administrative obstacles, a lack of understanding of cultural practices and normative frameworks of what constitutes 'good mothering' practices.

Not only do family migration policies operate in gendered ways, they also contribute to the construction of gendered family trajectories and permeate the relationships and everyday family realities of migrant mothers, spanning both home and destination countries. We showed that Ghanaian migrant mothers may avoid reunification if they have a care network available, without feeling guilty about the geographical separation from their children. Child raising norms that include extended kin and non-kin networks mitigate some of the negative impacts that migration may have on family life. Moreover, the low rate of reunification among Ghanaians in the Netherlands (Caarls et al., 2013), is not necessarily a result of restrictive migration policies, but can also be explained by child raising norms.

However, the legal restrictions to family reunion pose barriers for Ghanaian women to act upon changing circumstances in the care arrangement and condition mothers' flexibility in raising children. Our findings highlight that this does not only pertain to mother-child relationships, but also to partner relationships as the conditions on family reunion produce multiple dependencies within the household and reduce women's agency vis-à-vis their partners. At the same time, it should be noted that Ghanaian support networks are changing; reliance on extended families for child support is diminishing due to trends towards individualism (Marie, 1997) and the growing 
importance of the nuclear family advocated by the Pentecostal Church both in and outside of Ghana (Coe, 2008; Van Dijk, 2002b). This may have important consequences for the coping strategies of Ghanaian migrant women in the future, even more in the light of continued restrictions on migration in most popular destination countries. 


\section{8}

\section{Navigating Transnational Childcare Relationships: Migrant Parents and their Children's Caregivers in the Origin Country}

A slightly different version of this chapter has been published as: Poeze, M., Dankyi, E. K., and Mazzucato, V. (2017). Navigating transnational childcare relationships: migrant parents and their children's caregivers in the origin country. Global Networks, 17: 111-129. doi:10.1111/glob.12135. Sections and the table are re-numbered in order to fit the thesis format. 



\subsection{Introduction}

The literature on transnational families has shifted the perspective of the family as a bounded geographical unit to family as a social unit that can be maintained across distance and national boundaries (Bryceson \& Vuorela, 2002; Zontini, 2004). Despite the emotional suffering that results from geographical separation, family members can live 'apart-together' (Baldassar, 2007; Mazzucato \& Schans, 2011) through transnational family practices such as long-distance communication, return visits and the sending of money. While transnational family literature analyses daily transnational family interactions that keep families functioning across geographical distance (e.g. Bryceson \& Vuorela, 2002; Baldassar, 2007; Zontini, 2004), to our knowledge, no studies have investigated the day-to-day care work from the perspectives of those who migrate and those who stay behind simultaneously. This study employed the Simultaneous Matched Sample Methodology (SMS) (Mazzucato, 2009a), allowing us to give equal attention to both migrants and non-migrants. This approach enabled us to investigate from both perspectives, the day-to-day care work, and to do so in 'real time', rather than based on recall. The data collected simultaneously from both actors provide insights into the multi-actor performance of care. Furthermore, by comparing contrasting accounts of care within the same transnational family, we understand the multiple perspectives on care work that are influenced by where one is situated, socially and geographically, in the transnational family. We draw on di Leonardo's (1987) seminal work on kin work. While transnational care relationships are often embedded within tacit family practices, these relationships need to be 'worked at'. The concept of kin work allows us to focus on the work that is involved in 'doing' family across national boundaries.

Empirically, we focus on relationships between Ghanaian migrant parents in The Netherland and their children's caregivers in Ghana, who are not the children's biological parents, but who part of the extended family network. These caregivers perform the proximate care tasks for children when parents and children live separated across borders. Caregivers can be grandmothers, grandfathers, aunts, uncles, or cousins of the children they care for, and in some cases, they can also comprise non-kin members such as teachers, pastors or friends. While transnational families are broadly conceptualised to include 'both nuclear and extended family types whose members are actively engaged in family survival and maintenance' (Baldassar \& Merla, 2014: 12), scholarly work has focused primarily on the ways in which relationships are sustained in nuclear family units: children, parents and spouses and at times elderly parents. The dynamics and practices involved in creating care arrangements in extended care networks and maintaining relationships between migrant parents and caregivers has been given scant attention in transnational family literature (Mazzucato \& Schans, 2011), or if it is signalled as important, it is not the focus of analysis (Hondagneu-Sotelo \& Avila, 1997; Schmalzbauer, 2004). Yet such relationships are important in affecting the functioning of transnational families and how the different members involved 
experience living apart. Furthermore, studying such relationships contributes to our understanding of how transnationalism shapes family relations and organization.

Our study reveals how finances and communication are carefully managed by migrant parents and caregivers alike to maintain mutually trusting relationships across borders. While much of the literature on transnational families focuses on the emotional toll on parents and children (e.g., Bernhard, Goldring \& Landolt, 2005; Pribilsky, 2001), we focus on the family strategies to make long-distance childcare relationships work and how the different actors in different localities respond to problems they encounter. While acknowledging the challenging nature of transnational childcare arrangements, our study among migrant parents in the Netherlands and caregivers in Ghana reveals that these actors have adopted creative practices to navigate relationships across distance.

\subsection{Doing Kin Work in Transnational Families: A Review of the Literature}

The burgeoning literature on transnational families emphasises migrants' and nonmigrants' contributions to the maintenance of family life across borders through their interconnected productive and reproductive work. Reproductive work includes both caring work that refers to the care for family members and kin work that refers to the ways kinship relationships and mutual obligations are kept alive (di Leonardo, 1987; Zontini, 2004). We focus on kin work to understand how relationships within extended transnational family networks of care are created and maintained, which are necessary to perform the productive and caring work the different actors engage in.

Di Leonardo (1987) introduced and defined the concept of kin work as 'the conception, maintenance, and ritual celebration of cross household kin ties' (p. 442). The notion of kin work as a verb emphasises that kinship does not automatically result from 'being' kin, but is actively created through everyday family practices that requires 'time, intention, and skill' (di Leonardo, 1987: 443). In a transnational context, where family life is enacted without continued face-to-face contact, there is a need for explicit and deliberate actions to overcome geographical distance. Consequently, kin work has to be re-organised. Bryceson and Vuorela (2002) introduced the concept of 'relativizing', which applies the notion of kin work to the transnational context. They emphasise that the construction of family within a transnational space is more deliberate as it cannot rely on continuous face-to-face contact and the taken for granted everyday interactions.

Transnational family studies generally concentrate on how family relationships are sustained within nuclear families, notably between migrant parents and their children who stay behind in the country of origin (e.g., Hondagneu-Sotelo \& Avila, 1997; Hoang \& Yeoh, 2012; Parreñas, 2005a; Schmalzbauer, 2004), and to a lesser extent the caregiving relationships between migrant children and their elderly parents in the home country (e.g., Baldassar, 2007; Baldock, 2000; King et al., 2014) and spousal relationships 
(e.g., Mahler, 2001; Menjívar \& Agadjanian, 2007; Pribilsky, 2004). Such studies point to the diverse ways in which family members maintain a feeling of co-presence through long-distance communication, such as telephone calls, text messages, letters, and the sending of remittances and photos, and visits (Baldassar, 2007; Mason, 2004; Parreñas, 2005a; Zontini, 2004). New information and communication technologies (ICTs), particularly mobile phones (Vertovec, 2004) and Internet (Madianou, 2012; Wilding, 2006), have increased the possibilities for migrants and non-migrants to engage in each other's lives, facilitating the active re-creation of family ties and emotional bonds across borders (Baldassar, 2007).

Yet while technologies and travel have facilitated the maintenance of transnational family relationships, asymmetries characterise kin-work across borders. A family member's place in the transnational field, both geographically and socially, has consequences for access to transnational mobility, resources and communication. Geographical distance may create and exacerbate power dynamics, conflicts and inequalities, and shift power balances (Dreby \& Adkins, 2010).

Studies that take into account transnational care relationships within extended family networks do so by either taking the perspective of migrant parents (Bernhard et al., 2005; Coe, 2008; Hondagneu-Sotelo \& Avila, 1997; Parreñas, 2005a), or the perspective of children (Dreby, 2007; Poeze \& Mazzucato, 2014). The few studies on caregivers, mostly grandmothers (Moran-Taylor, 2008; Yarris, 2012) and other kin and non-kin (Dankyi, 2014; Dreby, 2010) highlight that kinship care is key to family survival in the context of transnational migration. Extended kin and non-kin caregivers in the origin country are important for filling care deficits left by the migrant, especially following maternal migration (Dreby, 2010; Leinaweaver, 2010; Parreñas, 2005a). Caregivers perform hands-on domestic and care tasks, provide financial and emotional support, and help children to understand their parents' absence (Dankyi, 2014; Dreby, 2010; MoranTaylor, 2008; Yarris, 2012). Caregivers' central and mediating roles in transnational families are captured in references to terms as 'other mothers' (Schmalzbauer, 2004), 'middle-women' (Dreby, 2010) and 'indirect mothering' (Fresnoza-Flot, 2009). At the same time, studies emphasise the emotional stress resulting from separation. Migrant parents grow concerned over the use of finances, abuse and neglect of children, authority and decision-making power, and loss of maternal status (Åkesson, Carling \& Drothbohm, 2012; Bernhard et al., 2005; Dreby, 2010; Hondagneu-Sotelo \& Avila, 1997; Moran-Taylor, 2008), while caregivers worry over insufficient remittances, protracted care arrangements, and difficulties to maintain control over children (Dankyi, 2014; Dreby, 2010; Moran-Taylor, 2008).

The above-mentioned studies focus primarily on the effects of transnational family care on the different members involved. However, they are either focused on one side of the family or they conduct research in two sites in a sequential manner, which misses many of the small day-to-day interactions that together constitute how people work at creating and maintaining networks of care (Mazzucato, 2009a). Hence, to date we know little about the considerations that go into selecting a caregiver and accepting the care 
role (but see Dreby, 2010; Winters, 2014), and the day-to-day strategies that migrant parents and caregivers develop to maintain trust and reciprocity that are at the basis of informal arrangements of care. In this paper, we explore the mechanisms used to generate and reinforce trust and how tensions are negotiated to sustain extended family care networks across national borders, by focusing on the everyday interactions and practices of migrant parents and caregivers through a simultaneous matched sample methodology.

\subsection{A Simultaneous Matched Sample Methodology and Respondent Characteristics}

The transnational context poses challenges for researchers, because it is difficult to study relationships when people are located in two or more localities. There is the risk that research either lacks depth - when one researcher has to split her time between multiple contexts in a multi-sited research design_or breadth — when only one side of the transnational family network is studied (Mazzucato, 2009a). To overcome this, we adopted a Simultaneous Matched Sample (SMS) methodology (Mazzucato, 2009a). This methodology allows for simultaneous ethnographic research among different members of the same transnational family in their respective locations by two or more researchers. For our study, two researchers simultaneously studied 11 families ${ }^{41}$ in which pairs of Ghanaian migrant parents in the Netherlands and their children's extended kin and nonkin caregivers in Ghana were followed. To our knowledge, this is one of the few studies employing this approach, which gives equal importance to each side of the transnational relationship.

The SMS methodology allowed us to examine interpersonal processes since it captures simultaneity in space and time. By being present in both sites simultaneously, we gained insight into the everyday practices, often tacit, that are difficult to recount in an interview based on recall information (Mazzucato, 2009a). We could observe how a single event was experienced on both sites and how migrant parents and caregivers responded to each other's actions. Moreover, our teamwork and the continuous sharing and discussion of interview data and the exchange of field visits gave each researcher insight into what happened on the other side and to follow up when necessary. This helped us identify and analyse important relationship dynamics and discrepancies in information (Poeze \& Dankyi, 2013).

At the same time, our methodology raises ethical issues of confidentiality as we come to know information that other family members may not know about. We responded to this by guaranteeing confidentiality to our respondents and making sure that we did not divulge information from one side to the other side of the family. We were also careful

\footnotetext{
41 The complete matched sample includes 15 pairs. In four families, the caregiver was the children's mother (3) and the child's sibling (1), which for the purpose of this paper were not included in our analysis.
} 
in our reporting on the families to not disclose information that could damage mutual trust within the family (Poeze \& Dankyi, 2013).

Fieldwork was conducted between mid-2011 and mid-2013. We began our search for matched samples in Amsterdam where a large percentage of the Ghanaian community in the Netherlands resides. Respondents were contacted through various ways: making announcements on community radio stations, in churches, and through the networks of key informants and Ghanaian interviewers who had previously been involved in the larger Transnational Child-Raising Arrangements-project. We selected families of which the caregiver resided in the Ashanti and Greater Accra regions in order to make it practical for the Ghana-based researcher to visit people with frequent regularity. These regions account for about half of all Ghanaian international migrants (GSS, 2012).

Table 8.1 shows the main characteristics of the matched sample. All but one of our matched sample respondents belong to the Akan (8) or the Ga (2) ethnic groups. The data were gathered through multiple qualitative interviews, observations during the interviews and on social visits, and regular phone calls. Interviews in the Netherlands were mainly conducted in English, whereas the interviews in Ghana were mainly conducted in Twi and later translated into English.

Our sample allowed us to investigate dynamics within care relationships. Despite a couple of refusals due to time constraints of the respondents, we are confident that we have a wide range of transnational care experiences due to: the variety of gateways through which we accessed respondents; the fact that characteristics could be checked against the wider survey of 300 migrant parents conducted for the TCRA project; and our supplementary data from a non-matched sample of 27 Ghanaian migrant parents in the Netherlands and 19 caregivers in Ghana who were part of extended family care networks. Of the total 57 families, 11 had a father who migrated, 32 a mother who migrated, and 14 had both father and mother who migrated. Thirty-six families had a grandmother (the majority maternal), 17 other kin and 5 non-kin as the caregiver. ${ }^{42}$ The majority of other kin caregivers were the mother's sister, and to a lesser extent more distant maternal kin and paternal close and distant kin. We selected migrant parents and caregivers who varied in terms of sex, age of children, and legal and socio-economic status to capture variety in migrant and caregiver types.

42 One family had two caregivers. 
Table 8.1. Main characteristics respondents: Migrant parents in the Netherlands and caregivers in Ghana ${ }^{1}$

\begin{tabular}{|c|c|c|c|c|c|c|c|c|}
\hline Migrant & $\begin{array}{l}\text { Transnationa } \\
\text { family type }\end{array}$ & $\begin{array}{l}\text { Yyears } \\
\text { abroad }\end{array}$ & $\begin{array}{l}\text { Documented } \\
\text { status }\end{array}$ & $\begin{array}{l}\text { Profession } \\
\text { migrant }\end{array}$ & Caregiver & $\begin{array}{l}\text { Relationship } \\
\text { to migrant } \\
\text { child }\end{array}$ & $\begin{array}{l}\text { Age and } \\
\text { sex of } \\
\text { migrant's } \\
\text { children in } \\
\text { care of } \\
\text { caregiver }\end{array}$ & $\begin{array}{l}\text { Profession } \\
\text { caregiver }\end{array}$ \\
\hline Miles & father-away & 21 & documented & $\begin{array}{l}\text { factory } \\
\text { worker }\end{array}$ & Daniel & $\begin{array}{l}\text { father's } \\
\text { nephew }\end{array}$ & $19 \mathrm{M}$ & fabricator \\
\hline Ernest & father-away & 15 & undocumented & cleaner & Richard & $\begin{array}{l}\text { father's } \\
\text { brother in lav }\end{array}$ & $\begin{array}{l}18 \mathrm{M} \\
15 \mathrm{M}\end{array}$ & car sprayer \\
\hline Benjamin & father-away & 12 & documented & $\begin{array}{l}\text { factory } \\
\text { worker }\end{array}$ & Mami & $\begin{array}{l}\text { father's } \\
\text { mother }\end{array}$ & $13 \mathrm{M}$ & unemployed \\
\hline Kofi & $\begin{array}{l}\text { father \& } \\
\text { mother-away }\end{array}$ & 3 & documented & priest & Agyeiwaa & $\begin{array}{l}\text { mother's } \\
\text { mother }\end{array}$ & $\begin{array}{c}19 \mathrm{M} ; \\
13 \mathrm{~F}\end{array}$ & unemployed \\
\hline Prince & $\begin{array}{l}\text { father \& } \\
\text { mother-away }\end{array}$ & 8 & undocumented & dishwasher & Felicia & $\begin{array}{l}\text { mother's } \\
\text { sister }\end{array}$ & $\begin{array}{l}19 \mathrm{~F} ; \\
17 \mathrm{~F} ; \\
14 \mathrm{M}\end{array}$ & unemployed \\
\hline Kwaku & $\begin{array}{l}\text { father \& } \\
\text { mother-away }\end{array}$ & 17 & documented & administrator & $\begin{array}{l}\text { Rosemund } \\
\text { Victoria }\end{array}$ & $\begin{array}{l}\text { father's } \\
\text { mother } \\
\text { non-kin }\end{array}$ & $\begin{array}{l}17 \mathrm{~F} ; \\
15 \mathrm{~F} ; \\
10 \mathrm{M}\end{array}$ & $\begin{array}{l}\text { trader } \\
\text { teacher }\end{array}$ \\
\hline Sophia & $\begin{array}{l}\text { father \& } \\
\text { mother-away }\end{array}$ & 12 & documented & cleaner & Efua & $\begin{array}{l}\text { mother's } \\
\text { sister }\end{array}$ & $14 \mathrm{~F}$ & trader \\
\hline Abena & mother-away & & undocumented & cleaner & Rose & $\begin{array}{l}\text { mother's } \\
\text { mother }\end{array}$ & $\begin{array}{l}19 \mathrm{M} ; \\
16 \mathrm{M}\end{array}$ & unemployed \\
\hline Candice & mother-away & & documented & cleaner & Richard & $\begin{array}{l}\text { mother's } \\
\text { nephew }\end{array}$ & $\begin{array}{l}18 \mathrm{M} ; \\
18 \mathrm{~F}\end{array}$ & $\begin{array}{l}\text { government } \\
\text { worker }\end{array}$ \\
\hline Joyce & mother-away & & documented & cleaner & Cecilia & mother's aun & $\begin{array}{l}17 \mathrm{~F} ; \\
15 \mathrm{~F} ; \\
13 \mathrm{~F} ; 4 \mathrm{M}\end{array}$ & unemployed \\
\hline Nicole & mother-away & & documented & unemployed & Akosua & $\begin{array}{l}\text { mother's } \\
\text { grandmother }\end{array}$ & $12 \mathrm{~F}$ & unemployed \\
\hline
\end{tabular}

Notes: ${ }^{1}$ All figures are based on moment of first contact.

Source: Own fieldwork, Transnational Child-Raising Arrangements project, Ghanaian parent data, the Netherlands, 2010-2013.

\subsection{Arranging Transnational Childcare}

Transnational childcare arrangements and practices are embedded in culturally prescribed notions of family care responsibilities (Åkesson et al., 2012; Mazzucato \& Schans, 2011). In Ghana, filial relationships include biological and social ties with childcare being the collective responsibility of kin and non-kin (Goody, 1982). Accordingly, biological parents and extended family members share parental rights and responsibilities. This manifests in large extended kin households and in practices of 'kinship fostering', an informal system outside of state involvement, whereby children move to non-natal homes for shorter or longer periods of time and for a myriad of reasons, among which collective cost sharing and to reinforce family ties (Goody, 1982; Isiugo-Abanihe, 1994). Child fostering is to date widely practiced in Ghana: in 2010, 16.4 
per cent of Ghanaian children, aged 0-18, lived in foster arrangements (GSS, 2012, table 8: 28).

Despite social parenthood norms, we find that the mobilization of caregivers and the creation of transnational childcare arrangements is not an easy process. Whereas both migrant parents and caregivers emphasise the obligation to care for somebody else's children, we find a myriad of tacit and non-tacit considerations on the part of both actors. In a transnational context, parents send remittances to cater for their children's high-quality education and to cover the day-to-day costs of child raising, while caregivers perform the daily care tasks that require proximity. Worries over the freedom that geographical distance provides for caregivers to potentially mistreat the child or to use remittances for their own benefits makes parents feel anxious about having somebody else care for their children in their absence. Consequently, grandmothers, including in a few cases previous foster-mothers of the migrant, are the preferred caregivers, as has been found among national fosterage arrangements (Verhoef, 2005) and transnational families elsewhere (Dreby, 2010; Hondagneu-Sotelo \& Avila, 1997). Both mothers and fathers trust grandmothers the most with the care of their children as they consider them to have a 'good heart' and to be affectionate towards grandchildren, and therefore to be the most likely caregivers to treat the child as 'their own'. Furthermore, grandmothers are often at a stage of their lives in which they have few productive and reproductive responsibilities that compete with the attention and resources they can give to a migrant's children. Whereas both paternal and maternal grandmothers are trusted, most families opt for the maternal grandmother. This is especially the case for single mothers and couples, and corresponds with the fact that the Akan ethnic group, to which the majority of our respondents belong, have a matrilineal lineage structure, meaning that children belong to the family of the mother (Assimeng, 1999). Single migrant fathers tended to send children to paternal relatives once children were out of their infant years, whereas in a few cases were children of a migrant couple sent to the paternal grandmother, due to availability or the father taking the decision. In one case this decision was met with incomprehension by both the wife and her family members in Ghana.

The issue of trust is emphasised by migrants who choose their child's grandmother as the caregiver, such as Nicole, whose child was cared for by Nicole's own fostermother:

For me, the child living with somebody else [than foster-mother] is not good. When your son or daughter lives with somebody else and the person is maybe your brother or sister, the way they treat your child...you will not be happy. Because some people are selfish. The money you will send for your child, they take it for themselves and only give a little bit to your child. Even the food they give your child to eat is not good [...] If the person does not have a good mind, then maybe he thinks: I can do whatever I want to you, you are my slave.

(Nicole, Amsterdam, February 2013) 
Despite issues of trust over treatment and finances, other kin and non-kin were selected by some migrants. This was the case when grandmothers were deceased or incapable of providing care due to their own migration, sickness, or old age. Moreover, the child's age and gender were a consideration for parents; the affectionate relationships between grandmothers and grandchildren were viewed positively for younger children but were considered as a hindrance to proper disciplining needed for adolescent children, especially for boys. Discipline is greatly valued in child upbringing in Ghanaian society (Coe, 2008). Accordingly, parents prefer adolescents to stay with younger caregivers to receive proper supervision. Usually, adolescent boys would stay with male relatives to receive proper male supervision, also if they had previously stayed with their birth mothers; it was usually the migrant father who had made the decision for the change. The choice for a specific caregiver is further guided by circumstantial characteristics, such as the proximity to quality schools, the caregiver's level of education, and the number of children in the person's household.

From the perspective of caregivers, most expressed their willingness to 'help out' and seemed to take on their role without much prior consideration as is illustrated by Kesewaa:

My sister called me from abroad and told me how overwhelmed she was with handling her four boys in the middle of an ugly divorce case and one of the boys constantly falling ill. This was going on for some time. One day after she had finished lamenting, she added: 'I am bringing them over to you'. And I said: 'Ok'. I didn't even have to think about it or ask her to call later for a reply.

(Kesewaa, Kumasi, July 2012)

Caring for non-birth children is a kinship obligation. Hence, while caregivers may take on the care role out of goodwill, performing the care role is also a way to adhere to societal duties and family responsibilities; it is considered 'the proper thing to do' (Finch \& Mason, 1991).

At the same time, there are tacit expectations that caregivers have of potential benefits that they will accrue. Receiving a child in a society in which child fostering is informally institutionalised offers status and respect to the caregiver ( $\AA$ kesson et al., 2012; Øien, 2006). Migrants' children are also a source of household labour and can be a potential source of old age care not only in the present, but also in the future as children are morally obliged to provide elderly care for those who raised them (Aboderin, 2004). Also, caring for a migrant's child brings with it the expectation that migrants will reciprocate the 'favour', such as through some seed money for a business venture or 'help' in constructing one's house, or financing one's own child's migration. Importantly though, all of these expectations are unspoken and part of generally accepted practices rather than explicitly marked agreements.

Despite norms of kinship care, there were people who tried to avoid childcare responsibilities. We encountered cases in which kin and non-kin had declined or were reluctant to accept the care role, based on their ability to care, their restrictive housing 
situation or the health of the child. In several cases, parents responded to this by 'forcing' caregivers into the care role. One female migrant, desperate to find a caregiver, promised the caregiver that the arrangement would last only a short time, even if she knew that her possibilities to reunite with her children were limited. Also, hesitant grandmothers could find themselves 'forced' into the caregiving role. Efua only told her mother that she had migrated to the Netherlands by phone, once she was already there and had left her two children with her mother. Efua worried that her mother would refuse due to her mother's old age in combination with Efua's son's chronic illness requiring extra care. Other parents were forced to make a 'care compromise' (Winters, 2014), meaning that in light of migration opportunities and no alternative caregivers, parents place children with a person they do not trust or whose caregiving practices they disagree with, usually with the expectation that reunification in the Netherlands can soon be accomplished.

\subsection{Navigating Childcare Relationships}

Maintaining family relationships across space and over time is mediated by challenges pertaining to the transnational context, often unforeseen. For caregivers, this mainly entails insufficient remittances and children complaining to their parents over the care they receive, whereas parents can grow worried over the material and immaterial care provided by the caregiver. In this section we discuss how, in light of challenges, parents and caregivers maintain relationships through kin work that involves the careful management and navigation of finances and communication.

\subsubsection{Finances}

Financial remittances have material and emotional implications. They signify parents' continued presence and are the financial support with which caregivers provide for the daily needs of the migrant's children, including school fees, feeding, clothing, and medical costs. Parents are financially responsible for their children, yet we find that the exact amount is not discussed. The unspoken nature of finances may be explained by the expectations that both caregivers and parents have of the financial rewards of migration. Largely shaped by success stories of migrants in the West, it is expected that after a short adjustment period remittances will be sent on a regular basis.

At the same time, caregivers abstain from negotiating finances to avoid the stigma of seeming to care for a child for financial profit. Especially caregivers who are not grandmothers are well aware of the issues of trust and not seeming to be involved in the care arrangement 'just for the money'. Although caregivers may benefit financially from the arrangement, the idea that a caregiver accepts the care role for their financial benefits can be a source of shunning from people in the community and caregivers go to great pains to avoid such accusations (Dankyi, 2014). This is clearly illustrated in Victoria's resistance to being financially remunerated for caring for Kwaku's twelve-year old son. 
In this case, the child was moved from his paternal grandmother to Victoria, a teacher, to help the child with his homework:

[The father] asked me how much I will charge for taking care of the child. I said I was not going to allow him to pay for this service. All I needed was for him to send money for the child's upkeep and ensure that this was done regularly. I was not amused by his suggestion to pay me. He insisted on paying me and I also insisted on not getting paid. We could not conclude the matter before he left for the Netherlands as we both stuck to our stance on the matter.

(Victoria, Kumasi, July 2012)

For the same reason, caregivers who are not grandmothers often do not inform parents when they experience profound economic hardship when remittances fall short, nor do they make financial demands, even when in a financial bind. Instead, caregivers resort to alternative strategies, such as borrowing money, finding ways to postpone payments, moving children from expensive private schools to inexpensive public schools, or letting them engage in income generating activities after school hours, in order not to have to make financial demands. Kwesi explains:

About the remittances for their upkeep, the only amount I am specific with is their school fees. Whatever they send apart from the fees is decided by them. I just manage it to the best of my abilities. I don't want to quote any amount for them to think that I want to spend their money or take advantage of their children and extort money from them. After all, these are my sister's children, and so they are mine too. I try to manage with what they bring. [...] There are times that I do not have anyone to turn to, to borrow money from and that puts me under a lot of stress.

(Kwesi, Kumasi, December 2011)

By managing finances, caregivers attempt to avoid accusations of mismanaging remittances, while at the same time fulfilling kinship obligations that prescribe the caregiver to care for someone else's child as their own. The caregiver's mitigation of financial shortages has a positive impact on the care relationship. Migrant parents appreciate the help provided by the caregiver to act collectively for family survival and it takes away worries that caregivers can be trusted with the finances. In the Netherlands, Kofi, who was unaware of Kwesi's financial difficulties, explained:

Kwesi supported us financially to survive. Sometimes when the children needed books, he would tell me how much it was. If I didn't have enough money, say when it was 50 euro, he would buy it for me and I would send the money later. [...] He helped me a lot.

(Kofi, Amsterdam, June 2013) 
The management of finances as a means to maintain trusting relationships is complicated for those caregivers who lack the necessary financial resources to alleviate remittance shortages. The case of Joyce (migrant mother) and Cecilia (maternal aunt and caregiver) illustrates this:

Cecilia, unemployed, never received enough remittances from Joyce to pay for the children's expenses, pushing her in a dire economic situation, which she only disclosed to Joyce on a few occasions. Despite Cecilia's efforts, Joyce grew suspicious over Cecilia's intentions: 'For the children it is very difficult to live with a caregiver, because whenever they need something, the caregiver doesn't give it to them. Whenever I send money for my children, Cecilia is using the money on something else. On the phone, my children tell me what they need. Maybe they need new panties, but Cecilia does not give it to them...You know, in Ghana, whatever happens, a caregiver will always spend some of your money when they have children of their own.' (Joyce, Amsterdam, March 2012). When Cecilia kept the children home from school for a few days because she was unable to pay the school fees, Joyce's reaction was one of distrust that Cecilia was not doing her best: 'If she was my own mother who gave birth to me, do you think she would allow my children to miss school for days because she does not have money? She needs to help me, she needs to stand for me as a mother.

(Joyce, Amsterdam, March 2013)

At the same time, remittances facilitate transnational 'kin-work', because they reinforce care commitments (Singh \& Cabraal, 2014). Migrants, who could afford to do so, made sure to send money and gifts for the caregiver and his or her children. This was considered necessary to ensure that caregivers would not misuse the remittances and gifts sent for the child for their own benefit - a complaint often heard by migrants, as demonstrated by the case of Joyce described earlier-but also to fulfil the obligation to have close kin partake in one's wealth and to acknowledge the time, energy, and finances spent on the care of the child. Accordingly, migrants carefully managed their finances to make sure that they had some surplus to send for the caregiver, ranging from the sending of gifts and remittances for Christmas to regular payments, such as for the school fees of the caregiver's child.

We find that when caregivers are grandmothers, the relationship of trust with migrant parents does not get called into question due to financial issues. The trusting relationship between migrants and their mothers gave the latter more leeway to make their situations known to their migrant children abroad. The case of Fosua, who took care of her son Kwaku's three children is illustrative:

Kwaku instructed his mother to provide the best possible care for his children, including a nutritious diet and catering for all their material needs. Fosua struggled to fulfil these expectations with the remittances she received from Kwaku and regularly pleaded with him to increase the monthly remittances. Kwaku was 
reluctant to admit that the remittances he sent were insufficient. To convince him, Fosua kept a logbook of the children's daily expenses and showed this to Kwaku on one of his trips to Ghana. The demands for money and the logbook did not impact Kwaku's trust in her but served to resolve the problem, as subsequently Kwaku sent more remittances.

\subsubsection{Communication}

In the absence of co-residency and limited face-to-face contact, long-distance communication is the primary means through which migrants and non-migrants exchange information and through which intimate relationships are maintained. For these reasons, parents attach great value in being able to communicate - mainly by mobile phone - with their family back home. Yet communication is carefully managed. Parents carefully select what to communicate, such as abstain from communicating their worries about their children's material and immaterial care to avoid breaking trust between them and the caregiver. Particularly parents with few care alternatives feel forced to accept situations even those they perceive to be less ideal. Parents realise that children can be difficult to handle and that the caregiver is not necessarily to blame for their children's behaviour, yet they also worry that caregivers may take it out on their children if they complain to caregivers, or worse, that caregivers may withdraw from their care role. Thus, parents often do not speak their mind, especially when caregivers other than grandmothers take care of their children. Continuing with Joyce and Cecilia's case, presented above:

On one occasion Marie, Joyce's seventeen-year-old daughter, complained that Cecilia was 'starving' her. This caused Joyce great worries over Marie's well-being, compounding the distrust that had already arisen over finances. Joyce immediately called Cecilia to ask about the situation, but was very careful not to sound accusatory. Cecilia explained that Marie had not come home to eat for two nights and that the third night she had not kept the food for her as she did not want to waste it. Although Joyce did not agree with Cecilia, she took Cecilia's side and told Marie to eat the food that Cecilia prepared.

Situations such as Joyce's place parents in a bind: they feel constrained in being able to vent their worries yet at the same time, their children expect them to solve their problems with the caregiver. The level of trust in the caregiver will determine whose story they will believe and a parents' room for manoeuvre in case of needing to change a caregiver, will affect what they will communicate to the caregiver and how. Kwaku's case illustrates this:

When his son Emmanuel, complained that Victoria, the teacher and caregiver, was beating him, Kwaku undertook no action. Whereas Kwaku expected to have more decision-making power over his child by paying Victoria, the lack of trust between him and Victoria due to the absence of a kinship relationship and the 
short time they had known each other, made him worry that speaking his mind would result in further maltreatment of the child. When Emmanuel reported that Victoria was picking on him because he ate too much, Kwaku decided to call Victoria to ask about the situation. Kwaku finally decided to speak his mind because of the availability of an alternative: if things did not work out with Victoria, his son could always return to Fosua, Kwaku's mother. This is exactly what happened shortly after the phone call, as Kwaku and his wife no longer trusted Victoria.

These same situations, viewed from the perspective of caregivers, show different considerations. Caregivers other than grandmothers expressed that the ease of communication with migrant parents limited their decision-making power because parents expected to be consulted about every decision with regards to the child. In transnational childcare arrangements, the role of the caregiver and that of the migrant parent carry different expectations than those of child fostering as it is practiced nationally (Mazzucato \& Schans, 2011). While in the latter, foster parents are the ones that make decisions about the child's upbringing, in transnational families, migrant parents remain engaged and parent from afar. Yet, parental involvement in the child's care can also make caregivers feel in a bind, as they do not feel trusted and respected when parents make decisions behind their back and when parents expect them to communicate the slightest details about their children's lives. At the same time, if there are problems, caregivers are questioned by the parents, as well as society at large, about their caregiving skills (Dankyi, 2014). In order to balance these issues, caregivers too, need to carefully select what to communicate to parents and what not. Especially in cases where a caregiver feels he/she needs to gain or maintain a parent's trust, caregivers may withhold information regarding insufficient remittances and deviant behaviour of children, and instead emphasise how well children do.

Withholding information, though, is a double-edged sword: whereas on both sides, it is part of an active strategy to sustain relationships across distances, it can also become the source of incomprehension and mistrust. Migrant parents worry that caregivers do not reveal everything about the care situation. As a way to increase the information they get, parents send mobile phones to their children as soon as they perceive them to be old enough, enabling communication with their children without the involvement of the caregiver. For caregivers, this has great implications: children may tell their parents only part of what is happening and they know that their actions will be communicated to the parents through the children's eyes. This makes caregivers intensely aware of avoiding any behaviour towards a migrant's child that may prompt bad reports. Kwesi remarked about the care of his two acquired nephews:

My greatest challenge with these children is the fact that they have phones and communicate directly with their father without my knowledge. For this reason, I am very wary of them because these children can easily disgrace you especially when it comes to issues regarding remittances. I am therefore careful how I 
handle the money I receive from their parents, because I am not sure if their father calls them to tell them how much he is sending them or not. Once in a while, you might use some of the money the parents send for a personal need, but I am really careful about that.

(Kwesi, Kumasi, June 2012)

Caregivers put a lot of effort in preventing children from complaining to their parents about how remittances are spent by adopting various strategies, such as informing children on the exact amount their parents send and actually having children accompany them to the bank to collect remittances. Additionally, to avoid children's complaints to their parents, caregivers are careful in how they respond to children's deviant behaviour. This was explained by Cecilia when narrating an incident that happened with one of the children:

I asked one of the two older girls, who was off from her apprentice job that day, to do some laundry for me this morning. After washing clothes, she did not immediately dry them on the line. Rather, she left the clothes in a bucket and went off to sleep [...]. If she were my own daughter, I would have gone ahead to wake her up to finish the work she started. But with these children, I am careful because the next minute they will call to inform their mother. They will usually not report the good things you do, but the ones that are bad.

(Cecilia, Accra, October 2011)

These accounts point to important shifts in power relations in transnational households. The ease of long-distance communication and the daily involvement of parents in their children's lives create inverted power relations between older children and their caregivers. Whether or not such situations occur is influenced by factors relating to the level of trust between the caregiver and the parent, and the quality of the relationship between the child and the caregiver. Especially children who experience lengthy separations from the parent and who stayed with the caregiver from a very young age, usually grow emotionally attached to their caregiver, and accordingly, complain less to their parents about the caregiver.

Parents who regularly visit their children are aided in developing a trusting relationship with the caregiver. Visits allow parents to see the situation for themselves, which helps to loosen some of the strains that are associated with 'truth and distance' (Baldassar, 2007). Caregivers may also benefit from visits since it provides the opportunity to reveal dire situations, which communication alone does not. This was painfully made clear when the Dutch researcher visited Cecilia in Ghana, the caregiver who was in charge of Joyce's four children. Cecilia begged the researcher to take pictures of Cecilia's disordered bedroom, which she shared with all five children. Cecilia complained to us about the children's untidy behaviour, yet, she felt she could not explain this to Joyce on the phone. By showing her situation to Joyce through a third 
party, the researcher, Cecilia hoped that Joyce would give her more leeway in the way she handled the children, without instigating distrust.

Many parents, like Joyce, have few opportunities to visit Ghana. In these cases, parents partly overcome distance by monitoring the care arrangement through mobilizing local and transnational networks, such as neighbours or family members who visit the child. Monitoring by a third party can have a positive impact on the relationship when parents' worries are appeased, but it can also instigate or exacerbate mistrust, and has the potential to disrupt the care arrangement, as the following case illustrates:

Kate, a migrant mother, regularly received complaints from her daughter about delays in the payment of her school fees, excessive household work, and physical abuse. Kate and her husband, both undocumented, asked a Ghanaian church member to check on the situation upon his next trip to Ghana. When the church member arrived at the caregiver's house and requested for Kate's daughter to join him for the weekend, the caregiver accused Kate of distrusting them. This eventually led to a break-up of the care arrangement and a prolonged family dispute.

The only cases in which communication is forthcoming in both directions, without breaching trust, and where visits are not deemed necessary to build trust, are those in which the caregiver is the grandmother. Parents do not worry that grandmothers abandon or maltreat their grandchildren in case they express their concerns about the care children receive. Instead, parents emphasise the advantages in terms of open communication since they can more easily instruct grandmothers on how to treat their children, or at least to have open discussions with them, as Akua, a migrant in Amsterdam, explains:

When the child is staying with your own mother, you can say that the way she treats the child, you don't like it. Because the grandmother takes it better, because she takes care of the child better than you.

(Akua, Amsterdam, February 2013)

Also, grandmothers do not worry that their complaints over children's behaviour instigates distrust on the part of the parents. In fact, there were numerous cases in which grandmothers complained to the migrant parent about the rebellious or deviant behaviour of grandchildren and their inability to control them. Such complaints, like complaints from children, do not erupt into open conflicts or mistrust as parents recognise how difficult it is to control adolescents, especially for grandmothers. Instead, parents respond to this by telling their children to obey their grandmother and the grandmothers to manage the situation to the best of their abilities. In some cases, grandmothers withheld information about rebellious behaviour of grandchildren, but more to protect the migrant parents from worries, rather than due to fears of not being trusted. 


\subsection{Conclusion}

In this paper, we have examined the day-to-day informal work within transnational care relationships, from the perspective of both migrant parents and their children's kin and non-kin caregivers, who are not the children's biological parents. We used kin work as a framework to understand the way transnational relationships need to be worked on both sides of the relationship. Our analysis reveals that physical distance complicates the mobilization of kinship care. Such care is often assumed by both parties but becomes problematic when expectations are not met. Moreover, we find that both actors engage in explicit and tacit practices to sustain relationships: the careful management of finances and communication that aim to build trust and avoid breaching it. The level of trust largely determines how much work has to be done to maintain relationships.

By employing the SMS methodology, we were able to observe what people on both sides do 'in real time', rather than based on recall. Di Leonardo's (1987) concept of 'kinwork' emphasises the activities, such as communication and the sending of gifts, that family members engage in to maintain kin relationships. Our approach allowed us to observe not only the visible, but also the invisible (Mazzucato, 2009a), hence, what people do and do not do on a day-to-day level, to make transnational care relationships work. This revealed that much managing of such relationships is built on 'not doing', 'not communicating' or selective communication. Furthermore, discrepancies in perceptions were identified because we could compare data obtained on both sides of the relationship. These findings contribute to our understanding of the ways in which long-distance practices - composed of things done or communicated and things not done or communicated - facilitate the maintenance of kin relationships and how the inability to perform these can lead to tensions.

Pre-existing norms of social parenthood and practices of child fostering are not exclusive to the Ghanaian case, but can be found in other regions, especially in West Africa (e.g. Whitehouse, 2009) and the Caribbean (e.g. Soto, 1989), making our study potentially relevant for other cases. Because child raising norms influence the choices that families make in arranging transnational childcare and the ways relationships are managed (Mazzucato \& Schans, 2011), our case contrasts those cases in which nuclear family ideals prevail, where a lack of kinship care obligations render care arrangements with other relatives than the grandmother fragile and short-lived (Dreby, 2010).

Relationships between migrant parents and caregivers are embedded in 'transnational moralities' (Carling, 2008) of kinship care obligations. Unequal access to information and resources between migrants and caregivers create new or exacerbate old asymmetries, power dynamics, and frustrations, but they are also the basis for longdistance cooperation within extended kinship networks. Both migrant parents and caregivers strategically manage finances and communication, not only out of altruistic attachment to the migrant/caregiver and the child, but also as a way to respond to kinship obligations of care and to avoid being shunned by members of the community when failing to do so. Moreover, these care transactions are part of longer term 
reciprocal relationships through which 'kinning' is done and lays the basis for future support from the child to the caregiver, both emotional and material (Shipton, 2007). A question for future research, now that the first generation of migrant parents enters the age of retirement, will be to see how children will engage in elderly care, a task that customarily falls upon them to perform for the people who raised them, when both their migrant parent in the Netherlands and the caregiver in Ghana will be in need of help (Mazzucato, 2008b). 



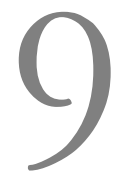

Conclusions 



\subsection{Introduction}

The central aim of this thesis was to explain how transnational child-raising arrangements_comprising practices, relationships and forms-are enacted, reconfigured and maintained by Ghanaian migrant parents in the Netherlands and their children who stay behind in the origin country in the care of the other biological parent or other kin or non-kin. Considering such cross-nationally-divided families as a particular form of transnational social space allowed for the examination of how transnationalism reconfigures kinship systems and family organisation (Faist, 1998; Glick Schiller, Basch \& Szanton-Blanc, 1992). This thesis applied a transnational family approach which considers family life and emotional bonds beyond bounded geographic units to include internationally dispersed social groups, which may constitute both biological and social ties (Baldassar, 2007; Baldassar \& Baldock, 2000; Baldassar a\& Merla, 2014). As such, this thesis builds upon an emerging body of literature that re-evaluates everyday family life that transcends national boundaries (Baldassar \& Merla, 2014; Mazzucato \& Schans, 2011; Suárez-Orozco, Todorova \& Louie, 2002).

Importantly, this thesis builds on and contributes to a recent body of literature that recognises that transnational family life and care exchanges are not free-floating, but rather that they are anchored within the institutional contexts of the sending and receiving countries and that, in turn, transnational processes impact localised norms and institutions (Bonizzoni \& Boccagni, 2014; Kilkey \& Merla, 2013; Mahler, 2001; Mazzucato \& Schans, 2011; Ryan, 2011; Zentgraf \& Chinchilla, 2012) This study's emphasis of the simultaneous embeddedness in multiple institutional contexts allowed for an examination of how host and home country contexts, more specifically family and child-raising norms of the home country and the political and socio-economic context of the host country, affect transnational child-raising arrangements and how they mediate the impacts of transnational family configurations.

By examining Ghanaian transnational families, this thesis is part of a wider shift in transnational family studies that seeks to include sending contexts that have for long been under-researched, but which are interesting to explore for comparative reasons (Grillo \& Mazzucato, 2008). As such, it contributes to recent literature that examines African transnational families and Ghanaian transnational families in particular (see among others Caarls, 2015; Caarls \& Mazzucato, 2015; Cebotari, Mazzucato \& Appiah, 2017; Cebotari, Mazzucato \& Siegel, 2017a, 2017b; Coe, 2008, 2011a, 2011b; Dankyi, 2014; Dankyi, Mazzucato \& Manuh, 2017; Dito, Mazzucato \& Schans, 2017; Haagsman, 2015, 2017; Haagsman \& Mazzucato, 2014; Haagsman, Mazzucato \& Dito, 2015; Mazzucato \& Cebotari 2017; Mazzucato et al., 2015; Mazzucato et al., 2017; Wong, 2014). Given the large share of a relatively young Ghanaian immigrant population in the country, alongside its restrictive migration and family reunification policies, the Netherlands provided an interesting receiving context from which to explore crossborder Ghanaian family life. 
The complex methodological design of this thesis was facilitated by the broader Transnational Child-Raising Arrangements (TCRA) project that integrated a multidisciplinary team of researchers in the home (Ghana) and host (the Netherlands) countries. Benefits of this collaboration included easy access to a large number of staybehind children in Ghana and gaining a broad understanding of everyday care practices and family relationships. Moreover, the TCRA project allowed for a simultaneous matched sample (SMS) methodology (Mazzucato, 2009a), which in this particular case involved two researchers conducting ethnographic research simultaneously among a selected number of families in the Netherlands and Ghana.

Built into the SMS methodology is the recognition that not the individual migrant but his or her multi-sited network should be the starting point for empirical research (Mazzucato, 2009a). The SMS methodology enabled the incorporation of actors in multiple locations, thereby giving equal importance to both sides of the transnational care relationships. Having two researchers collecting data on both sides of the transnational child-raising arrangement helped bridge depth and breadth-one of which is often lost in case of step-wise multi-sited research conducted by a single researcher. Capturing simultaneity in space and time revealed relationship dynamics and allowed for a better understanding of how, from the perspective of different actors, care and kin work is practiced, received and experienced. Moreover, through intensive and long-term contact with the families, it was possible to observe how transnational child-raising arrangements and care relationships developed over time. Exchanging and comparing notes, as well as visiting the other researcher's field site, were invaluable to reach the method's fullest potential. Alongside uncovering discrepancies between what was said and done and exposing important events that would otherwise have remained unobserved, it also provided the necessary time to discuss in more detail field notes, methodological and theoretical approaches, and ownership of the data.

The multi-sited research design facilitated the incorporation of multiple actors-not only the migrant fathers and mothers on which the bulk of work in this thesis centres, but also the children who stay behind and their experiences with migrant mothers and fathers. Moreover, in the examination of migrant parents' and stay-behind children's experiences, I included the often-neglected and underestimated role of the caregiver. The examination of multiple actors in one study provided a deeper understanding of how transnational care arrangements work from the point of view of the different actors, what the different actors do to make cross-border families work and how such arrangements are experienced by the different actors involved, depending on their social and geographical location. In this way, I could capture a nuanced and complete comprehension of how family life and child care is practiced and experienced.

The present thesis draws on multiple samples, methodologies and field sites. First, data was collected through one-off semi-structured interviews with 54 Ghanaian staybehind children aged 12 to 22, who had either one or both parents living in the Global North. Second, ethnographic research was conducted, which included multiple in-depth interviews, non-participant observations and a network mapping tool, with 15 Ghanaian 
migrant parents living in the Netherlands. These migrant parents were part of a matched sample, meaning that the Ghana-based caregivers and children of these same families were simultaneously studied. Third, a less intense form of ethnographic research was conducted - including one-off interviews along with a similar range of multiple in-depth interviews, non-participant observations and a network mapping tool-with 41 Ghanaian migrant parents living in the Netherlands. The main selection criteria for migrant parents was having experience with separation from a child in Ghana below the age of 21 years. In the total sample of migrant parents, 32 were female and 24 were male, with variation in terms of family type, caregiver, and socio-economic, legal, and marital status. Fourth, data was collected via one-off interviews with six key informants in the Netherlands who had expertise in transnational family life, the migrant community and/or legal issues. Data collection occurred over different periods between mid-2010 and mid-2013. The main field site in the Netherlands was Amsterdam Zuidoost, more specifically the Bijlmer area, and to a lesser extent The Hague. The children in Ghana were interviewed in their schools in Accra and Kumasi.

The next section summarises the key findings of the thesis. I conclude this chapter with suggestions for future research.

\subsection{Key Findings and Contributions to Transnational Family Studies}

Maintaining child-raising arrangements across national borders is a complicated and delicate process that involves a complex web of emotions and consequences. This section sums up the key findings of this thesis and connects the case of Ghanaian transnational child-raising arrangements to broader theoretical issues.

\subsubsection{The Home Country Context: Gendered Care Cultures}

This thesis builds on recent literature that recognises the need to situate individuals in multiple institutional contexts, constituting 'laws and institutions' (Levitt \& Glick Schiller, 2004: 10) to understand the full scope and complexity of everyday practices and interconnections in transnational families. Hence, it recognises that transnational family lives continue to be locally anchored and that in turn localised norms and institutions are shaped by transnational processes. One of the many regimes and parameters that shape transnational caregiving and that mediates its impacts is 'gendered care cultures', which can be understood as 'norms on appropriate division of labour and appropriate forms of care for dependents’ (Kilkey \& Merla, 2013: table 3, p. 216).

This thesis situated family practices and caregiving exchanges within locally-anchored family and child-raising norms. From my empirical findings, I discerned two conclusions that contribute to the understanding of how gendered care cultures of the home country context shape transnational child-raising arrangements: 1) gender ideologies prescribe, but do not dictate, how and by whom care is practiced and how transnational childraising arrangements are experienced by the different actors involved, and 2) inclusive 
parenting ideologies shape how transnational child-raising arrangements are organised, maintained and experienced.

\section{a. Gender ideologies prescribe, but do not dictate, how and by whom care is practiced}

The findings of this thesis re-emphasise that gender is an important organizing principle in the experiences of migrant parents and stay-behind children and that gender norms are perpetuated in the transnational context (Dreby, 2006; Parreñas, 2008). Chapter Five showed that stay-behind children assessed the relationship with their overseas parents in terms of what they considered to be appropriate gendered forms of parenting. The relationship with the migrant father was assessed in terms of his ability, or willingness, to provide for the children's material needs, whereas the relationship with the mother was mainly assessed in terms of her ability to attend to the children's emotional needs. Hence, whether children felt loved and cared for by their physically-absent parent was largerly described in terms of gendered-parenting expectations. Consequently, insufficient material and emotional care from fathers and mothers, respectively, could be met with anger, frustration and feelings of emotional loss on the part of the staybehind children. In a few cases, this even resulted in children ostracizing the migrant parent from their lives, thereby making use of geographical distance to take control over their family lives and relationships.

Chapter Six showed that Ghanaian migrant fathers also evaluate the relationship with their children in terms of their ability to provide what cultural ideologies prescribe as 'good fathering'. In conformity with cultural expectations of Ghanaian fatherhood, the migrant fathers of this study primarily addressed their parental role in terms of financial support for their families as 'breadwinners'. The father, who is considered to bear the bulk of financial responsibilities, has always played a key role in the child's upbringing, also in matrilineal family structures of the Akan ethnic group, to which the majority of respondents belong. Generally, the interviewed fathers cited enhanced earning to provide schooling and a better life for their children as their main reason for migrating to the Netherlands from Ghana.

This research, however, finds that gender ideologies prescribe but do not dictate how geographical separation and long-distance care are practiced and experienced by migrant parents and stay-behind children. The findings of this study point out that whereas child care in a transnational context continues to be highly-gendered, the actual care work performed-or envisioned-by fathers and mothers is very similar (see for instance Doucet, 2011 for similar findings outside the transnational context). Hence, alongside breadwinning responsibilities, a majority of the Ghanaian fathers espoused more 'engaged' parenting ideals. This finding challenges stereotypes of the uncaring and distant migrant father who neglects his stay-behind children's non-material needs. Through long-distance communication and direct face-to-face contact, fathers seek to nurture emotional bonds with their children and to maintain an active role in their lives. By studying transnational fatherhood as a phenomenon in itself, this thesis demystified common perceptions of the migrant father as irresponsible and absent in their children's 
lives, an image that is often reproduced in transnational family literature (Coe, 2008; Landolt \& Da, 2005; Parreñas, 2008).

Likewise, the stay-behind children of this study expressed appreciation of care tasks beyond gender norms. Children valued fathers' efforts to provide social and emotional care though phone calls and return visits. Also, mothers' efforts to provide financially for the family back home were appreciated. As such, this study underlines that the shifting paradigm that moves care practices and norms beyond the gender binary of caring mothers and breadwinning fathers (Cooklin et al., 2014; De Souza, 2014), is not limited to parenting in the national context and developed countries; it also applies to cross-border families from the Global South.

This non-binary perspective on gender ideologies and care practices also helps explain why some of the fathers of my study showed signs of emotional suffering similar to what has been previously described by transnational mothers when possibilities to maintain intimate relationships across borders are limited, or why children were not worse off when their mothers had migrated compared to when their fathers had migrated. As such, a lack of intimacy and feelings of abandonment that were aroused by the physical separation from the migrant parent in itself, especially the mother (Parreñas, 2005b), was not found among the Ghanaian stay-behind children of this study.

At the same time, it is worth mentioning that Mazzucato and Cebotari (2017) found a slightly lower psychological well-being for Ghanaian stay-behind children in motheraway families compared to children living together with their parents; children in fatheraway families reported similar well-being effects compared to children living with both parents. Based on my research, I would suggest that the lower well-being outcome for children whose mothers have migrated cannot merely be explained by the physical separation. In fact, Mazzucato and Cebotari (2017) found that, in particular, it was children who stayed in the household of their biological father who experienced a lower emotional well-being. Worse well-being outcomes for children whose mother had migrated may also be related to migrant mothers' difficulties abroad-especially when having to combine care for physically close children and paid work - that may challenge their possibilities to attend to their Ghanaian-based children's emotional needs.

A final plausible reason for the difference in psychological well-being may be related to the stability of the child-raising arrangement. Mazzucato and Cebotari (2017) found that Ghanaian stay-behind children who change caregivers once or more often are more likely to experience a lower emotional well-being. Caarls et al. (2017) found that the child-raising arrangements of Ghanaian migrant mothers are less stable compared to those of transnational fathers, mainly because the latter rely on the biological mother for the care of their children, whereas mothers generally rely on maternal relatives.

These findings confirm my proposition that it are not only the gendered ideological frameworks but also the type of caregiver, the circumstance of migrants and the stability of the child-raising arrangement that explain how Ghanaian stay-behind children experience their parent's migration to the Global North. 


\section{b.Inclusive parenting ideologies shape transnational child-raising arrangements}

A second key finding that concerns 'gendered care cultures' relates to home country family and care norms. Previous transnational family research has not always considered the importance of local cultural norms and instead has largely assumed Western cultural ideals of the family that emphasise a privileged position of the biological mother-child dyad as well as geographical proximity (Mazzucato \& Schans, 2011). In line with previous research among immigrant groups from societies in which more inclusive parenting forms are practiced (Olwig, 1999, 2012; Suàrez-Orozco, Todorova \& Louie, 2012; Whitehouse, 2009), this thesis found that such family forms facilitate transnational childraising arrangements and that they mediate the impacts of family separation for the different actors involved.

In the home country context of Ghana, family and childcare norms and practices centre around the extended family unit, thereby positioning kin and non-kin as central actors in child rearing. These norms of social parenthood that move beyond the biological parent-child dyad as the central axes within child-raising arrangements can be practiced within and outside the child's natal home. In the latter instance, children are transferred to the homes of other kin or non-kin, a practice referred to as child fostering. Child fostering is culturally accepted and, at times, the preferred child-raising arrangement, for instance in case of crisis or to better the educational opportunities of the child (Akresh, 2005; Andres, 2009; Andvig, 2000; Desai, 1992; Goody, 1982). Hence, in this context, reasons that point to the betterment of the child and/or the wider family render physical proximity between parents and children of secondary importance.

In Chapter Eight, my co-authors and I showed that norms of social parenthood and practices of child fostering provide the normative groundwork for migration and transnational child-raising arrangements when the caregiver is not the biological parent. Hence, established traditions influence who migrant parents ask to take care of their children and how relationships are maintained across distance. They lay the basis for long-term and long-distance cooperation within cross-border care networks comprising kin and non-kin (Mazzucato \& Schans, 2011). This study showed for both migrant parents and their children's caregivers the unquestioned participation in transnational child-raising arrangements, a response to kinship obligations of care. The normative framework of inclusive childcare makes care arrangements that involve other kin and non-kin long-lasting and often conflict-free, contrary to what has been found among transnational families from sending contexts where nuclear family ideals prevail (Dreby, 2010). At the same time, however, we found that these care arrangements are not always unproblematic and that a great deal of kin work (Di Leonardo, 1987) is involved in maintaining such arrangements (see section 9.2.3).

How such care arrangements are experienced from the perspectives of different actors was further explored in Chapters Five and Seven. As mentioned above, for the stay-behind children of this study (Chapter Five), the geographical separation from their parents was not necessarily considered problematic as long as their parents continued to show their love and affection through the sending of remittances, long-distance phone 
calls and return visits. In other words, for these children, being physically close to the biological parent was not a prerequisite for a warm and affectionate parent-child relationship. The acceptance of non-proximate care can be explained by inclusive parenting norms that facilitate the circulation of care for children among a wider care network (Baldassar \& Merla, 2014). Rather than considering their parents' absence as a failure to fulfil a social ideal, the children accepted the transfer of 'motherly' and 'fatherly' tasks to other kin and non-kin caregivers. In other words, the flexible and inclusive kinship norms helped children cope with the transnational arrangement and to value their parents' migration more positively compared to what has been found among staybehind children from other sending contexts (Bernhard, Landolt \& Goldring, 2009; Parreñas, 2005b).

The findings further suggest that, contrary to research that has assumed a limited role for caregivers in transnational child-raising arrangements (Artico, 2003; Bernhard, Landolt \& Goldring, 2009), in transnational families from societies where inclusive parenting norms prevail, caregivers play a key role in alleviating the emotional consequences for the children who stay behind. Children's negative feelings could therefore not be related to the geographical separation in itself since children do not necessarily expect their parents to provide parental care tasks in close proximity. Rather, it was the absence or presence of transnational care practices - that is, the sending of remittances and goods, return visits and long-distance communication, as well as the quality of care received from the caregiver-that determined how children responded emotionally to their parents' absence.

Some of the interviewed children expressed a longing for physical presence and the nuclear family form. Whereas such longing may be explained by broader modernizing processes, notably the uprising of the Pentecostal Church and urbanisation trends that promote nuclear family forms in Ghana, it should also be related to the circumstances of the care arrangement. Usually these children had experienced inadequate care from the caregiver and/or conflict between parents and caregivers. In other cases were parents unable to forge or maintain intimate relationships across distance. Besides, some children longed for the nuclear family ideal in case of divorced parents, although children did not necessarily wish for all family members to reside in the same physical household.

Also among Ghanaian migrant mothers (Chapter Seven), this study found that transnational child-raising arrangements is an accepted family form. Even though women generally argued that children should ideally live with their biological mother, they reasoned that under certain working and living circumstances, physical separation could be favoured over physical proximity. These mothers accepted that other caregivers were taking care of their children in the origin country. Contrary to what has been reported for transnational mothers from other sending regions (Aranda, 2003; Bernhard, Landolt \& Goldring, 2009; Dreby, 2006; Fresnoza-Flot, 2009; Hondagneu-Sotelo \& Avila, 1997; Parreñas, 2001), feelings of depression, shame, guilt or estrangement from their children resulting from the physical separation and the impossibility to provide proximate care tasks were uncommon among the migrant mothers of this study. For 
these mothers, physical separation from the child was not stigmatised, nor was family reunification necessarily the preferred outcome. Having children cared for by a trustworthy and reliable caregiver in the home country instead was a strategy that allowed mothers to make the most of the opportunities that presented themselves, similar as what has been found among Caribbean migrant mothers (Olwig, 2012).

The findings of this thesis underscore that inclusive family forms and historically practiced child circulation facilitate and normalise transnational child-raising arrangements. In such contexts, transnational families may be considered contemporary, even favoured, family configurations where care is exchanged between migrants and non-migrants (Baldassar \& Merla, 2014). This deconstructs the ideal that living together is the best option and suggests that the commonly-held idea that transnational family life is imposed on migrants and that physical separation between parents and children inevitably has negative implications for the different actors involved does not necessarily apply to all contexts. The Ghanaian case study therefore further challenges Western nuclear family ideals that prioritise the mother-child dyad and intimacy created in proximity (Mazzucato \& Schans, 2011), and makes the argument for further refining transnational family theory, given the diversity among transnational families from different sending contexts.

\subsubsection{The Host Country Context: The Political and Socio-Economic Contexts}

Alongside gendered care cultures of the home country context, this thesis has demonstrated how structural factors of the host country context provide opportunities and constraints to transnational child-raising arrangements and how this impacts on different actors and interpersonal relationships. This thesis therefore builds upon and contributes to transnational scholarship which recognises the continued importance of nation state policies in facilitating or hindering how migrants organise their lives within and across borders (Szanton-Blanc, Basch \& Glick Schiller, 1995; Bonizzoni, 2009; Faist, 1998; Fresnoza-Flot, 2009, 2015; Kofman, 2010; Levitt, De Wind \& Vertovec, 2003; Strik, de Hart \& Nissen, 2013; Vertovec, 2007; Waldinger \& Fitzgerald, 2004). I have shown how state policies that define who can and cannot enter the host society and under what conditions influence transnational family lives and relationships. My empirical study brings to the fore two key findings: 1) whereas transnational family life may be a choice, family migration policies constrain this choice and impose negatively on the lives of those involved, and 2) alongside gender ideologies, migrants' socioeconomic and legal status largely influences care practices, intimate relationships with stay-behind children and interfamilial household dynamics.

\section{a.Family migration policies constrain the choices for family life and negatively affect the daily lives and relationships of different actors involved}

In Chapter Seven, I focused on the role of family reunification policies in the ways in which transnational mothers' family lives are shaped. For these women, residency alone does not guarantee freedom to choose their geographical and temporal family life 
trajectories. I identified that, in addition to citizenship status, requirements regarding income and proof of the family bond are key barriers that at least partly explain the low rate of family reunion among Ghanaian female migrants (Caarls et al., 2013). As such, the income requirement increases the significance of socio-economic status in determining whose family members are eligible for family reunion.

The thesis further identified gender as a discriminatory category in family reunification policy: the income requirement is more difficult to meet for women, as they often have to combine their jobs in low-paying, informal and volatile niches in the labour market with care for Dutch-based children. Hence, women's living and job characteristics constrain their possibilities to reconcile transnational family life and work. Moreover, this study found discrepancies between the normative frameworks that underlie formal conditions to family reunion and female migrants' family lives. Also, women may enter and stay in abusive relationships to meet citizenship and income requirements for family reunification. As such, family reunification policies do not only reproduce inequalities along lines of gender, class, and origin, but also reinforce multiple dependencies and inequalities within the household, reducing women's agency vis-à-vis their partner in the Netherlands.

This study did not only reaffirm that restrictions to family reunification prolong separations (Åkesson, Carling \& Drothbohm, 2012; Bernhard, Landolt \& Goldring, 2009; Kofman, 2004; Strik, de Hart \& Nissen, 2013), but also that the free choice to organise family life is increasingly restricted by tightened family migration policies, since they constrain women's flexibility to organise their family lives. Hence, whereas prolonged separations in the Ghanaian case are not always forced upon these families (see section 9.2.1), the conditions for family reunion take away the flexibility that is characteristic of Ghanaian family life. Women are obstructed from acting upon the circumstances that present themselves, such as death or sickness of the caregiver or better working and living conditions in the host country. I also noted that women who were unwillingly separated from their children had to cope with children who reproached them for leaving them in bad care situations, with jealousy among multi-local siblings and heightened emotional stress. Whereas de facto family reunification was not very common among the female respondents of this study, as has been found elsewhere (Bonizzoni, 2009), I did find that unstable care arrangements could provoke counterstrategies, including high-risk unofficial reunification pathways, posing considerable risks to children and adolescents who are forced to grow up in illegality. I have argued that such unforeseen outcomes or side effects of migration control are not sufficiently taken into account by policy makers.

\section{b. Socio-economic and legal status influence transnational parenting and quality of family relationships}

Another key finding links the socio-economic and legal status of the migrant parent to the ways in which transnational parenting is enacted and experienced. In Chapter Six, I showed that, whereas the majority of fathers espoused more 'engaged' parenting ideals, it was their legal and socio-economic status that influenced the way fathers were able to 
perform their material and emotionally-engaged paternal ideals. The frequency of electronic telecommunication and above all fathers' visits to Ghana to see their children determined the quality of the emotional relationship with their children. The financial cost of travel was a severe impediment to migrants earning low wages or being unemployed, whereas the more affluent fathers with residence permits were likely to make one or more visits to Ghana per year and consequently were better able to nurture close relationships with their stay-behind children.

This study showed that it is through the intersection of gender norms, legal immigration status and access to financial resources that men steer their fathering across national borders. Fathers facing lack of finances or illegal residency in the Netherlands were likely to reinforce traditional gender norms whereby mothers not fathers were responsible for children's emotional support. Emotional distance, I found, is particularly pronounced for undocumented and low-income migrants who are legally or financially incapable of bridging the emotional gulf arising from physical distance. For them, migration becomes a double-edged sword: they celebrate the material benefits of income derived from migration for the enhancement of their children's education, but they question the consequences of their physical absence from their offspring.

My findings give body to the argument that political and economic constraints shape transnational fatherhood practices and experiences (Kilkey et al., 2014), and adds a male perspective to more recent literature that investigates the intersection of migration policies, access to economic resources and transnational family life that tends to focus on transnational mothers (Baldassar \& Wilding, 2014; Banfi \& Boccagni, 2011; Fresnoza-Flot, 2009; Horton, 2009; Menjívar, 2012; Parreñas, 2005a; Zontini, 2004). My examination has allowed for a better understanding of how larger macro-economic and structural factors shape cross-border kin relationships and care practices, and how these factors create and recreate inequalities between migrants and their transnational families along gender, class and ethnic lines, all the while recognising that migrants do not all share the same precarious conditions. This recognition has added an important layer to the analysis of the ways in which transnational family ties are maintained, which, as also Hoang and Yeoh (2012) argued, is not only a matter of family dynamics and personal preferences, as implied by Bryceson and Vuorela's (2002) concept of 'relativising'. Significantly, the political and socio-economic contexts in which such families operate regulate the options and choices of transnational caregiving (Wong, 2014; Zentgraf \& Chinchilla, 2012). In fact, this study corroborates recent quantitative studies that found that legal and socio-economic statuses are better predictors of transnational parents' emotional well-being (Dito, Mazzucato \& Schans, 2017) and patterns of transnational communication (Hoang \& Yeoh, 2012) than gender. This re-emphasises Horton's (2009: 21) warning that studying transnational separation primarily through a gendered lens reduces the emotional distress of the different actors involved to mere 'gender false consciousness'. Hence, consequences of separation are not homogenous and should not only be related to gendered scripts, but also to external factors that mediate how the 
different actors experience family separation and how they cope with this (DuquePáramo, 2012; Mazzucato \& Schans, 2011).

\subsubsection{Perpetuation and Creation of Inequalities and Shifting Child-Raising Arrangements}

Finally, this thesis emphasises that cultural norms of parenting and family care are not static, but undergo shifts, as the micro-politics of power and status within the transnational context complicate everyday kin work and caregiving. This forces a constant mediation and renegotiation of inequalities, expectations and responsibilities between those who move and those who stay behind (Bryceson \& Vuorela, 2002; Dreby \& Adkins, 2010; Drothbohm, 2009). Here I wish to emphasise two findings: 1) the migration project and the geographical distance complicate the maintenance of kinship care in different ways, yet, through the careful management of communication and finances, care relationships are navigated, and 2) inequalities in gender relationships are perpetuated in case fathers migrate and mothers stay behind.

\section{a. Managing childcare relationships within extended kinship networks}

Cultural norms of fostering and social parenthood provide the normative groundwork for transnational child-raising arrangements, making flexible family arrangements for transnational families, whereby migrant parents and caregivers work together to maintain cross-border family life and care (see section 9.2.1). However, maintaining relationships of care across national borders is a complicated process. Parents move abroad with the idea of providing a better future for their children in material terms. Having a caregiver who handles the remittances sent by the migrant parent properly and who treats the child as 'his or her own' is a necessity to make the migration project successful.

Transnational child-raising arrangements operate in a context which does not only bring opportunities, in terms of access to finances, but also uncertainties in accessing finances and curtailed mobility through strict migration regimes (see section 9.2.2). It is within this context that family members on both sides work hard to maintain relationships of care through everyday kin work, a term my co-authors and I borrowed from Di Leonardo (1987) to emphasise the active and deliberate nature to forge and maintain care relationships across national borders. As we showed in Chapter Eight, this process is not automatic. The implicit nature of informal care arrangements creates challenges on both sides of the care relationship and it is through the careful management of communication and finances that care relationships are navigated.

We found that the day-to-day care and kin work involves not only the visible, but also the invisible actions - what people do and do not do — to make kinship relationships of care work. Caregivers abstain from communicating to the parent financial shortcomings and deviant behaviour of the child. In an effort to limit children's complaints to the migrant parent, they treat children carefully and fill financial gaps left by the migrant parent. Hence, even in stressful situations, caregivers manage communication and use the geographic distance to hide the truth. This behaviour, we argue, is guided by norms 
of social parenthood and the societal disgrace that would result from being considered a person who wants to profit from the care arrangement or who does not treat a child the proper way (see also Dankyi, 2014).

Contrary to what is reported for traditional fostering arrangements (Bledsoe, 1990; Notermans, 2008), migrant parents maintain a more active role in their children's lives via regular long-distance communication, the sending of gifts, as well as monetary remittances and return visits. At the same time, they too have a stake in maintaining trustworthy relationships especially in case of limited care alternatives and constrains in terms of financial resources and legal status. Consequently, they tend to keep their worries over material and immaterial care to themselves, and secretly have others check on the children when their financial resources and legal status permits them from traveling to the origin country.

Maintaining care relationships is thus a delicate process that involves a lot of time and effort on both sides. This is especially the case, as was found in this study, when such care arrangements involve caregivers who are not the child's grandparents or, generally, when care relationships do not build on long-term relationships of trust. Yet since both migrant parents and caregivers have a stake in maintaining such relationships, limited remittances and alleged misuse of remittances or maltreatment of the child rarely leads to open conflicts, as has been suggested for migrants from other destination countries (see for instance Dreby, 2010 on Mexican transnational families). In the few cases that conflicts erupted and trust was impaired, both children and migrant parents confessed that this had a negative impact on the care provided by the caregiver and on the emotional well-being of the different actors involved.

My study reveals that whereas moral kinship obligations provide the basis for longlasting cooperation within extended kinship care networks, the migration project and the geographical distance complicate the maintenance of kinship care. In other words, cultural child-raising norms and practices are not blueprints for the transnational context (Mazzucato \& Schans, 2011). Rather, the transnational context has a transformative effect on established traditions. Tacit expectations, enduring moral obligations, and constraints related to the actors' legal and socio-economic status make both parties work hard to maintain care relationships through the strategic navigation of finances, communication, and control. These findings contribute to our understanding of the ways in which long-distance practices facilitate the maintenance of family life and kin relationships and how the inability to perform these can lead to tensions. At the same time, this study counters the idea that child mobility is unproblematic and corroborates more recent anthropological kinship studies and transnational family studies that point to tensions within African parent-caregiver relationships (Akesson, Drothbohm \& Carling, 2012; Notermans, 2008). By including the perspectives of both migrant parents and the caregivers, my study sheds light on dynamics within care relationships in case the caregiver is not the child's biological parent, thereby adding original knowledge to the study of transnational families. 


\section{b. Perpetuation of gender inequalities when fathers migrate and mothers stay bebind}

How migration accentuates and feeds into new power inequalities, thereby transforming familial relationships, was demonstrated in Chapter Six. Here I revealed that men's financial and emotional support roles occasionally led to transnational family discord. Matrilineal family structures prescribe children as belonging to the mother's family. Concurrently, the one who financially caters for the child is assigned privileged rights. While not particular to the migration context, global wage inequalities and men's role as long-distance family breadwinners gives them greater decision-making power over their children. Fathers who became dissatisfied with the way their (ex-)wives or her relatives managed their remittances or disapproved of the care received by their children, in some cases, chose to challenge their wives' childcare and matrilineal customs, then took action to informally transfer the care of their children to their relatives on the paternal side of the extended family. Such a transfer stimulated in transnational fathers an active engagement in their children's lives, especially following strained relationships with the children's mother. At the same time, however, stay-behind mothers were pushed into dependent positions and forced separations from their children.

Given the matrilineal customs and gendered care responsibilities, it was more common for children of female migrants to already stay with their maternal relatives. The few female migrants whose children were living with their ex-husband in Ghana remarked that their migration project was largely motivated by the prospect of increased financial resources. They hoped that this would give them more decision-making power over their children's lives and increased leverage to move their children to maternal relatives. There are indications that the migration project increases Ghanaian female migrants' power vis-à-vis their stay-behind husbands, since women who migrate alone are more likely to divorce (Caarls and Mazzucato, 2015). Nonetheless, if and how migration rearranges gendered care roles and inequalities from the perspective of female migrants and male caregivers does merit more research (see also Section 9.3).

As I showed, migration may enhance the socio-economic position of the migrant's family in the origin country, whereas at the same time it may perpetuate asymmetries in gender relations, for migrants' resource accumulation increases their social power and leverage vis-à-vis those in the home country (Levitt and Glick Schiller, 2004). These findings underline that, while migration and transnational child-raising arrangements may be considered a particular form of 'cross-border social protection' that 'constitute(s) an adaptive response to social risks and related inequalities of opportunities' (Faist \& Bilecen, 2015: 283), they at the same time perpetuate, exacerbate, and recreate intrahousehold conflicts, inequalities and power imbalances (Dreby \& Adkins, 2010).

More generally, the multi-sited research design enabled me to show how both the home and host country contexts shape the way families function across national borders. I have demonstrated from the perspectives of migrant parents and stay-behind children how cultural repertoires of gendered caregiving pertaining to the home society shape transnational child-raising arrangements and how the transnational context in turn transforms traditional practices of care. Moreover, I have shown how the political 
context of the host society, alongside gendered scripts, determines transnational family configurations, practices and its consequences for and between the different members involved.

\subsection{Where to go from Here? Directions for Future Research}

Although this study filled some of the knowledge gaps left in transnational family research and contributed to a growing body of literature that recognises migrants and non-migrants' situatedness in the home and host countries' contexts, the study was not all-comprehensive. In this final section, I identify some of the methodological limitations as well as interesting directions for future research.

This research offered unique opportunities to study transnational child-raising arrangements from the perspectives of different actors in their respective host and home country contexts through the collection of multi-sited and in-depth data, and the use of a variety of methodological tools. However, since the findings of qualitative studies are confined to the time, place and people studied (Baxter \& Eyles, 1997), it would be inappropriate to claim that my findings on its own can be transferred to other contexts or to a wider population. Nonetheless, my collaboration in the larger TCRA team allowed me to check my findings against those obtained from the quantitative study where data were collected in a more systematic way and compared against a control group of parents and children who had no experience living in transnational family configurations. Despite the qualitative nature of the study and the relatively small sample size, I would like to argue that the findings are still of broader interest as this specific case forms a relevant comparison for transnational families from other sending regions and points to more general observed dynamics within transnational child-raising arrangements. At the same time, it would be worth investigating, in-depth, transnational families from other African countries to better understand how these particular sending contexts affect transnational child-raising arrangements.

Second, the lack of a comparison group of national and regional fostering limited the possibility to differentiate the specificities of child-raising arrangements in the intercontinental context in detail. This is particularly relevant since one of the aims of the research was to discern how long-distance migration affects locally practiced childraising arrangements. Although I was able to identify particular changes in child-raising practices that could be related to intercontinental migration of the parents, a comparative study of child-raising arrangements in the national context or in the context of intracontinental migration is necessary to assess how different migration flows and destination countries affect families and caregiving across borders. The recent research project 'The functioning and consequences of transnational child-raising arrangements in South and North: Angolan, Nigerian and Ghanaian migrant parents living in South Africa and the Netherlands' (TCRA-SAN) by Maastricht University and the University of Cape Town is worth mentioning as it has undertaken a study that compared 
transnational child-raising arrangements within the context of South-North and SouthSouth migration. More studies that incorporate a comparative dimension that includes internal and/or South-South migration are necessary to expose the dynamics and effects of particular migration flows.

Third, different actors in the child-raising arrangement were included in the current study. Nonetheless, it has largely focused on transnational families that included kin and non-kin caregivers, since one of the aims of the study was to assess child fostering norms and practices in the context of international migration and to include a category of caregivers which to date were largely missing from transnational family literature. The decision to pay less attention to transnational families where the caregiver was the child's biological parent left certain empirical gaps, for instance, I was unable to assess-from the perspective of those who stay and those who move-how migrants and their (ex-) spouses maintain relationships and how power asymmetries in (ex-)spousal relationships are affected over time and space.

Moreover, whereas this study has contributed to literature that examines the care activities of migrant fathers, thereby shedding more light on men's caring activities in a transnational context (Dreby, 2010; Nobles, 2011; Parreñas, 2008; Pribilsky, 2004), like others, it did not include the care work of stay-behind fathers when mothers migrate (see Fresnoza-Flot, 2014 for a notable exception). The study of stay-behind fathers who care for their children would help to develop further insight regarding men's care work within transnational families. For instance, it can be asked what factors influence fatherchild co-residence in case of absent mothers, and it may be useful to explore the types of care the father and his support network provide. Moreover, it may be interesting to understand if and how the transnational arrangement recreates gender roles and power inequalities, and how it changes relationship dynamics, both between stay-behind fathers and migrant mothers, and between stay-behind fathers and their children.

Fourth, like the bulk of transnational family studies, this study concentrated on family members who live geographically-dispersed, thereby failing to take into account postreunification dynamics. The few studies that explore post-reunification processes conclude that family reunion, especially after protracted separations, is often complicated due to loss of parental authority, estrangement, and difficulties in reestablishing intimate relationships (Artico, 2003; Bernhard, Goldring \& Landolt, 2005; Bonizzoni, 2009; Fresnoza-Flot, 2015; Menjívar, 2012; Suárez-Orozco, Todorova \& Louie, 2002). Interviews with key persons in the Ghanaian community in the Netherlands revealed that also among Ghanaian families, family reunion is often problematic after lengthy separations. Problems are related to transnational differences in socio-economic status, different expectations surrounding the child's daily life upon reunion, and estrangement after lengthy separations. Nonetheless, one of the key experts from the Ghanaian migrant community mentioned that the majority of reunited families are relatively problem-free. It would be interesting to study in greater depth the factors that influence post-reunification processes and how parents and children respond to problems that arise. Caarls et al. (2013) found that a large percentage of reunification 
between parents and children occurs in the origin country. It would therefore also be useful to study the reunification processes not only in terms of length of separation, with whom and under what circumstances, but also where reunification occurs.

I would also like to call for research that examines the long-term effects of transnational family configurations, of which much currently remains unclear (Castañeda \& Buck, 2011). It would be particularly useful to examine the long-term effects of transnational family life on children's educational, familial and migration decisions and aspirations once they move into adulthood. This will help us better understand intergenerational transmission of parental migration and transnational family life. Such research could also include how former stay-behind children respond to double care responsibilities for aged migrant parents and caregivers. Although traditionally this task falls upon the children whom caregivers and parents have raised, little is known about the ways in which former stay-behind children respond to aged care demands in a transnational context.

Furthermore, it would be useful for future research to focus more attention on transnational family arrangements which include hired help. Migrants increasingly turn to institutionalised and commercialised care within transnational family care arrangements (Coe, 2011b; Dankyi, 2014). The increased reliance on paid caregivers for the elderly and for minor children can be related to the diminished role of extended family care networks, especially in urban areas, but is also a result of migrants wanting to avoid familial tensions and conflicts that may arise from extended family care (Coe, 2011b). Researching such care arrangements could shed light on transnational exchanges of money and care within the Global South — a field of study that has largely centred around migrant women who perform paid care in the Global North. Since it can be expected that it is especially higher earning and higher-educated families who participate in paid care arrangements, such a focus would also allow us to better understand the dynamics and outcomes for highly-skilled transnational family care, which to date remains under-researched (see Wong, 2014 for an exception).

This study has made an original contribution to transnational family studies in terms of its theoretical and methodological approaches. By situating transnational child-raising arrangements in the home and host country contexts, this study provided a deeper understanding of the ways in which transnational family care is locally anchored and how, in turn, these local norms and practices reconfigure in transnational social space. Moreover, the multi-sited research design, and, more specifically, the innovative SMS methodology that was first applied to the study of transnational families in this research project, facilitated the incorporation of multiple actors within the transnational care network and revealed important relationship dynamics that would otherwise have been more difficult to capture. I therefore call for more collaborative transnational research projects that allow for the incorporation of multiple actors and localities in which the actors are located.

Such a research design that includes different researchers in different localities does not only acknowledge that people in transnational networks are simultaneously engaged 
with more than one locality, but also enables one to observe how this simultaneous engagement in turn shapes the social fabric of transnational care networks. Finally, I would like to call attention to the advantages of having a mixed team of origin and destination country researchers operating in a single study. Alongside advantages pertaining to gaining access to respondents and having a thorough understanding of the different cultural repertoires and contexts, it also allows knowledge to circulate between the Global North and South and to be applied in the multiple research settings. Such a research setup breaks with more conventional research where the researcher and the research setting in the Global North usually remain beneficiaries of the research. 



\section{References}

Aboderin, I. (2004). Decline in material family support for older people in urban Ghana, Africa: Understanding processes and causes of change. Journal of Gerontology: Social Sciences, 59(3), 128-137.

Abrego, L. (2009). Economic Well-Being in Salvadoran Transnational Families: How Gender Affects Remittance Practices. Journal of Marriage and Family, 71(4), 1070-1085.

Adepoju, A. (1988). International migration in Africa South of the Sahara. In R. Appleyard (Ed.), International Migration Today: Vol. 1 Trends and Prospects (pp. 17-88). Paris/Canberra: UNESCO and Australian National University.

Adepoju, A. (1995). Emigration dynamics in Sub-Saharan Africa. International Migration, 33(3/4), 205-223.

Adepoju, A. (2000). Recent trends in international migration in Sub-Saharan Africa. International Social Sciences Journal, 52(165), 383-394.

Adepoju, A. (2001). Regional organization and intraregional migration in sub-Saharan Africa: Challenges and prospects. International Migration, 39(6), 43-60.

Adepoju, A. (2005) African Families in the Twenty-First Century. Prospects and Challenges. New York: iUniverse.

Adepoju, A. (2006). Internal and international migration within Africa. In P. Kok, D. Gelderblom, J. O. Oucho \& J. van Zyl (Eds.), Migration in South and Southern Africa (pp. 26-45). Cape Town: Human Sciences Research Council Press.

Adviescommissie voor Vreemdelingenzaken (CVZ) (2002). V reemdelingen in bewaring: Advies over vreemdelingenbewaring en verwijdering van 'criminele' vreemdelingen. Den Haag: Adviescommissie voor Vreemdelingenzaken.

Akabzaa, T., Asiedu, A., Budu, A., Quartey, P., \& Akuoni, S. (2010). Migration and economic development in Ghana. Accra: Woeli Publishing Services.

Åkesson, L., Carling, J., \& Drotbohm, H. (2012). Mobility, moralities and motherhood: Navigating the contingencies of Cape Verdean lives. Journal of Ethnic and Migration Studies, 38(2), 237-260.

Akresh, R. (2005). Risk, Network Quality, and Family Structure: Child Fostering Decisions in Burkina Faso. (Discussion paper series IZA DP No. 1471). Bonn: Institute for the Study of Labor.

Akyempong, E. (2000). Africans in the Diaspora: The Diaspora in Africa. African Affairs, 99(395), 183-215.

Alber, E. (2003). Grandparents as foster parents. Changes in caregiving relationships between grandparents and grandchildren among the Baatombu in northern Benin. Anthropos, 98(2), 445-460.

Allman, J. (1996). Rounding up spinsters: gender chaos and unmarried women in colonial Asante. Journal of African History, 37(2), 195-214.

Anarfi, J.K. (1982). International labour migration in West Africa: A case study of the Ghanaian migrants in Lagos, Nigeria. Accra: Regional Institute for Population Studies.

Anarfi, J.K., Awusabo-Asare, K., \& Nsowah-Nuamah, N. (2000). Push and pull factors of international migration. Country report: Ghana (Eurostat Working Papers 2000/E (10)). European Commission, Statistical Office of the European Communities.

Anarfi, J.K., Kwankye, S., Ababio, O-M., \& Tiemoko, R. (2003). Migration from and to Ghana: A background paper. Brighton: Development Research Centre on Migration, Globalisation \& Poverty, University of Sussex.

Andres, C. (2009). Being in fosterage: An exploration of the experiences of Ghanaian children and youth. Unpublished master's thesis, Universitetet I Oslo, Oslo.

Andvig, J. (2000). An Essay on Child Labour in Sub-Sabaran Africa - A Bargaining Approach (Working Paper 613). Oslo: Norwegian Institute of International Affairs.

Aranda, E.M. (2003). Global care work and gendered constraints. The case of Puerto Rican transmigrants. Gender \& Society, 17 (4), 609-626.

Arendell, T. (2000). Conceiving and investigating motherhood: The decade's scholarship. Journal of marriage and family, 62(4), 1192-1207.

Artico, C. (2003). Latino Families Broken by Immigration: The Adolescents'Perception. New York: LFB Scholarly Publishing.

Asis, M. (2006). Living with migration: experiences of children left-behind in the Philippines. Asian Population Studies, 2(1), 45-67.

Assimeng, M. (1999). Social structure of Ghana. A study of persistence and change. Accra: Ghana Publishing Corporation.

Avila, E.M. (2008). Transnational motherhood and fatherhood: Gendered challenges and coping. University of Southern California. 
Awumbila, M., Alhassan, O., Badasu, D.M., Antwi Bosiakoh, T., \& Dankyi, E.K. (2011). Socio-cultural dimensions of migration in Ghana. Centre for Migration Studies. Migration Studies Technical Paper Series, No. 3. Accra: Woeli Publishing Services.

Awumbila, M., Manuh, T., Quartey, P., Tagoe, C. A., \& Bosiakoh, T. A. (2008). Migration country paper (Ghana). Legon: Centre for Migration Studies, University of Ghana.

Badasu, D. M. (2004). Child care among ewe migrants in the city of Accra: cases of crisis. Institute of African Studies Research Review, (Supplement 6), 17-37.

Bakewell, O., \& De Haas, H. (2007). African Migrations: continuities, discontinuities and recent transformations. In L. Haan, U. Engel \& P. Chabal (Eds.), African alternatives (pp. 95-118). Leiden: Brill.

Baldassar, L. (2007). Transnational families and the provision of moral and emotional support: The relationship between truth and distance. Identities: Global Studies in Cultural and Power, 14(4), 385-409.

Baldassar, L. (2008). Missing kin and longing to be together: Emotions and the construction of co-presence in transnational relationships. Journal of Intercultural Studies, 29(3), 247-266.

Baldassar, L., \& Baldock, C. (2000). Linking migration and family studies: Transnational migrants and the care of ageing parents. In B. Agozini (Ed.), Theoretical and methodological issues in migration research (pp. 61-89). Aldershot: Ashgate.

Baldassar, L., \& Merla, L. (2014). Introduction: Transnational family caregiving through the lens of circulation. In L. Baldassar \& L. Merla (Eds.), Transnational families, migration and the circulation of care. Understanding mobility and absence in family life (pp. 3-24). New York: Routledge.

Baldassar, L., \& Wilding, R. (2014). Middle-class transnational caregiving: The circulation of care between family and extended kin networks in the Global North. In L. Baldassar \& L. Merla (Eds.), Transnational families, migration and the circulation of care. Understanding mobility and absence in family life (pp. 235-252). New York: Routledge.

Baldock, C. (2000). Migrants and their parents. Journal of Family Issues, 21(2), 205-225.

Banfi, L., \& Boccagni, P. (2011). Transnational family life and female migration in Italy: one or multiple patterns? In A. Kraler, E. Kofman, M. Kohli, \& C. Schmoll (Eds.), Gender, generations and the family in international migration (pp. 287-311). Amsterdam: Amsterdam University Press.

Barglowski, K., Bilecen, B., \& Amelina, A. (2015). Approaching transnational social protection: methodological challenges and empirical applications. Population, Space and Place, 21(3), 215-226.

Basch, L., Glick Schiller, N., \& Szanton-Blanc, C. (1994). Nations unbound: Transnational projects, postcolonial predicaments, and deterritorialized nation-states. London: Routledge.

Baxter, J., \& Eyles, J. (1997). Evaluating qualitative research in social geography: establishing 'rigour' in interview analysis. Transactions of the Institute of British geographers, 22(4), 505-525.

Bernardes, J. (1999). We must not define 'The Family'! Marriage and Family Review, 28 (3), 21-41.

Bernhard, J.K., Goldring, L., \& Landolt, P. (2005). Transnational, multi-local motherhood: Experiences of separation and reunification among Latin American families in Canada (CERIS Working Paper No. 40). Toronto: Joint Centre for Excellence for Research on Immigration and Settlement.

Bernhard, J.K, Landolt, P., \& Goldring, L. (2009). Transnationalizing families: Canadian immigration policy and the spatial fragmentation of care-giving among Latin American newcomers. International Migration, 47(2), 3-31.

Biblarz, T.J., \& Stacey, J. (2010). How does the gender of parents matter? Journal of Marriage and Family, 72(1), 3-22.

Bijlmer in tijd (n.d.). In chronologische volgorde, van opbouw naar afbraak, sloop en eengezins. Retrieved from https://bijlmermuseum.wordpress.com/de-bijlmer-in-tijd/

Black, R., Quartey, P., Castagnone, E., Nazio, T., Schoumaker, B., \& Rakotonarivo, N. (2013). Understanding AfroEuropean labour trajectories: Integration of migrants into the European labour market \& reintegration into the country of origin: The case of Ghana (MAFE Working Paper 28). Retrieved from http://www.ined.fr/fichier/s_rubrique/ 22089/wp28._ghana_economy.fr.pdf.

Bledsoe, C. (1990). 'No success without struggle'. Social mobility and hardship for foster children in Sierra Leone. Man, 25(1), $70-88$.

Bledsoe, C., Houle, R., \& Sow, P. (2007). High fertility Gambians in low fertility Spain: The dynamics of child accumulation across transnational space. Demographic research, 16(12), 375-412.

Bledsoe, C., \& Sow, P. (2008). Family reunification ideals and the practice of transnational reproductive life among Africans in Europe (MPIDR Working paper WP 2008-001). Rostock: Max Planck Institute for Demographic Research.

Bledsoe, C., \& Sow, P. (2011). Back to Africa: Second chances for the children of West African immigrants. Journal of Marriage and Family, 73(4), 747-762.

Block, K., Warr, D., Gibbs, L., \& Riggs, E. (2012). Addressing ethical and methodological challenges in research with refugee-background young people: reflections from the field. Journal of Refugee Studies, 26(1), 69-87. 
Boateng, D.S. (1996). The changing family and national development in Ghana. In E. Ardayfio-Schandorf (Ed.), The changing family in Ghana (pp. 1-4). Accra: Ghana Universities Press.

Boccagni, P. (2012). Practising motherhood at a distance: Retention and loss in Ecuadorian transnational families. Journal of Ethnic and Migration Studies, 38(2), 261-277.

Boehm, D.A. (2008). 'For my children:' Constructing family and navigating the state in the U.S.-Mexico transnation. Anthropological Quarterly, 81(4), 777-802.

Bögels, S., \& Phares, V. (2008). Fathers' role in the etiology, prevention and treatment of child anxiety: A review and new model. Clinical psychology review, 28(4), 539-558.

Boni, S. (2001). Twentieth-century transformations in notions of gender, parenthood, and marriage in Southern Ghana: A critique of the hypothesis of 'retrograde steps' for Akan women. History in Africa, 28, 15-41.

Bonizzoni, P. (2009). Living together again: families surviving Italian immigration policies. International Review of Sociology, 19(1), 83-101.

Bonizzoni, P., \& Boccagni, P. (2014). Care (and) circulation revisited: a conceptual map of diversity in transnational parenting. In L. Baldassar \& L. Merla (Eds.), Transnational Families, Migration and the Circulation of Care: Understanding Mobility and Absence in Family Life (pp. 78-93). New York: Routledge.

Bonjour, S. (2009). Grens en Gezin. Beleidsvorming Inzake Gezinsmigratie in Nederland, 1955-2005. Ph.D. dissertation, Maastricht University. Amsterdam: Aksant.

Bonjour, S., \& de Hart, B. (2013). A proper wife, a proper marriage. Constructions of 'us' and 'them' in Dutch family migration policy. European Journal of Women's Studies, 20(1), 61-76.

Bowie, F. (2004). Adoption and the circulation of children. A comparative perspective. In F. Bowie (Ed.) Crosscultural approaches to adoption (pp. 3-20). London: Routledge.

Brettell, C.B. (2000). Theorizing migration in anthropology. The social construction of networks, identities, communities, and globalscapes. In C.B. Brettell \& J.F. Hollifield (Eds.), Migration theory (pp. 97-137). New York: Routledge.

Brettell, C. B., \& de Berjeois, P. A. (1992). Anthropology and the study of immigrant women. In D. Gabaccia (Ed.), Seeking common ground: multidisciplinary studies of immigrant women in the United States (pp. 41-63). Westport, CT: Greenwood Press.

Broeders, D. (2010). Return to sender? Administrative detention of irregular migrants in Germany and the Netherlands. Punishment \& Society, 12(2), 169-186.

Broeders, D., \& Engbersen, G. (2007). The fight against illegal migration. Identification policies and immigrants' counterstrategies. American Behavioral Scientist, 50(12), 1592-1609.

Bryceson, D.F. (2002). Europe's transnational families and migration: Past and present. In D.F. Bryceson \& U. Vuorela (Eds.), The transnational family. New European frontiers and global networks (pp. 31-59). Oxford and New York: Berg.

Bryceson, D.F., Vuorela, U. (2002). Transnational families in the twenty-first century. In D.F. Bryceson, \& U. Vuorela (Eds.), The transnational family. New European frontiers and global networks (pp. 3-30). Oxford and New York: Berg.

Brydon, L. (1985). Ghanaian responses to the Nigerian expulsions of 1983. African Affairs, 84(337), 561-585.

Burawoy, M. (1991). The extended case method. In M. Burawoy (Ed.), Ethnography unbound: power and resistance in the modern metropolis (pp. 271-290). Berkeley: University of California Press.

Burgers, J., \& Engbersen, G. (1999). De ongekende stad I. Ilegale vreemdelingen in Rotterdam. Amsterdam: Boom.

Burt, R.S. (1984). Network items and the general social survey. Social networks, 6(4), 293-339.

Caarls, K. (2015). Living apart together across borders. How Ghanaian couples form, transform, or dissolve in the context of international migration. Doctoral thesis, Maastricht University.

Caarls, K., Haagsman, K, Kraus, E.K., \& Mazzucato, V. (2018). African transnational families: cross-country and gendered comparisons. Population, Space and Place, 24: e2162.

Caarls, K., \& Mazzucato, V. (2015). Does International Migration Lead to Divorce? Ghanaian Couples in Ghana and Abroad. Population, English edition, 70(1), 127-150.

Caarls, K., Mazzucato, V., Schans, D., Quartey, P., \& Addoquaye Tagoe, C. (2013). Transnational families between Ghana, The Netherlands and the U.K (MAFE Working Paper 32). Retrieved from http://www.ined.fr/ fichier/t_telechargement/65536/telechargement_fichier_fr_wp32_working.paper_ghana_family_v3_131202 .pdf.

Caarls, K., Schans, D., Mazzucato, V., Quartey, P., \& Tagoe, C.A. (2017). Transnational families between Ghana, the Netherlands and the UK. In C. Beauchemin (Ed.), Migration between Africa and Europe. Verlag Berlin Heidelberg, New York: Springer. 
Cabrera, N.J., Tamis-LeMonda, C.S., Bradley, R.H., Hoffert, S., \& Lamb, M.E. (2000). Fatherhood in the twentyfirst century. Child Development, 71(1), 127-136.

Caldwell, J.C. (1968). Population growth and family change in Africa: the new urban elite in Ghana. Canberra: Australian National University Press.

Campbell, K.E., \& Lee, B.A. (1991). Name generators in surveys of personal networks. Social networks, 13(3), 203221.

Carling, J. (2008) The human dynamics of migrant transnationalism. Ethnic and Racial Studies, 31(8), 1452-1477.

Carling, J., Menjívar, C., \& Schmalzbauer, L. (2012). Central themes in the study of transnational parenthood. Journal of Ethnic and Migration Studies, 38(2), 191-217.

Castañeda, E., \& Buck, L. (2011). Remittances, transnational parenting, and children left behind: Economic and psychological implications. The Latin Americanist, 55(4), 85-110.

Castles, S., \& Miller, M.J. (2009). The age of migration. International population movements in the modern world (4 ${ }^{\text {th }}$ edition). New York: Palgrave MacMillan.

Cebotari, V., \& Mazzucato, V. (2016). Educational performance of children of migrant parents in Ghana, Nigeria and Angola. Journal of Ethnic and Migration Studies, 42(5), 834-856.

Cebotari, V., Mazzucato, V., \& Appiah, E. (2017). A Longitudinal Analysis of Well-Being of Ghanaian Children in Transnational Families. Child development. doi:10.1111/cdev.12879

Cebotari, V., Mazzucato, V., \& Siegel, M. (2017a). Child development and migrant transnationalism: The health of children who stay behind in Ghana and Nigeria. The Journal of Development Studies, 53(3), 444-459.

Cebotari, V., Mazzucato, V., \& Siegel, M. (2017b). Gendered perceptions of migration among Ghanaian children in transnational care. Child indicators research, 10(4), 971-993.

Centraal Bureau voor de Statistiek (CBS) (2016). Immigratie van niet-Nederlanders migratiemotief, geboorteland, leeftijd. Retrieved from http://statline.cbs.nl/Statweb/publication/?DM=SLNL\&PA=70693ned\&D1=1$6 \& \mathrm{D} 2=0 \& \mathrm{D} 3=26 \& \mathrm{D} 4=0 \& \mathrm{D} 5=\mathrm{a} \& \mathrm{HDR}=\mathrm{T}, \mathrm{G} 1, \mathrm{G} 2, \mathrm{G} 3 \& \mathrm{STB}=\mathrm{G} 4 \& \mathrm{VW}=\mathrm{T}$

Centraal Bureau voor de Statistiek (CBS) (2018a). Bevolking; generatie, geslacht, leeftijd en migratieachtergrond. Retrieved from http://statline.cbs.nl/Statweb/publication/?DM=SLNL\&PA=37325\&D1=a\&D2=0\&D3= $0 \& \mathrm{D} 4=0 \& \mathrm{D} 5=85 \& \mathrm{D} 6=0,4,9,14,19-21 \& \mathrm{VW}=\mathrm{T}$

Centraal Bureau voor de Statistiek (CBS) (2018b). Bevolking op 1 januari; leeftijd, geboorteland en regio. Retrieved from http://statline.cbs.nl/Statweb/publication/?DM=SLNL\&PA=70648ned\&D1=0\&D2=a\&D3=21\&D $4=0,5,82,272 \& D 5=0,4,9,14,1 \& H D R=G 4, T, G 3 \& S T B=G 2, G 1 \& V W=T$

Chelpi-den Hamer, M., \& Mazzucato, V. (2007). Goodwill-limited capacities: The role of support networks in the settlement of African newcomers in the Netherlands. Paper presented at conference 'International migration, multi-local livelihoods and human security: Perspectives from Europe, Asia and Africa. The Hague, Institute of Social Studies.

Chereni, A. (2015). Fathering and gender transformations in Zimbabwean transnational families. Forum: Qualitative Social Research, 16(2). Retrieved from http://nbn-resolving.de/irm:nbn:de:014-fqs1502209.

Chiswick, B. (2000). The economics of illegal immigration for the host economy. In D. Çinar, A. Gächter \& H. Waldrauch (Eds.), Irregular migration: dynamics, impact, policy options (pp. 165-174). Vienna: European Centre.

Clark, G. (1994). Negotiating Asante family survival in Kumasi, Ghana. Africa, 69(1), 66-86.

Clark, G. (1999). Mothering, work, and gender in urban Asante ideology and practice. American Anthropologist, 101(4), 719-729.

Coakley, T.M., Shears, J.K., \& Randolph, S.D. (2014). Understanding Key Barriers to Fathers' Involvement in Their Children's Lives. Child \& Youth Services, 35(4), 343-364.

Coe, C. (2008). The structuring of feeling in Ghanaian transnational families. City \& Society, 20(2), 222-250.

Coe, C. (2011a). What is the impact of transnational migration on family life? Women's comparisons of internal and international migration in a small town in Ghana. American Ethnologist, 38(1), 148-163.

Coe, C. (2011b). What is love? The materiality of care in Ghanaian transnational families. International Migration, 49(6), 7-24.

Cohen, R. (2000). 'Mom is a stranger': the negative impact of immigration policies on the family life of Filipina domestic workers. Canadian Ethnic Studies, 32(3), 76-88.

Cohen, J. (2004). The culture of migration in the Southern Mexico. Austin: University of Texas Press.

Cole, M, \& Cole., S. (2001). The development of children. New York: W.H. Freeman and Company.

College voor de Rechten van de Mens (2014). Gezinnen gezien? Onderzoek naar Nederlandse regelgeving en uitvoeringspraktijk in het licht van de Europese Gezinsherenigingsrichtlijn. Utrecht: College voor de Rechten van de Mens. Retrieved from http://www.mensenrechten.nl/publicaties/detail/34772. 
Cooklin, A.R., Westrupp, E.M., Strazdins, L., Giallo, R., Martin, A., \& Nicholson, J.M. (2014). Fathers at work: work-family conflict, work-family enrichment and parenting in an Australian cohort. Journal of Family Issues, $37(11), 1-25$.

Council of the European Union (2003). Council Directive 2003/86/EC of 22 September 2003 on the Right to Family Reunification. Official Journal of the European Union, 251, 3 November 2003.

Crawford-Brown, C., \& Rattray, J.M. (2002). Parent-child relationships in Caribbean families. In N. Boyd Webb \& D. Lum (Eds.), Culturally diverse parent-child and family relationships (pp.107-130). New York. NY: Columbia University Press.

Croucher, S. (2009). Migrant of Privilege. The Political Transnationalism of American Migrants in Mexico. Identities, 16(4), 463-491.

Dankyi, E.K. (2014). Transnational child raising arrangements: An ethnographic study of transnational caregivers in Ghana. Unpublished Doctoral Thesis submitted to the University of Ghana.

Dankyi, E.K., Mazzucato, V., \& Manuh, T. (2017). Global social protection as a reciprocal process: The work of caregivers in providing care for migrants' children. Oxford Development Studies. DOI: 10.1080/13600818.2015.1124078.

D’Aubeterre, M. (2000). Mujeres y espacio transnacional: maniobras para renegociar el vinculo conyugal. In D. Barrera Bassols \& C. Oehmichen (Eds.), Migración y relaciones de género en México (pp. 63-85). Mexico: GIMTRAP. IIA/UNA.

D’Emilio, A.L., Cordero, B., Bainvel, B., Skoog, C., Comini, D., Gough, J., Dias, M., Saab, R., \& T. Kilbane (2007). The impact of international migration: Children left behind in selected countries of Latin America and the Caribbean. New York: Unicef.

Defence for Children and Unicef (2012). Jaarbericht Kinderrechten 2012. Retrieved from http://dfc.sitespirit.nl/images/20/1897.pdf.

De Hart, B., van Rossum, W., and Sportel, I.D.A. (2013). Law in the everyday lives of transnational families: an introduction. Oñati Socio-Legal Series, 3(6), 991-1003.

Desai, S. (1992). Children at Risk - the Role of Family-Structure in Latin-America and West-Africa. Population and Development Review, 18(4), 689-717.

De Souza, R.N.A. (2014). 'This Child is a Planned Baby': Skilled Migrant Fathers and Reproductive Decisionmaking. Journal of Advanced Nursing. Doi:10.1111/jan.12448.

Diepenhorst, D. (2012). Praktische maatregelen tegen illegale migratie in Nederland. Rijswijk: Ministerie van Binnenlandse Zaken en Koninkrijksrelaties.

Di Leonardo, M. (1987). The female world of cards and holidays: women, families and the work of kinship. Signs, 12(3), 440-453.

Dito, B., Mazzucato, V., \& Schans, D. (2017). The effects of transnational parenting on the subjective well-being of Ghanaian migrant parents in the Netherlands. Population Space and Place, 23(3). DOI: 10.1002/psp.2006.

Doucet, A. (2006). 'Estrogen-filled worlds': fathers as primary caregivers and embodiment. The Sociological Review, 54(4), 696-716.

Doucet, A. (2011). 'It's Just Not Good for a Man to be Interested in Other People's Children': Fathers, Public Displays of Care and 'Relevant Others. In E. Dermott \& J. Seymour (Eds.), Displaying Families: new theoretical directions in family and intimate life (pp. 81-101). London: Palgrave Macmillan.

Dreby, J. (2006). Honor and virtue: Mexican parenting in the transnational context. Gender \& Society, 20(1), 32-59.

Dreby, J. (2007). Children and power in Mexican transnational families. Journal of Marriage and Family, 69(4), 105064.

Dreby, J. (2010). Divided by borders. Mexican migrants and their children. Berkeley: University of California Press.

Dreby, J., \& Adkins, T. (2010). Inequalities in transnational families. Sociology Compass, 4(8), 673-689.

Drotbohm, H. (2009). Horizons of long-distance intimacies: reciprocity, contribution and disjuncture in Cape Verde. The History of the Family, 14(2), 132-149.

Duque-Páramo, M.C. (2012). Parental Migration in Colombia: Children's Voices in National and International Perspectives. The Journal of Latin American and Caribbean Anthropology, 17(3), 472-492.

Ehrenreich, B., \& Hochschild, A.R. (2002). Introduction. In B. Ehrenreich \& A.R. Hochschild (Eds.), Global woman: Nannies, maids, and sex workers in the new economy (pp. 1-14). New York: Macmillan.

Emery, B.C., \& Lloyd, S.A. (2001). The evolution of family studies research. Family and Consumer Sciences Research Journal, 30(2), 197-222.

Engbersen, G., \& Broeders, D. (2009). The state versus the alien: Immigration control and strategies of irregular immigrants. West European Politics, 32(5), 867-885. 
Entzinger, H., \& Fermin, A. (2007). Gidsland achter de Waterlinie. Het recente Nederlandse immigratie- en integratiebeleid. In F. Van Tubergen \& I. Maas (Eds.), Allocbtonen in Nederland in internationaal perspectief (pp. 3763). Amsterdam: Amsterdam University Press.

Engbersen, G., Staring, R., Van der Leun, J., de Boom, J., van der Heijden, P., \& Cruijff, M.. (2002). Illegale vreemdelingen in Nederland. Omvang, overkomst, verblijf en uitzetting. Rotterdam: RISBO Contractresearch $\mathrm{BV} /$ Erasmus Universiteit.

Engbersen, G., Van der Leun, J., \& De Boom, P. (2007). Fragmentation of migration and crime in the Netherlands. Crime and justice, 35(1), 389-452.

Engbersen, G., van San, M., \& Leerkes, A. (2006). A room with a view. Irregular immigrants in the legal capital of the world. Ethnography, 7(2), 209-242.

Erel, U. (2002). Reconceptualizing motherhood: Experiences of migrant women from Turkey living in Germany. In D. Bryceson \& U. Vuorela (Eds.), The transnational family. New European frontiers and global networks (pp. 127146). Oxford: Berg.

Eurostat (2001). Push and pull factors of international migration: Country report. Ghana. Accra (Working Papers, 10). Luxembourg: Eurostat.

Faist, T. (1998). Transnational social spaces out of international migration: evolution, significance and future prospects. European Journal of Sociology/Archives Européennes de Sociologie, 39(2), 213-247.

Faist, T. (2012). Toward a transnational methodology: methods to address methodological nationalism, essentialism, and positionality. Revue européenne des migrations internationales, 28(1), 51-68.

Faist, T., \& Bilecen, B. (2015). Social inequalities through the lens of social protection: notes on the transnational social question. Population, Space and Place, 21(3), 282-293.

Falzon, M.A. (2009). Introduction. In M.A. Falzon (Ed.), Multi-sited ethnography: Theory, praxis and locality in contemporary research (pp. 1-23). Farnham: Ashgate Publishing.

Fedyuk, O. (2012). Images of transnational motherhood: the role of photographs in measuring time and maintaining connections between Ukraine and Italy. Journal of Ethnic and Migration Studies, 38(2), 279-300.

Finch, J. (2007). Displaying families. Sociology, 41(1), 65-81.

Finch, J., \& Groves D. (1983). A labour of love: Women, work, and caring. London: Routledge.

Finch, J., \& Mason, J. (1991). Obligations of kinship in contemporary Britain: Is there normative agreement? The British Journal of Sociology, 42(3), 345-67.

Fitzgerald, D. (2006). Towards a theoretical ethnography of migration. Qualitative Sociology, 29(1), 1-24.

Fleischer, A. (2011) Marriage across space and time among male migrants from Cameroon to Germany. In A. Kraler, E. Kofman, M. Kohli \& C. Schmoll (Eds.), Gender, Generations and the Family in International Migration (pp. 243264). Amsterdam: Amsterdam University Press.

Fonseca, M.L., \& Ormond, M. (2008). Defining 'family' and bringing it together: The ins and outs of family reunification in Portugal. In R. Grillo (Ed.), The family in question: immigrant and ethnic minorities in multicultural Europe (pp. 59-111). Amsterdam: Amsterdam University Press.

Foner, N. (1997a). What's new about transnationalism? New York immigrants today and at the turn of the century. Diaspora: A Journal of Transnational Studies, 6(3), 355-375.

Foner, N. (1997b). The immigrant family: Cultural legacies and cultural changes. International migration review, 31(4), 961-974.

Foner, N. (2000). From Ellis island to JFK: New York's two great waves of immigration. New Haven: Yale University Press.

Fosu, A.K. (1992). Political instability and economic growth: Evidence from Sub-Saharan Africa. Economic Development and Cultural Change, 40(4), 829-839.

Fouron, G., \& Glick Schiller, N. (2001). All in the family: gender, transnational migration, and the nationstate. Identities Global Studies in Culture and Power, 7(4), 539-582.

Fox, R.C. (2004). Observations and reflections of a perpetual fieldworker. The ANNALS of the American Academy of Political and Social Science, 595(1), 309-326.

Fresnoza-Flot, A. (2009). Migration status and transnational mothering: The case of Filipino migrants in France. Global networks, 9(2), 252-270.

Fresnoza-Flot, A. (2014). Men's Caregiving Practices in Filipino Transnational Families. In L. Baldassar and L. Merla (Eds.), Transnational families, migration and the circulation of care: Understanding mobility and absence in family life (pp. 170-184). New York: Routledge.

Fresnoza-Flot, A. (2015). Bumpy landscape of family reunification: experiences of first- and 1.5-generation Filipinos in France. Journal of Ethnic and Migration Studies, 41(7), 1152-1171.

Geddes, A., \& Scholten, P. (2016). The politics of migration and immigration in Europe. Los Angeles: Sage Publications. 
Geertz, C. (1973). The interpretation of cultures. New York: Basic.

Ghana Statistical Service (GSS) (2009). Ghana Demographic and Health Survey 2008. Accra: Ghana Statistical Service. Retrieved from https://www.dhsprogram.com/pubs/pdf/FR221/FR221[13Aug2012].pdf

Ghana Statistical Service (GSS) (2012). 2010 population \&o bousing census. Summary report of final results. Accra: Sakoa Press Limited.

Ghana Statistical Service (GSS), Ghana Health Service (GHS), and ICF International (2015). Ghana. Demographic and bealth survey 2014. Rockville, Maryland, USA: GSS, GHS, and ICF International.

Ghencea, B., \& Igor, G. (2004). Labour Migration and Remittances in the Republic of Moldova. Chisinau: Moldova Microfinance Alliance.

Glaser, B., \& Strauss, A. (1967). The discovery of grounded theory. Hawthorne, New York: Aldine Publishing Company.

Glick Schiller, N., Basch, L., \& Szanton-Blanc, C. (1992). Transnationalism: a new analytical framework for understanding migration. Annals of the New York. Academy of Sciences, 645(1), 1-24.

Glick Schiller, N., Basch, L., \& Szanton Blanc, C. (1995). From immigrant to transmigrant: theorizing transnational migration. Anthropological Quarterly, 68(1): 48-63.

Glick Schiller, N., \& Levitt, P. (2006). Haven't we heard this somewhere before? A reply to Waldinger and Fitzgerald. Transnational Studies Initiative. Retrieved from www.transnational- studies.org/pdfs/Waldinger_ Reply.pdf?abstract_id $=556993$.

Goldring, L. (2002). The Mexican state and transmigrant organizations: Negotiating the boundaries of membership and participation. Latin American Research Review, 37(3), 55-99.

Goodman, R., Meltzer, H., \& Bailey, V. (1998). The Strengths and Difficulties Questionnaire: a pilot study on the validity of the self-report version. European Child and Adolescent Psycbiatry, 7(3), 125-130.

Goody, E.N. (1982). Parenthood and social reproduction. Fostering and occupational roles in West Africa. Cambridge: Cambridge University Press.

Goulbourne, H., \& Chamberlain; M. (2001). Caribbean families in Britain and the transatlantic world. London and Oxford: Macmillan.

Grillo, R., \& Mazzucato, V. (2008). Africa-Europe: A double engagement. Journal of Ethnic and Migration Studies, 34(2), 175-198.

Grzywacz, J.G., Quandt, S.A., Early, J., Tapia, J., Graham, C.N., \& Arcury, T.A. (2006). Leaving family for work: Ambivalence and mental health among Mexican migrant farmworker men. Journal of Immigrant and Minority Health, 8(1), $85-97$.

Guarnizo, L.E. (1997). The emergence of a transnational social formation and the mirage of return migration among Dominican transmigrants. Identities Global Studies in Culture and Power, 4(2), 281-322.

Haagsman, K. (2015). Parenting across borders. Effects of transnational parenting on the lives of Angolan and Nigerian migrant parents in the Netherlands. Doctoral thesis, Maastricht University.

Haagsman, K. (2017). Do transnational child-raising arrangements affect job outcomes of migrant parents? Comparing Angolan parents in transnational and non-transnational families in the Netherlands. Journal of Family Issues, 1-25, Doi: 0192513X17710773.

Haagsman, K., \& Mazzucato, V. (2014). The quality of parent-child relationships in transnational families: Angolan and Nigerian migrant parents in the Netherlands. Journal of Ethnic and Migration Studies, 40(11), 1677-1696.

Haagsman, K., Mazzucato, V., \& Dito, B.B. (2015). Transnational families and the subjective well-being of migrant parents: Angolan and Nigerian parents in the Netherlands. Ethnic and Racial Studies, 38(15), 2652-2671.

Hammersley, M., \& Atkinson, P. (1995). Ethnography. Routledge: London.

Hannerz, U. (2003). Being there... and there... and there! Reflections on multi-site ethnography. Ethnography, 4(2), 201-216.

Hashim, I.H. (2005). Exploring the Linkages between Children's Independent Migration and Education: Evidence from Ghana (Working Paper T12). Sussex: Sussex Centre for Migration Research.

Heijke, J. (1986). Migratie van Mediterranen: economie en arbeidsmarkt. Leiden: Stenfert Kroese.

Herbert, S. (2000). For ethnography. Progress in Human Geography, 24(4), 550-568.

Heymann, J. (2006). Forgotten families: Ending the growing crisis confronting children and working parents in the global economy. Oxford: Oxford University Press.

Higazi, A. (2005). Ghana Country Study. A part of the report on Informal Remittance Systems in Africa, Caribbean and Pacific (ACP) countries. Oxford: University of Oxford.

Ho, C. (1993). The internationalization of kinship and the feminization of Caribbean migration: the case of AfroTrinidadian immigrants in Los Angeles. Human Organization, 52(1), 32-40. 
Hoang, L.A., \& Yeoh, B.S.A. (2012). Sustaining families across transnational spaces: Vietnamese migrant parents and their left-behind children. Asian Studies Review, 36(3), 307-325.

Hochschild, A. (1983). The Managed Heart. Berkeley: University of California Press.

Hondagneu-Sotelo P. (2001). Domestica: Immigrant Workers Cleaning and Caring in the Shadows of Affluence. Berkeley: University of California Press.

Hondagneu-Sotelo, P., \& Avila, E. (1997). 'I'm here, but I'm there'. The meanings of Latina transnational motherhood. Gender \& Society, 2(5), 548-71.

Horton, S. (2009). A mother's heart is weighed down with stones: a phenomenological approach to the experience of transnational motherhood. Culture, Medicine and Psychiatry, 33(1), 21-40.

Huijzer, A., \& Jakobs, E. (2013). Imago Zuidoost 2013. Vierde meting. Amsterdam: Gemeente Amsterdam, Bureau Onderzoek en Statistiek.

Human Rights Watch (2008). The Netherlands: discrimination in the name of integration. Migrants' rights under the integration abroad act. Retrieved from https://www.hrw.org/report/2008/05/13/netherlands-discrimination-nameintegration/migrants-rights-under-integration.

Iredale, R., Turpin, T., Hawksley, C., Go, S., Kanchai, S., Kuang, Y.M., Lyon, K. (2002). Migration Research and Policy Landscape. Case Studies of Australia, the Philipines and Thailand. Working Paper No. 9. Retrieved from http://unesdoc.unesco.org/images/0014/001411/141125eo.pdf

Isiugo-Abanihe, U.C. (1985). Child fosterage in West Africa. Population and Development Review, 11(1), 53-73.

Isiugo-Abanihe, U.C. (1994). Reproductive motivation and family size preferences among Nigerian men. Studies in Family Planning, 25 (3), 149-161.

Joppke, C. (2007a). Beyond national models: Civic integration policies for immigrants in Western Europe. Western European Politics, 30(1), 1-22.

Joppke, C. (2007b). Do obligatory civic integration courses for immigrants in Western Europe further integration? Focus Migration, Policy Brief. Retrieved from http:// focus-migration.hwwi.de/Do-Obligatory-Civic.25 62.0.html?\&L=1

Kastner, K. (2010). Moving relationships: family ties of Nigerian migrants on their way to Europe. African and Black. Diaspora: An International Journal, 3(1): 17-34.

Kearney, M. (1995). The local and the global: The anthropology of globalization and transnationalism. Annual Review of Anthropology, 24(1), 547-65.

Kilkey, M., \& Merla, L. (2013). Situating transnational families' care-giving arrangements: the role of institutional contexts. Global Networks, 14(2), 210-229.

Kilkey, M., Perrons, D., \& Plomien, A. (2013). Gender, migration and domestic work: masculinities, male labour and fathering in the UK and USA. New York: Palgrave Macmillan.

Kilkey, M., Plomien, A., \& Perrons, D. (2014). Migrant Men's Fathering Narratives, Practices and Projects in National and Transnational Spaces: Recent Polish Male Migrants to London. International Migration, 52(1), 178191.

King R., Cela, E., Fokkema, T., \& Vullnetari, J. (2014) The migration and well-being of the zero generation: Transgenerational care, grandparenting, and loneliness amongst Albanian older people. Population, Space and Place, 20(8), 728-738.

Kingsbury, N., \& Scanzoni, J. (2009). Structural-functionalism. In P. Boss, W.J. Doherty, R. LaRossa, W.R. Schumm \& S.K. Steinmetz (Eds.), Sourcebook of family theories and methods (pp. 195-221). Boston, MA: Springer.

Kofman, E. (1999). Female "birds of passage" a decade later: gender and immigration in the European Union. International Migration Review, 33(2), 269-299.

Kofman, E. (2004). Family-related migration: a critical review of European Studies. Journal of Ethnic and Migration Studies, 30(2), 243-262.

Kofman, E. (2012). Rethinking care through social reproduction: Articulating circuits of migration. Social Politics, 19(1), 142-162.

Kofman, E., Kraler, A., Kohli, M., \& Schmoll, C. (2011). Introduction. Issues and debates on family-related migration and the migrant family: A European perspective. In A. Kraler, E. Kofman, M. Kohli \& C. Schmoll (Eds.), Gender, Generations and the Family in International Migration (pp. 13-54). Amsterdam: Amsterdam University Press.

Konadu-Agyemang, K. (1999). Characteristics and migration experience of Africans in Canada with specific reference to Ghanaians in Greater Toronto. The Canadian Geographer, 43(4), 400-414.

König, R.S., \& de Regt, M. (2010). Family dynamics in transnational African migration to Europe: an introduction. African and Black Diaspora: An International Journal, 3(1), 1-15. 
Kraan, M. (2001). Blijven of teruggaan? Een sociologische analyse van potenties en problemen van Ghanezen in Amsterdam Zuidoost. Amsterdam: Vrije Universiteit Amsterdam.

Kraler, A. (2010). Civic stratification, gender and family migration policies in Europe. International Centre for Migration Policy Development, Vienna. Retrieved from http://www.maiz.at/sites/default/files/files/final_ report_family_migration_policies_online_final.pdf.

Kraler, A., \& Kofman, E. (2009). Family migration in Europe: policies vs. reality. IMISCOE Policy Brief, 16: 1-8.

Landolt, P., \& Da, W.W. (2005). The spatially ruptured practices of migrant families: A comparison of immigrants from El Salvador and the People's Republic of China. Current Sociology, 53(4), 625-653.

Lashley, M. (2000). The unrecognized social stressors of migration and reunification in Caribbean families. Transcultural Psychiatry, 37(2), 201-215.

Leerkes, A., \& Kulu-Glasgow, I. (2011). Playing hard(er) to get: the state, international couples, and the income requirements. European Journal of Migration and Law, 13(1), 95-121.

Leinaweaver, J.B. (2007). On moving children: The social implications of Andean child circulation. American Ethnologist, 34(1), 163-180.

Leinaweaver, J.B. (2010). Outsourcing care: How Peruvian migrants meet transnational family obligations. Latin American Perspectives, 37(5), 67-87.

Levitt, P. (2001). Transnational migration: taking stock and future directions. Global networks, 1(3), 195-216.

Levitt, P., De Wind, J., \& S. Vertovec (2003). International perspectives on transnational migration: An introduction. International Migration Review, 37(3), 565-575.

Levitt, P., \& Glick Schiller, N. (2004). Conceptualizing simultaneity: a transnational social field perspective on society. International Migration Review, 38(3), 1002-1039.

Levitt, P., \& Jaworsky, B.N. (2007). Transnational migration studies: past developments and future trends. Annual Review of Sociology, 33, 129-56.

Lloyd, C.B., \& Desai, S.D. (1992). Children's living arrangements in developing countries. Population research and policy review, 11(3), 193-216.

Loucky, J., \& Moors, M.M. (2000). The Maya diaspora: Guatemalan roots, new American lives. Philadelphia: Temple University Press.

Madianou, M. (2012). Migration and the accentuated ambivalence of motherhood: The role of ICTs in Filipino transnational families. Global Networks, 12(3), 277-95.

Madianou, M. (2014). Polymedia communication among transnational families: what are the long-term consequences for migration? In M. Kilkey \& E. Palenga-Möllenbeck (Eds.), Family life in an age of migration and mobility. Global perspectives through the life course (pp. 71-93). London: Palgrave MacMillan.

Madianou, M., \& Miller, D. (2011). Mobile phone parenting: reconfiguring relationships between Filipina migrant mothers and their left-behind children. New Media and Society, 13(3), 457-470.

Madison, S. (2012). Critical ethnography: method, ethics and performance. Los Angeles: Sage.

Mahler, S.J. (2001). Transnational relationships: The struggle to communicate across borders. Identities, 7(4), 583619.

Mahler, S.J., \& Pessar, P.R. (2001). Gendered geographies of power: analysing gender across transnational spaces. Identities, 7(4), 441-459.

Manuh, T. (1994). Ghana: Women in the public and informal sectors under the economic recovery programme. In P. Sparr (Ed.), Mortgaging Women's Lives: Feminist Critiques of Structural Adjustments (pp. 61-77). Geneva: Zed Books.

Manuh, T. (1997). Wives, children, and intestate succession in Ghana. In G. Mikell (Ed.), African feminism. The politics of survival in Sub-Saharan Africa (pp. 77-95). Philadelphia: University of Pennsylvania Press.

Manuh, T. (1999). This place is not Ghana: Gender and rights discourse among Ghanaian migrants in Toronto, Canada. Ghana Studies, 2(1999), 77-95.

Marcus, G.E. (1995). Ethnography in/ of the world system: The emergence of multi-sited ethnography. Annual review of anthropology, 24(1), 95-117.

Marie, A. (1997). L'Afrique des individus. Paris: Karthala.

Mason, J. (2004). Managing kinship over long distances: The significance of "The visit". Social Policy and Society, 3(4), 421-29.

Mazzucato, V. (2005). Ghanaian migrants' double engagement: a transnational view of development and integration policies. Global Migration Perspectives, 48 Global Commission on International Migration, Geneva.

Mazzucato, V. (2007). The role of transnational networks and legal status in securing a living: Ghanaian migrants in the Netherlands (COMPAS working paper 43). Oxford: University of Oxford. 
Mazzucato, V. (2008a). The double engagement: transnationalism and integration. Ghanaian migrants' lives between Ghana and the Netherlands. Journal of Ethnic and Migration Studies, 34(2), $199-216$.

Mazzucato, V. (2008b). Transnational reciprocity: Ghanaian migrants and the care of their parents back home. In E. Alber, S. van der Geest, W. Geissler, \& S Whyte (Eds.), Generations in Africa: Connections and conflicts (pp. 111133). Münster: LIT Verlag.

Mazzucato, V. (2008c). Unpublished Research Proposal for The Netherlands Organisation for Scientific Research.

Mazzucato, V. (2009a). Bridging boundaries with a transnational research approach: A simultaneous matched sample methodology. In M.-A. Falzon (ed.), Multi-sited ethnography. Theory, praxis and locality in contemporary research (pp. 215-32). Bodmin, Cornwall: MPG Books Ltd.

Mazzucato, V. (2009b). Informal insurance arrangements in Ghanaian migrants' transnational networks: The role of reverse remittances and geographic proximity. World Development, 37 (6), 1105-15.

Mazzucato, V. (2011). Reverse remittances in the migration - development nexus: Two-way flows between Ghana and the Netherlands. Population Space and Place, 17(5), 454-468.

Mazzucato, V. (2013). Transnational families, research and scholarship. In I. Ness (Ed.), The Encyclopaedia of Global Human Migration. Oxford: Blackwell Publishing.

Mazzucato, V., \& Cebotari, V. (2017). Psychological well-being of Ghanaian children in transnational families. Population, Space and Place. DOI: 10.1002/psp.2004.

Mazzucato, V., Cebotari, V., Veale, A., White, A., Grassi, M., \& Vivet, J. (2015). International parental migration and the psychological well-being of children in Ghana, Nigeria, and Angola. Social Science e Medicine, 132(2015), 215-224.

Mazzucato, V., Dankyi, E., \& Poeze, M. (2017). Mapping transnational networks of care from a multi-actor and multi-sited perspective. In C. Bolzman, L. Bernardi \& J.-M. Le Goff (Eds.), Situating children of migrants across borders and origins (pp. 269-284). Dordrecht: Springer.

Mazzucato, V., Dito, B.B., Grassi, M., \& Vivet, J. (2017). Transnational parenting and the well-being of Angolan migrant parents in Europe. Global Networks, 17(1), 89-110.

Mazzucato, V., Kabki, M., \& Smith, L. (2006). Transnational migration and the economy of funerals: Changing practices in Ghana. Development and Change, 37(5), 1047-72.

Mazzucato, V., \& Schans, D. (2008). Transnational families, children and the migration-development nexus. In Social Science Research Council Migration and Development Conference, Paper (No. 20).

Mazzucato, V., \& Schans, D. (2011). Transnational families and the well-being of children: Conceptual and methodological challenges. Journal of Marriage and Family, 73(4), 704-12.

Mazzucato, V., Van den Boom, B., \& Nsowah-Nuamah, N.N.N. (2005). Origin and destination of remittances in Ghana. In T. Manuh (Ed.), At home in the world? International migration and development in contemporary Ghana and West Africa (pp. 139-152). Accra: Sub-Saharan Publishers.

Mazzucato, V., Van Dijk, R., Horst, C., \& De Vries, P. (2004). Transcending the nation: Explorations of transnationalism as a concept and phenomenon. In D. Kalb, W. Pansters \& H. Siebers (Eds.) Globalization and Development: Themes and concepts in current research (pp. 131-162). Dordrecht: Kluwer Academic Publishers.

McDaniel, A., \& Zulu, E. (1996). Mothers, fathers, and children: Regional patterns in child-parent residence in SubSaharan Africa. African Population Studies, 11(1), 1-28.

McIntyre, J. (1966). The structure-functional approach to family study. In F. I. Nye \& F. M. Berardo (Eds.), Emerging conceptual frameworks in family analysis (pp. 52-77). New York: The MacMillan Company.

McKay, D. (2007). 'Sending dollars shows feeling'-emotions and economies in Filipino migration. Mobilities, 2(2), 175-194.

McKenzie, S., \& Menjívar, C. (2011). The meanings of migration, remittances and gifts: views of Honduran women who stay. Global Networks, 11(1), 63-81.

McGuire, S., \& Martin, K. (2007). Fractured migrant families: Paradoxes of hope and devastation. Family \& Community Health, 30(3), 178-188.

Menjivar, C. (2012). Transnational parenting and immigration law: Central Americans in the United States. Journal of Ethnic and Migration Studies, 38(2), 301-322.

Menjívar, C., \& Abrego, D. (2009). Parents and children across borders. Legal instability and intergenerational relations in Guatamalan and Salvadoran families. In N. Foner (Ed.), Across generations: Immigrant families in America (pp. 160-189). New York: New York University Press.

Menjívar, C., \& Agadjanian, V. (2007). Men’s Migration and Women's Lives: Views from Rural Armenia and Guatemala. Social Science Quarterly, 88(5), 1243-1262. 
Mensa-Bonsu, H.J.A.N., \& Dowuona-Hammond, C. (1996). The child within the Ghanaian family. In E. ArdayfioSchandorf (Ed.), The changing family in Ghana (pp. 5-20). Accra: Ghana Universities Press.

Merla, L. (2010). La gestion des émotions dans le cadre du devoir filial. Le cas des migrants salvadoriens vivant en Australie occidentale. Recherches sociologiques et anthropologiques, 41(1), 39-58.

Merla, L. (2014). A macro perspective on transnational families and care circulation: situating capacity, obligation and family commitments. In L. Baldassar \& L. Merla (Eds.), Transnational families, migration and the circulation of care. Understanding mobility and absence in family life (pp. 115-129). New York: Routledge.

Meyer, B. (1999). Translating the devil: Religion and modernity among the Ewe in Ghana. London: Edinburgh University Press.

Mikell, G. (1997). Please for domestic relief: Akan women and family courts. In G. Mikell (Ed.), African feminism. The politics of survival in Sub-Sabaran Africa (pp. 96-125). Philadelphia: University of Pennsylvania Press.

Miles, M.B., \& Huberman, A.M. (1994). Qualitative data analysis: An expanded sourcebook. London: Sage.

Moran-Taylor, M.J. (2008). When mothers and fathers migrate north: caretakers, children and child rearing in Guatemala. Latin American Perspectives, 35(4), 79-95.

Morawska, E. (2004). Exploring diversity in immigrant assimilation and transnationalism: Poles and Russian Jews in Philadelphia. International Migration Review, 38(4), 1372-1412.

Morgan, H.G.D. (1996). Family connections: an introduction to family studies. Cambrigde: Polity Press.

Nicolaas, H., \& Sprangers, A.H. (2000). De nieuwe gastarbeider: manager uit de VS of informaticus uit India. Maandstatistiek, van de bevolking, 9(2000), 9-12.

Ní Laoire, C., Grassi, M., \& Poeze, M. (2013). Family friendly? European immigration regimes in comparative context. Paper presented at the TCRAf-Eu conference, Maastricht, March 26-29.

Nobles, J. (2011). Parenting from abroad: migration, nonresident father involvement, and children's education in Mexico. Journal of Marriage and Family, 73(3): 729-746.

Notermans, C. (2008). The emotional world of kinship. Children's experiences of fosterage in East Cameroon. Childhood. A global journal of child research, 15(3), 355-377.

Nukunya, G.K. (2003). Tradition and change in Ghana: An introduction to Sociology. Accra: Ghana Universities Press.

Nyarko, K. (2014). Childrearing, motherhood and fatherhood in Ghana. In H. Selin (Ed.), Parenting across cultures (pp. 231-239). Dordrecht: Springer.

$\mathrm{O}+\mathrm{S}$ (2006). Fact sheet. Gemeente Amsterdam, Dienst Onderzoek en Statistiek. Retrieved from http://www.ois.amsterdam.nl/pdf/2006_factsheets_2.pdf

Organisation for Economic Co-operation and Development (OECD) (2011). International Migration Outlook 2011. SOPEMI, OECD Publishing. Retrieved from http://dx.doi.org/10.1787/migr_outlook-2011-en.

Organisation for Economic Co-operation and Development (OECD) (2015). International Migration Outlook 2015. Paris: OECD Publishing. Retrieved from: http://dx.doi.org/10.1787/migr_outlook-2015-en.

Øien, C. (2006). Transnational networks of care: Angolan children in fosterage in Portugal. Ethnic and Racial Studies, 29(6), 1104-1117.

OIS Amsterdam (2015). Amsterdam in cïfers 2015. Onderzoek, informatie en statistiek. Gemeente Amsterdam. Goudriaan: De Groot Drukkerij.

Olwig, K.F. (1999). Narratives of the children left behind: Home and identity in globalised Caribbean families. Journal of Ethnic and Migration Studies, 25(2), 267-284.

Olwig, K.F. (2012). The care chain, children's mobility and the Caribbean migration tradition. Journal of Ethnic and Migration Studies, 38(6), 933-952.

Olwig, K.F. (2014). Migration and care: intimately related aspects of Caribbean family and kinship. In L. Baldassar and L. Merla (eds.), Transnational families, migration and the circulation of care. Understanding mobility and absence in family life (pp. 133-148). New York: Routledge.

Olwig, K.F., \& Sørensen, N.N. (2002). Mobile livelihoods. In K.F. Olwig \& N.N. Sorensen (Eds.), Work and migration: Life and livelihoods in a globalizing world (pp. 1-19). New York: Routledge.

Onwuka, R.I. (1982). The Ecowas protocol on the free movement of persons: A threat to Nigerian security? African Affairs, 81(323), 193-206.

Oppong, C. (1981). Middle class African marriage. London: Allen and Unwin.

Oppong, C. (1997). African family systems and socio-economic crisis. In A. Adepoju (Ed.), Family, Population and Development in Africa (pp. 158-182). London and New Jersey: Zed Books.

Oppong, C. (2006). Demographic innovation and nutritional catastrophe: change, lack of change and difference in Ghanaian family systems. In G. Therborn (Ed.), African families in a global context (pp. 49-78). Göteborg: Elanders Infologistics Väst AB. 
Oppong, C., \& Bleek, W. (1982). Economic models and having children: Some evidence from Kwahu, Ghana. Africa, 52(4), 15-33.

Oppong, C., Okali, C., \& Houghton, B. (1975). Woman power: retrograde steps in Ghana. African Studies Review, 18(3), 71-84.

Oppong, J.R. (2004). Ghana: Internal, International, and Transnational Migration. In M.I. Toro-Morn \& M. Alicea (Eds.), Migration and Immigration: A Global View (pp. 81-95). Westport: Greenwood Press.

Orellana, M.F., Thorne, B., Chee, A., \& Lam, W.S.E. (2001). Transnational childhoods: The participation of children in processes of family migration. Social problems, 48(4), 572-591.

Owusu, T.Y. (2003). Transnationalism among African immigrants in North America: The case of Ghanaians in Canada. Journal of International Migration and Integration, 4(3), 395-413.

Palenga-Möllenbeck, E. (2013). Care Chains in Eastern and Central Europe: Male and Female Domestic Work at the Intersections of Gender, Class and Ethnicity. Journal of Immigrant \& Refugee Studies, 11(4), 364-383.

Parreñas, R.S. (2001). Mothering from a distance: emotions, gender, and intergenerational relations in Filipino transnational families. Feminist Studies, 27(2), 361-390.

Parreñas, R.S. (2005a). Long distance intimacies: class, gender and intergenerational relations between mothers and children in Filipino transnational families. Global Networks, 5(5), 317-336.

Parreñas, R.S. (2005b). Children of global migration: Transnational families and gendered woes. Stanford University Press.

Parreñas, R.S. (2008). Transnational fathering: Gendered conflicts, distant disciplining and emotional gaps. Journal of Ethnic and Migration Studies, 34(7), 1057-1072.

Pascouau, Y., \& Labayle, H. (2011). Toegangsvoorwaarden voor gezinshereniging ter discussie: een vergelijkende studie in negen lidstaten van de EU. Koning Boudewijnstichting.

Peil, M. (1995). Ghanaians abroad. African Affairs, 94(376), 345-367.

Penninx, R. (2005). Bridges between research and policy? The case of post-war immigration and integration policies in the Netherlands. International Journal on Multicultural Societies, 7(1), 33-48.

Pertierra, R. (2002). The work of culture. Manila: De La Salle University Press.

Pessar, P. (2005). Women, gender, and international migration across and beyond the Americas: inequalities and limited empowerment. In Expert group meeting on international migration and development in Latin America and the Caribbean. Retrieved from http://citeseerx.ist.psu.edu/viewdoc/download?doi=10.1.1.552.8444\& rep=rep1\&type=pdf.

Pilon, M. (2003). Foster care and schooling in West Africa: The state of knowledge (The UNESCO 2003 EFA Monitoring Report). Institute Recherche pour le Developpement, Unité d'Enseignement and de Recherche en Démographie.

Poeze, M. \& Dankyi, E.K. (2014). Experiences with a Simultaneous Matched Sample Methodology, Newsletter Migration: paths of exploration, Norface Migration: 16-17.

Poeze, M., \& Dankyi, E.K. (2013). Eén familie, twee landen, twee onderzoekers. Ervaringen met een simultaneous matched sample-methodologie. Kwalon, 3(18), 41-46.

Poeze, M., \& Mazzucato, V. (2014). Ghanaian children in transnational families: Understanding the experiences of left-behind children through local parenting norms. In L. Baldassar \& L. Merla (Eds.), Transnational families, migration and the circulation of care. Understanding mobility and absence in family life (pp. 149-169). New York: Routledge.

Portes, A. (1999). Conclusion: Towards a new world - the origins and effects of transnational activities. Ethnic and Racial Studies, 22(2), 463-477.

Portes, A., Guarnizo, L.E., \& Landolt, P. (1999). The study of transnationalism: pitfalls and promise of an emergent research field. Ethnic and Racial Studies, 22(2), 217-237.

Pribilsky, J. (2001) Nervios and "modern childhood". Migration and shifting contexts of child life in the Ecuadorian Andes. Childhood, 8(2), 251-273.

Pribilsky, J. (2004). 'Apprendemos a convivir': Conjugal relations, co-parenting, and family life among Ecuadorian transnational migrants in New York and the Ecuadorian Andes. Global Networks, 4(3), 313-334.

Pribilsky, J. (2012). Consumption dilemmas: tracking masculinity, money and transnational fatherhood between the Ecuadorian Andes and New York City. Journal of Ethnic and Migration Studies, 38(2), 323-343.

Pries, L. (2001). New Transnational Social Spaces: International Migration and Transnational Companies in the Early Twentyfirst Century. London: Routledge.

Pries, L. (2005). Configurations of geographic and societal spaces: a sociological proposal between 'methodological nationalism' and the 'spaces of flows'. Global Networks, 5(2), 167-190.

Rabe M. (2006). Being a father in a man's world: The experience of goldmine workers. In L. Richter \& R. Morrell (Eds.), Baba: Men and fatherbood in South Africa (pp. 250-264). Cape Town: HSRC Press.

Radcliffe-Brown, A.R., \& Forde, D. (1950). African systems of kinship and marriage. New York: Routledge. 
Ranson, G. (2010). Against the grain: Couples, gender, and the reframing of parenting. University of Toronto Press.

Reynolds, T. (2004). Families, Social Capital and Caribbean Young People's Diasporic Identities, Families \& Social Capital. ESRC Research Group, Working Paper Series, No. 11, London South Bank University.

Reynolds, T., \& Zontini, E. (2006). A comparative study of care and provision across Caribbean and Italian transnational families. London: London South Bank University.

Richter, L., \& Morrell, R. (2008). Fathering: the role of men in raising children in Africa-holding up the other half of the sky. In M.H. Garcia, A. Pence \& J. Evans (Eds.), Africa's future, Africa's challenge: early childhood and development in Sub-Saharan Africa (pp. 151-166). Washington: The Worldbank.

Rouch, J. (1959). The study of migration. West Africa, 29(1959), 417-419.

Rouse, R. (1992). Making sense of settlement: Class transformation, cultural struggle, and transnationalism among Mexican migrants in the United States. Annals of the New York. Academy of Sciences, 645(1), 25-52.

Ryan, L. (2007) Migrant women, social networks and motherhood: the experiences of Irish nurses in Britain. Sociology, 41(2), 295-312.

Ryan, L. (2011). Transnational relations: Family migration among recent Polish migrants in London. International Migration, 49(2), 80-103.

Schmalzbauer, L. (2004) Searching for wages and mothering from afar: the case of Honduran transnational families. Journal of Marriage and Family, 66(5), 1317-1331.

Schmalzbauer, L. (2005). Striving and surviving: A daily life analysis of Honduran transnational families. New York: Routledge.

Schmalzbauer, L. (2008). Family divided: The class formation of Honduran transnational families. Global Networks, 8(3), 329-346.

Schneider, D. M. (1984). A critique of the study of kinship. Ann Arbor: university of Michigan Press.

Selin, H. (2014). Parenting across cultures. Dordrecht: Springer.

Shipton, P. (2007). The nature of entrustment: Intimacy, exchange, and the sacred in Africa. Yale University Press, New Haven.

Simon, R.J., \& Brettell, C. B. (1986). International migration: the female experience. Totowa, New Jersey: Rowman and Allanheld.

Singh, S., \& Cabraal, A. (2014). "Boomerang remittances" and the circulation of care: A study of Indian transnational families in Australia. In L. Baldassar \& L. Merla (Eds.), Transnational families, migration and the circulation of care. Understanding mobility and absence in family life (pp. 220-234). New York: Routledge.

Slaughter, A.M. (2015). Unfinished business. Women men work family. London: Oneworld Publications.

Smith, R.C. (2006). Mexican New York: Transnational Lives of New Immigrants. Berkeley, CA: University of California Press.

Smith, M.P., \& Guarnizo, L.E. (1998). The locations of transnationalism. In M.P. Smith \& L.E. Guarnizo (Eds), Transnationalism from below (pp. 3-34). New Brunswick: Transaction Publishers.

Smith, A., Lalonde, R.N., \& Johnson, S. (2004). Serial migration and its implications for the parent-child relationship: A retrospective analysis of the experiences of the children of Caribbean immigrant. Cultural Diversity and Ethnic Minority Psychology, 10(2), 107-122.

Soto, I. (1989). West Indian child fostering: its role in migrant exchanges. Centre for Migration Studies special issues, 7(1), 121-137.

Strasser, E., Kraler, A., Bonjour, S., \& Bilger, V. (2009). Doing family: responses to the constructions of 'the migrant family' across Europe. The History of the Family, 14(2), 165-176.

Strik, T., de Hart, B., \& Nissen, E. (2013). Family reunification. A barrier or facilitator of integration? A comparative study. Nijmegen: Wolf Legal Publishers.

Suárez-Orozco, C., Todorova, I.L.G., \& Louie, J. (2002). Making up for lost time: The experience of separation and reunification among immigrant families. Family Process, 41(4), 625-643.

Sudarkasa, N. (1977). Migrants and Women Who Wait: Women and Migration in Contemporary West Africa. Signs, 3(1), 178-189.

Suddhi-Dhamakit, K. (2010). You, me or us? Conjugal separations and parent-child separation in family migration: a case of rural Thailand. UNU-MERIT MGSoG Working papers.

Suksomboon, P. (2011). Cross-border marriage as a migration strategy: Thai women in the Netherlands. In A. Kraler, E. Kofman, M. Kohli \& C. Schmoll (Eds.), Gender, Generations and the Family in International Migration (pp. 221-241). Amsterdam: Amsterdam University Press.

Takyi, B.K., \& Gyimah, S.O. (2007). Matrilineal family ties and marital dissolution in Ghana. Journal of Family Issues, 28(5), 682-705. 
Tammivaara, J., \& Enright, D.S. (1986). On eliciting information: Dialogues with child informants. Anthropology \& Education Quarterly, 17(4), 218-238.

Therborn, G. (2006). African families in a global context. In G. Therborn (Ed.), African families in a global context (pp. 17-48). Uppsala: Nordiska Afrika Institutes.

Tiemoko, R. (2004). Migration, return and socio-economic change in West Africa: the role of the family. Population, Space and Place, 10(2), 155-174.

Tonah, S. (2007). Ghanaians abroad and their ties home: cultural and religious dimensions of transnational migration. Paper presented at Transnationalisation and development(s): Towards a North-South perspective, May 31-June 01, 2007, Centre for Interdisciplinary Research, Bielefeld, Germany.

Twum-Baah, K.A. (2005). Volume and characteristics of international Ghanaian migration. In T. Manuh (Ed.), At bome in the world? International migration and development in contemporary Ghana and West Africa (pp. 55 - 77). Accra: Sub-Saharan Publishers.

Twum-Baah, K.A., Nabila, J.S., \& Aryee, A. F. (1995). Migration research study in Ghana. Accra: Ghana Statistical Service.

Twum-Dansoo, A. (2009). Reciprocity, respect and responsibility: the 3rs underlying parent-child relationships in Ghana and the implications for children's rights. The International Journal of Children's Rights, 17(3), 415-432.

Urry, J. (2003). Social networks, travel and talk. The British journal of sociology, 54(2), 155-175.

Van der Geest, S. (2002). Respect and reciprocity: care of elderly people in Ghana. Journal of Cross-Cultural Gerontology, 17(1), 3-31.

Van der Heijden, G.M., Van Gils, G., Cruijff, M., \& Hessen, D. (2006). Een schatting van het aantal in Nederland verblijvende illegale vreemdelingen in 2005 (paper commissioned by the Ministry of Justic, 2006-2). Utrecht: Utrecht University.

Van der Leun, J. (2003). Looking for loopholes. Processes of incorporation of illegal immigrants in the Netherlands. Amsterdam: Amsterdam University Press.

Van der Leun, J. (2006). Excluding illegal migrants in the Netherlands: Between national policies and local implementation. West European Politics, 29(2), 310-326.

Van der Leun, J., Engbersen, G., \& Van der Heijden, P. (1998). Illegaliteit en criminaliteit: schattingen, aanhoudingen en uitzettingen. Rotterdam: Faculteit Sociale Wetenschappen.

Van der Leun, J., \& Kloosterman, R. (2006). Going underground: immigration policy changes and shifts in modes of provision of undocumented immigrants in the Netherlands. Tijdschrift voor Economische en Sociale Geografie, 97(1), 59-68.

Van Dijk, R. (2002a). Ghanaian churches in the Netherlands. Religion mediating a tense relationship. In L. Kessel (Ed.), Merchants, Missionaries and Migrants: 300 Years of Dutch-Ghanaian Relations (pp. 89-97). Amsterdam: KIT/Sub-Saharan Publishers.

Van Dijk, R. (2002b). Religion, reciprocity and restructuring family responsibility in the Ghanaian Pentecostal Diaspora. In D. Bryceson \& U. Vuorela (Eds.), The transnational family. New European frontiers and global networks (pp. 173-196). New York: Berg.

Van Hear, N. (1982). Child labour and the development of capitalist agriculture in Ghana. Development and Change, 13(4), 499-514.

Van Hear, N. (1998). New diasporas: the mass exodus, dispersal and regrouping of migrant communities. London: UCL Press.

Van Kalmthout, A. (2007) Het regiem van de vreemdelingenbewaring. Justitiële Verkenningen, 33(4), 89-102.

Van Kalmthout, A., \& Hofstee-van der Meulen, F. (2007). Netherlands. In A. van Kalmthout, F. Hofstee-van der Meulen \& F. Dünkel (Eds.), Foreigners in European prisons (pp. 623-660). Nijmegen: Wolf Legal Publishers.

Van Kalmthout, A., Hofstee-van der Meulen, F., \& Dünkel, F. (2007). Comparative overview, conclusions and recommendations. In A. van Kalmthout, F. Hofstee-van der Meulen \& F. Dünkel (Eds.), Foreigners in European prisons (pp. 7-88). Nijmegen: Wolf Legal Publishers.

Van Liempt, I., \& Bilger, V. (2009). The ethics of migration research methodology: dealing with vulnerable immigrants. Sussex Academic Press.

Van Liempt, I., \& Bilger, V. (2012). Ethical challenges in research with vulnerable migrants. In C. Vargas-Silva (Ed.), Handbook of research methods in migration (pp. 451-466). Cheltenham: Edward Elgar Publishing.

Van Meeteren, M., Sonja, M.R.P.J.R., San, V., \& Engbersen, G. (2008). 'Zonder papieren': over de positie van irreguliere migranten en de rol van het vreemdelingenbeleid in België. Acco.

Van Ours, J.C., \& Veenman, J. (2005). The Netherlands: Old emigrants - Young immigrant country. In K.F. Zimmermann (Ed.), European migration: what do we know? (pp. 173-196). Oxford: Oxford University Press. 
Van Walsum, S.K. (2000). De schaduw van de grens: Het Nederlandse vreemdelingenrecht en de sociale zekerheid van Javaanse Surinamers. Doctoral Thesis. Gouda: Gouda Quint.

Van Walsum, S.K. (2008). The family and the nation. Dutch family migration policies in the context of changing family norms. Newcastle upon Tyne: Cambridge Scholars Publishing.

Van Walsum, S.K. (2009). Against all odds: how single and divorced migrant mothers were eventually able to claim their right to respect for family life. European Journal of Migration and Law, 11(3), 295-311.

Verhoef, H. (2005). "A child has many mothers": Views of child fostering in northwestern Cameroon. Childhood, 12(3), 369-390.

Vertovec, S. (1999). Conceiving and researching transnationalism. Ethnic and Racial Studies, 22(2), 447-462.

Vertovec, S. (2004). Cheap calls: The social glue of migrant transnationalism. Global Networks, 4(2), 219-224.

Vertovec, S. (2007). Introduction: new directions in the anthropology of migration and multiculturalism. Ethnic and Racial Studies, 30(6), 961-978.

Waldinger, R., \& Fitzgerald, D. (2004). Transnationalism in question. American Journal of Sociology, 109(5), 1177-95.

Weismantel, M. (1995). Making kin: kinship theory and Zumbagua adoptions. American Ethnologist, 22(4), 685-704.

Whitehead, A., \& Hashim, I. (2005). Children and migration. Background paper for DFID migration team. Retrieved from http://www.childtrafficking.com/Docs/dfid_05_child_mig_bac_0408.pdf.

Whitehouse, B. (2009). Transnational childrearing and the preservation of transnational identity in Brazzaville, Congo. Global Networks, 9(1), 82-99.

Wiesbrock, A. (2010). Legal migration to the European Union. Ten years after Tampere. Nijmegen: Wolf Legal Publishers.

Wilding, R. (2006). "Virtual" intimacies? Families communicating across transnational contexts. Global Networks, $6(2), 125-42$.

Wimmer, A., \& Glick Schiller, N. (2003). Methodological nationalism, the social sciences, and the study of migration: An essay in historical epistemology. International Migration Review, 37(3): 576-610.

Winters, N. (2014). Responsibility, mobility, and power: Translocal carework negotiations of Nicaraguan families. International Migration Review, 48(2), 415-441.

Wong, M. (2014). Geographies and strategies of caregiving among skilled Ghanaian migrant women. Women's Studies International Forum, 42(1), 28-43.

Worby, P.A., \& Organista, K.C. (2007). Alcohol use and problem drinking among male Mexican and Central American im/migrant laborers. A review of the literature. Hispanic Journal of Behavioral Sciences, 29(4), 413-455.

Wusu, O., \& Isiugo-Abanihe, U.C. (2006). Interconnections among changing family structure, childrearing and fertility behaviour among the Ogu, Southwestern Nigeria: A qualitative study. Demographic Research, 14(8), 139156.

Yarris, K.E. (2012). Money, love, and the shifting substance of kinship in Nicaraguan transnational families. Anthropology News, 54(4). Retrieved from http://www.academia.edu/4855401/Money_Love_and_ Kinship_in_Nicaraguan_Transnational_Families_Anthropology_News_.

Yeboah, I.E.A. (1986). Migrant workers in West Africa, with special reference to Nigeria and Ghana (Working paper No. 251882). International Labour Organization.

Yeoh, B. \& Lam, T. (2006). The cost of (im)mobility: Children left behind and children who migrate with a parent. Invited papers for ESCAP.

Yerby, J. (1995). Family systems theory reconsidered: Integrating social construction theory and dialectical process. Communication Theory, 5(4), 339-365.

Zentgraf, K.M., \& Chinchilla, N.S. (2012). Transnational family separation: A framework for analysis. Journal of Ethnic and Migration Studies, 38(2), 345-366.

Zmegač, J.C. (2007). Spanning national borders: Split lives of Croatian migrant families. Migracijske I etnickě teme, 23(1-2), 33-49.

Zontini, E. (2004). Immigrant women in Barcelona: Coping with the consequences of transnational lives. Journal of Ethnic and Migration Studies, 30(6), 1113-44. 



\section{Appendices}

\section{Appendix A. Sample characteristics of stay-behind children}

\begin{tabular}{|c|c|c|c|c|c|c|}
\hline $\mathrm{Nr}$ & Child & Sex & Age & $\begin{array}{l}\text { Transnational family } \\
\text { type }\end{array}$ & $\begin{array}{l}\text { Duration of } \\
\text { separation (in } \\
\text { years) }\end{array}$ & $\begin{array}{l}\text { Main caregiver (relationship to } \\
\text { child) }\end{array}$ \\
\hline 1 & Tryphaena & $\mathrm{F}$ & 13 & father-away & 13 & father's sister \\
\hline 2 & Catherina & $\mathrm{F}$ & 12 & father-away & 1 & mother \\
\hline 3 & Owusu & $\mathrm{M}$ & 14 & father-away & 8 & mother \\
\hline 4 & Abibata & $\mathrm{F}$ & 16 & father-away & 10 & mother \\
\hline 5 & Abigail & $\mathrm{F}$ & 16 & father-away & 8 & mother \\
\hline 6 & Morisha & $\mathrm{F}$ & 13 & father-away & 8 & mother \\
\hline 7 & Vanessa & $\mathrm{F}$ & 16 & father-away & 16 & mother's sister \\
\hline 8 & Henrietta & $\mathrm{F}$ & 17 & father-away & 10 & mother \\
\hline 9 & Sara & $\mathrm{F}$ & 17 & father-away & 7 & mother \\
\hline 10 & Frank & $\mathrm{M}$ & 16 & father-away & 16 & mother \\
\hline 11 & Stanley & M & 18 & father-away & 11 & mother's sister \\
\hline 12 & Acheampong & $\mathrm{M}$ & 15 & father-away & 12 & mother \\
\hline 13 & Edith & $\mathrm{F}$ & 13 & father-away & 13 & mother \\
\hline 14 & Precious & $\mathrm{F}$ & 15 & father-away & 7 & mother \\
\hline 15 & Kate & $\mathrm{F}$ & 15 & father-away & 5 & mother \\
\hline 16 & Richied & M & 15 & father-away & 8 & mother \\
\hline 17 & Fatima & $\mathrm{F}$ & 13 & father-away & 13 & mother \\
\hline 18 & Nada & $\mathrm{F}$ & 16 & father-away & 8 & mother \\
\hline 19 & Gilbert & $\mathrm{M}$ & 15 & father-away & 7 & mother \\
\hline 20 & Ivana & $\mathrm{F}$ & 16 & father-away & 7 & mother \\
\hline 21 & Evans & $\mathrm{M}$ & 17 & father-away & 8 & mother \\
\hline 22 & Sylvester & $\mathrm{M}$ & 17 & father-away & 5 & mother \\
\hline 23 & Elsie & $\mathrm{F}$ & 18 & father-away & 8 & mother's sister \\
\hline 24 & Emmanuel & $\mathrm{M}$ & 17 & father-away & 7 & mother \\
\hline 25 & Candice & $\mathrm{F}$ & 13 & father-away & 11 & mother \\
\hline 26 & Ralph & $\mathrm{M}$ & 14 & mother-away & 5 & mother's friend \\
\hline 27 & Anna & $\mathrm{F}$ & 14 & mother-away & 5 & father \\
\hline 28 & Gottlieb & $\mathrm{M}$ & 13 & mother-away & 5 & father \\
\hline 29 & Wendy & $\mathrm{F}$ & 16 & mother-away & 1 & sister \\
\hline 30 & Sheila & $\mathrm{F}$ & 21 & mother-away & 8 & mother's sister \\
\hline 31 & Kwabena & $\mathrm{M}$ & 18 & mother-away & 15 & father \\
\hline
\end{tabular}




\begin{tabular}{|c|c|c|c|c|c|c|}
\hline $\mathrm{Nr}$ & Child & Sex & Age & $\begin{array}{l}\text { Transnational family } \\
\text { type }\end{array}$ & $\begin{array}{l}\text { Duration of } \\
\text { separation (in } \\
\text { years) }\end{array}$ & $\begin{array}{l}\text { Main caregiver (relationship to } \\
\text { child) }\end{array}$ \\
\hline 32 & Kwame & $\mathrm{M}$ & 16 & mother-away & 9 & mother's mother \\
\hline 33 & Jackeline & $\mathrm{F}$ & 12 & mother-away & 1 & mother's mother \\
\hline 34 & Kwaku & M & 17 & mother-away & 7 & mother's mother \\
\hline 35 & Emmanuela & $\mathrm{F}$ & 15 & mother-away & 2 & father \\
\hline 36 & Edudzie & $\mathrm{F}$ & 15 & mother-away & 3 & mother's sister \\
\hline 37 & Barbara & $\mathrm{F}$ & 17 & mother-away & 5 & mother's sister \\
\hline 38 & Poomah & $\mathrm{F}$ & 18 & mother-away & 1 & sister \\
\hline 39 & Jonathan & M & 16 & mother-away & 16 & father \\
\hline 40 & Daniella & $\mathrm{F}$ & 18 & mother-away & 10 & father \\
\hline 41 & Peter & M & 21 & mother-away & 21 & mother's mother \\
\hline 42 & Rhoda & $\mathrm{F}$ & 18 & mother-away & 3 & mother's mother \\
\hline 43 & Kimberley & $\mathrm{F}$ & 15 & father \& mother-away & $10(\mathrm{~F} \& \mathrm{M})$ & mother's friend \\
\hline 44 & Francisca & $\mathrm{F}$ & 14 & father \& mother-away & $7(\mathrm{M}) ; 13(\mathrm{~F})$ & mother's brother's son \\
\hline 45 & Sophia & $\mathrm{F}$ & 17 & father \& mother-away & $11(\mathrm{M}) ; 17(\mathrm{~F})$ & mother's mother \\
\hline 46 & Esther & $\mathrm{F}$ & 16 & father \& mother-away & $9(\mathrm{M}) ; 16(\mathrm{~F})$ & mother's mother \\
\hline 47 & Nicole & $\mathrm{F}$ & 17 & father \& mother-away & $4(\mathrm{M}) ; 17(\mathrm{~F})$ & mother's sister \\
\hline 48 & Josephine & $\mathrm{F}$ & 16 & father \& mother-away & $11(\mathrm{M}) ; 17(\mathrm{~F})$ & mother's mother \\
\hline 49 & James & M & 16 & father \& mother-away & $3(\mathrm{M}) ; 5(\mathrm{~F})$ & father's mother \\
\hline 50 & Rita & $\mathrm{F}$ & 13 & father \& mother-away & $13(\mathrm{M}) ; 3(\mathrm{~F})$ & stepmother \\
\hline 51 & Charles & M & 17 & father \& mother-away & $13(\mathrm{M}) ; 17(\mathrm{~F})$ & sister \\
\hline 52 & Seth & M & 22 & father \& mother-away & $5(\mathrm{M}) ; 7(\mathrm{~F})$ & sister \\
\hline 53 & Benjamin & M & 16 & father \& mother-away & $16(\mathrm{M}) ; 17(\mathrm{~F})$ & mother's father \\
\hline 54 & Prince & M & 12 & father \& mother-away & $4(\mathrm{M}) ; 6(\mathrm{~F})$ & mother's sister \\
\hline
\end{tabular}

Source: Own fieldwork, Transnational Child-Raising Arrangements project, Ghanaian child data, Ghana, 2010. 


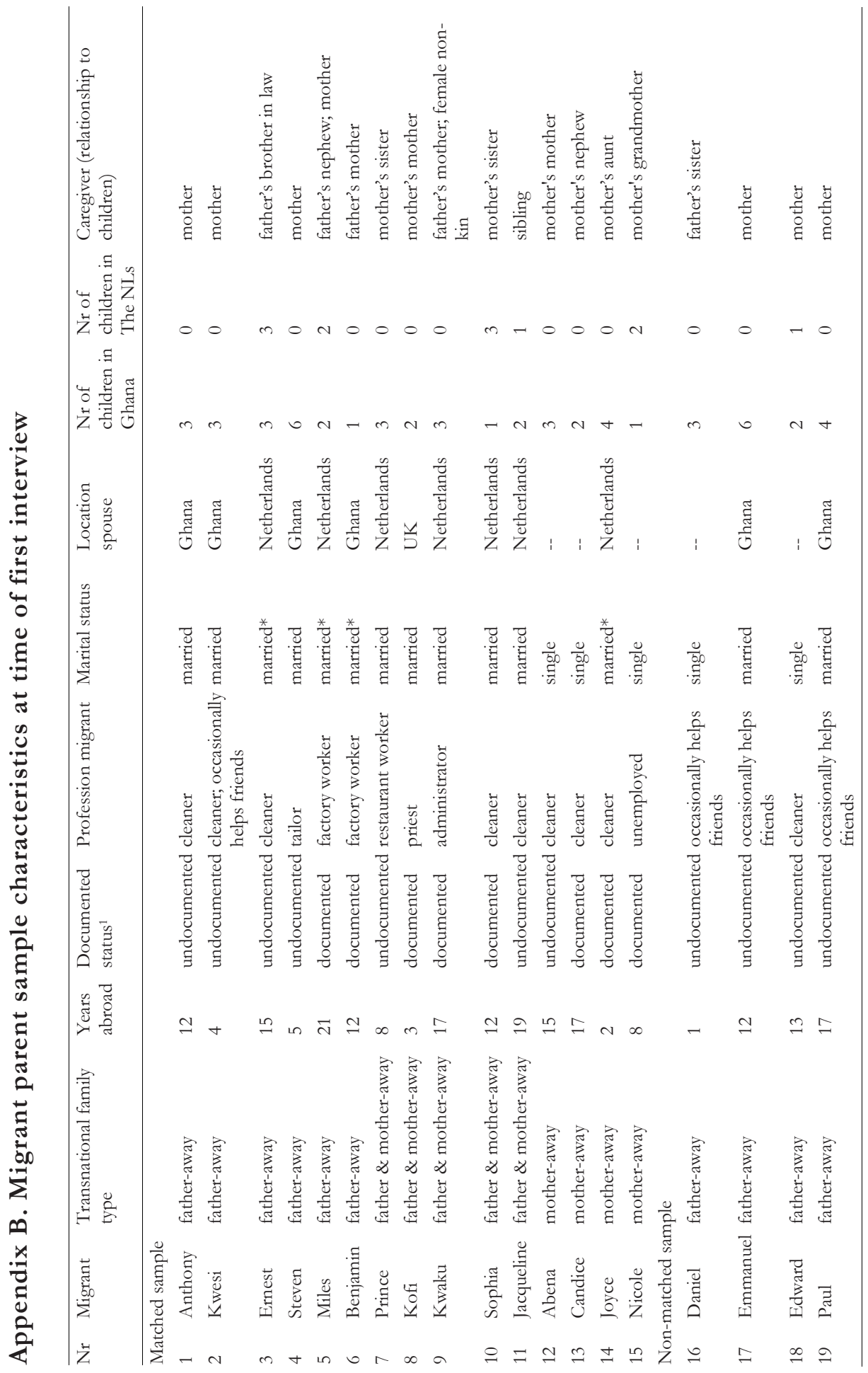




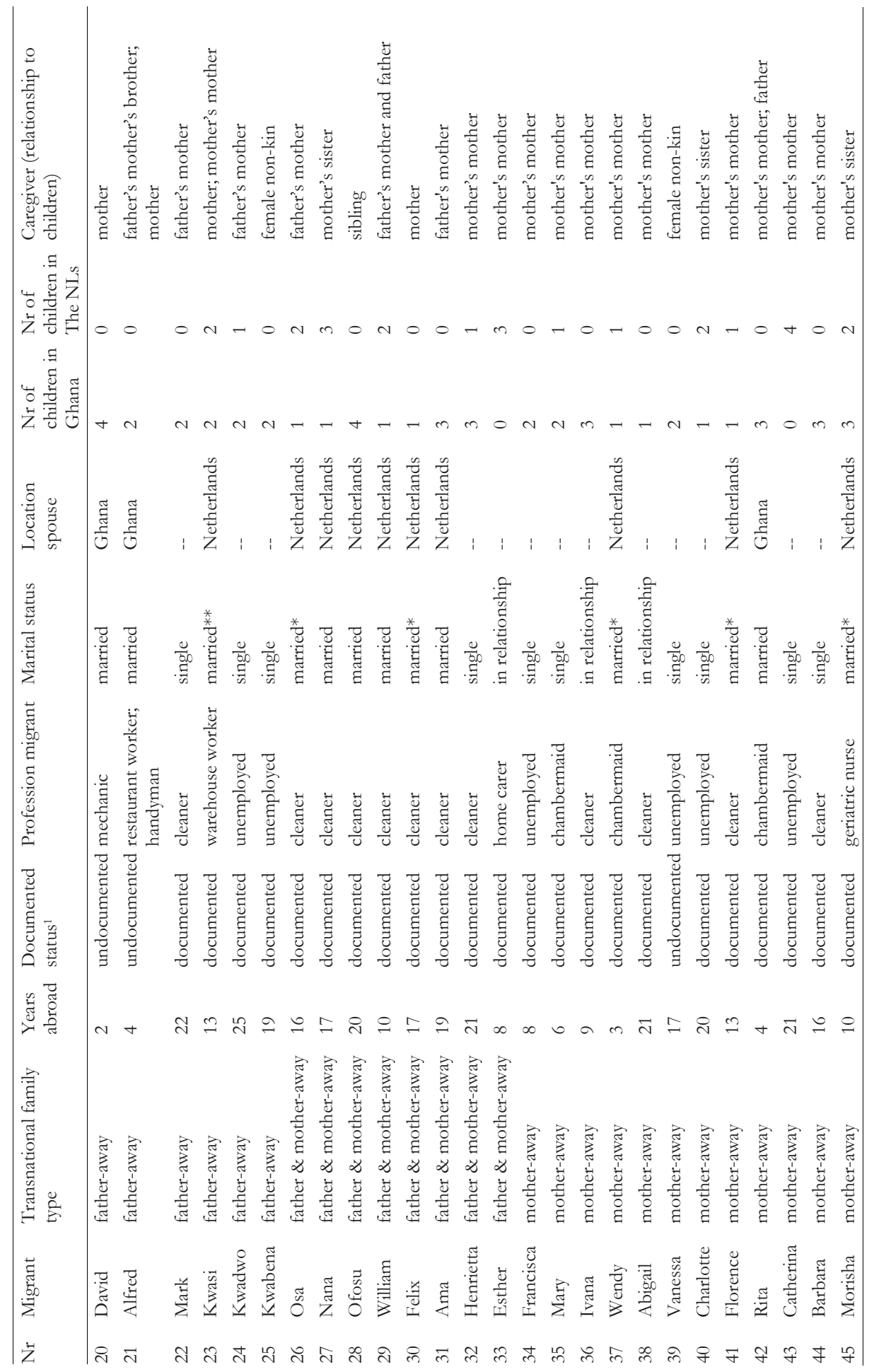


Appendices

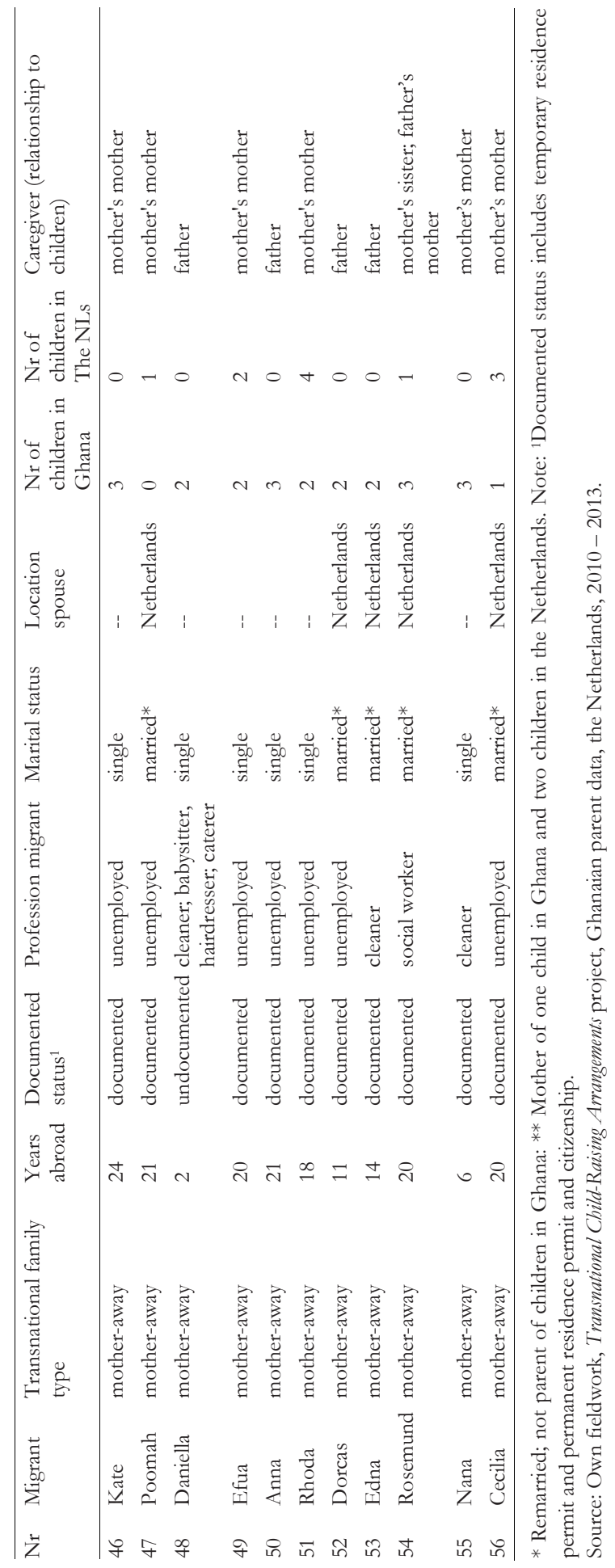




\section{Appendix C. Overview of the most important changes in Dutch family migration policy, $1982-2013$}

\begin{tabular}{lll}
\hline Year Regulation & Description \\
\hline 1982 Effective family bond criterion & The 'effective family bond' criterion was included in the Aliens Circular, \\
the first official migration policy in the Netherlands. The criterion was & initially introduced to enable family migration beyond the nuclear family \\
& (Vc 1982, B19 2.1.1.). This meant that not only spouses and children \\
& were eligible for family migration, but also other dependent family \\
& members, such as adult children and single parents above 65 years of \\
& age, on the condition that they had already been part of the family of \\
& the migrant in the origin country, if they were dependent on him, and if \\
& non-reunification would result in extreme deprivation of the person in \\
& the home country (Pascouau and Labayle, 2011). No clear definition of \\
& what constitutes an 'effective family bond', or when it was supposed to \\
& be broken, was provided.
\end{tabular}

Dependent partners receive an Dependent partners are eligible for an independent residence permit independent residence permit after three years of marriage and one year of residency in the after three years of marriage and Netherlands, provided that the person had sufficient and durable

1986 Definition of 'effective

1987 Reduction maximum age for one year residency in the Netherlands belonging' to the family reunification with children

Only children belonging to the nuclear family are eligible for family reunion

\section{income within the next 12 months (TK 1997-1008 19637 (279); TK} 1981-198217501 (2))

The definition of 'effective belonging' to the family was included in the Alien Circular. The family bond between the migrant parent and the child had to exist prior to the parent's departure. The family bond was perceived to be definitively broken when a) the child was taken up in another household for an extended period of time; b) the migrant parent had lost authority over the child; c) the migrant parent did not provide financially for the child; d) the child lived independently and provided for him or herself, or when the child married or cohabitated (Vc 1982, B19 2.2.2 (Vc Suppl. 3 June 1986)). The longer parents waited with their application for family reunification, the more they risked rejection, given that with time the burden of proof increased (Vc 1994, B1 5.1.; Bonjour, 2009). Whereas no time period was mentioned, in practice it turned out that the longer parents waited to apply for family reunion with their child after obtaining a residence permit, the more difficult it was to prove that a family bond still existed (Bonjour, 2009; Van Walsum, 2008).

The maximum age of children eligible for family reunion was reduced from 21 to 18 years to limit the number of family migrants (Wiesbrock, 2010). Due to the transition phase, the new age limit was officially implemented in 1991.

Whereas the 'effective family bond' criterion was initially introduced to amplify family reunification, it was now adjusted in such a way that it excluded all children who did not belong to the nuclear family of the migrant (Bonjour, 2009).

Legalization of birth certificates The legalization of birth certificates was introduced as a requirement to proof the family bond (Vc 1994, B1 5.1.). For a few selected countries, including Ghana and Nigeria, the information on the documents were verified and examined (Bonjour, 2009). Other official documents necessary to prove the family bond included documents that stated permission from the other birth parent and parental custody, or proof that the other parent was deceased (Pascouau and Labayle, 2011). When the other birth parent refused to give permission or could not be traced, the proper authorities could provide permission. Additional oral interviews were performed at the embassy in the origin country to further investigate the family bond. For those who could not provide the necessary documents a DNA test was offered. 


\begin{tabular}{|c|c|c|}
\hline Year & Regulation & Description \\
\hline & $\begin{array}{l}\text { Income requirement for family } \\
\text { migration }\end{array}$ & $\begin{array}{l}\text { Since family migrants were considered a burden to the national } \\
\text { economy, an income requirement was introduced (Strik, de Hart and } \\
\text { Nissen 2013). This was initially set at } 70 \% \text { of the minimum wage for at } \\
\text { least } 12 \text { more months at the moment of application, excluding } \\
\text { dependents on social benefits (Vc } 1994 \text {, B1 5.1). Exempted were those } \\
\text { above } 571 / 2 \text { years of age, those fully unfit for paid work, and those } \\
\text { responsible for children below the age of five years. }\end{array}$ \\
\hline
\end{tabular}

Increased controls on 'marriages Marriages with Third Country Nationals are subject to increased of convenience' controls by means of simultaneous interviews with spouses, house calls and information from third parties (Strik, de Hart en Nissen, 2013).

1997 Requirements for independent Dependent partners are now also eligible for an independent residence residency of dependent partners permit if they have temporary work. Women are eligible if they have are relaxed school-going children or when they are victim of domestic abuse, before the end of the three-year period (TK 197-1998 19637 (306)).

1998 The provisional residence permit The application for a provisional residence permit (MVV-machtiging voorlopig verblijf) had to be awaited in the country of origin (VC 1994, A4-5).

Introduction of mandatory civic The Netherlands was the first European country to introduce a integration test

$$
\begin{aligned}
& \text { mandatory civic integration test under the Integration Newcomers Act. } \\
& \text { This test assessed potential migrants' knowledge of basic Dutch } \\
& \text { language and knowledge about Dutch society and was a condition upon } \\
& \text { which authorization to enter the country as a family migrant was } \\
& \text { granted (OECD 2011). This test was a response to the shortcomings of } \\
& \text { the previous integration measures and the continued marginalised } \\
& \text { position of unskilled family migrants and refugees on the labour market, } \\
& \text { while it also aimed at increasing migrants' autonomy and participation in } \\
& \text { society (Bonjour, 2009). }
\end{aligned}
$$

1999 Increase income requirement for family migration

The income requirement increased to 100 per cent of the minimum wage for family migration (Vc 2000 (B), art. 4.3.3.).

2000 Income requirements for independent residency is The income requirement or an independent residence permit for dependent partners is annulled, but the required period of stay in the annulled and required period of Netherlands is extended to three years (TK 1999-2000 27111 (1)). residency in the Netherlands extended to three years

2001 'Effective family bond' considered to be broken after five years

2004 Increase income requirement for family formation

Increase minimum age for family formation

2005 Fee for provisional residence permit

The 'effective family bond' was considered to be broken when separation exceeded five years. It was expected that after this period children would be rooted in the origin country (TK 2001-2002 26732 (98)).

Income requirement for family formation increased to $120 \%$.

With the argument that young people should be prevented from forced and arranged marriages, the minimum age limit for spouses was increased from 18 to 21 years (Strik, de Hart en Nissen, 2013)

A non-refundable fee of $€ 830$ had to be paid when applying for a MVV - machtiging voorlopig verblijf, which is the entry visa that has to be applied for at the Dutch Embassy in the origin country (www.mvvgezinshereniging.nl, Legetarieven MVV en verblijfsvergunningen fors omhoog, 28 June).

Adoption of the Civic Integration Abroad Act

The state's attempt to control cultural integration resulted in the adoption of the Civic Integration Abroad Act, stating that family migrants from 'non-western countries' have to pass a pre-integration test in the country of origin before they are granted an entry visa (TK 2003-2004 29700 (3)). 


\begin{tabular}{lll}
\hline Year $\quad$ Regulation & Description \\
\hline $2006 \quad$ Relaxation of 'effective family & The European Court of Human Rights (ECtHR) ruled twice against the \\
& Dutch government over the five-year reference period for the effective \\
& family bond criterion in the cases Sen (2005) and Tuquabo-Tekle \\
& $(2006)$. The Dutch District courts also ruled against the effective family \\
& bond criterion in several cases (Strik, de Hart and Nissen, 2013). \\
& Although these decisions were annulled by the Judicial Division of the \\
& Council of State, shortly after, the Dutch Minister of Alien Affairs and \\
& Integration announced the eradication of the five-year period within the \\
& effective family bond criterion. Since then, the indicative 'effective \\
& family bond' comes from the notion of 'family life' of the ECHR, which \\
& means that, in principal, a family bond between parents and minor \\
children can be assumed, except when the child is married or establishes & a family or household of its own (Van Walsum, 2009).
\end{tabular}

2010 Eradication of distinction The distinction between family reunification and formation was between family formation and eradicated in 2010 when in the case of Chakroun the European Court reunification, with reduction of of Justice ruled that it was in conflict with European guidelines for income requirement for family family reunification (Directive 2003/86/EC). (EcJ case C-578/08, formation

Chakroun, $<<J V>>2010 / 177$.) This caused a reduction of the income requirement for family formation from $120 \%$ to $100 \%$ of the minimum wage (www.mvv-gezinshereniging.nl, 120 procent inkomenseis afgeschaft, 15 March 2010)

2011 Difficulty level of the preintegration test is increased

The difficulty level of the pre-integration test was increased, which ultimately resulted in a drop of the pass rate from 95\% to $86 \%$ (OECD 2015). In this way, the pre-integration test is in reality meant to prevent “"unwanted” immigration' (Joppke 2007b: n.p.).

Fees for provisional residence The non-refundable fee for the provisional residence permit (MVV) permit increase was increased to $€ 1250$. Fees for a one-year staying permit were $€ 300$ (www.mvv-gezinshereniging.nl, Legetarieven MVV en verblijfsvergunningen fors omhoog, 28 June 2011).

2012 Increase length of marriage and Dependent partners are only eligible for an independent residence residency in the Netherlands before dependent spouse is eligible for independent permit after having been married and having remained in the Netherlands for at least five years (TK 2011-2012, 33000 VII (53); TK 2010-2011, 32175 (15)).

residence permit

Eradication of extended family Only members belonging to the nuclear family are eligible for family reunification reunification, which excludes unmarried or unregistered partners, adult children and family members of 65 years (TK 2011-2012, 33000 VII (53); TK 2010-2011, 32175 (15))

Implementation of a one year waiting period

TCNs can only apply for family reunification with a spouse after having resided in the Netherlands for at least one year (TK 2011-2012, 33000 VII (53); TK 2010-2011, 32175 (15)) 
Nederlandse samenvatting (Dutch summary) 



\section{Inleiding}

In de context van internationale migratie van het globale Zuiden naar het Noorden worden ouders en kinderen vaak van elkaar gescheiden. Dit kan het gevolg zijn van restrictief migratiebeleid, welke ouders behoedt om samen met hun kinderen te migreren, maar het kan ook een vrijwillige keuze zijn van ouders, bijvoorbeeld omdat ze van mening zijn dat hun kinderen in het herkomstland een betere opvoeding en beter onderwijs zullen genieten. Deze grensoverschrijdende familievorm waarbij ouders migreren naar het globale Noorden en kinderen achterblijven in het herkomstland, onder de hoede van de achtergebleven ouder of een andere verzorger, is het onderwerp van mijn dissertatie. Hierbij focus ik op Ghanese migrantenouders in Nederland. Tegelijkertijd heb ik ook de ervaringen van achtergebleven kinderen in Ghana onderzocht, en in mindere mate die van degenen die voor de kinderen zorgen, voornamelijk vanuit de perspectieven van migrantenouders en achtergebleven kinderen. Als zodanig biedt deze dissertatie een diepgaand begrip en een kritische analyse van de manier waarop transnationale zorgpraktijken tussen Ghana en Nederland tot stand komen en worden georganiseerd, hoe over zorgregelingen wordt onderhandeld, zoals de impliciete en expliciete afspraken tussen ouders en zorgverleners; maar ook de relaties en wat daaruit voortvloeit, zoals de zorg en spanningen. Meer algemeen beschrijft deze dissertatie hoe globale processen alledaagse gelokaliseerde zorgpraktijken en ervaringen penetreren als familiale zorg de landsgrenzen overstijgt.

De grensoverschrijdende familievormen worden bestudeerd vanuit een transnationaal kader. Transnationalisme verwijst hier naar de processen waarbij migranten sociale relaties smeden en onderhouden tussen het land van herkomst en het ontvangende land. Centraal hierbij staat het idee van gelijktijdige verbondenheid. Het concept van 'transnationale families' benadert door migratie gescheiden families als entiteiten die ondanks de fysieke afstand een gevoel van nabijheid ervaren. Recente technologische ontwikkelingen, zoals goedkope intercontinentale vluchten en communicatiemiddelen, faciliteren hedendaagse transnationale connecties. Desalniettemin roept de reorganisatie van familie en zorg over landsgrenzen vragen op omtrent ons begrip van familie en sociale reproductie, alsook omtrent de sociale en emotionele gevolgen voor individuele familieleden. Immers, ondanks de positieve effecten die internationale migratie kan hebben in termen van materiele welvaart en onderwijskansen, vormt ouderlijke migratie ook uitdagingen voor de manier waarop zorg voor kinderen is georganiseerd en wordt de rol van de ouder als voornaamste verzorger van het kind kwalitatief getransformeerd.

Deze dissertatie put uit literatuur waarin wordt erkent dat acties, attitudes en ervaringen binnen transnationale families niet enkel worden gevormd door ongelijkheden op globaal niveau, maar ook door de plaats die verschillende actoren innemen in de lokale en nationale contexten. Met andere woorden, lokale plaatsen en de grenzen van natiestaten blijven belangrijk in het structureren van het dagelijks leven en moeten daarom worden erkend in studies omtrent transnationale fenomenen. Door de institutionele contexten van het herkomst- en ontvangende land in ogenschouw te 
nemen, houdt mijn onderzoek rekening met deze meervoudige verankering. Hierdoor zijn nieuwe inzichten ontstaan over de manier waarop variaties tussen instituties van de ontvangende- en herkomstlanden de dynamieken van transnationale zorgregelingen beïnvloeden.

In deze dissertatie staat de vraag centraal hoe zorgregelingen voor kinderen tussen Ghana en Nederland-zorgpraktijken, relaties en normen-worden uitgevoerd, behouden en hervormd vanuit het perspectief van migrantenouders en achtergebleven kinderen. Om deze vraag te beantwoorden wordt gefocust op de situering van individuen in meervoudige lokale contexten, meer specifiek: 1) hoe achtergebleven kinderen de scheiding van hun migrantenvaders- en moeders ervaren, met inachtneming van culturele normen en praktijken rondom zorg voor kinderen in het herkomstland; 2) hoe de politieke en socio-economische context van het ontvangende land, naast gendernormen- en patronen voor ouderschap, transnationale praktijken en emotionele ervaringen van vaders beïnvloeden; 3) de ervaringen van migrantenmoeders met gezinshereniging en de manier waarop de voorwaarden voor gezinshereniging het alledaagse familieleven en familiestrategieën binnendringt; 4) hoe migrantenouders onderhandelen over de relaties met de familiale en niet-familiale verzorgers van hun kinderen, en de manier waarop deze relaties worden behouden, vervormd en uitgedaagd in een transnationale context.

Deze studie kadert binnen het grotere Transnational Child-Raising Arrangements (TCRA) project waarbij meerdere onderzoekers, disciplines en onderzoekslocaties zijn betrokken. Naast de bijdrage aan grensoverschrijdende en cross-disciplinaire uitwisseling, heeft het teamwerk een methodologische contributie aan kwalitatieve studies van transnationale families mogelijk gemaakt vanwege de toepassing van de innovatieve simultaneous matched sample (SMS) methodologie. Hierdoor werd door twee onderzoekers gelijktijdig etnografisch onderzoek verricht in de verschillende locaties waar de actoren van het transnationale familienetwerk zich bevonden. Praktisch gezien betekende dit dat ikzelf onderzoek verrichtte onder Ghanese migrantenouders in Nederland, terwijl Ernestina Dankyi tegelijkertijd data verzamelde onder de verzorgers van hun kinderen in Ghana. De nauwe samenwerking en de constante uitwisseling van data leverde de nodige inzichten op over wat er aan de andere zijde gebeurde. Dit stelde mij in staat om het perspectief van mijn respondenten beter te begrijpen en om meer de diepte in te gaan in mijn eigen onderzoekslocatie. Doordat we de verschillende perspectieven van deze migrantenouders en de verzorgers van hun kinderen samen konden brengen, was het ook mogelijk om interpersoonlijke processen langdurig gedurende meer dan tweeënhalf jaar - en vanuit twee locaties van dichtbij en intensief te volgen. Van 15 matched cases, dat wil zeggen, de paren van migrantenouders in Nederland en de verzorgers van hun kinderen in Ghana die we tegelijkertijd bestudeerden, werden door middel van etnografische methodes gegevens verzameld: meervoudige diepteinterviews, niet-participerende observaties en een network mapping tool.

Deze data werd aangevuld met data verzameld door middel van een minder intensieve vorm van etnografisch onderzoek - waaronder eenmalige interviews samen 
met een gelijk aantal meervoudige diepte-interviews, niet-participerende observaties en een network mapping tool_onder 41 Ghanese migrantenouders in Nederland. Tenslotte werden in Ghana eenmalige semigestructureerde interviews afgenomen onder 54 Ghanese achtergebleven jongeren in de leeftijd van 12 tot 22 jaar, waarvan één of beide ouders waren gemigreerd naar een bestemming in het globale Noorden.

\section{Resultaten}

In vier empirische hoofdstukken worden de meervoudige perspectieven van migrantenouders en achtergebleven kinderen, en de contexten van het herkomst- en ontvangende land waarin de transnationale familienetwerken en alledaagse ervaringen zijn gesitueerd, beschreven. Hoofdstuk vijf bespreekt transnationale zorgregelingen vanuit het standpunt van Ghanese jongeren in de leeftijd van 12 tot 22 jaar, woonachtig in Accra en Kumasi. De focus ligt op de ervaringen van achtergebleven kinderen in transnationale families en hun relaties met de migrantenouders in het Westen en de verzorgers in Ghana, die in dit geval niet de biologische ouders van de kinderen zijn. De bevindingen tonen dat culturele ideologieën omtrent genderspecifieke ouderschapsverdeling grotendeels doordringen in de manier waarop kinderen de scheiding van hun ouders evalueren. Relaties met migrantenvaders worden gevierd als er materiele en financiële verbeteringen optreden, terwijl van migrantenmoeders wordt verwacht dat zij emotionele banden behouden en stimuleren door middel van langeafstandscommunicatie. Het tegenovergestelde komt ook voor; als vaders en moeders er niet of onvoldoende in slagen om respectievelijk geld te sturen of te communiceren met hun kinderen, wordt de afwezigheid van de migrantenouder als negatief ervaren. In enkele gevallen werden, als gevolg daarvan, migrantenouders uit het leven van de kinderen verbannen, waarbij de kinderen gebruik maakten van de geografische afstand om controle uit te oefenen over hun familieleven.

Daarnaast stelde ik vast dat kinderen niet noodzakelijkerwijs de geografische scheiding van hun ouders en de zorg door een ander dan hun biologische ouder als problematisch ervaren wanneer deze familiale en niet-familiale verzorgers voor het kind zorgden als was het kind 'van zichzelf'. In Ghana wordt de zorg van kinderen gezien als een gedeelde verantwoordelijkheid van biologische ouders en nabije en verre verwanten. Deze normen van 'sociaal ouderschap', vertaald in inclusieve en flexibele zorg voor kinderen, worden weerspiegeld in gangbare praktijken van informele adoptie, waarbij kinderen een deel van hun kinderjaren bij anderen dan hun biologische ouders verblijven. Deze inclusieve ouderschapsnormen en -praktijken problematiseren het westerse middenklasse ideaal van het kerngezin waarbij nabijheid tussen ouders en kinderen als voorwaarde wordt gezien voor het goed functioneren van ouder-kind relaties en voor de ontwikkeling van een kind. Ook helpen zij Ghanese kinderen om de migratie van hun ouders_-en de zorg door een ander-vanuit een positief daglicht te bekijken. Toch heb ik ook vastgesteld dat kinderen verlangen naar het kerngezin in geval 
van ontoereikende zorg door de migrantenouder en/of verzorger in Ghana en in het geval van gescheiden ouders. Anderen verlangen naar fysieke nabijheid omwille van het smeden van intieme banden, hoofdzakelijk wanneer kinderen hun ouder gedurende lange tijd niet in levenden lijve hebben gezien. De afwezigheid van de migrantenouder kan dus resulteren in een complex web van emotionele ervaringen.

Hoofdstukken zes en zeven bespreken, vanuit het perspectief van respectievelijk transnationale moeders en vaders in Nederland, hoe de politieke en socio-economische context van het ontvangende land familiale mobiliteit, relaties, en zorgpraktijken beïnvloedt. Hoofdstuk zes onderzoekt hoe de interactie van gendernormen, verblijfsstatus en toegang tot financiële middelen de attitudes en daadwerkelijke zorgpraktijken van in Nederland gevestigde Ghanese transnationale vaders sturen. Op basis van etnografisch onderzoek met Ghanese transnationale vaders laat dit hoofdstuk zien dat in lijn met culturele verwachtingen van Ghanees vaderschap, de vaders hun vaderlijke rol primair beoordelen vanuit het kostwinnersmodel. Echter, naast de verantwoordelijkheid van financiële ondersteuning voor kinderen, omhelst een overgrote meerderheid van de vaders meer 'geëngageerde' ouderschapsidealen, waardoor stereotypen van de onverschillige en afstandelijke migrantenvader die de emotionele behoeften van zijn achtergebleven kinderen veronachtzaamt, op de proef worden gesteld. Het verblijfsstatuut en de socio-economische status bepaalt evenwel grotendeels hoe vaders hun materiële en 'emotioneel geëngageerde' vaderlijke idealen volbrengen. Voor vaders met een gebrek aan financiële middelen of legale verblijfsvergunning in Nederland is het waarschijnlijk dat binnen hun gezin traditionele gendernormen worden versterkt, waarbij moeders, niet vaders, verantwoordelijk zijn voor de emotionele ondersteuning van hun kinderen. Deze vaders zijn niet in staat om de emotionele afstand als gevolg van de fysieke scheiding te overbruggen. Verder onthult dit hoofdstuk dat de rol van vaders als financiële en emotionele ondersteuners kan leiden tot onenigheid binnen transnationale families als vaders de kwaliteit van de zorg door hun ex-vrouwen in twijfel trekken. Matrilineale gebruiken worden betwist wanneer vaders vervolgens de zorg voor hun kinderen overhevelen naar verwanten aan vaders kant van de familie. De reeds bestaande maar uitvergrootte ongelijke machtsposities in de context van internationale migratie duwt achtergebleven moeders in afhankelijke posities en geforceerde scheidingen van hun kinderen.

Hoofdstuk zeven verkent vanuit een gender-sensitieve benadering de confrontaties van Ghanese transnationale moeders met het Nederlandse gezinsherenigingsbeleid en de impact die dit beleid heeft op gezinsherenigingstrajecten en de gevolgen voor familierelaties en -strategieën. Op basis van diepte-interviews met vrouwelijke Ghanese migranten in Nederland met één of meer kinderen woonachtig in Ghana, werden naast het verblijfsstatuut enkele belangrijke barrières tot gezinshereniging geïdentificeerd: de inkomensvoorwaarde en het bewijzen van de familieband. Deze verklaren-tenminste gedeeltelijk-het lage aandeel gezinshereniging met minderjarige kinderen onder Ghanese moeders in Nederland, in vergelijking met andere groepen migrantenmoeders. Tegelijkertijd heb ik discrepanties waargenomen tussen onderliggende normatieve 
kaders waarop formele condities voor gezinshereniging zijn gebaseerd en het familieleven van vrouwelijke migranten. Vanuit een westers perspectief wordt van vrouwen verondersteld dat zij ten alle tijden met hun kinderen willen samenleven, terwijl dit voor vrouwelijke Ghanese migranten niet altijd mogelijk of wenselijk is. Fysieke scheiding tussen moeders en kinderen kan een voorkeur zijn voor Ghanese moeders waardoor fysieke nabijheid niet altijd en noodzakelijkerwijs als in het beste belang voor het kind wordt beschouwd. Dit kan worden verklaard door de inclusieve normen en praktijken omtrent zorg voor kinderen, welke ook in Hoofdstuk vijf werden besproken. Als deze moeders echter niet aan het westerse normatieve kader beantwoorden, kunnen zij obstakels ondervinden wanneer een aanvraag tot gezinshereniging wordt ingediend. Dus terwijl scheiding voor vrouwen niet per se het gevolg is van het restrictieve gezinsherenigingsbeleid, maar een vrijwillige keuze kán zijn, laat dit hoofdstuk zien dat beleidsmaatregels de flexibiliteit om het familieleven naar eigen wensen in te richteneen essentieel aspect van Ghanees familieleven—sterk beperken. Tevens creëren voorwaarden voor gezinshereniging, met name verblijfsstatuten en minimuminkomen, afhankelijkheden en ongelijkheden, waardoor vrouwen in kwetsbare partnerrelaties worden gedrukt. Het onvermogen om met kinderen te herenigen vanwege restrictief beleid, de reacties van achtergebleven kinderen op langdurige scheiding en jaloezie onder broers en zussen 'hier en daar' kan verder leiden tot emotionele stress onder moeders. Dit kan resulteren in onofficiële gezinsherenigingstrajecten, welke vaak gepaard gaan met grote risico's voor de betrokken kinderen.

Hoofdstuk acht onderzoekt het dagelijkse werk dat het onderhouden van informele transnationale zorgrelaties tussen migrantenouders en familiale en non-familiale verzorgers in het thuisland-anders dan de biologische ouders van het achtergebleven kind-met zich meebrengt. Door toepassing van het concept kin work werd getracht te begrijpen wat actoren aan beide zijden moeten doen en laten om transnationale zorgrelaties te behouden. Hoewel het multi-sited perspectief de hele dissertatie heeft geïnformeerd, is dit hoofdstuk het duidelijkst geënt op de matched sample methodologie, doordat er gebruik werd gemaakt van zowel data verzameld onder migrantenouders in Nederland, alsook van data verzameld onder de verzorgers van hun kinderen in Ghana.

De analyse laat zien dat fysieke afstand de mobilisatie van familiale zorg compliceert. Hoewel beide partijen deze vorm van zorg vaak als vanzelfsprekend ervaren, wordt deze problematisch wanneer niet of onvoldoende aan vooropgestelde, en vaak onuitgesproken, verwachtingen wordt voldaan. Ongelijke toegang tot informatie en middelen tussen migranten en verzorgers creëert nieuwe en verergert oude ongelijkheden, machtsdynamieken en frustraties. Tegelijkertijd is familiale zorg ook de basis voor samenwerking binnen verwantschapsnetwerken. We stelden vast dat beide actoren de zorgrelaties strategisch managen door middel van expliciete en stilzwijgende praktijken, voornamelijk via de zorgvuldige behandeling van financiële middelen en communicatie waardoor onderling vertrouwen kan groeien. Het combineren en vergelijken van data stelde ons dus in staat om vanuit beide perspectieven het dagelijkse kin work te bestuderen, niet enkel het zichtbare, maar ook de onzichtbare acties-wat 
mensen doen en laten-om familiale zorgrelaties te doen slagen. Dit heeft duidelijk gemaakt dat de navigatie van zulke relaties veelal gestoeld is op het 'niet doen', het 'niet communiceren' of selectieve communicatie. We concludeerden dat het managen van zorgrelaties niet enkel een altruïstische uiting is van intieme verbintenis met de migrant/verzorger en het kind; het is ook een manier om te beantwoorden aan familiale zorgverplichtingen en om te voorkomen dat er op de persoon wordt neergekeken door leden uit de gemeenschap als niet aan normatieve familiale zorgverplichtingen wordt voldaan. Tenslotte kan worden gesteld dat de transnationale zorgtransacties onderdeel zijn van wederkerige relaties op de lange termijn; er wordt een basis gelegd voor toekomstige ondersteuning van het kind naar de verzorger, zowel emotioneel als materieel. Deze bevindingen dragen bij aan een meer diepgaand begrip van de manieren waarop lange-afstandspraktijken het behoud van familiale relaties faciliteren, en hoe het onvermogen om deze uit te voeren spanningen kunnen veroorzaken.

\section{Conclusie}

Deze studie heeft een originele bijdrage geleverd aan transnationale familiestudies dankzij de methodologische en theoretische benaderingen. Theoretisch bouwt deze dissertatie voort op literatuur welke stelt dat transnationale zorgregelingen dienen te worden gesitueerd in de contexten van het herkomst- en ontvangende land om tot een beter begrip te komen van de manieren waarop transnationale familiale zorg lokaal is verankerd en hoe, op zijn beurt, lokale normen en gebruiken transformeren in een transnationale context.

De multi-sited onderzoeksopzet, waaronder de innovatieve SMS-methodologie welke in deze studie als eerste werd toegepast op de studie van transnationale families, faciliteerde de opname van meerdere actoren binnen het transnationale zorgnetwerk en onthulde belangrijke relationele dynamieken. Het bestuderen van meerdere actoren in één studie verschafte een beter inzicht op de manier waarop transnationale zorgregelingen werken vanuit het standpunt van de verschillende actoren, wat de verschillende actoren doen om grensoverschrijdende familievormen te laten werken en hoe zulke regelingen worden ervaren door de betrokken actoren, afhankelijk van hun sociale en geografische locatie.

Uit de empirische hoofdstukken is gebleken dat het onderhouden van grensoverschrijdende zorgregelingen een ingewikkeld en delicaat proces is welke gepaard gaat met complexe en soms tegenstrijdige emoties en gevolgen voor de verschillende betrokken actoren. Tevens kon worden geobserveerd hoe gelijktijdige betrokkenheid met meer dan één locatie op zijn beurt het sociale weefsel van transnationale zorgnetwerken (her-)vormt. Ik heb aangetoond vanuit het perspectief van migrantenouders en achtergebleven kinderen hoe culturele repertoires van gendered zorg transnationale zorgregelingen vormen. Ten eerste laten mijn bevindingen zien dat gender ideologieën voorschrijven, maar niet dicteren, hoe en door wie zorg wordt beoefend en 
hoe transnationale zorgregelingen worden ervaren door de verschillende betrokken actoren. Ten tweede laat het zien dat inclusieve ouderschapsnormen en -praktijken beïnvloeden hoe transnationale zorgregelingen worden georganiseerd, behouden en ervaren.

Tevens heb ik aangetoond hoe structurele factoren met betrekking tot het ontvangende land, naast gendered scripts, mogelijkheden en beperkingen bieden aan transnationale familieconfiguraties en zorggebruiken, en hoe dit de verschillende actoren en interpersoonlijke relaties beïnvloedt. Als zodanig bouwt deze dissertatie voort op transnationaal onderzoek welke het voortdurende belang van nationaal beleid erkent in het faciliteren en verhinderen van hoe migranten hun leven over staatsgrenzen heen organiseren. In deze dissertatie heb ik laten zien hoe migratiebeleid, welke definieert wie er wel en niet het gastland mag binnentreden en onder welke voorwaarden, inwerkt op het transnationale familieleven en onderlinge relaties. Hoewel transnationaal familieleven een vrijwillige keuze kán zijn, beperken voorwaarden voor gezinshereniging familiestrategieën, met als gevolg onbedoelde nadelige effecten voor de levens van betrokkenen. Tevens laat deze studie zien dat naast gender ideologieën, de socioeconomische en legale status van migranten een grote invloed hebben op transnationale zorgpraktijken, intieme relaties met achtergebleven kinderen en intrafamiliale dynamieken.

Tenslotte benadrukt deze dissertatie dat culturele normen omtrent ouderschap en familiale zorg niet statisch zijn, maar veranderingen ondergaan, doordat de micropolitiek van macht en status binnen de transnationale context het alledaagse kin work en zorg compliceren. Dit dwingt een constante bemiddeling en heronderhandeling af van ongelijkheden, verwachtingen en verantwoordelijkheden tussen zij die migreren en zij die achterblijven. Ik concludeer dat het migratieproject en de geografische afstand het behoud van familiale zorg bemoeilijkt, maar dat relaties vaak behouden blijven door het zorgvuldig navigeren van communicatie en financiën. Tevens stel ik vast dat ongelijkheden binnen gender relaties worden bestendigd als vaders migreren en moeders achterblijven. 

Valorisation addendum 

The university's regulation stipulates that doctoral students include in their dissertation a valorisation addendum. These last pages of the dissertation force researchers to think about the social relevance of their study. As a researcher studying vulnerable people I am in favour of this regulation for it offers the opportunity to discuss the relevance of my findings beyond the academic community and to highlight the different ways in which my research may benefit the people I have studied over the past years.

In the next pages I will discuss recommendations for policies that target transnational families and indicate how state and non-state actors may play a role in reducing the risks and enhancing the benefits of migration for individual family members both in the origin and destination countries. Since such policies are a shared responsibility of the host and home country, I have formulated recommendations for both the Netherlands and Ghana. In the last section I describe how my research results have been disseminated to a larger audience and stress its importance in the light of policy development.

\section{Policy Recommendations for the Netherlands}

One of the aims of this study was to provide a deeper understanding of how the mechanisms of migration policies impact those who are affected by them. This is particularly relevant for the Netherlands where over the past decades the policy climate has become more restrictive and demanding in the formulation of regulations and requirements for those who wish to enter and stay in the country. Moreover, given the short term focus on reducing the influx of 'unwanted' immigrants, policy makers have largely turned a blind eye to the long-term social, emotional and financial costs for those who are affected by these policies. From my research findings I have discerned several policy lessons for the Netherlands.

Firstly, the application of the income requirement for sponsorship in family reunification policy deserves attention. When the guidelines of the European Directive on Family Reunification (2003/86/EC) were translated into Dutch migration policy in 2004, policy makers failed to prioritise the Directive's goal of securing third-country nationals' right to family life. Rather, restrictive family migration requirements - among which standardised income requirements - were implemented that aimed at selecting migrants at the border on the basis of financial capacity (COFACE, 2012). While policy makers stressed that a certain level of income is crucial to promote integration and to reduce dependency on the state's resources, the income requirement in family reunification policy has never been evaluated - leaving unknown whether it reaches its intended goal and how it impacts vulnerable groups (The Netherlands Institute for Human Rights, 2014).

My study demonstrates the gendered impact of the income requirement. I found that women are more likely to express a wish to reunite with their children compared to transnational fathers. Whereas some women resign themselves to a life separated from their children or even consider this the most favourable family situation, instable care 
networks in the origin country and the wish to reconnect emotionally may engender a need for reunification. Women, especially single mothers, however, face particular difficulties meeting the income requirement. Alongside their vulnerable labour market positions in the host society that result from language difficulties, discrimination, and unrecognised diploma's and work experience from the origin country, they also tend to carry the burden of care for Dutch-based children. It is therefore not surprising that most transnational mothers from Ghana, but also from other African origin countries in different European countries, are single compared to nontransnational parents and transnational fathers (Caarls et al., 2018). The difficulty to combine paid work with care for underaged children prevents single mothers from meeting the financial requirements of family reunion with stay-behind children. As my study made clear, single mothers who for different reasons wish to reunite with their children, tend to end up in dependent and vulnerable partner relationships in an effort to meet the income requirement. This subsequently diminishes women's autonomy and produces inequalities. Or in case of protracted separations when reunification is hindered due to formal requirements, the consequences for mothers and their children in the origin country are devastating especially when a care crisis unfolds, for instance when the caregiver in the origin country dies or falls ill. Other unintended side effects of, among others, the income requirement are alternative routes to reunification, such as reunification via the Belgian route or via human smuggling.

Based on these results and in line with others (COFACE, 2012; The Netherlands Institute for Human Rights, 2014), I want to re-emphasise the need to move away from strict and standardised requirements towards individual assessments of the income requirement in family reunification applications. The Netherlands Institute for Human Rights (2014) stated that the income requirement for family reunion as interpreted in the Netherlands is too strict. In other words, the income requirement is applied as an absolute norm whereas it should be a guideline that can be interpreted with some flexibility. For instance, when a person earns less than the income requirement this should not immediately result in a rejection. Moreover, the immigration services should take into account the individual needs of the sponsor to consider what is 'sufficient income'. The Netherlands Institute for Human Rights therefore suggests that in individual applications, securing the third-country nationals' right to family life, not denying them this right, should be prioritised.

Interpreting the income requirement in individual applications with increased flexibility does not mean that children should be reunited with mothers and fathers who live below the poverty line; stable and regular financial resources which are sufficient to support the family may be expected. However, parents should not have to worry that their application is rejected because their monthly wage is 20 euro below the necessary income level. Moreover, what is sufficient income is not a fixed given but may be dependent on the personal needs and circumstances of the sponsor and his or her family. It is this flexibility that should be applied to individual assessments for family reunion. Certainly, this shift would add to the already long waiting time for the assessment of 
applications, but it would potentially increase women's chances to reunite with their children when the need arises and it diminishes the negative consequences for women and their family members.

Second, the IND should improve data registration with regards to decisions of individual applications. Collecting motivations for rejections helps improve the assessment of policy consequences for specific groups of migrants. For instance, proving the family bond between parents and children-or a genuine love relationships in case of partner reunifications - may turn out to be an important reason for rejection among certain groups of migrants compared to others. This is potentially problematic. Registering motivations for decisions would make the immigration services' decision making process more transparent and receptive to adjustment. Third, immigration clerks at the IND should be offered specialised training to enhance their knowledge of migrants' life conditions as well as non-Western family practices to understand what family and parenthood mean in other contexts. This helps reduce the chances that migrants' applications get rejected or that migrants experience obstacles during the decision making process, based on normative frameworks of what constitutes 'good parenting' practices, a few cases of which I came across in my study. For instance, a woman's application for family reunion was initially rejected because the immigration clerk did not believe that the woman had sent her Dutch-born child to the origin country at a young age to be raised by the grandparents. She believed that 'a real mother' would never do this. Whereas from the point of view of the single and undocumented mother, whose own cultural framework did not prioritise proximity in the mother-child relationship, sending her child to the origin country was perceived an act of 'good mothering'. Although the hospital papers proved that the child was indeed born in the Netherlands and the application eventually received a positive decision, the objection by the immigration clerk delayed the process and imprinted in the migrant woman's head an image of 'bad mothering'.

Fourth, my study highlights the long-term effects in case of strained relationships on both parents and children, an issue which deserves wider awareness and attention, not only in academia but also among policy makers. In line with others (Parreñas, 2005; Smith, 2006), my research has demonstrated the centrality of parental care for longdistance parent-child relationships, and its impact on the life chances for both children and the migrant parents. I found that a lack of emotional exchanges can easily lead to feelings of resentment and anger towards overseas parents and may even result in children ostracizing all contact with their migrant parent. Other studies have also reported lower school performance among Ghanaian stay-behind children (Cebotari and Mazzucato, 2016), and lower levels of well-being in case of strained relationships with the migrant father (Mazzucato and Cebotari, 2017). Likewise, parents who are unable to establish affectionate relationships across distance express feelings of guilt, emotional hardship and material compensation. A strained parent-child relationship may also associate with worse job outcomes amongst transnational parents (Haagsman, 2015). To mitigate the negative implications of family separation on family members in both 
countries, I suggest that policies facilitate rather than obstruct long-distance intimacy between migrant parents and their stay-behind children, a few suggestions of which I will discuss below.

In Ghana, as elsewhere, economics and intimacy are closely intertwined, meaning that the sending of remittances is often understood by both parents and children as a way of showing affection. Priority should therefore be given to policies that aim at improving the position of documented and undocumented immigrants on the Dutch labour market. Programmes and measurements should open up pathways to legal work for undocumented migrant workers, for instance by facilitating temporary migration, but should also more generally aim at reducing racism on the labour market and at facilitating the recognition of diplomas and skills that immigrants bring from their home countries. Moreover, efforts should be made to reduce fees for money transfers to family members in the origin country.

Alongside economic concerns, policies could improve emotional exchanges through facilitating short-term visits of children to their migrant parents. Moments of face-toface contact are highly valued by migrant parents and stay-behind children for they provide opportunities for children and parents to spend time in each other's presence. Personal exchanges help build relationships of trust, generate feelings of emotional closeness, and alleviate negative feelings in case monetary remittances are insufficient. However, visiting children in the origin country is hampered by the high costs in case parents have to bring along their Dutch-based children and migrants' instable labour market position that prevents long term job leave. Policies to improve migrants' labour market position can facilitate return visits, but at the same time policies could facilitate visits of children to their parents in the Netherlands. Applications for short-term visits of family members, including underaged children, from countries in the Global South, are often rejected because of fears that children — and other family members — do not return to the origin country on the preset time. This is especially the case when the visiting family member cannot prove attachment to the origin country or when a family reunification application has been rejected in the past. I suggest that policies prioritise the long-term consequences on the life chances of migrant parents and stay-behind children over potential risks for society, by improving the possibilities for short-term visits as a means to reconnect emotionally.

\section{Policy recommendations for Ghana}

Whereas supporting the wellbeing of transnational families is not only a responsibility of the receiving country, policy makers in migrant-sending countries rarely implement policies that aim at improving the lives of stay-behind family members (Yeoh and Lam, 2006). In line with the focus of my research, I formulate policy recommendations that target stay-behind children. For policy recommendations regarding caregivers I refer to Dankyi (2014). 
First, the impacts of family separation on stay-behind children should be recognised and data collection, analysis and dissemination could be improved to present a clearer picture of the long term social, educational and psychological impacts of children growing up in transnational families as a way to strengthen the evidence base of policies. This will enable state and non-state actors to better address the needs of this group of children, particularly the most vulnerable, to reach their full potential despite challenging circumstances. For instance, support in terms of counselling in schools and community centres could be offered to those in need. To this end, specialised training programmes could help school staff and social workers to better equip themselves to signal problems among stay-behind children and to respond to the children's needs. Likewise, family counselling programmes could be developed whereby counsellors in Ghana and the Netherlands work together transnationally to improve long-distance family bonds and communication.

Second, awareness-raising programmes that point future migrants to the potential implications of family separation could be implemented to ensure that parents make an informed decision with regards to their migration and the care arrangement of their children, prior to departure. Such programmes should include realistic information about possibilities for reunification, work and family life in the host country, as well as information about what informal care work entails for kin and non-kin caregivers and their families in terms of emotional, financial and social demands. Such programmes would therefore ideally include embassies of popular host countries, family organisations-preferably those that operate transnationally-, local NGOs and experiential experts, notably previous and/or current caregivers and stay-behind children.

\section{Dissemination of research results}

I am well aware that the influence of my research-like research in general-on migration policy processes and agenda-setting is limited, especially when it involves recommendations via academic publications and research that is not carried out by national policy institutions or in close collaboration with government agencies (Iredale et al., 2002). In the Netherlands specifically, academic research has lost its foothold in policy processes since the policy climate became more polarised from the 1990s onwards - unless research plays the card of politicians (Penninx, 2005). The position of research in migration policy development can at present therefore at best be described as marginal.

The migration policy-agenda tends to be more responsive to the public opinion than to mere research findings (Iredale et al., 2002). As Penninx (2005: 46) argues, in a policy climate that has significantly reduced researchers' political influence, 'researchers do not have much choice other than to act as "responsible citizens". Hence, it is in the public debate that the researcher has to operate and to share knowledge with a broader 
audience. In collaboration with colleagues, Ghanaian organizations, and artists, I have pursued various avenues to disseminate research findings in an effort to inform the public and political debate:

- Several actions were taken to inform the Ghanaian migrant community about the research. At the start of my research, prof. dr. Valentina Mazzucato and I presented the TCRA-project at an Amsterdam-based Ghanaian radio station. We also organised a session around the topic of transnational families in the talk show of Veronica van der Kamp, an excerpt of which was included in the introduction of the thesis. Together with five invited Ghanaian immigrants, Veronica van der Kamp discussed the implications of parent-child separation in the context of long-distance migration. The show aired several times in July 2010. A few years into the research, Ernestina Dankyi and I presented the research findings at another Amsterdam-based Ghanaian radio station.

- The TCRA-team organised two conferences_one in Ghana (2012) and a closing conference in the Netherlands (2014) — with policy makers, practitioners and other stakeholders, to share research results and to discuss how our results could be of use beyond the academic community.

- In preparation for the closing conference in the Netherlands, two policy briefs were written that translated the research findings into policy recommendations. ${ }^{43}$

- Two newspaper articles were published that discussed the topic of Ghanaian transnational families and reflected on key research findings. One article appeared in Dutch quality newspaper De Volkskrant (Bolwijn, 2013) ${ }^{44}$ and one on the website of Graphic Online (Ardayfio, 2014). ${ }^{45}$

- I co-authored a publication for NORFACE newsletter, which discussed the transnational methodology of the research to a wider academic audience (Poeze and Dankyi, 2014).

- I am preparing a photobook together with photographer Bas Niemans and graphic designer Paul Wolterink for which we received generous funding from WOTRO. The photobook contains vivid and intimate narratives and pictures of Ghanaian migrant parents in the Netherlands and their stay-behind children in Ghana. Its objectives are to raise awareness and understanding among the wider public of transnational families' experiences; to challenge common ideas about family separation; and to expose the sometimes destructive consequences of current migration policies for cross-border family members.

- A project website was developed that contains all information about the project, as well as publications, events, photos and related research projects. ${ }^{46}$

\footnotetext{
${ }^{43}$ See http:// fasos-research.nl/tcra/files/2013/05/TCRA-POLICY-BRIEF_def.pdf; http:/ / fasosresearch.nl/tcra/files/2015/04/MU_POLICY_BRIEF_02_2014-06-15.pdf

${ }^{4}$ See http:// fasos-research.nl/tcra/files/2013/Artikel-Marjon-Bolwijn1.pdf

${ }^{45}$ See https://www.graphic.com.gh/features/features/left-behind-when-parents-migrate-and-children-staybehind.html

${ }^{46}$ See http://tcra.nl
} 
In my present role as lecturer at the Social Work department of Vives University of Applied Sciences, I integrate my doctoral research into teaching about migration and intercultural work. By presenting my research findings and showing examples of real cases I try to make my students aware of the implications for families whose lives are organised transnationally. It is for future social workers important to realise that transnational families are not only victims of global inequality, but that alongside their vulnerabilities, such families can thrive and often display a high degree of resilience. Moreover, my teaching helps social workers understand that the experiences of transnational parents in the host country is an interplay of individual and family wishes on the one hand, and of opportunities and restrictions of the origin and receiving countries, such as migration policies, labour market position, (il)legality, and transnational care networks and normative frameworks of care, on the other hand. In this way, my research informs future social workers about the transnational context in which many migrants live today and helps them to adequately respond to the needs of vulnerable transnational families. 



\section{Curriculum Vitae}

Miranda Poeze was born February 12, 1981 in Hoorn, the Netherlands. After obtaining her first year of the Bachelor 'General Social Sciences' at Utrecht University, she went on to obtain a Bachelor 'Social and Cultural Anthropology' at the University of Amsterdam in 2001. Her interest in the topic of international migration resulted in a Bachelor's thesis on identity and belonging among Javanese Surinamese immigrants in the Netherlands. Miranda proceeded her education with the Research Master 'Social Research-Cultural Anthropology' at VU University of Amsterdam, which she completed in 2009. Her continued interest in the topic of migration led her to focus her Master's thesis on the decision-making process of Senegalese men to migrate to Europe via the risky sea route. This thesis was awarded the African Thesis Award (2009) from the African Studies Centre Leiden.

In January 2010, Miranda became a Ph.D. candidate at Maastricht University within the NWO-funded international research project 'Transnational Child-Raising Arrangements' (TCRA, grant number W01.65.316.00). Her individual Ph.D. research focused on Ghanaian transnational families and examined how local, national and global processes interlink and impinge on everyday care practices and relationships when parents migrate and children stay behind. During her Ph.D. research, Miranda presented at numerous national and international conferences, organised seminars, workshops and a conference, and reviewed papers for several academic journals. She was also a member of the Dutch Association for Migration Research (DAMR) and the Research School for Resource Studies for Development (CERES). In addition to her research work, Miranda taught undergraduate courses - 'Globalization and Inequality' and a writing seminar - at Maastricht University.

Since January 2017, Miranda works at the department of Social Work of VIVES University of Applied Sciences in Kortrijk (Belgium). Here she is coordinator and lecturer of the Bachelor's specialization 'Migration and Intercultural Work', and researcher on projects that seek to improve the educational integration of refugees and non-EU migrants. 
